\title{
WestVirginiaUniversity
}

THE RESEARCH REPOSITORY @ WVU

Graduate Theses, Dissertations, and Problem Reports

2021

\section{The Road Less Traveled: Economic Analysis of Roads and Highways}

Margaret C. Bock

West Virginia University, mbock1@mix.wvu.edu

Follow this and additional works at: https://researchrepository.wvu.edu/etd

Part of the Public Economics Commons, and the Regional Economics Commons

\section{Recommended Citation}

Bock, Margaret C., "The Road Less Traveled: Economic Analysis of Roads and Highways" (2021).

Graduate Theses, Dissertations, and Problem Reports. 8128.

https://researchrepository.wvu.edu/etd/8128

This Dissertation is protected by copyright and/or related rights. It has been brought to you by the The Research Repository @ WVU with permission from the rights-holder(s). You are free to use this Dissertation in any way that is permitted by the copyright and related rights legislation that applies to your use. For other uses you must obtain permission from the rights-holder(s) directly, unless additional rights are indicated by a Creative Commons license in the record and/ or on the work itself. This Dissertation has been accepted for inclusion in WVU Graduate Theses, Dissertations, and Problem Reports collection by an authorized administrator of The Research Repository @ WVU.

For more information, please contact researchrepository@mail.wvu.edu. 
Graduate Theses, Dissertations, and Problem Reports

2021

The Road Less Traveled: Economic Analysis of Roads and Highways

Margaret C. Bock

Follow this and additional works at: https://researchrepository.wvu.edu/etd

Part of the Public Economics Commons, and the Regional Economics Commons 


\title{
The Road Less Traveled: Economic Analysis of Roads and Highways
}

\author{
Margaret Bock
}

\author{
Dissertation submitted to the \\ John Chambers College of Business and Economics \\ at West Virginia University \\ in partial fulfillment of the requirements for the degree of \\ Doctor of Philosophy \\ in \\ Economics
}
Joshua C. Hall, Ph.D., Committee Chairperson
Brad R. Humphreys, Ph.D.
Adam Nowak, Ph.D.
Janet Fraser, Ph.D.
Department of Economics
Morgantown, West Virginia
2021

Keywords: Roads, Transportation, Commuting, Road Maintenance, Mortality Copyright (C) 2021 Margaret Bock 


\title{
Abstract \\ The Road Less Traveled: Economic Analysis of Roads and Highways
}

\author{
by Margaret Bock
}

Roads are an integral component of civilization, connecting people, markets, and ideas. In different settings and geographies, roads can take on many different purposes. In rural, more isolated areas, roads can serve as a cost-saving benefit and can be used as tools to increase accessibility. In urban, more congested areas, roads can be seen as an externality-producing hindrance. Naturally, given this view, the overall analysis of roads should reflect these different settings. To date, however, the study of roads in the economics literature has surprisingly large pitfalls, notably in terms of topics of study and methodologies used.

Spending on roads is a non-negligible portion of government budgets across the country, making this topic relevant to study to make informed policy suggestions. This dissertation research, titled The Road Less Traveled: Economic Analysis of Roads and Highways, analyzes one overarching theme using three different perspectives: urban, political economy, and regional.

Chapter 1 examines the impact of high occupancy vehicle lanes (HOV) on commuting times. The effects of HOV lanes studied from a causal perspective have been minimal in the economics literature. Knowing the impacts of these types of infrastructure projects is beneficial in terms of public policy and resource allocation. Using an instrumental variable (IV) approach to overcome the endogeneity problems associated with HOV lane location selection, this study aims to uncover the impacts of HOV lanes on commuters' time spent going to and coming home from work in California. Making use of the 2017 National Household Travel Survey, and after data pre-processing through coarsened exact matching (CEM), this paper finds that both having HOV lanes in workplace counties and living closer to HOV lanes cause increased commute times to and from work for commuters, lending credence to earlier works on road construction and traffic outcomes citing induced demand from increased road construction (Duranton \& Turner, 2011).

Chapter 2 studies the impact of mayoral election cycles impact the timing and location of road maintenance. Political incentives affect infrastructure construction, but how incentives affect infrastructure upkeep, like road maintenance, is sparsely documented. Previous empirical results find different conclusions than theoretical evidence about road maintenance perceptions. Political alignment and local election cycles are leveraged using difference-in-differences to investigate if political incentives cause shifts in road maintenance. Robust results identify political distortions in invasive road maintenance timing. Local election cycles, which are widespread and frequent, shift road maintenance timing. Conservative calculations suggest local US elections cost at least $\$ 185.5$ million from 1960-2020, equivalent to 4 million meters of maintenance or maintaining all local Pittsburgh roads $\approx 1.45$ times.

Chapter 3 looks at the impact of rural roads on mortality outcomes in the Appalachian region. Specific attention to federally funded rural roads and highways is sparse given implicit endogeneity concerns about road placement decisions for the sake of rural development and market exposure. 
This study examines the impact of the Appalachian Development Highway System (ADHS), one of the largest and most expensive federal infrastructure projects in the United States, on mortality outcomes in the region. IV results suggest ADHS construction significantly reduced travel-timesensitive mortality rates, such as heart disease and hypertension, in earlier decades of the sample. IV results also suggest the ADHS may be associated with increased mortality rates, notably accidents, in later decades of the sample. The additional cost caused by the ADHS in terms of mortality is estimated to be $\$ 24.2$ billion dollars over the length of the sample. However, benefits such as improved travel times, employment, and income increases outweigh these costs. 


\section{Acknowledgments}

The road here has not been an easy one. I could not have done this alone, and I have many to thank.

First, many thanks to my dissertation committee for your insight and motivation. Dr. Josh Hall, thanks for the reassurance and guidance in navigating the tougher parts of the Ph.D. process. I appreciate that you always were confident in my ability to pull this dissertation off. Dr. Brad Humphreys, thanks for reminding me to not doubt myself and that I deserve all of my success. Dr. Adam Nowak, thanks for telling me I have too many tables in my papers and for being an IV skeptic. Dr. Janet Fraser, thanks for providing insight about Appalachian hospitals and introducing me to Phil Gaglardi quotes. All of you brought much-needed variation in perspective on my research for which I am forever grateful.

There are many others outside of WVU to thank as well. To others in the field at conferences or presentations who have given feedback on my work, thank you for making me feel validated that I am in the right profession. Thanks to the undergraduate professors at Shepherd University, particularly Dr. Kinney, Dr. Reid, and Dr. Holtslag, who believed in me and encouraged me to go to graduate school. My undergraduate experience shaped me to be self-motivated, persistent, and empathetic; these traits still define who I am as a scholar and a teacher.

Thanks to all my family and friends, near and far, who provided a foundation to fall back on if I faced uncertainty. Mom and Dad, thanks for always being my biggest cheerleaders. Anna and Clay, thanks for bringing fun every time you would visit me in Morgantown. Ben, thank you for being a compassionate listener and the "concepts" guy while I focused on the "details." Also, your connections to Sasha and Partner brought much needed therapy throughout the dissertation writing process.

Finally, thanks to the state of West Virginia for educating me and affording me seemingly endless opportunity. From preschool to graduate school,

County roads, take me home. 


\section{Contents}

$\begin{array}{ll}\text { Abstract } & \text { ii }\end{array}$

Acknowledgments $\quad$ iv

List of Figures $\quad$ viii

List of Tables $\quad$ x

1 The Causal Effect of High Occupancy Vehicle Lanes on Commuting Times in Califor$\begin{array}{ll}\text { nia } & 1\end{array}$

1.1 Literature: Commuting and HOV Lanes . . . . . . . . . . . . . . . 3

1.2 Institutional Setting and Data . . . . . . . . . . . . . 6

1.2.1 HOV Lanes in California . . . . . . . . . . . . . . . . . . 6

1.2.2 Commuting in California . . . . . . . . . . . . . . 7

1.2.3 Naive Linear Regression . . . . . . . . . . . . . . . . . . . . 9

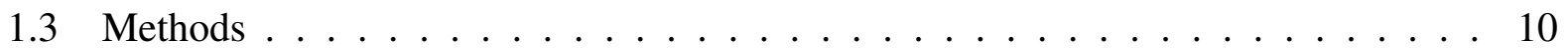

1.3.1 Coarsened Exact Matching (CEM) . . . . . . . . . . . . . 10

1.3.2 Instrumental Variable (IV): Democratic Vote Share in 2000 . . . . . . . . . 12

1.3.3 IV: 1947 U.S. Highway Plan . . . . . . . . . . . . . . . . . . . 14

1.4 IV Results . . . . . . . . . . . . . . . . . . . . . . . . 15

1.4.1 Limitations and Extensions . . . . . . . . . . . . . . 17

1.5 Conclusions and Policy Implications . . . . . . . . . . . . . . . . . 17 
2.1 Literature . . . . . . . . . . . . . . . . . . . . . 35

2.1.1 Theoretical Political Economy and Infrastructure $\ldots \ldots \ldots$

2.1.2 Political Alignment . . . . . . . . . . . . . . . . . . . . . 35

2.1.3 Road Maintenance, Public Capital Expenditure, and Growth . . . . . . . 36

2.2 Data . . . . . . . . . . . . . . . . . . 36

2.2.1 Maintenance Projects . . . . . . . . . . . . . . . . . . . 37

2.2.2 Pittsburgh Political Wards . . . . . . . . . . . . . . . . 37

2.2 .3 Pittsburgh Institutional Details . . . . . . . . . . . . . . . . 37

2.2 .4 Sample Creation $\ldots \ldots \ldots \ldots \ldots$

2.2 .5 Descriptive Statistics . . . . . . . . . . . . . . . . . . 38

2.3 Method . . . . . . . . . . . . . . . . . . . . . 39

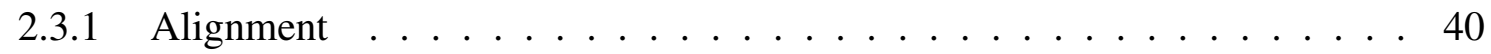

2.3 .2 Identification . . . . . . . . . . . . . . . . . 41

2.4 Results . . . . . . . . . . . . . . . . . . . . . . . . 43

2.4.1 Difference in Differences . . . . . . . . . . . . . . . . . . . . 43

2.4.2 Inference Robust to Few Clusters . . . . . . . . . . . . . . . . . 44

2.5 Ward Boundaries as Variation in Political Alignment $\ldots \ldots$. . . . . . . . . 45

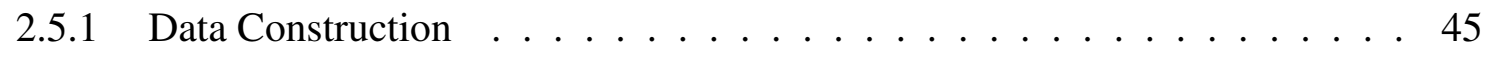

2.5.2 Distribution of Roads at the Ward Boundary Cutoff . . . . . . . . . . . 46

2.5.3 Maintenance Differences at Ward/Alignment Boundaries . . . . . . . . . 46

2.6 Costs of Elections for Road Maintenance $\ldots \ldots \ldots$

2.6.1 Across Comparable Cities . . . . . . . . . . . . . . . . . . . . . 49

2.6.2 Low Political Competition Implies Estimates are Lower Bounds _ . . . . . 50

2.6.3 Maintenance Shifts Have Consequences for Road Safety . . . . . . . . . 51

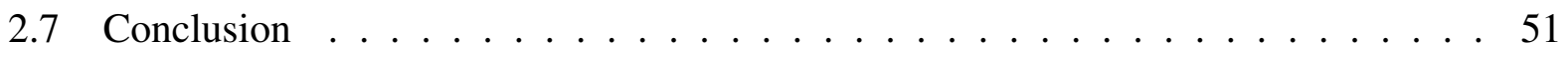




\section{Unintended Consequences of the Appalachian Development Highway System on Mor-}

tality $\quad 63$

3.1 Historical Background and Literature Review _ . . . . . . . . . . . . . 67

3.1.1 Appalachian Development Highway System _ . . . . . . . . . . 67

3.1.2 Mortality and Place-Based Policies _ . . . . . . . . . . . . . . . . . . 69

3.1.3 Quantifying Impact of Roads . . . . . . . . . . . . . . . . . . 71

3.1.4 General Analysis of ARC Policies . . . . . . . . . . . . . . . 73

3.2 Primary Data Sources . . . . . . . . . . . . . . . . . . . . 74

3.2.1 Data Creation: Appalachian Development Highway System (1965-2018) 74

3.2.2 NVSS: NCHS Restricted-Use Mortality Files (1968-2017) . . . . . . . . 75

3.3 Method and Identification Strategy . . . . . . . . . . . . . . 76

3.3.1 Endogeneity Concerns of ADHS Segment Construction _ . . . . . . 76

3.3.2 Instrumental Variable Approach . . . . . . . . . . . . . . . 77

3.3.3 Potential Threats to Internal Validity . . . . . . . . . . . . . . . 79

3.4 IV Results: ADHS and Heterogeneous Impacts Across Time $\ldots \ldots \ldots \ldots$

3.5 Robustness and Mechanism . . . . . . . . . . . . . . . . . . 83

3.6 Benefit-Cost Analysis . . . . . . . . . . . . . . . . . . . . . . . 86

3.7 Conclusion $\ldots \ldots \ldots \ldots \ldots \ldots$

$\begin{array}{lr}\text { References } & 109\end{array}$

$\begin{array}{lr}\text { Appendix } & 120\end{array}$

A Additional Tables and Figures for Chapter $1 \ldots \ldots$. . . . . . . . . . . 120

B Additional Tables and Figures for Chapter $2 \ldots \ldots$. . . . . . . . . 131

C Additional Tables and Figures for Chapter 3 . . . . . . . . . . . . . . . . . 140

C.1 Other Mortality Outcomes _ . . . . . . . . . . . . . . . 151

C.2 IV Results without Controls _ . . . . . . . . . . . . . . 156

C.3 Cumulative Effect of the ADHS on Mortality . . . . . . . . . 166 


\section{List of Figures}

1.1 California Primary Roads and HOV Lane Locations . . . . . . . . . . . . . . 20

1.2 Votes for $\mathrm{Al}$ Gore in the 2000 Presidential Election . . . . . . . . . . . . 26

1.3 HOV Lanes, Primary Roads, and Caltrans Districts . . . . . . . . . . . . . . . 28

1.41947 Interstate Highway Plan . . . . . . . . . . . . . . . . . . . . . . . . . . . . . 29

2.1 Monthly Completion of Heavy Road Maintenance in Pittsburgh, Pennsylvania . . . 53

2.2 Within-Ward Political Alignment by Time and Space . . . . . . . . . . . . 55

2.3 Meters of Maintenance by Within-Ward Political Deviation Z-Score and Month in

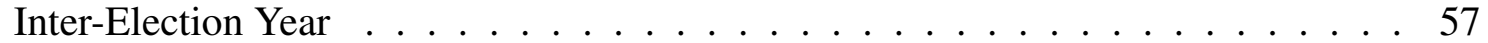

2.4 Political Alignment and Maintenance Project Trends by Year . . . . . . . . . . . 58

2.5 Randomization Inference . . . . . . . . . . . . . . . . . . . 60

2.6 Ward-Level Spatial RD Plots, Combining Tests and Falsification . . . . . . . . . 61

3.1 1964 President's Appalachian Regional Commission (PARC) Highway Plan . . . . 91

3.2 Appalachian Development Highway System Progress: 1968-2017 . . . . . . . . 92

3.3 Appalachian Mortality Rates 1968-2017: Per 100,000 _ . . . . . . . . . . . 93

3.4 Appalachian County Change in Mortality Rates: 1968-2017 . . . . . . . . . . . . 94

3.5 Appalachian County Change in Heart Disease Mortality Rates: 1968-2017 . . . . . 95

3.6 Appalachian County Change in Total Accident Mortality Rates: 1968-2017 . . . 96

3.71964 PARC Planned Highways vs. 1966 ADHS Planned Highways . . . . . . . 97

3.8 Hospitals in Appalachia over Time . . . . . . . . . . . . . . . . . 98 
3.9 Count of ARC Investment Projects: 1968-2016 _ . . . . . . . . . . . . . . . 99

3.10 Disaggregating Total Accidents: Car Accidents and Overdoses . . . . . . . . . . 100

3.11 Proportion of Appalachian Counties with More Residents Dying Outside of the County . . . . . . . . . . . . . . . . . . . . . . . . 101

A.1 1947 Interstate Highway Plan Digitized ～. . . . . . . . . . . . . . 130

B.1 Pittsburgh Expenditures (2009-2017) ‥ . . . . . . . . . . . . . . . . 132

B.2 Maintenance Projects and Roads Superimposed Above Political Wards . . . . . . 133

B.3 Distribution of Political Alignment . . . . . . . . . . . . . . . . . 134

B.4 Number of 1 Meter Road Segments by Distance to Ward Boundary . . . . . . . . 135

B.5 Ward-Level Spatial RD Plots, Combining Tests and Falsification . . . . . . . 136

B.6 The Cost of Road Maintenance Delays . . . . . . . . . . . . . . . . . . 137

C.1 Appalachian Regional Commission (ARC) Counties Over Time . . . . . . . . . 141

C.2 1966 ARC Plan for the ADHS . . . . . . . . . . . . . . . . . . 142

C.3 Appalachian County Change in Hypertension Mortality Rates: 1968-2017 . . . . . 143

C.4 Appalachian County Change in Cerebrovascular Disease Mortality Rates: 1968-2017144

C.5 Appalachian County Change in Aortic Aneurysm Mortality Rates: 1968-2017 . . . 145

C.6 Appalachian County Change in Pneumonia and Influenza Mortality Rates: 1968-

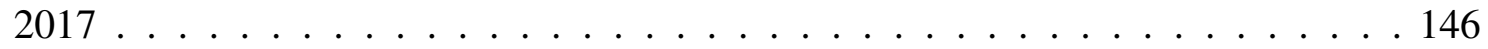

C.7 Hospitals in Appalachia in 2020 . . . . . . . . . . . . . . . . . 147

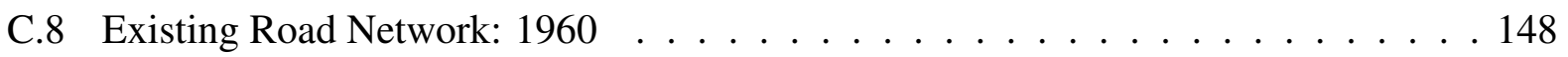

C.9 Appalachian Population: $1970-2014 \ldots \ldots 149$ 


\section{List of Tables}

1.1 California HOV Lanes and Commuting $\ldots \ldots \ldots$

1.2 Urban Size Classifications . . . . . . . . . . . . . . . . . . . . 21

1.3 Naive Linear Regression Before Matching: Effect of HOV Lanes on Commute Time 22

1.4 Summary Statistics Before Matching . . . . . . . . . . . . . . . . . 23

1.5 Summary Statistics After Matching . . . . . . . . . . . . . . . . . . . . . 24

1.6 Naive Linear Regression After Matching: Effect of HOV Lanes on Commute Time 25

1.7 Timing of HOV Lane Openings . . . . . . . . . . . . . . . . . 27

1.8 Open HOV Lanes by Caltrans District $\ldots \ldots \ldots \ldots$

1.9 2SLS Estimates With 2000 Democratic Vote Share After Matching: HOV Lanes on Commute Times . . . . . . . . . . . . . . . . . . . 30

1.10 2SLS Estimates With 1947 Highway Plan After Matching: HOV Lanes on Commute Times . . . . . . . . . . . . . . . . . . . . 31

2.1 Types of Maintenance Projects . . . . . . . . . . . . . . . . . . 54

2.2 Descriptive Statistics, Number of Heavy Maintenance Projects Completed . . . . . 56

2.3 How Narrowing Months Affects Number of Heavy Maintenance Projects _ . . . 59

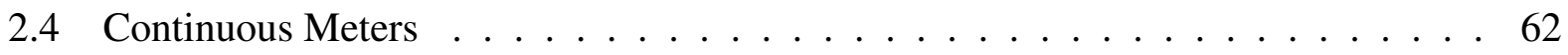

3.1 Summary Statistics by Decade . . . . . . . . . . . . . . . . . . . 102

3.2 2SLS Estimates of Appalachian Development Highway System on Total Mortality Rate With Controls . . . . . . . . . . . . . . . . . . . . 103 
3.3 2SLS Estimates of Appalachian Development Highway System on Heart Disease Mortality Rate With Controls . . . . . . . . . . . . . . . . . . . . . . . 104

3.4 2SLS Estimates of Appalachian Development Highway System on Hypertension Mortality Rate With Controls . . . . . . . . . . . . . . . . . . . . 105

3.5 2SLS Estimates of Appalachian Development Highway System on Accident Mortality Rate With Controls . . . . . . . . . . . . . . . . . . . . . 106

3.6 2SLS Estimates of Appalachian Development Highway System on Car Accident Mortality Rate With Controls . . . . . . . . . . . . . . . . . . . . . 107

3.7 2SLS Estimates of Appalachian Development Highway System on Accidental Overdose Mortality Rate With Controls . . . . . . . . . . . . . . . . . . . . 108

A.1 Trip and Driver Characteristics Before Matching: 50 miles or less . . . . . . . . 121

A.2 Trip and Driver Characteristics After Matching: 50 miles or less . . . . . . . . 122

A.3 Trip and Driver Characteristics Before Matching: 25 miles or less . . . . . . . 123

A.4 Trip and Driver Characteristics After Matching: 25 miles or less . . . . . . . . . 124

A.5 Trip and Driver Characteristics Before Matching: 10 miles or less . . . . . . . 125

A.6 Trip and Driver Characteristics After Matching: 10 miles or less . . . . . . . . . 126

A.7 Trip and Driver Characteristics Before Matching: 5 miles or less . . . . . . . . . 127

A.8 Trip and Driver Characteristics After Matching: 5 miles or less . . . . . . . . 128

A.9 Nearest Neighbor Matching Analysis . . . . . . . . . . . . . . . . . . . . . . 129

B.1 Federal Highway Administration State \& Urbanized Area Statistics: Population

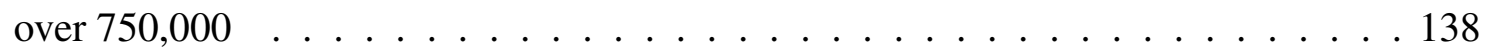

B.2 Investigating Political Cycles on Car Crashes . . . . . . . . . . . . . . 139

C.1 ICD Code Definitions and Changes . . . . . . . . . . . . . . . . 150

C.2 ARC Investment Projects: $1968-2016 \ldots \ldots$. . . . . . . . . . . . . 151

C.1.12SLS Estimates of Appalachian Development Highway System on Cerebrovascular Disease Mortality Rate With Controls . . . . . . . . . . . . . . . . 153 
C.1.22SLS Estimates of Appalachian Development Highway System on Aortic Aneurysm Mortality Rate With Controls . . . . . . . . . . . . . . . . . . . . . 154

C.1.32SLS Estimates of Appalachian Development Highway System on Pneumonia and Influenza Mortality Rate With Controls . . . . . . . . . . . . . . . . 155

C.1.42SLS Estimates of Appalachian Development Highway System on Complications with Pregnancy Mortality Rate With Controls . . . . . . . . . . . . . . . . . . 157

C.2.12SLS Estimates of Appalachian Development Highway System on Total Mortality Rate Without Controls . . . . . . . . . . . . . . . . 158

C.2.22SLS Estimates of Appalachian Development Highway System on Heart Disease Mortality Rate Without Controls . . . . . . . . . . . . . . . . . . . . 159

C.2.32SLS Estimates of Appalachian Development Highway System on Hypertension Mortality Rate Without Controls . . . . . . . . . . . . . . . . . . . . 160

C.2.42SLS Estimates of Appalachian Development Highway System on Cerebrovascular Disease Mortality Rate Without Controls . . . . . . . . . . . . . . . . . . 161

C.2.5 2SLS Estimates of Appalachian Development Highway System on Aortic Aneurysm Mortality Rate Without Controls . . . . . . . . . . . . . . . . . . . . 162

C.2.62SLS Estimates of Appalachian Development Highway System on Pneumonia and Influenza Mortality Rate Without Controls . . . . . . . . . . . . . . . . . . 163

C.2.72SLS Estimates of Appalachian Development Highway System on Complications with Pregnancy Mortality Rate Without Controls . . . . . . . . . . . . . . . . . . 164

C.2.82SLS Estimates of Appalachian Development Highway System on Accident Mortality Rate Without Controls . . . . . . . . . . . . . . . . 165

C.3.1 Panel 2SLS Estimates of Appalachian Development Highway System on Mortality Rate With Controls . . . . . . . . . . . . . . . . . . . . 167 


\section{Chapter 1}

\section{The Causal Effect of High Occupancy Vehicle Lanes on Commuting Times in \\ California}

From correlational psychological surveys to more causal empirical econometric techniques, extensive work has been conducted to uncover the effects of the negative externalities associated with traffic congestion. The policy response to combat congestion has varied across urban areas throughout the world. Several places have implemented congestion pricing in city-centers or high traffic areas to decrease the marginal benefit of traveling in the tolled area during peak travel times. Several well-known examples include London (Leape, 2006), Stockholm (Eliasson, 2009), and the country of Singapore (Santos, 2005). New York City recently became the first U.S. city to embrace congestion pricing to help curb congestion. ${ }^{1}$

One of the many proposed solutions to help eliminate traffic congestion, specifically congestion associated with commuting, are high occupancy vehicle (HOV) lanes. Each vehicle that wishes to

\footnotetext{
${ }^{1}$ https://www.nytimes.com/2019/03/31/nyregion/budget-new-york-congestion -pricing.html
} 
travel in an HOV lane must be carrying the minimum number of people posted at the entrance sign. A notable characteristic of an HOV lane is that there is no charge associated with its use. ${ }^{2}$

In many urban centers across the United States, policy makers and urban planners tout the advantages of the construction of HOV lanes; some of the benefits cited include improving highway efficiency in terms of congestion, vehicle volumes, and emissions. In addition, many state and federal reports cite the benefits of HOV lanes over general purpose lanes and exempt these lanes from certain regulations that general purpose road lanes face. ${ }^{3}$ Despite the rising costs of road construction and repair, minimal efforts have been conducted to determine whether or not HOV lanes have been effective in reducing driving times or congestion. For example, in 2012, just 10 miles of HOV lane construction in Los Angeles county cost over $\$ 10$ billion. Understanding the mechanisms behind these special road lane policies would be beneficial to both urban planners and commuters alike.

To attempt to analyze the effects of HOV lanes on traffic congestion, I employ an instrumental variable technique to capture the causal effects of HOV lanes on commuting times in California. After data pre-processing using coarsened exact matching (CEM), the vote share for Al Gore in the 2000 presidential election is used to instrument for the location of HOV lanes in California, as well as the distance commuters live from the nearest HOV lane. As additional robustness, the 1947 highway plan used in Baum-Snow (2007), Duranton and Turner (2011), and others is used to instrument for the location of HOV lanes in California, as well as the distance commuters live from the nearest HOV lane. This paper finds evidence that additional HOV lanes in commuters' workplace counties and living near HOV lanes lead to higher commute times to and from work and thus are not meeting the goals of policymakers. Arguably, the induced demand to drive on a route from the construction of an HOV lane increases the commute time of all commuters who take that route, not just the ones who take the HOV lane. This finding extends the results found

\footnotetext{
${ }^{2}$ This is in contrast with high occupancy toll (HOT) lanes, where a toll is also required in addition to the carpooling guidelines.

${ }^{3} \mathrm{http}: / /$ www.dot.ca.gov/trafficops/tm/hov.html outlines the California laws governing the purpose of HOV lanes.
} 
in previous studies on induced demand for roadway usage by showing these results hold true even for heterogeneous road lane types.

The remainder of the paper is as follows: Section 1 discusses publications surrounding HOV lanes and commuting and highlights the major trends in the literature; Section 2 details the data sources used; Section 3 outlines methods and model specifications used to identify the causal relationship between HOV lanes and commuting times in California; results and robustness checks are discussed in Section 4, along with limitations of the current study design; Section 5 concludes.

\subsection{Literature: Commuting and HOV Lanes}

There is a large literature base that examines the impacts of traffic congestion in general. Several psychology studies, including Hennessy and Wiesenthal (1999) note the adverse effects associated with sitting in traffic congestion. Specifically, increased time spent in traffic congestion is associated with increased aggressiveness. Following in this vein, the majority of the work on traffic congestion in economics has focused on the health outcomes of those directly impacted by the congestion. ${ }^{4}$ Currie and Walker (2011) examine the impact of pollution from E-ZPass terminals ${ }^{5}$ along interstates. This study finds that mothers who lived closer to these terminals necessarily live along highways prone to more traffic congestion, hence more pollution in the air; these women gave birth to children with significantly lower birth weights when compared to mothers living near, but not as close to the E-ZPass terminals. Knittel, Miller, and Sanders (2016) also examines the negative impacts pollution from traffic congestion has on infant health. Exploiting changes in wind direction across highways, Deryugina, Heutel, Miller, Molitor, and Reif (2016) explores the medical costs associated with pollution from traffic.

\footnotetext{
${ }^{4}$ There have also been several studies that try to quantify quality of life indexes taking congestion levels into account. See Albouy and Lue (2015) for example.

${ }^{5} \mathrm{E}$-ZPass is an electronic toll collection system used on most tolled roads, bridges, and tunnels in the Midwestern and Eastern United States. These electronic toll collection terminals can become quite congested during peak rush hour times.
} 
Several theoretical studies have included HOV lanes to model the effect on congestion. Dahlgren (1998) creates a model to assess the benefits of several different road layout alternatives to combat congestion. A newer theoretical contribution to the study of HOV lanes comes from Konishi and Mun (2010). The authors construct a model to determine when it is socially beneficial to construct an HOV lane. The paper also examines whether converting an HOV to an HOT lane improves road use efficiency. Again, like most other theoretical models in the realm of study, the results depend entirely on the initial parameter values and the welfare functional form.

Duranton and Turner (2011) provide a clear starting point for any empirical research on HOV lanes and their impact on travel times. They evaluate the effect of building additional kilometers of roads on VKT (vehicle kilometers traveled) in the U.S. Interesting and innovative instruments are used to overcome the endogeneity problems associated with road construction including historical maps of highway routes, railway routes, and exploration trails in the United States. Using a comprehensive city-level data set, the authors find that VKT increases proportionally with kilometers constructed (no relief to congestion if additional roads are built). The sources for the extra VKT stem from people migrating to places with more roads, increases in commercial traffic, and current residents just driving more.

With respect to HOV lanes, a new lane may temporarily relieve congestion by drawing vehicles away from the congested general purpose lanes. But, as motorists adjust, those who were constrained by congestion start taking more trips. Additionally, one main assumption in Duranton and Turner (2011) is that all types of interstate road lanes are homogeneous in their purpose for construction; this assumption runs counter to the entire purpose of HOV lanes. Therefore, it is worth exploring to see if these different types of lanes are having similar or different impacts on outcomes such as vehicle miles traveled, congestion, commuting, and pollution than those predicted in Duranton and Turner (2011); that is what the current work directly does with respect to HOV lanes.

Empirical efforts have been made to examine the effect of carpooling and HOV lanes. Examples include: Bento, Hughes, and Kaffine (2013), J. D. Hall (2018), Hanna, Kreindler, and Olken 
(2017), and Hughes and Kaffine (2019). Arguably, the estimates proposed in these studies do not take the endogeneity of HOV lane locations into account: HOV lanes are generally placed in urban areas with high levels of congestion. Therefore, estimating the true treatment effect of HOV lanes with respect to commute times will likely be underestimated by naive OLS specifications.

The paper that is most related to this study is a recent working paper (Shewmake, 2018). This paper theoretically and empirically tests for the impacts of HOV lanes on vehicle miles traveled (VMT). This paper finds the theoretical impacts of HOV lanes on VMT depend upon local conditions, and that empirically, the impacts of HOV lanes are even more ambiguous. Importantly, carpooling is considered endogenous in the model, and the author uses an instrumental variables technique to address the potential bias in the regression estimates. Because of the structure of the Clean Air Act, attainment status may predict where HOV lanes will be built but does not have a direct impact on traffic volume. She uses this instrument (Clean Air Attainment status) to predict the number of HOV lane miles built. However, this instrument is not statistically "strong" on its own. But, when the instrument is interacted with population, Shewmake (2018) finds that HOV lanes are associated with an increase in VMT.

In summary, the negative externalities that stem from commuting have a solid footing in the economics, psychology, and health literatures. However, the economic and behavioral impacts of HOV lanes on commute times has been vastly understudied, especially from an empirical causal inference perspective. ${ }^{6}$ This work aims to fill an important gap in the study of transportation and infrastructure investment from a methodological standpoint.

\footnotetext{
${ }^{6}$ Welfare implications of urban commuting policies have been generally examined (Akbar, Couture, Duranton, Ghani, \& Storeygard, 2018; Anderson, 2014; Barrios, Hochberg, \& Yi, 2019; Green, Heywood, \& Navarro Paniagua, 2020), but HOV lanes less so.
} 


\subsection{Institutional Setting and Data}

\subsubsection{HOV Lanes in California}

When examining HOV lanes in the United States, in general, there is some concern about missing data and comparability which could lead to considerable measurement error and biased estimates of the effect of HOV lanes. To the author's knowledge, the most up-to-date across-state compilation of HOV lane location and construction dates was published in 2008 (Chang \& Bilotto, 2008). Individually, some states do not have up-to-date transportation and infrastructure information on their respective department of transportation's websites. Therefore, even if data across states' departments of transportation is available, they may or may not be comparable. ${ }^{7}$ To avoid these issues, this study focuses on one state that has recently updated HOV lane data: California. California also has the most HOV miles of constructed HOV lanes in the country, making this an ideal place to begin to address if HOV lanes cause increases or decreases in commuting times.

According to the California Department of Transportation, all HOV lanes constructed in California are never converted from existing lanes on highways; due to a mix of state and federal funding laws, all new HOV lanes require new construction. ${ }^{8}$ This is unique to California and important to my identification strategy. These lanes are different from HOT (high occupancy toll) or express lanes in that there is no toll or fee associated with using the lane. HOT lanes are not considered in the current analysis.

In addition to the infrastructure institutional set-up discussed above, building roads in California is quite expensive compared to the national average. According to one study, California spent about $\$ 420,000$ per mile in 2013 compared with the national average spending of about $\$ 160,000$ per mile in the same year. Building just 10 miles of HOV lanes on I-405 in Los Angeles was estimated to cost over $\$ 1$ billion. ${ }^{9}$ Thus, understanding if the HOV lanes are effective has important policy and budget implications.

\footnotetext{
${ }^{7}$ This fact is especially true if one wants to analyze HOV lane construction and locations pre-2000.

${ }^{8}$ See Matute and Pincetl (2013) for more details.

${ }^{9}$ Source: http://media.metro.net/projects_studies/pm/images/pm_october_2013_i 405 _sepulveda_pass_improvements2.pdf
} 


\section{Caltrans Data}

The main source of HOV lane data for this paper comes from the California Department of Transportation (Caltrans). ${ }^{10}$ Caltrans provides information on the specific location of HOV lanes and other characteristics, including length of the lanes, the location of the lanes, the types of vehicles allowed in the lanes, and other characteristics such as opening and closing times of the lanes. The data from Caltrans were manipulated in QGIS $^{11}$ to determine the presence of HOV lanes at the county level. Summary statistics are shown in Panel A of Table 1.1. Notably, there is considerable variation across the 58 counties of California. Figure 1.1 maps the locations of all currently constructed HOV lanes in California. Despite there being over 1300 miles of HOV lanes in California, most of these lanes are concentrated in specific urban areas. This apparent selection into certain areas requires addressing. An instrumental variable approach is used to overcome this bias. Additionally, matching methods are used in data pre-processing. Specific details on the instrument, matching methods, and the model specification are discussed in Section 3 of the paper.

\subsubsection{Commuting in California}

Travel data is obtained from the National Household Travel Survey (NHTS) for 2017. ${ }^{12}$ The California sub-sample is utilized in this study. 26,112 unique households were surveyed in the subsample. The California NHTS data consists of four main files: Household, Person, Trip, and Vehicle. The household file includes information about the households surveyed: home ownership status, family income, how many cars owned, and even the gas price on the day surveyed. The person file includes information about the individuals that make up the households: age, driver status, education level, relationship status, employment status, how they got to work, and how long it took them to get to work. The trip file describes the times of trips taken by those that were surveyed. Finally, the vehicle file includes detailed information about the make, model, and type

\footnotetext{
${ }^{10}$ California Department of Transportation (2018): http://www.dot.ca.gov/hq/tsip/gis/ datalibrary/Metadata/HOV.html

${ }^{11}$ QGIS (Quantum Geographic Information System) is a free, open-source geographic information system software.

${ }^{12}$ U.S. Department of Transportation: Federal Highway Administration (2018): https: / / nhts . ornl . gov/
} 
of cars owned and driven by those surveyed. These files can be merged and linked with location information that describes where the homes and workplaces of those surveyed are. For this study, all analyses will be conducted at the county level. ${ }^{13}$

Several studies have utilized both the individual state sub-samples, as well as the entire national sample of the National Household Travel Survey. Notably, Plotz, Konduri, and Pendyala (2010) examine the impact of HOV lanes across the entire United States. Conservatively, they attempt to back out the upper and lower bound of HOV lane-induced trip reduction. They find that the impacts of an HOV lane on trip reduction are minimal or modest at best and have little to no impact on operating performance of different lanes. The data have also been used to estimate the effect of different government policies on driving (Spiller, Stephens, Timmins, \& Smith, 2012).

Differing from the above studies, the main outcome variable of interest in this study is the amount of time that it takes people to get to or from work (two separate trips) in minutes. This information is taken from the trip file of the NHTS. Analysis was restricted to individual trips whose purpose was to or from work. In this sample, those in the survey that worked outside of the United States were dropped from the analysis, as well as those who worked in another state. Everyone who did not drive to work or worked from home was also dropped from the analysis. Because it is not known with $100 \%$ certainty if the survey respondents took an HOV lane to or from work, this specification can only be considered an intent to treat (ITT) analysis. However, if in line with previous empirical studies, the induced demand to drive on a certain road caused by the construction of an additional road lane impacts all drivers who drive on that road, not just those who would take an HOV lane. The main mechanisms to be tested are the following: (1) does the presence of any HOV lanes in your workplace county cause an increase or decrease in your commute time to or from work? and (2) does living closer to an HOV lane increase or decrease your commute time to or from work?

Summary statistics for commuting characteristics are shown in Panel B of Table 1.1. Similar to HOV lane locations in California, there is considerable variance across the sample of commuters.

\footnotetext{
${ }^{13}$ Publicly available data from the NHTS includes only a county-level indicator for location of home and work.
} 
The average time it takes a commuter to get to or from work is about 28 minutes. In general, 70 percent of counties in California have "short commutes" on average (less than the state average of 27.89 minutes) and 30 percent have longer average commutes. The average distance to work is 21 miles. The distance to work is not the straight line distance but the road network distance, in miles, between respondent's home location and work location. This information was sourced using the Google Distance Matrix API. Additionally, information on the dispersion of living locations is provided in the data. As shown in Table 1.2, the California NHTS surveyed a wide variety of people living in different types of urban areas. Most people in the commuter sub-sample live in urban areas with heavy rail systems and with 1 million or more people. Approximately one fifth of the sample does not live in an urban area.

\subsubsection{Naive Linear Regression}

As a first approximation of the effect of HOV lanes on commute times in California, simple naive linear regression models are employed. More specifically, the commute time of driver $i$ in county $c$ in the 2017 California NHTS is estimated in the following way:

$$
\text { CommuteTime }_{i c}=\beta_{1} \text { HOVTreatment }_{c}+\gamma_{i}+\phi_{c}+\epsilon_{i c}
$$

where $\mathrm{HOV}$ treatment is one of the above treatment specifications, $\beta_{1}$ is the variable of interest, $\gamma_{i}$ are individual person and trip controls, and $\phi_{c}$ are county fixed effects. All standard errors in these naive regressions are clustered at the county level.

Table 1.3 employs a naive linear regression approach to try to get a baseline estimate of the effect of HOV lanes on commuting times in California. Different treatment definitions are used to try to tease out any heterogeneous impacts. More specifically, five different treatment definitions are used: 1) a 1 or 0 indicator for whether a county has at least one HOV lane passing through it, 2) if a driver's home county centroid is 50 miles or closer to an HOV lane, 3) if a driver's home county centroid is 25 miles or closer to an HOV lane, 4) if a driver's home county centroid is 10 
miles or closer to an HOV lane, and 5) if a driver's home county centroid is 5 miles or closer to an HOV lane. Distances between California county centroids and HOV lanes were calculated using QGIS.

In all specifications, controls for the individual driver (age, gender, educational attainment, and occupation type), roadway distance to work, size of the urban area of residence as described in Table 1.2, and day of travel are employed in the fully specified forms.

Panel A of Table 1.3 shows the regression results without county fixed effects and Panel B of Table 1.3 shows the regression results with county fixed effects. In all treatment definitions, HOV lanes and distance to HOV lanes seem to have a positive effect on commute times; in other words, more HOV lanes in the home county of the driver and living relatively close to a HOV lane is related to increased commute times to and from work.

Adding county fixed effects to the naive regression approach, as shown in Panel B of Table 1.3, does not change the direction and level of significance; there still appears to be a positive, statistically significant relationship between being treated with HOV lanes and increased commute times to or from work. In naive models, however, this positive effect may be underestimated because HOV lanes are not randomly assigned across the state.

The following section describes the matching procedure implemented as well as the different approaches used to overcome the potential endogeneity problems associated with HOV lane locations and household location decisions.

\subsection{Methods}

\subsubsection{Coarsened Exact Matching (CEM)}

One issue with the naive regression approach is that there is concern that the control and treatment groups across all treatments are not comparable to one another. If these groups are not comparable on observables, then accurate treatment effects cannot be estimated. Table 1.4 examines the sample means of trip characteristics between treated and non-treated counties in California. The 
differences between these statistics are shown in Table 1.4 as well. It is noteworthy that there are significant differences between the treated counties and the control counties in this sample in terms of trip characteristics as well as individual characteristics.

To insure that the treatment and control groups are relatively comparable to accurately estimate the true treatment effect, I employ coarsened exact matching (CEM). Specifically, observations in the treatment group are exactly matched with replacement to observations in the control group: age, gender, educational attainment, occupation type and the trip length measured in roadway miles. CEM matching also helps by not only ensuring individual observation level balance across covariates, but works to ensure global balance across the entire sample (Iacus, King, \& Porro, 2011). ${ }^{14}$

Summary statistics for the treated and control groups before matching are shown in Table 1.4. The means of the control and treatment groups across a select number of covariates are displayed, along with standard errors in parentheses. A t-test was conducted to determine if there are significant differences between the two groups. For the majority of covariates, there are significant differences between the control and treatment groups, lending credence to the motivation for some type of data pre-processing. All additional treatment definitions show a similar pattern; specific estimates for other treatment definitions can be found in the Appendix.

After exact matching with replacement, the means and differences between control and treatment groups are shown in Table 1.5. There are far fewer differences between the control and treatment groups for the main variables of interest (commute time and distance to work). The remaining differences between the two groups, notably in the industries of employment, are to be expected when comparing urban to non-urban areas. Because of this, one can claim that these groups form more comparable comparison groups.

Because the matching appears to have corrected much of the covariate imbalance between the control and treatment groups across all treatment definitions, the same linear regression shown in equation 1.1 was run on the matched samples. The matching had no impact on the level and

\footnotetext{
${ }^{14}$ See Patrick and Mothorpe (2017) for an empirical application of CEM.
} 
direction of significance of the coefficients associated with HOV lane treatment. However, the magnitude of the coefficients are smaller. Panel A of Table 1.6 shows the naive regression after matching without county fixed effects; Panel B of Table 1.6 shows the same linear regression with county fixed effects.

In addition to CEM, nearest neighbor matching is imposed on the sample as a robustness test. Using the nearest four neighbors, average treatment effects and average treatment effects on the treated are estimated. Although much smaller than the estimated coefficients from the linear regression approach, the significant, positive relationship between HOV treatment and commute times remains. Treatment effects using this matching approach can be found the Appendix Table A.9.

\subsubsection{Instrumental Variable (IV): Democratic Vote Share in 2000}

To accurately consider the effects of HOV lanes on commuter behavior, one has to consider the possibly endogenous location choice of HOV lanes, as well as the endogenous choice location of households. Intuitively, one could claim that California is building HOV lanes in more populous, urban areas where traffic congestion is a more of an issue facing commuters. Based on Figure 1.1, this would seem to be the case. Although California has the most HOV lane miles in the country, most are concentrated in very specific urban areas. A similar conclusion can be drawn from Table 1.8 below. Unfortunately, up until now, most research conducted to determine the impacts on HOV lanes has not taken this endogeneity of HOV lane location selection into account.

To overcome this endogeneity problem in HOV lane location selection, an instrumental variables technique will be used. To use HOV lanes to predict commuting times in California, the following two stage estimation is utilized:

$$
\begin{gathered}
\text { HOVTreatment } \\
c=\phi_{1} D V_{c}+\gamma_{i}+\epsilon_{c i} \\
\text { CommuteTime }_{i}=\beta_{1} \text { HOVTreatment }_{c}+\gamma_{i}+v_{c i}
\end{gathered}
$$


where HOVTreatment are the different treatment definitions described in Section 2.3, $D V$ is share of Democratic votes for president in the 2000 election in county $c$. $\gamma_{i}$ includes individual controls (age, sex, educational attainment, and occupation category). Observations (trips) are matched exactly by trip distance in miles and also by individual (trip taker) characteristics.

To the author's knowledge, this is one of the first studies to use political outcome data to instrument for infrastructure construction projects. Many papers cite the link between political outcomes and infrastructure (Brueckner \& Selod, 2006; Glaeser \& Ponzetto, 2018; Huet-Vaughn, 2019), but using past political outcomes as an instrument for the location of current infrastructure projects is a contribution of the current work. Knowing that one of the major purposes behind the construction of HOV lanes is pollution reduction, counties in California that had a higher vote share for $\mathrm{Al}$ Gore in the 2000 presidential election arguably put a higher weight on these environmental issues when compared to counties with a lower vote share.

To add further weight to the relevance of the instrument, Table 1.7 summarizes the time trend of HOV lane openings in California. As one can see, the majority of current HOV lanes were opened after 2000. These lanes counted do not even take those lanes currently under construction or approved for construction. Using the vote share in 2000 seems to be a potentially relevant instrument to predict where HOV lanes would later be constructed. Further disaggregation of the open HOV lane data shows that Caltrans Districts 4 and 7 had the most open HOV lanes before 2000; these same districts also had the most construction of new lanes after 2000. Comparing Table 1.8 with the voting data displayed in Figure 1.2, it appears that these districts with the highest propensity for existing and future construction of HOV lanes in and after 2000 correspond to counties with some of the highest Democratic vote shares in the 2000 election. $^{15}$

One could worry that 2000 vote shares for Al Gore is highly correlated with present and potentially future urban density, a factor that would have strong impacts on commute times. If this were the case, the excludability argument for the proposed instrument would not hold. To this point, it is important to note that the voting behaviors in individuals' home counties in 2000 do

\footnotetext{
${ }^{15} \mathrm{~A}$ map of the Caltrans districts is shown in Figure 1.3.
} 
not have an impact on traffic volumes and the time that it takes these individuals to get to work in 2017. But, to control for this potential confounding factor, urban size controls are included in all IV specifications. With this, and other individual and county level controls, conditional exclusion arguments are more grounded.

\subsubsection{IV: 1947 U.S. Highway Plan}

For robustness, a second instrument is proposed. Following prominent literature (i.e. Baum-Snow (2007); Duranton and Turner (2011)), the 1947 U.S. Interstate Highway Plan will be used to instrument for current HOV lane locations in California (United States House of Representatives, 1947). Figure 1.4 displays the 1947 interstate highway plan. This plan to drawn with the purpose of increasing the mobility between large cities for trade and national defense purposes. Local driving patterns and commutes were not considered or attempted to be altered with this highway plan. ${ }^{16}$

Specifically, this two-stage estimation technique takes the following form:

$$
\begin{gathered}
\text { HOVTreatment }_{c}=\phi_{1} \text { 1947Plan }_{c}+\gamma_{i}+\epsilon_{c i} \\
\text { CommuteTime }_{i}=\beta_{1} \text { HOVTreatment }_{c}+\gamma_{i}+v_{c i}
\end{gathered}
$$

where HOVTreatment are the different treatment definitions described in Section 2.3, 1947Plan is county c's centroid distance to the 1947 highway plan. $\gamma_{i}$ includes individual controls (age, sex, educational attainment, and occupation category). Observations (trips) are matched exactly by trip distance in miles and also by individual (trip taker) characteristics.

$\beta_{1}$ is the main coefficient of interest. With conditions of relevance and exclusion, $\beta_{1}$ represents the causal effect of HOV lanes on commuting times. This instrument is relevant to the current analysis because the plan was drawn to efficiently connect urban areas. As shown in Figure 1.4, the counties in California with more HOV lanes today are also relatively closer to the proposed

\footnotetext{
${ }^{16}$ The digitized map data used is shown in Figure A.1.
} 
highways in the 1947 plan. This instrument follows the exclusion restriction because it is unlikely that county distance to nearest 1947 proposed highway impacts an individual's commute time in 2017 except through the plan's influence on future HOV lane location. Because the 1947 plan was drawn without local travel conditions in mind, this adds additional weight to the excludibility of this proposed instrument in predicting commute times. Controls for urban area size, as well as individual and travel controls will be used to further enhance conditional exclusion arguments.

\subsection{Results}

Results for the IV models are presented in Tables 1.9 and 1.10. Table 1.9 reports reduced form, first stage, and second stage results using the 2000 Democratic vote share as an instrument for HOV lane locations. Table 1.10 reports the reduced form, first stage, and second stage results using the 1947 highway plan as an instrument for HOV lane locations. Robust standard errors are shown in parentheses and first stage F-statistics are also reported. In all model specifications, first-stage F-statistics are well above 10.

When examining the first stage results using the 2000 vote share as an instrument for county distance to HOV lanes, there is a significant and positive coefficient for all treatment definitions. This is shown in column 2 of Table 1.9. The positive, statistically significant second stage coefficients (column 3 of Table 1.9) indicate the HOV lanes cause increases in times for people to get to work in California after controlling for the size of the urban area of residence, day of travel, and the individuals' personal characteristics (age, sex, occupation) and living distance from work. These results are in line with an induced demand mechanism similar to that found in Duranton and Turner (2011): an increase in the number of road lanes causes an increase in demand to drive on that road, thereby increasing commute times of all who drive on that road.

Noting the coefficient magnitudes, it appears that the induced demand effects of HOV lanes are felt most by those who live relatively close to an HOV lane (5 miles or less). This falls in line with the proposed mechanism as those that live closer to an HOV lane are likely to take a route 
that has an HOV lane, even if those commuters do not take the HOV lane themselves. Because of the induced demand for the roadway due to the HOV lane, more commuters are likely to take that route, thereby underestimating the amount of commuters who actually use the HOV lane.

Recalling that all new HOV lane construction in California requires the creation of a new lane and not a conversion from an existing lane, the results presented here confirm conclusions posed in Duranton and Turner (2011) that building new road lanes is associated with more vehicle congestion. If some kind of toll was implemented on these lanes, then the desired outcome of reduced travel times to work might be achieved. ${ }^{17}$

To overcome potential concerns with using vote share as an instrument for HOV lanes, county distance to the 1947 highway plan is used as an instrument for $2017 \mathrm{HOV}$ lane treatments. The first stage results using this instrument, shown in column 2 of Table 1.10, display a consistently negative and significant relationship. This result would suggest that the larger the county centroid distance to the 1947 plan, the closer that county is to an HOV lane in 2017.

The second stage results are shown in column 3 of Table 1.10. Similar to Table 1.9, the second stage results with the 1947 instrument show HOV lanes consistently cause increased commute times, conditional on individual, urban size, and travel day controls. Interestingly, the results found with this instrument do not exhibit the same U-shaped relationship found with the 2000 Democratic vote share instrument - living closer to an HOV lane does not increase commute times relatively to living farther away. Still, it is important to note that, no matter the treatment definition or instrument used, the causal effect of HOV lanes is found to be positive and statistically significant. Naive OLS models underestimate the impact of HOV lanes on commute times in California.

\footnotetext{
${ }^{17}$ There has been some work regarding the welfare impacts of HOT (high occupancy toll) lanes. The results seem to vary across different areas, and this could be for a number of different reasons beyond the creation of an HOT lane (varying carpooling preferences across places, exogenous factors influencing carpooling, and just the underlying fluctuations in carpooling from day to day and from year to year across places). See Burris, Alemazkoor, Benz, and Wood (2014).
} 


\subsubsection{Limitations and Extensions}

One of the major limitations to this study is the lack of detailed commuting data across time. This study only utilizes data from 2017 in California. Additionally, because the commuting data does not ask respondents if they use HOV lanes when they go to or from work, this can still just be seen as an intent to treat analysis. However, if the mechanism of induced demand is at play, the impact of HOV lanes on commute times affects all commuters, not just those who take an HOV lane to or from work.

For further extensions of this paper, more detailed data on HOV lanes could be obtained. Data on HOV lane locations and statuses varies considerably across the country, so expanding this idea beyond California would take a considerable amount of effort. Additionally, the level of analysis in this work may still not be detailed enough to try to accurately capture the effects of HOV lanes. 18

\subsection{Conclusions and Policy Implications}

HOV lane construction can be a costly project, but the benefits from this type of project have been arguably understudied, particularly from a causal inference perspective. This paper finds that HOV lanes generally cause an increase in commute times to or from work in California using an instrumental variable approach. To reach these findings, a newly proposed instrument, historic county vote share, as well as a more well-established instrument, the 1947 highway plan, are utilized. The results runs counter to the intended purpose of HOV lanes. This finding follows previous literature discussing the impact of additional road lane construction (Duranton \& Turner, 2011). The induced demand from an additional road lane, regardless of its intended purpose, seems to directly influence the commute times of all who drive on that road. If these lanes are not

\footnotetext{
${ }^{18}$ Confidential data from the NREL does include information about the drivers' census tract, and even exact latitude and longitude of residence. Re-running the above empirical analysis at the census tract level seems like the next step to try to uncover the true treatment effect of HOV lanes on commute times.
} 
reducing commute times, as is their intention, the potential negative consequences associated with increased commutes and congestion are numerous. ${ }^{19}$

The policy implications of these findings are particularly important considering that all new HOV lanes in California are essentially new roads (never converted from existing roads). Not only is road construction expensive, it is particularly expensive in California due to high land and labor costs. To recover some lost revenue from constructing these lanes, the California Department of Transportation could convert them into HOT or express lanes. If places want to keep them free, counties could promote the use of ride sharing apps and make carpooling easier for those going to or coming home from work.

\footnotetext{
${ }^{19}$ Most obvious are the increase in aggressive and stressful emotions of drivers and additional health risks associated with pollution from car emissions. See Currie and Walker (2011) and Hennessy and Wiesenthal (1999) for two of numerous examples of consequences of increased traffic and commute times.
} 
Table 1.1: California HOV Lanes and Commuting

\begin{tabular}{lccccc}
\hline & Mean & S.D. & Min & Max & Total (State) \\
\hline Panel A: HOV Lanes by County & & & & & \\
\hline Count of HOV Lanes & 2.1 & 5.07 & 0.00 & 29.00 & 124.0 \\
Total HOV miles & 23.6 & 69.20 & 0.00 & 438.20 & 1370.6 \\
\hline$N$ & 58 counties & & & & \\
\hline Panel B: Commuting Characteristics & & & & & \\
\hline Time to Work & 27.89 & 28.66 & 1.00 & 600.00 & 18,939 \\
Short Commute & 0.68 & 0.47 & 0.00 & 1.00 & 18,939 \\
Long Commute & 0.33 & 0.47 & 0.00 & 1.00 & 18,939 \\
Distance to Work & 20.87 & 112.56 & 0.01 & 3135.34 & 18,939 \\
\hline$N$ & 18,939 trips & & & & \\
\hline
\end{tabular}

Notes: Summary statistics for HOV lanes by California county are shown above in Panel A. Data on HOV lanes were sourced from the California Department of Transportation. Summary statistics for California commuting are shown in Panel B. Data is taken from the "Trip" file of the NHTS. Time to work is measured in minutes. Only trips that indicated they were to or from work were examined. Short commute indicates the proportion of California counties that had an average commute time below the state average (27.89 minutes). Long commute indicates the proportion of California counties that had an average commute time above the state average. Distance to work is measured in miles. 
Figure 1.1: California Primary Roads and HOV Lane Locations

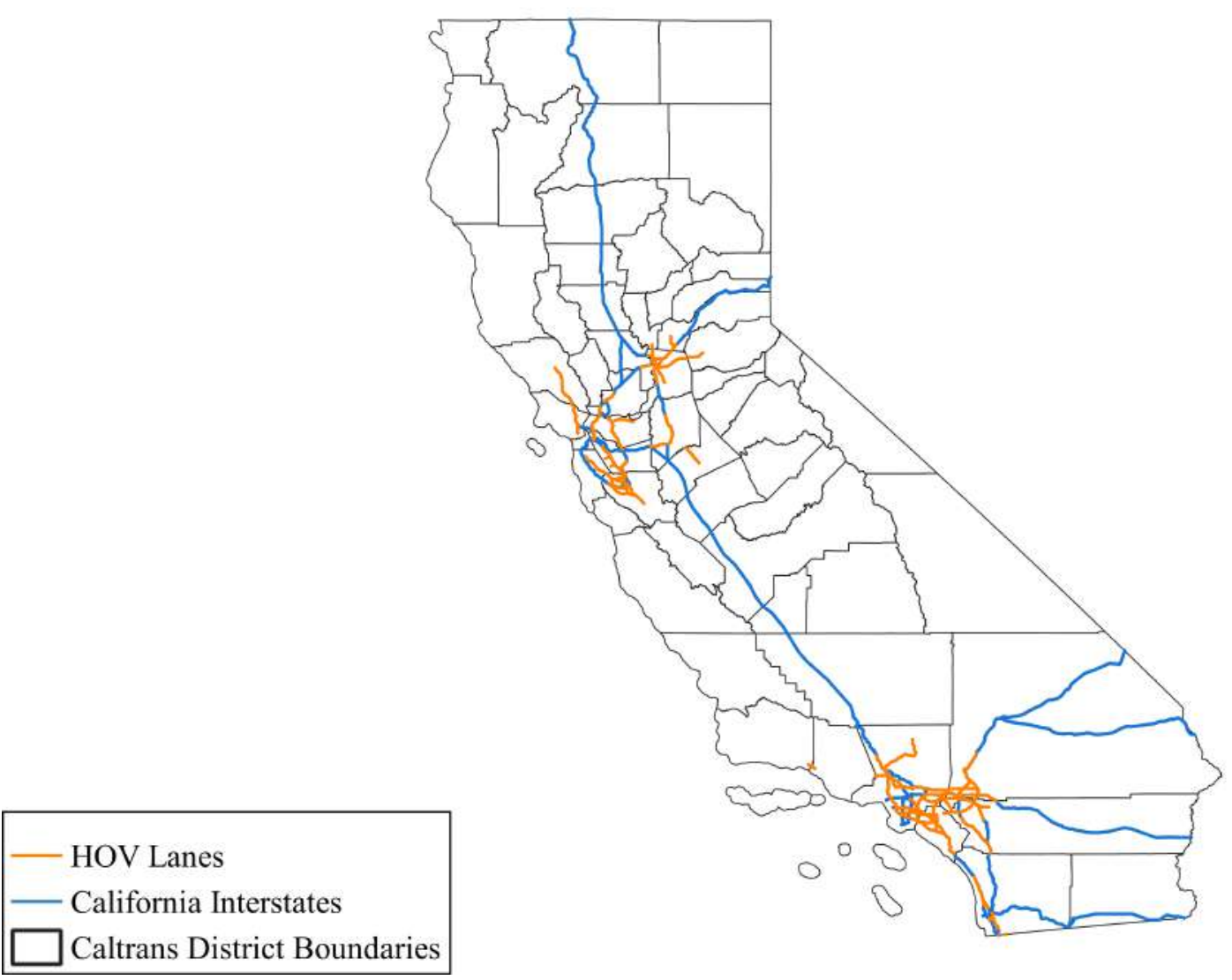

Note: Figure displays map of California. Interstates are shown in blue and completed HOV lanes as of 2017 are shown in orange. Although California has the most miles of HOV lanes in the country, most are concentrated in Sacramento, San Francisco, and Los Angeles. HOT (high occupancy toll) lanes, those lanes in which a toll is charged to use the carpool lane, are not included in the analysis. 
Table 1.2: Urban Size Classifications

\begin{tabular}{lcc}
\hline Population & Count of Commuters & Percent of Commuters \\
\hline $50,000-199,999$ & 3,175 & 16.76 \\
200,000-499,999 & 1,505 & 7.95 \\
$500,000-999,999$ & 1,062 & 5.61 \\
1 million or more without heavy rail & 4,594 & 24.26 \\
1 million or more with heavy rail & 4,767 & 25.17 \\
Not an urban area & 3,836 & 20.25 \\
\hline Total & 18,939 & 100.00 \\
\hline
\end{tabular}

Notes: Summary statistics for household urban size classification are shown above. 
Table 1.3: Naive Linear Regression Before Matching: Effect of HOV Lanes on Commute Time

\begin{tabular}{lccccc}
\hline Treatment & $\begin{array}{c}(1) \\
\text { Binary }\end{array}$ & $\begin{array}{c}(2) \\
50 \text { miles }\end{array}$ & $\begin{array}{c}(3) \\
\leq 25 \text { miles }\end{array}$ & $\begin{array}{c}(4) \\
10 \text { miles }\end{array}$ & $\begin{array}{c}(5) \\
\text { Panel A: No County F.E. }\end{array}$ \\
\hline HOV Lanes & $11.04^{* * *}$ & $10.77^{* * *}$ & $9.96^{* * *}$ & $8.31^{* * *}$ & $7.28^{* * *}$ \\
& $(3.93)$ & $(2.25)$ & $(2.27)$ & $(2.46)$ & $(2.25)$ \\
& {$[0.01]$} & {$[0.00]$} & {$[0.00]$} & {$[0.01]$} & {$[0.02]$} \\
\hline$N$ & 18939 & 18939 & 18939 & 18939 & 18939 \\
\hline Individual Controls & $\mathrm{X}$ & $\mathrm{X}$ & $\mathrm{X}$ & $\mathrm{X}$ & $\mathrm{X}$ \\
Distance to Work Control & $\mathrm{X}$ & $\mathrm{X}$ & $\mathrm{X}$ & $\mathrm{X}$ & $\mathrm{X}$ \\
Urban Size Controls & $\mathrm{X}$ & $\mathrm{X}$ & $\mathrm{X}$ & $\mathrm{X}$ & $\mathrm{X}$ \\
Travel Day Controls & $\mathrm{X}$ & $\mathrm{X}$ & $\mathrm{X}$ & $\mathrm{X}$ & $\mathrm{X}$ \\
County Fixed Effects & - & - & - & - & - \\
\hline$R^{2}$ & 0.056 & 0.057 & 0.061 & 0.054 & 0.050 \\
Cluster-Robust S.E. & $\mathrm{X}$ & $\mathrm{X}$ & $\mathrm{X}$ & $\mathrm{X}$ & $\mathrm{X}$ \\
\hline Panel B: County F.E. & & & & & \\
\hline HOV Lanes & $17.77^{* * *}$ & $32.28^{* * *}$ & $17.77^{* * *}$ & $17.77^{* * *}$ & $17.77^{* * *}$ \\
& $(2.42)$ & $(2.24)$ & $(2.42)$ & $(2.42)$ & $(2.42)$ \\
& {$[0.00]$} & {$[0.00]$} & {$[0.00]$} & {$[0.00]$} & {$[0.00]$} \\
\hline$N$ & 18939 & 18939 & 18939 & 18939 & 18939 \\
\hline Individual Controls & $\mathrm{X}$ & $\mathrm{X}$ & $\mathrm{X}$ & $\mathrm{X}$ & $\mathrm{X}$ \\
Distance to Work Control & $\mathrm{X}$ & $\mathrm{X}$ & $\mathrm{X}$ & $\mathrm{X}$ & $\mathrm{X}$ \\
Urban Size Controls & $\mathrm{X}$ & $\mathrm{X}$ & $\mathrm{X}$ & $\mathrm{X}$ & $\mathrm{X}$ \\
Travel Day Controls & $\mathrm{X}$ & $\mathrm{X}$ & $\mathrm{X}$ & $\mathrm{X}$ & $\mathrm{X}$ \\
County Fixed Effects & $\mathrm{X}$ & $\mathrm{X}$ & $\mathrm{X}$ & $\mathrm{X}$ & $\mathrm{X}$ \\
\hline$R^{2}$ & 0.11 & 0.11 & 0.11 & 0.11 & 0.11 \\
Cluster-Robust S.E. & $\mathrm{X}$ & $\mathrm{X}$ & $\mathrm{X}$ & $\mathrm{X}$ & $\mathrm{X}$ \\
\hline
\end{tabular}

Notes: $* \mathrm{p}<0.1, * * \mathrm{p}<0.05$, *** $\mathrm{p}<0.01$. Cluster-robust standard errors are shown in parentheses and $\mathrm{p}$ statistics are shown in brackets. All models include individual controls (age, sex, education level, occupation type), distance to work controls, urban size controls, and travel day controls. County fixed effects are added in Panel B. Standard errors are clustered at the county level. 
Table 1.4: Summary Statistics Before Matching

\begin{tabular}{lccc}
\hline & Control County & Treated County & Difference \\
\hline Trip Characteristics & & & \\
\hline Time to Work & 22.86 & 31.37 & $-20.30^{* * *}$ \\
Short Commute & $(0.30)$ & $(0.280)$ & {$[0.00]$} \\
& 0.93 & 0.50 & $67.88^{* * *}$ \\
Long Commute & $(0.003)$ & $(0.005)$ & {$[0.00]$} \\
& 0.08 & 0.50 & $-67.88^{* * *}$ \\
Distance to work & $(0.003)$ & $(0.005)$ & {$[0.00]$} \\
& 20.47 & 21.14 & -0.41 \\
Driver Characteristics & $(1.50)$ & $(0.92)$ & {$[0.34]$} \\
\hline Male driver & & & \\
Female driver & 0.48 & 0.52 & $-4.66 * * *$ \\
& $(0.006)$ & $(0.005)$ & {$[0.00]$} \\
Less than high school & 0.52 & 0.48 & $4.66 * * *$ \\
Age & $(0.006)$ & $(0.005)$ & {$[0.00]$} \\
& 0.03 & 0.02 & $3.84 * * *$ \\
& $(0.002)$ & $(0.001)$ & {$[0.00]$} \\
Work Characteristics & 46.24 & 45.16 & $5.15 * * *$ \\
\hline Sales & $(0.17)$ & $(0.13)$ & {$[0.00]$} \\
\hline Manufacturing & & & \\
\hline
\end{tabular}

Notes: ${ }^{*} \mathrm{p}<0.1,{ }^{* *} \mathrm{p}<0.05,{ }^{* * *} \mathrm{p}<0.01$. Means for control and treated counties are shown above. T-tests were used to test for the difference in means. Standard errors are shown in parentheses and p-values are shown in brackets. 
Table 1.5: Summary Statistics After Matching

\begin{tabular}{|c|c|c|c|}
\hline & Control County & Treated County & Difference \\
\hline \multicolumn{4}{|l|}{ Trip Characteristics } \\
\hline \multirow[t]{2}{*}{ Time to Work } & 22.66 & 30.73 & $-18.88 * * *$ \\
\hline & $(0.28)$ & $(0.32)$ & {$[0.00]$} \\
\hline \multirow[t]{2}{*}{ Short Commute } & 0.92 & 0.52 & $62.11 * * *$ \\
\hline & $(0.003)$ & $(0.006)$ & {$[0.00]$} \\
\hline \multirow[t]{2}{*}{ Long Commute } & 0.08 & 0.48 & $-62.11 * * *$ \\
\hline & $(0.003)$ & $(0.006)$ & {$[0.00]$} \\
\hline \multirow[t]{2}{*}{ Distance to work } & 13.35 & 16.46 & $-4.50 * * *$ \\
\hline & $(0.48)$ & $(0.49)$ & {$[0.00]$} \\
\hline \multicolumn{4}{|l|}{ Driver Characteristics } \\
\hline \multirow[t]{2}{*}{ Male driver } & 0.48 & 0.48 & 0.00 \\
\hline & $(0.006)$ & $(0.006)$ & {$[0.50]$} \\
\hline \multirow[t]{2}{*}{ Female driver } & 0.52 & 0.52 & 0.00 \\
\hline & $(0.005)$ & $(0.005)$ & {$[0.50]$} \\
\hline \multirow[t]{2}{*}{ Less than high school } & 0.02 & 0.02 & 0.00 \\
\hline & $(0.002)$ & $(0.002)$ & {$[0.50]$} \\
\hline \multirow[t]{2}{*}{ Age } & 46.01 & 45.99 & 0.07 \\
\hline & $(0.17)$ & $(0.13)$ & {$[0.53]$} \\
\hline \multicolumn{4}{|l|}{ Work Characteristics } \\
\hline \multirow[t]{2}{*}{ Sales } & 0.23 & 0.23 & -1.12 \\
\hline & $(0.005)$ & $(0.005)$ & {$[0.13]$} \\
\hline \multirow[t]{2}{*}{ Manufacturing } & 0.13 & 0.10 & $5.28 * * *$ \\
\hline & $(0.004)$ & $(0.004)$ & {$[0.00]$} \\
\hline Number of trips & 7,507 & 7,507 & \\
\hline
\end{tabular}

Notes: ${ }^{*} \mathrm{p}<0.1,{ }^{* *} \mathrm{p}<0.05,{ }^{* * *} \mathrm{p}<0.01$. Means for control and treated counties are shown above. T-tests were used to test for the difference in means. Standard errors are shown in parentheses and p-values are shown in brackets. 
Table 1.6: Naive Linear Regression After Matching: Effect of HOV Lanes on Commute Time

\begin{tabular}{lccccc}
\hline & $\begin{array}{c}(1) \\
\text { Treatment }\end{array}$ & $\begin{array}{c}(2) \\
\leq 50 \text { miles }\end{array}$ & $\begin{array}{c}(3) \\
\leq 25 \text { miles }\end{array}$ & $\begin{array}{c}(4) \\
\leq 10 \text { miles }\end{array}$ & $\begin{array}{c}(5) \\
\leq 5 \text { miles }\end{array}$ \\
\hline Panel A: No County F.E. & & & & & \\
\hline HOV Lanes & $8.39^{* * *}$ & $9.68^{* * *}$ & $8.95^{* * *}$ & $7.84^{* * *}$ & $7.33^{* * *}$ \\
& $(3.72)$ & $(2.00)$ & $(1.97)$ & $(2.21)$ & $(2.25)$ \\
& {$[0.03]$} & {$[0.00]$} & {$[0.00]$} & {$[0.01]$} & {$[0.01]$} \\
\hline$N$ & 15014 & 10420 & 16376 & 15712 & 14016 \\
\hline Individual Controls & $\mathrm{X}$ & $\mathrm{X}$ & $\mathrm{X}$ & $\mathrm{X}$ & $\mathrm{X}$ \\
Distance to Work Control & $\mathrm{X}$ & $\mathrm{X}$ & $\mathrm{X}$ & $\mathrm{X}$ & $\mathrm{X}$ \\
Urban Size Controls & $\mathrm{X}$ & $\mathrm{X}$ & $\mathrm{X}$ & $\mathrm{X}$ & $\mathrm{X}$ \\
Travel Day Controls & $\mathrm{X}$ & $\mathrm{X}$ & $\mathrm{X}$ & $\mathrm{X}$ & $\mathrm{X}$ \\
County Fixed Effects & - & - & - & - & - \\
\hline$R^{2}$ & 0.09 & 0.09 & 0.09 & 0.08 & 0.07 \\
Cluster-Robust S.E. & $\mathrm{X}$ & $\mathrm{X}$ & $\mathrm{X}$ & $\mathrm{X}$ & $\mathrm{X}$
\end{tabular}

\begin{tabular}{lccccc}
\hline Panel B: County F.E. & \multicolumn{7}{c}{} \\
\hline HOV Lanes & $14.59^{* * *}$ & $24.21^{* * *}$ & $15.65^{* * *}$ & $16.58^{* * *}$ & $13.62^{* * *}$ \\
& $(2.17)$ & $(1.99)$ & $(1.99)$ & $(1.99)$ & $(2.10)$ \\
& {$[0.00]$} & {$[0.00]$} & {$[0.00]$} & {$[0.01]$} & {$[0.01]$} \\
\hline$N$ & 15014 & 10420 & 16376 & 15712 & 14016 \\
\hline Individual Controls & $\mathrm{X}$ & $\mathrm{X}$ & $\mathrm{X}$ & $\mathrm{X}$ & $\mathrm{X}$ \\
Distance to Work Control & $\mathrm{X}$ & $\mathrm{X}$ & $\mathrm{X}$ & $\mathrm{X}$ & $\mathrm{X}$ \\
Urban Size Controls & $\mathrm{X}$ & $\mathrm{X}$ & $\mathrm{X}$ & $\mathrm{X}$ & $\mathrm{X}$ \\
Travel Day Controls & $\mathrm{X}$ & $\mathrm{X}$ & $\mathrm{X}$ & $\mathrm{X}$ & $\mathrm{X}$ \\
County Fixed Effects & $\mathrm{X}$ & $\mathrm{X}$ & $\mathrm{X}$ & $\mathrm{X}$ & $\mathrm{X}$ \\
\hline$R^{2}$ & 0.12 & 0.14 & 0.13 & 0.12 & 0.11 \\
Cluster-Robust S.E. & $\mathrm{X}$ & $\mathrm{X}$ & $\mathrm{X}$ & $\mathrm{X}$ & $\mathrm{X}$ \\
\hline
\end{tabular}

Notes: $* \mathrm{p}<0.1, * * \mathrm{p}<0.05, * * * \mathrm{p}<0.01$. Cluster-robust standard errors are shown in parentheses and $\mathrm{p}$ statistics are shown in brackets. All models include individual controls (age, sex, education level, occupation type), distance to work controls, urban size controls, and travel day controls. County fixed effects are added in Panel B. Standard errors are clustered at the county level. 
Figure 1.2: Votes for Al Gore in the 2000 Presidential Election

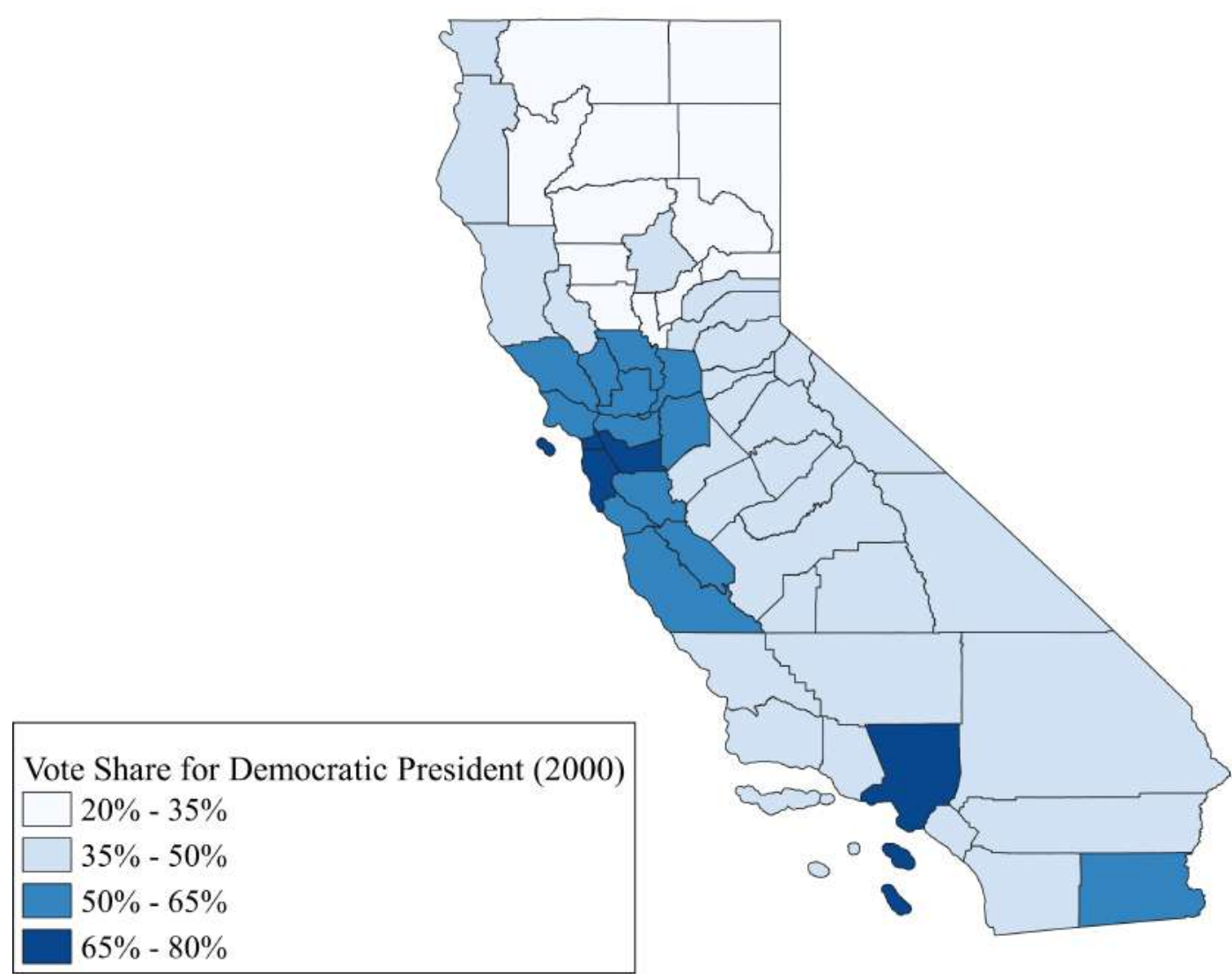

Note: Figure displays heat map of votes for Al Gore in the 2000 presidential election. Higher concentrations of votes may indicate preferences for environmentally friendly pursuits. Comparing with Figure 1.1, the locations of HOV lanes are highly correlated with larger vote shares for the Democratic party in the 2000 election. 
Table 1.7: Timing of HOV Lane Openings

\begin{tabular}{lccc}
\hline & Before 2000 & In or After 2000 & Total \\
\hline \# of HOV lanes open (as of 2017) & 43 & 81 & 124 \\
Under Construction (as of 2017) & - & 57 & 57 \\
Planned Construction & - & 11 & 11 \\
\hline
\end{tabular}

Notes: Table shows the timing of HOV lane construction across the state of California. 
Figure 1.3: HOV Lanes, Primary Roads, and Caltrans Districts

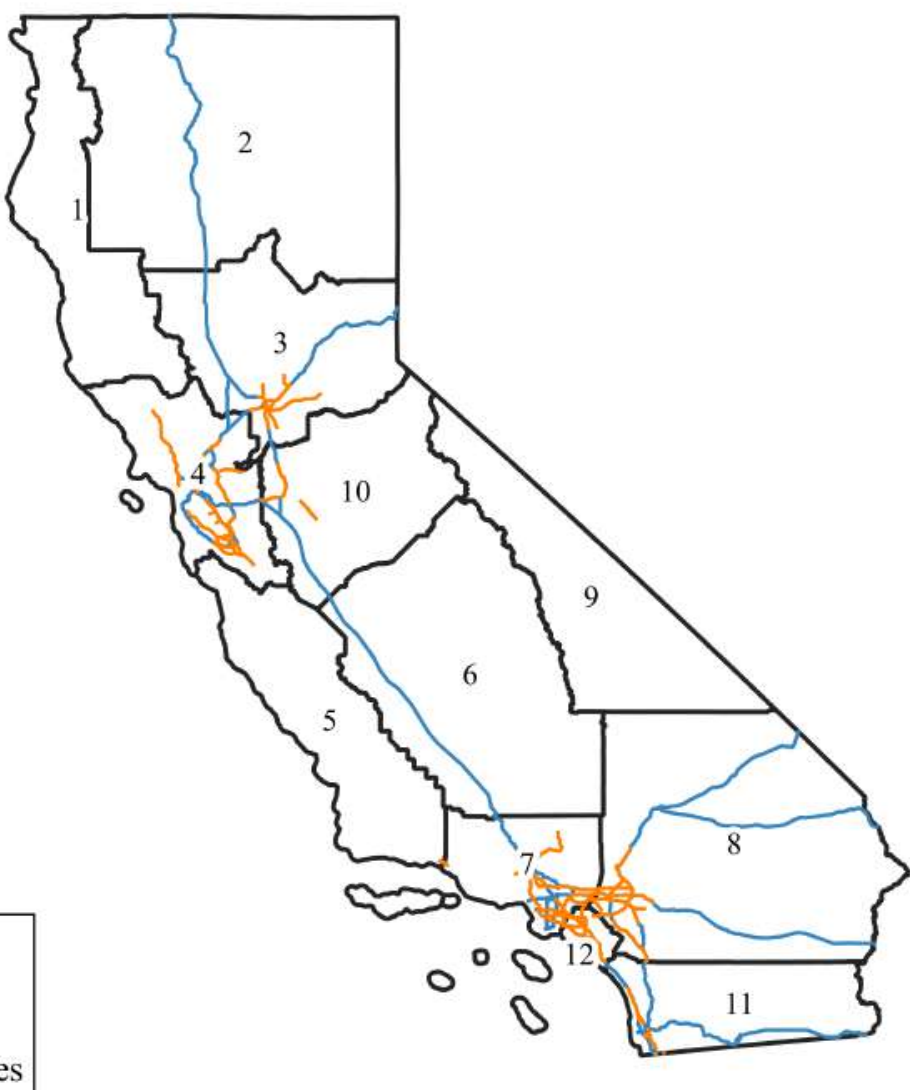

Note: Map shows the divisions of Caltrans districts. Blue lines represent California primary roads, while orange lines represent HOV lanes. Source: https: //dot.ca.gov/caltrans-near-me

Table 1.8: Open HOV Lanes by Caltrans District

\begin{tabular}{lcccccc}
\hline $\begin{array}{l}\text { Caltrans District } \\
\text { Major Metro. Area }\end{array}$ & 3 & 4 & 7 & 8 & 11 & 12 \\
\hline \# of HOV lanes open before 2000 & 4 & 10 & 14 & 5 & 4 & 6 \\
\# of HOV lanes open after 2000 & 8 & 34 & 17 & 12 & 3 & 7 \\
\hline
\end{tabular}

Notes: HOV lanes by Caltrans district are shown above. The sample is split before and after 2000 to highlight the persistent nature of HOV lane construction - places that historically had more HOV lanes continued to construct them. 
Figure 1.4: 1947 Interstate Highway Plan

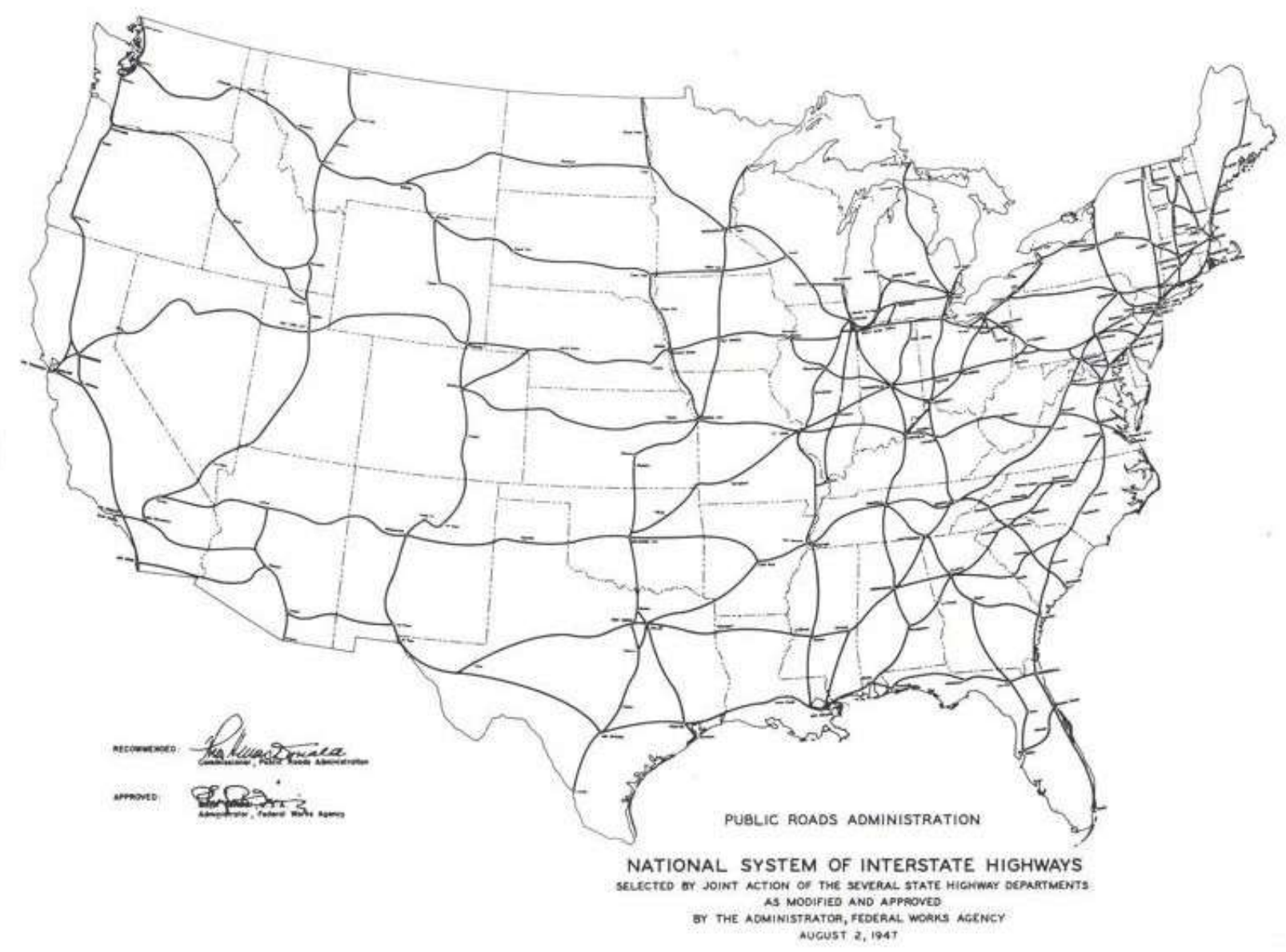

Note: Figure displays the 1947 highway plan drawn by the U.S. House of Representatives. This plan was drawn to increase mobility between U.S. cities for the purposes of domestic trade and national defense. Source: United States House of Representatives (1947). 
Table 1.9: 2SLS Estimates With 2000 Democratic Vote Share After Matching: HOV Lanes on Commute Times

\begin{tabular}{|c|c|c|c|}
\hline Panel A: Any HOV Lane in County & $\begin{array}{c}(1) \\
\text { Reduced Form }\end{array}$ & $\begin{array}{c}(2) \\
\text { 1st Stage }\end{array}$ & $\begin{array}{c}(3) \\
\text { 2nd Stage }\end{array}$ \\
\hline County Vote Share for Democratic President & $\begin{array}{l}49.473 * * * \\
(3.679)\end{array}$ & $\begin{array}{c}0.731 * * * \\
(0.040)\end{array}$ & \\
\hline Commute Time to Work & & & $\begin{array}{c}67.651 * * * \\
(5.627)\end{array}$ \\
\hline $\mathrm{N}$ & & & 15014 \\
\hline Kleibergen-Paap F & & & 320.12 \\
\hline \multicolumn{4}{|l|}{ Panel B: $\leq 50$ miles to nearest HOV Lane } \\
\hline County Vote Share for Democratic President & $\begin{array}{c}46.653 * * * \\
(3.926)\end{array}$ & $\begin{array}{c}1.992 * * * \\
(0.040)\end{array}$ & \\
\hline Commute Time to Work & & & $\begin{array}{c}23.419 * * * \\
(1.984)\end{array}$ \\
\hline $\mathrm{N}$ & & & 10420 \\
\hline Kleibergen-Paap F & & & 2481.92 \\
\hline \multicolumn{4}{|l|}{ Panel C: $\leq 25$ miles to nearest HOV Lane } \\
\hline County Vote Share for Democratic President & $\begin{array}{c}48.149 * * * \\
(3.319)\end{array}$ & $\begin{array}{c}2.509 * * * \\
(0.033)\end{array}$ & \\
\hline Commute Time to Work & & & $\begin{array}{c}19.191 * * * \\
(1.313)\end{array}$ \\
\hline $\mathrm{N}$ & & & 16376 \\
\hline Kleibergen-Paap F & & & 5959.17 \\
\hline \multicolumn{4}{|l|}{ Panel D: $\leq 10$ miles to nearest HOV Lane } \\
\hline County Vote Share for Democratic President & $\begin{array}{c}52.542 * * * \\
(3.610)\end{array}$ & $\begin{array}{c}1.740 * * * \\
(0.041)\end{array}$ & \\
\hline Commute Time to Work & & & $\begin{array}{c}30.190 * * * \\
(2.107)\end{array}$ \\
\hline $\mathrm{N}$ & & & 15712 \\
\hline Kleibergen-Paap F & & & 1790.41 \\
\hline \multicolumn{4}{|l|}{ Panel E: $\leq 5$ miles to nearest HOV Lane } \\
\hline County Vote Share for Democratic President & $\begin{array}{l}53.237 * * * \\
(3.615)\end{array}$ & $\begin{array}{c}1.216 * * * \\
(0.043)\end{array}$ & \\
\hline Commute Time to Work & & & $\begin{array}{c}43.784 * * * \\
(3.124)\end{array}$ \\
\hline $\begin{array}{l}\mathrm{N} \\
\text { Kleibergen-Paap F }\end{array}$ & & & $\begin{array}{l}14016 \\
800.30\end{array}$ \\
\hline
\end{tabular}

Notes: $* \mathrm{p}<0.1, * * \mathrm{p}<0.05, * * * \mathrm{p}<0.01$. Dependent variable is commute time to work in minutes. Robust standard errors are shown in parentheses. First stage F-statistics are reported, as well as the number of trips included in each treatment definition (N). Instrument for HOV lane treatment is the 2000 vote share for a Democratic president. All models include individual controls (age, sex, education lelel, occupation type), distance to work controls, urban size controls, and travel day controls. 
Table 1.10: 2SLS Estimates With 1947 Highway Plan After Matching: HOV Lanes on Commute Times

\begin{tabular}{|c|c|c|c|}
\hline Panel A: Any HOV Lan & $\begin{array}{c}(1) \\
\text { Reduced Form }\end{array}$ & $\begin{array}{c}(2) \\
\text { 1st Stage }\end{array}$ & $\begin{array}{c}(3) \\
\text { 2nd Stage }\end{array}$ \\
\hline Distance to 1947 Plan & $\begin{array}{c}-0.071 * * * \\
(0.009)\end{array}$ & $\begin{array}{c}-0.004 * * * \\
(0.000)\end{array}$ & \\
\hline Commute Time to Work & & & $\begin{array}{c}16.675^{* * * *} \\
(2.146)\end{array}$ \\
\hline $\mathrm{N}$ & & & 15014 \\
\hline Kleibergen-Paap F & & & 1532.11 \\
\hline \multicolumn{4}{|c|}{ Panel B: $\leq 50$ miles to nearest HOV Lane } \\
\hline Distance to 1947 Plan & $\begin{array}{c}-0.055^{* * * *} \\
(0.010)\end{array}$ & $\begin{array}{c}-0.002 * * * \\
(0.000)\end{array}$ & \\
\hline Commute Time to Work & & & $\begin{array}{c}25.590 * * * \\
(4.623)\end{array}$ \\
\hline $\mathrm{N}$ & & & 10420 \\
\hline Kleibergen-Paap F & & & 215.941 \\
\hline \multicolumn{4}{|c|}{ Panel C: $\leq 25$ miles to nearest HOV Lane } \\
\hline Distance to 1947 Plan & $\begin{array}{c}-0.073 * * * \\
(0.009)\end{array}$ & $\begin{array}{c}-0.004 * * * \\
(0.000)\end{array}$ & \\
\hline Commute Time to Work & & & $\begin{array}{c}14.719 * * * \\
(1.881)\end{array}$ \\
\hline $\mathrm{N}$ & & & 16376 \\
\hline Kleibergen-Paap F & & & 1734.42 \\
\hline \multicolumn{4}{|c|}{ Panel D: $\leq 10$ miles to nearest HOV Lane } \\
\hline Distance to 1947 Plan & $\begin{array}{c}-0.080 * * * \\
(0.010)\end{array}$ & $\begin{array}{c}-0.007 * * * \\
(0.000)\end{array}$ & \\
\hline Commute Time to Work & & & $\begin{array}{c}12.154 * * * \\
(1.536)\end{array}$ \\
\hline $\mathrm{N}$ & & & 15712 \\
\hline Kleibergen-Paap F & & & 2872.85 \\
\hline \multicolumn{4}{|c|}{ Panel E: $\leq 5$ miles to nearest HOV Lane } \\
\hline Distance to 1947 Plan & $\begin{array}{c}-0.079 * * * \\
(0.012)\end{array}$ & $\begin{array}{c}-0.007 * * * \\
(0.000)\end{array}$ & \\
\hline Commute Time to Work & & & $\begin{array}{c}11.024 * * * \\
(1.628)\end{array}$ \\
\hline $\mathrm{N}$ & & & 14016 \\
\hline Kleibergen-Paap F & & & 2816.89 \\
\hline
\end{tabular}

Notes: $* \mathrm{p}<0.1, * * \mathrm{p}<0.05, * * * \mathrm{p}<0.01$. Dependent variable is commute time to work in minutes. Robust standard errors are shown in parentheses. First stage F-statistics are reported, as well as the number of trips included in each treatment definition $(\mathrm{N})$. Instrument for HOV lane treatment is the county centroid distance to nearest segment of the 1947 highway plan. All models include individual contro31s (age, sex, education level, occupation type), distance to work controls, urban size controls, and travel day controls. 


\section{Chapter 2}

\section{The Empirical Political Economy of Local}

\section{Road Maintenance}

Roads and highways are linked to location of employment, population, and economic growth (A. Agrawal, Galasso, \& Oettl, 2017; Baum-Snow, 2007; Chandra \& Thompson, 2000; Duranton \& Turner, 2011). Maintaining transportation links is crucial for economic activity, and U.S. states under-provide maintenance investment (Kalyvitis \& Vella, 2015). However, maintenance is expensive; state and local investment in government nonresidential fixed assets, like infrastructure, cost \$304.3 billion in 2018 (Zhao, Fonseca-Sarimento, \& Tan, 2019).

According to Winston (2013), policymakers have wasted resources by investing, or not investing, in infrastructure projects not selected by careful analysis. ${ }^{1}$ If political motivations shift timing and location of road maintenance projects at the local level (Glaeser \& Shleifer, 2005), measuring the size and nature of shifts is crucial given the importance of infrastructure maintenance for economic activity (Kalaitzidakis \& Kalyvitis, 2004; Rioja, 2003). In Figure 2.1, we graph the count of road maintenance projects in the city of Pittsburgh, Pennsylvania. Strikingly, the month before the local mayoral election (October) has less projects during mayoral election years, which sug-

\footnotetext{
${ }^{1}$ Elected officials respond to incentives and one of their goals is to retain their position. Re-election is determined by receiving votes from specific geographic units, which could lead to inefficient spending patterns (Weingast, Shepsle, \& Johnsen, 1981).
} 
gests political incentives are relevant for road maintenance in Pittsburgh. ${ }^{2}$ The research question we examine is if reduced autumn maintenance, during mayoral election years, is due to political incentives.

A shift in maintenance across city wards and months due to election year incentives likely represents a deviation from the optimal maintenance plan. ${ }^{3}$ Deviating from the optimal maintenance plan is costly, since longer delays in maintenance work leads to higher costs of maintenance (Burningham \& Stankevich, 2005). Furthermore, new road construction is often more politically favorable in the long-run compared to road maintenance (Schmitt, 2015). Balancing new construction and maintenance of existing infrastructure has been shown to increase aggregate output and reduce income inequality (Gibson \& Rioja, 2017).

Existing results in the literature find seemingly contradictory signs for the political value of road maintenance/construction. Empirical results suggest road maintenance increases party vote share in a county-level analysis for one state (Huet-Vaughn, 2019), but the theoretical results suggest urban voters oppose road construction (Glaeser \& Ponzetto, 2018). Brueckner and Selod (2006) and Glaeser and Ponzetto (2018) both consider the traffic and disruption of urban interstate construction a disamenity to local residents. ${ }^{4}$ One discrepancy between theoretical (Brueckner $\&$ Selod, 2006; Glaeser \& Ponzetto, 2018) and empirical analyses (Huet-Vaughn, 2019) is the geographic level of interest. Different levels of analysis could be the sole reason the findings differ, but prior empirical work only takes place at a scale larger than the local city level. Previous attempts to estimate the effect of political incentives on urban infrastructure have occurred at the regional (Knight, 2005) or national (Rioja, 2003) level, despite the fact that government agents in the theoretical models (Brueckner \& Selod, 2006; Glaeser \& Ponzetto, 2018; Glaeser \& Shleifer, 2005)

\footnotetext{
${ }^{2}$ Pittsburgh, Pennsylvania data is used in this paper.

${ }^{3}$ Deviating from optimal maintenance due to election cycles implies Road Needs Repair $=f(\beta *$ Election Year $=1$, Climate, Truck VMT, other $), \beta=0$. The amount of road repair necessary is not a function of election cycles, absent political incentives.

${ }^{4}$ The empirical results in Huet-Vaughn (2019) suggest vote-maximizing politicians should strategically locate maintenance in places that are less likely to vote for them in an upcoming election, as that election approaches. The theoretical findings (Brueckner \& Selod, 2006; Glaeser \& Ponzetto, 2018) suggest vote-maximizing politicians should do the opposite.
} 
are best thought of as being local leaders exercising power at the local level. More empirical work towards discovering the source of these discrepancies is warranted.

This paper uncovers the causal effect of political incentives on road maintenance decisions at the local city level using difference-in-differences (DD). The post period is mayoral election years. Treatment and control groups are defined using registered voters of the opposite party of the mayor. Proportion of registered voters of the opposite party is a plausible measurement of the intensity of political incentive to complete maintenance at certain times in city wards. The data are well-suited to address spatial scale as being a factor in seemingly contrasting prior findings. ${ }^{5}$

Road maintenance projects are shifted across months during mayoral election cycles according to alignment deviation of the constituency. During mayoral election years, wards with relatively large deviations in political alignment away from the mayor see a significant increase in road maintenance projects in summer months compared to more similar wards. This suggests road maintenance is perceived as a signal of competence to unaligned areas in the summer months of an election year. However, this pattern flips in October, the month before the votes are cast in mayoral election years. This is consistent with political leaders not wanting to upset constituencies with the disamenity of road maintenance as the election draws closer. These results suggest that road maintenance is both as a disamenity and signal of competence.

Using estimates from the literature on the cost of maintenance as a function of how long maintenance is delayed (Burningham \& Stankevich, 2005), the DD coefficients are used to quantify the infrastructure maintenance financial cost due to local political incentives. These cost calculations are conservative due to the relatively uncontested political environment of Pittsburgh. The calculations suggest local elections in medium-large cities in the U.S. have cost over $\$ 185.5$ million in the past sixty years, over $\$ 3$ million a year. ${ }^{6}$

\footnotetext{
${ }^{5}$ The spatial scale of the current analysis is the local level; this allows investigation into whether spatial scale causes differences between previous empirical and theoretical findings.

${ }^{6}$ Cities with at least 100,000 people are considered at least medium-sized (World Population Review, 2020).
} 


\subsection{Literature}

First, we discuss the political economy and road maintenance. Then, we describe the political alignment literature, since it influences the methods. Finally, we summarize research on road maintenance.

\subsubsection{Theoretical Political Economy and Infrastructure}

Political economy matters for infrastructure investment and maintenance. Glaeser and Ponzetto (2018) highlight the rise of disamenities in urban areas associated with road construction and the response by political actors to these constituent-faced disamenities. ${ }^{7}$ The disamenities of construction explicitly mentioned include noise, pollution, and eminent-domain concerns. Glaeser and Shleifer (2005) show theoretically and through three case study examples, some mayors shape the electorate to benefit their re-election possibilities. The so-called "Curley Effect," named for the infamous Boston mayor's extraordinary proclivity to pursue politically-minded transfers, shows local, elected officials reallocate public funds when political gains can be accrued.

\subsubsection{Political Alignment}

Many studies investigate the effect of political alignment on transfers resulting from federalist systems of government, where nationally collected taxes are distributed to lower levels of government. Solé-Ollé and Sorribas-Navarro (2008) study Spain's 900 municipalities over 10 years and finds intergovernmental transfers are more likely among levels of government that are of the same party. Similar investigations use data from India (Asher \& Novosad, 2017), Brazil (Brollo \& Nannicini, 2012), Portugal (Migueis, 2013), and Italy (Bracco, Lockwood, Porcelli, \& Redoano, 2015). Bracco et al. (2015) develops a theoretical model which assumes rational voters who interpret public good provision as a signal of incumbent competence. This assumption stands in contrast to the

\footnotetext{
${ }^{7}$ The conclusions of the model in Glaeser and Ponzetto (2018) are supplemented using an analytic narrative of U.S. road infrastructure in the post World War II era. The narrative simplifies the era into three rough chapters of U.S. national investment in roads: a period of over-investment due to national subsidies, a period of under-investment as the disamenities of construction became clear, and then a period where large sums were spent to mitigate the disamenities.
} 
disamenity assumption of Glaeser and Ponzetto (2018). Bracco et al. (2015) also assume the electorate does not observe the grant allocation; however, road maintenance is a visually salient public good (Glaeser \& Ponzetto, 2018).

\subsubsection{Road Maintenance, Public Capital Expenditure, and Growth}

Road maintenance, in general, has been linked to economic growth. Rioja (2003) finds evidence of substitution to road maintenance from new "prestige projects" could increase GDP in a sample of Latin American countries. The theory is extended by Kalaitzidakis and Kalyvitis (2004) to allow the government to allocate towards maintenance and new public capital. Other extensions of the theory between maintenance and growth include: allowing maintenance to increase durability and quality of infrastructure (Agénor, 2009) and heterogeneous agents (Gibson \& Rioja, 2017). ${ }^{8}$

\subsection{Data}

The city of Pittsburgh defines the boundaries of the analysis in this paper. Pittsburgh is unique in that it keeps a record of historical road maintenance projects. Type of maintenance, date of completion, and location are included in this detailed data set.

Below, we further detail the data sources. Next, we describe the political institutions of Pittsburgh to justify the data used. Then, we describe the formation of the sample. We show descriptive statistics and interpret initial t-tests for differences in means, which are the foundation of the DD method.

\footnotetext{
${ }^{8}$ Empirical findings suggest that Canada spends too much on public capital and that the reduction in spending should come primarily from maintenance instead of new capital to be optimal for economic growth (Kalaitzidakis \& Kalyvitis, 2005). However, evidence from U.S. states suggests that maintenance spillover effects are more productive than new capital expenditures spillover effects (Kalyvitis \& Vella, 2015).
} 


\subsubsection{Maintenance Projects}

Pittsburgh differs from many other cities in that it publishes a detailed road paving schedule which includes the year a project started, the exact date it finished, and the type of maintenance job it was. ${ }^{9}$ Only the most heavy/invasive maintenance projects are used, because they are most inconvenient. They are most disruptive in terms of noise and air pollution and need a longer time to complete, potentially adding travel time to trips along that route. ${ }^{10}$ Table 2.1 details project types.

\subsubsection{Pittsburgh Political Wards}

The Pittsburgh ward shapefile is publicly available from the Western Pennsylvania Regional Data Center. Measures of voter registration are annually updated after the May primary elections. ${ }^{11}$ Figure 2.2 displays how wards deviate from the within ward average proportion of registered Republicans in Pittsburgh across wards across all years in the sample. Wards in orange signify relatively unaligned wards in a given year, while navy wards represent wards that were relatively more politically aligned. Mayoral election years (2009, 2013, and 2017) are shown on the diagonal. Figure 2.2 demonstrates adequate within- and across-ward variation in political alignment over the sample.

\subsubsection{Pittsburgh Institutional Details}

There are several relevant institutional details about the city of Pittsburgh. Pittsburgh is governed under a mayor-city council system; the mayor acts as the head of a nine person council. Under leadership of the mayor, the council decides the location and timing of road maintenance projects on city-owned roads. The council "...regulates revenues and expenditures, incurs debt, and ap-

\footnotetext{
${ }^{9}$ The road maintenance data for the city of Pittsburgh, Pennsylvania is publicly available via the Western Pennsylvania Regional Data Center. There are $\mathrm{N}=5,978$ completed maintenance projects recorded in this data set for the period 2009-2017. Start date is not observed.

${ }^{10}$ Classification of "heavy" and "non-heavy" road maintenance based off of the authors' research and judgement.

${ }^{11}$ Source: https://www.alleghenycounty.us/elections/election-results.aspx. This data is publicly available in every year of the sample from the Allegheny County Election Results website.
} 
proves the final operating and capital budgets for the city." ${ }^{12}$ In this system, mayoral political incentives could affect road maintenance location and timing.

The mayor is the only executive official elected through a city-wide vote, meaning the mayor's constituents are located across the whole city. ${ }^{13}$ The city council members are only elected by votes in their respective districts, meaning the council members' constituents are only located in the members' districts. Using city council votes is not appropriate for studying city-wide maintenance decisions, while alignment during mayoral election years may affect city-wide maintenance.

\subsubsection{Sample Creation}

Road maintenance projects are joined to political wards using the boundaries they are geographically within. Each project has an associated date, enabling the creation of a ward-month-year level dataset. Next, yearly voter registration data are merged to maintenance projects. There are 32 wards over 9 years and 8 months, resulting in a sample of 2,592 observations. ${ }^{14}$

\subsubsection{Descriptive Statistics}

Table 2.2 shows descriptive statistics for the number of completed heavy maintenance projects by alignment and whether it is a mayoral election year. Wards are considered aligned if they deviate from their within-ward average towards being very aligned. Months are split into aligned and unaligned wards, because that is how the treatment/control groups are formed. The table is split by mayoral election year, because the method uses non-election years as years when difference in alignment has no justification for mattering for maintenance decisions.

\footnotetext{
${ }^{12}$ Source: https://pittsburghpa.gov/council/index.html. The council includes a standing committee that handles all details associated with the city Public Works department. The Public Works department may initiate contracts to pursue road maintenance projects, but the projects' timing, location and budget need final approval by the council and mayor. See https://pittsburghpa.gov/council/public-works for more details.

${ }^{13}$ The City Controller is also a city-wide vote, but the City Controller is not involved in road maintenance planning. See https: / / pittsburghpa.gov/controller/.

${ }^{14}$ January-March observations are dropped, because there is little maintenance activity in these months. December 2017 is dropped, because the majority of these projects do not finish until after the sample period ends.
} 
The research design compares the difference between unaligned wards and aligned wards in non-mayoral election years to the difference in mayoral election years. Table 2.2 shows row-wise t-tests for differences in means, between mayoral and non-mayoral election years of the same treatment group and month. In aligned wards in June, 2.64 more projects are completed in nonelection years compared to election years. However, for politically unaligned wards 2.84 fewer projects are done in non-election years in July. During election years, there is less maintenance in aligned wards in June and more maintenance projects in unaligned wards in July. In October, there are 2.55 more projects completed in unaligned districts in non-election years than election years.

\subsection{Method}

The econometric model is difference-in-differences, in which June-October of mayoral election years is the treated period. ${ }^{15}$ The model is specified

$$
\text { Maintenance }_{m y w}=\exp \left(\beta_{1} I E P_{m y}+\beta_{2} P A_{y w}+\beta_{3} P A_{y w} * I E P_{m y}+\boldsymbol{\mu}_{w}+\phi_{y}+\boldsymbol{\gamma}_{m}\right),
$$

in which $m$ stands for month, $y$ for year, and $w$ for ward. $\mu_{w}$ is a vector of ward fixed effects to control for unobservable, time-invariant ward-level heterogeneity. $\phi_{y}$ is a vector of year and $\gamma_{m}$ is a vector of month fixed effects to control for variation in maintenance over time and seasonal, monthly maintenance. Maintenance stands for number of completed heavy maintenance projects. IEP stands for the inter-election period. Poisson estimation is appropriate, because the dependent variable is discrete. ${ }^{16}$ To facilitate interpretation of the DD coefficient $\left(\beta_{3}\right)$, OLS models are also used with the dependent variable being meters of completed heavy road maintenance.

\footnotetext{
${ }^{15}$ During mayoral election years, these are the months between the primary and the election date.

${ }^{16}$ Poisson models estimate unbiased, consistent coefficients if the conditional mean is correctly specified (Wooldridge, 1999). Poisson is preferred over negative binomial for two reasons. The first is that errors in the model are likely correlated by ward, so the preferred model estimates cluster-robust standard errors at the ward level. An implication of using cluster-robust standard errors in a Poisson model is that it has been shown to correct for overdispersion of the dependent variable (Cameron \& Trivedi, 2005). Another reason Poisson is preferred for panel data is negative binomial models have been shown to not be "true fixed-effects" models (Allison \& Waterman, 2002).
} 


\subsubsection{Alignment}

Ideally, treatment signifies a subset of wards where the mayor has different re-election incentives. Prior research defines treatment two ways: one, considering areas above a 50\% threshold for a geographic area to be affiliated with a specific representatives' party. Two, comparing small differences near 50\% (Lehne, Shapiro, \& Eynde, 2018; Migueis, 2013). Leveraging a 50\% threshold is impossible in this data, because $50 \%$ is outside the range of registered Republicans $(2.5 \%-25 \%) .{ }^{17}$

To define a treatment indicator for an area where the mayor faces different re-election incentives, in the absence of a 50\% threshold, within-ward deviation from ward averages are used. From the May primary elections files, the number of registered voters of each party is used to construct a measure of the political alignment. Political alignment is defined as $P A_{w y}=1$ if:

$$
P A_{w y}=1\left(Z_{w y}-\bar{Z}_{w}>\tilde{Z}\right)
$$

in which $Z_{w y}$ stands for registered Republicans (in standard deviations from within ward average) in a ward in a year, $\bar{Z}_{w}$ is the mean political alignment in a ward over the entire sample, and $\tilde{Z}$ is the median deviation across all 288 (32 wards X 9 years) ward-year combinations. ${ }^{18,19}$

Pittsburgh's political environment is relatively uncompetitive. One may worry that even the within-ward deviation approach may not accurately capture the political behavior of the mayor given the lack of within- and across-party challengers during the sample period. We argue that if potential challengers within or across parties gain enough support, incumbency or re-election is no longer guaranteed. It is, therefore, in the controlling party's interests, even in the face of low levels of perceived competition, to make the greatest number of constituents happy. This prevents the rise in popularity of future political opponents.

\footnotetext{
${ }^{17}$ The distribution of proportion Republican in a ward-year is shown in Figure B.3b.

${ }^{18}$ The distribution of within-ward deviations are shown in Figure B.3a.

${ }^{19}$ This approach combines investigation of the head elected official (Glaeser \& Shleifer, 2005) with the literature on federal grants and local governments based on political alignment (Bracco et al., 2015; Solé-Ollé \& Sorribas-Navarro, 2008).
} 
Sensitivity to Choice of Political Alignment Cutoff One issue is choosing $\tilde{Z}$ for $P A_{w y}$ in Equation 2.2. ${ }^{20}$ Figure 2.3 shows how meters maintained depends on within-ward, registered Republican Z-score to probe for sensitivity to choice of $\tilde{Z}$. Figure 2.3 suggests results are insensitive to choice of $\tilde{Z}$, an effect is found over the entire distribution of $Z_{w y}$. The relative slopes of the effects are consistent with the differences identified in Table 2.2.

Increase in Unaligned Deviation Affects Maintenance Differently by Month Panel A in Figure 2.3 suggests wards with higher proportions of registered Republicans receive more maintenance in summer of election years, and Panel B shows wards with more registered Republicans receive less maintenance in October of election years. This is caused by high Republican Z-scores having many non-zero values of meters of heavy maintenance in summer months of election years (Panel A, Figure 2.3), but many zero values of meters in October of election years (Panel B, Figure 2.3). The estimated effect of higher proportions of Republicans (slope of dotted, orange line) does not change paved meters of road completed by season in non-mayoral election years, consistent with a political incentives mechanism.

\subsubsection{Identification}

The model addresses seasonality of road maintenance in two ways. First, it compares politically aligned to politically unaligned wards in the same years and months when weather and other unobservables affecting maintenance are unlikely to be different across wards. Second, it controls for monthly differences using month fixed effects. This ensures results are not driven by seasonal maintenance patterns. Other covariates that are related to maintenance include the price of inputs and weather. It is highly unlikely that these unobservables are different across different wards, making them unlikely to bias $\beta_{3}$, the key variable of interest.

The identifying assumption is in the absence of the mayoral inter-election period altering political incentives, road maintenance in politically aligned and politically unaligned wards contin-

\footnotetext{
${ }^{20}$ Table 2.2 relied on choosing $\operatorname{Med}(Z)_{w}$ over all years.
} 
ues trending similarly during the months between the primary and general elections. Only two pre-registration months are observed in each of the three mayoral election years, so the common pre-trends are difficult to observe. An implication of the identifying assumption, which is more visually noticeable, is there are no discernible patterns or differences between aligned and unaligned wards in non-mayoral election years which begin during placebo periods of June-October.

Parallel Trends Figure 2.4 presents maintenance over time, disaggregated by alignment, to investigate the implications of the identification assumption visually. Every year of data (2009-2017) is represented by a separate figure, because treated wards change every year as the within-ward political alignment deviation changes relative to the within-ward median. Mayoral election years (2009, 2013, and 2017) are shown on the diagonal; red vertical lines define the inter-election period. Non-election years are shown in all other figures and use black vertical lines to define the months of interest. In each figure, navy represents politically aligned wards and orange represents unaligned wards. The figure also complies with the expectation that maintenance is seasonal: more maintenance takes place in the summer months.

In non-mayoral election years (off-diagonal figures), the number of completed maintenance projects is not systematically different for aligned compared to unaligned wards. ${ }^{21}$ There is no systemic difference, aligned compared to unaligned wards, in October in non-mayoral election years. In election years (figures on the diagonal), there is a systematic difference between aligned and unaligned wards during the inter-election period. In June, July, and August of the three mayoral election years, unaligned wards have the same or more maintenance in 7 out of 9 months; in October, aligned wards have more or the same maintenance in all mayoral election year Octobers. Figure 2.4 is consistent with a corollary of the common trends assumption: there is no difference between aligned and unaligned wards in non-mayoral election years, giving some confidence to a causal interpretation of the results.

\footnotetext{
${ }^{21}$ In 2010 and 2011, the aligned and unaligned wards cross frequently. In 2012 and 2016, the unaligned wards are on a higher level. In 2014 and 2015, the aligned wards are on a higher level. In almost all of these off-mayoral election years, the month to month change looks to be either noise or the trend looks the same. This non-systematic difference/pattern in differences between aligned and unaligned wards in off-mayoral election cycle years supports the implication of the identifying assumption.
} 


\subsection{Results}

This section presents main results. First, difference-in-differences results are presented. Next, randomization inference shows statistical significance is not due to few overall or treated clusters.

\subsubsection{Difference in Differences}

Table 2.3 presents estimates from Equation 2.1. Panel A, column 1 considers the entire JuneOctober period between voter registration and when votes are cast for the mayoral election; the DD coefficient is not statistically significant. A possible explanation is column 1 aggregates all months in the IEP together, and the opposite effects at the tail ends of the IEP cause the magnitude to appear relatively small and insignificant in the DD coefficient. Empirical studies have documented that time to election matters for how strong political incentives are (e.g. Berdejó and Yuchtman (2013)). Column 2 of Panel A only includes August-October in the IEP and finds no effect.

Column 3 only includes October in the IEP. The DD coefficient is positive and becomes statistically significant above 99 percent confidence in column 3. The DD coefficient can be interpreted that even though there is less maintenance during October, specifically October of the mayoral election years, there is comparatively more maintenance being completed in politically aligned wards. $^{22}$ The magnitude of the DD coefficient suggests there are 267 percent more projects in October of an election year in politically aligned wards, compared to unaligned wards. ${ }^{23}$

Panel B investigates months further from when votes are cast in November. In column 2, the effect of political alignment during election seasons is negative and statistically significant. Although there are more projects being completed in June-August, which is consistent with this time being prime maintenance season and shown by the June-August in election year dummy, those maintenance projects are occurring in primarily unaligned areas. The magnitude of the DD coefficient can be interpreted as an 118 percent increase of projects in politically unaligned wards compared to politically aligned wards in June-August of election years.

\footnotetext{
${ }^{22}$ Note that this holds the effect of October constant with month fixed effects also.

${ }^{23}$ The coefficient magnitude is calculated: $\left(e^{1.30}-1\right) * 100=267$ percent.
} 
The results suggest there is a detectable effect of political incentives on road maintenance timing and location. Additionally, the signs are strongest and opposite in the tail months of the inter-election period. This finding is consistent with the political incentive argument: the election is most salient to voters the closer it is to the election. To avoid potentially upsetting or inconveniencing potential voters in the unaligned areas of the city close to the election, projects are strategically shifted. The relative magnitudes of the significant DD coefficients suggest there is a net reduction in the amount of maintenance completed in an election year since there are less projects substituted into aligned wards during October than are substituted out in June-August. It also suggests maintenance projects are both a disamenity and a signal of competence.

\subsubsection{Inference Robust to Few Clusters}

The confidence intervals in Table 2.3 are calculated using cluster-robust standard errors at the ward level. There are 32 wards and only some are treated in each mayoral election year, so the cluster-robust confidence intervals could be inappropriately narrow (Cameron \& Miller, 2015). To address the potentially narrow standard errors, a permutation test is used which is less vulnerable to low amounts of clusters (Fisher, 1935). ${ }^{24}$ This procedure is based on Fisher's exact p-value. The procedure randomly shuffles political competition Z-scores within wards across different years. ${ }^{25}$

Placebo distributions of test statistics are displayed in Figure 2.5. Figure 2.5a investigates inference on the DD coefficient for summer months. The actual test statistic from the DD coefficient, IEP X PAUp, in Table 2.3, Panel B, column 2, is less than 999 of the false test statistics. This implies an exact Fisher p-value of $1 / 1000=0.001$. Figure $2.5 \mathrm{~b}$ shows the distribution of Z-statistics for the same procedure, except now the coefficient of interest is IEP X PAUp from Column 3, Panel A, of Table 2.3. In this case, the actual Z-statistic on IEP X PAUp is greater than 992/1000 placebo Z-statistics, implying a Fisher exact p-value of $8 / 1000=0.008$. Using an inference method less vulnerable to issues involving few clusters strengthens the conclusions of statistical significance.

\footnotetext{
${ }^{24}$ This is a similar approach used by Cunningham and Shah (2018) to deal with narrow confidence intervals from few clusters.

${ }^{25}$ This keeps the distribution of political alignment within wards the same.
} 


\subsection{Ward Boundaries as Variation in Political Alignment}

Several concerns are addressed with spatial discontinuity plots. ${ }^{26}$ The estimated DD coefficients could not be interpreted as causal if road maintenance causes changes in the political alignment of wards. ${ }^{27}$ Although this is unlikely, the possibility cannot be ruled out in a DD framework. Additionally, if there are omitted third variables which are correlated with the treatment (political alignment) and outcome (road maintenance), then the DD coefficient is biased. Finally, leveraging geographic variation helps address concerns about low variation in the treatment of proportion of registered Republicans in the DD coefficient of Equation 2.1. The plots compare road segments close to either side of ward borders where the political alignment is different between wards, leveraging geographic variation in how far the project is from being located in a certain ward. ${ }^{28}$ Roads close to boundaries are probably similar; plausibly, the only difference is road segments on either side are treated by different levels of political alignment. ${ }^{29}$

\subsubsection{Data Construction}

We split the roads of Pittsburgh into 1-meter segments. The universe of roads in Pittsburgh is used to construct the road-segment level data set. The 2018 TIGER/Line shapefile of Allegheny County roads comes from the U.S. Census Bureau website. The 2018 file includes all roads in Allegheny County as of January 1, 2018, ensuring all roads that could have ever been maintained in the sample period are included. ${ }^{30}$ A dummy variable is created for every 1-meter segment to indicate if that segment was maintained for every possible month-year combination in the sample. ${ }^{31}$

\footnotetext{
${ }^{26}$ D. R. Agrawal (2015) uses state borders to examine discontinuous differences in state retail taxes. Cantoni (2020) studies differences in voting costs (distance to polling location) for individuals that live near a voting precinct border. This study extends approaches that use spatial boundaries for geographic units to a new question.

${ }^{27}$ If the lack of road maintenance causes a certain ward to become less politically aligned, for instance, this would threaten the causal interpretation of the DD estimates.

${ }^{28}$ Wards boundaries are plausibly arbitrary and do not change in the sample.

${ }^{29}$ The unobservables that affect road maintenance such as labor costs, weather, auto traffic, etc. are likely similar on either side of the political boundary. This implies unobservables are unlikely to bias the effect of political alignment.

${ }^{30}$ Interstates and state routes are excluded to limit the data to only roads the city of Pittsburgh is responsible for maintaining. The roads and projects are displayed in Figure B.2.

${ }^{31}$ There are approximately 210 million segment-month-year level observations.
} 
The distance from the midpoint of segments to nearest political ward boundary is calculated. Distances are converted to negative values if the political alignment deviation of the ward the project took place in was more negative than the political alignment deviation of the closest bordering ward. ${ }^{32}$ Each boundary is assigned either an alignment switch or no alignment switch classification, for each year based on the political alignment deviation in wards on either side. ${ }^{33}$

\subsubsection{Distribution of Roads at the Ward Boundary Cutoff}

Figure B.4 shows there is a large increase in the number of 1-meter segments near the ward boundary border/cutoff. The large increase is consistent with roads also serving as ward boundaries. In the following analyses, road segments within ten meters of the border are dropped. ${ }^{34}$

\subsubsection{Maintenance Differences at Ward/Alignment Boundaries}

Figure 2.6 shows maintenance changes at ward boundaries for different combinations of months, in years with and without a mayoral election, and for differing alignment statuses on either side of the cutoff. ${ }^{35}$ Due to sparse data, lowess fits are used to summarize mean maintenance instead

\footnotetext{
${ }^{32}$ The possible closest ward boundaries are restricted to those interior in the city; boundaries defining the city limit or those bordering rivers on one side are dropped as possible closest boundaries.

${ }^{33}$ If a boundary is classified as unaligned, the two wards on either side of the boundary deviated in opposite directions in a given year. An aligned boundary had wards that deviated in the same direction of political alignment in that year. If a maintenance project is located in a ward with positive alignment, but was closest to an unaligned boundary, a positive distance value was assigned to that project; projects in relatively unaligned wards closest to unaligned boundaries were assigned negative distances. For example, if maintenance took place on a 1-meter segment in a ward that deviated towards political alignment that year and that project is closest to a boundary with an unaligned ward on the other side, the distance for that road segment in that year is defined as positive.1-meter segments that are located in wards with the largest deviation towards political alignment are assigned positive distances in cases where the two wards on either side of the ward boundary both deviated towards political alignment. 1-meter segments that are located in wards with the smallest deviation towards political unalignment are assigned positive distances in the cases where both wards on either side of a boundary deviated towards political unalignment.

${ }^{34}$ This dropping is similar to donut RD approach. This approach is not what the donut approach is typically used for; it is mainly utilized for dealing with those observations most likely to have sorted into/out of treatment. An advantage of dropping projects is projects could extend over borders or be applied to boundary roads where it is difficult to differentiate between which alignment to assign to a ward. Road segments may also differ substantially due to their use as ward boundaries.

${ }^{35}$ Figure 2.6 shows mean probability of maintenance on either side of the ward boundary cutoff. Observations just to the right of the red line are road segments which are just inside a politically aligned ward. The y-variable has the interpretation of the probability that the segment is maintained, conditional on distance from being in a more politically aligned ward. The y-variable is a small number because there are thousands of road segments within each bin and maintenance is a relatively rare outcome.
} 
of global fits, so differences at the cutoff are not influenced by distant outliers. Points right of the cutoff are in more politically aligned wards than wards to the left.

In Figure 2.6a, only summer months where alignment status changes at the cutoff in mayoral election years, are included. Figure 2.6a shows a reduction in mean heavy maintenance at the ward boundary cutoff for politically aligned wards. Both slopes are negative as the cutoff is approached from either side, but is steeper for aligned wards. In Figure 2.6b, there is no difference right at the cutoff. However, there is a difference that becomes apparent at 70 meters away from the cutoff. ${ }^{36}$ In aligned wards, at 70 meters away from the cutoff in election years, there is an increase in road maintenance that does not also happen for unaligned wards.

Three falsification exercises are performed. The first examines non-mayoral election years, where the alignment status changes at the border, because there is no mechanism for maintenance to differ by alignment status outside of mayoral election years. Figures $2.6 \mathrm{c}$ and $2.6 \mathrm{~d}$ show no difference in maintenance at the cutoff in non-election years. The next falsification exercises leverage wards where alignment does not change at the border. ${ }^{37}$ In Figure 2.6e, there is a slight difference at the border, but the slopes are oppositely signed and so the difference is converging towards 0 at the cutoff. In Figure 2.6f, maintenance increases far from the borders on both sides of the cutoff.

Figure 2.6g uses wards where alignment status does not change at the boundary, in non-mayoral election years, finding no difference in maintenance at the cutoff. Figure $2.6 \mathrm{~h}$ shows a difference in maintenance at the cutoff; however, the difference is due to the last point closest to the cutoff in aligned wards which is much lower than nearby points on the same side of the cutoff. The effects in Figures 2.6a and 2.6b are plausible and consistent with the DD results and a majority of falsification exercises are supportive of the mechanism of political incentives for differences at the border.

\footnotetext{
${ }^{36}$ Whether roads 70 meters away from a cutoff are similar enough for unobservables to be similar on either side of the cutoff is debatable. It is believed this is a fair assumption.

${ }^{37}$ Boundaries of wards that deviated in similar directions and intensities are included. For reference, ward boundaries that divide either two dark navy wards or two dark orange wards in Figure 2.2 are the boundaries classified as "alignment same."
} 


\subsection{Costs of Elections for Road Maintenance}

Table 2.4 replicates Table 2.3 using meters of completed maintenance as the new dependent variable, because it is easier to use for cost calculations. The DD coefficient in column 4 of Table 2.4 is interpreted as 605.76 meters less maintenance are completed in aligned wards during June-August of election year. The DD coefficient in column 1 suggests that 565.48 meters of that maintenance is substituted into politically aligned wards in October of election year.

The estimates from Table 2.4, along with some supplemental data, are used to calculate the cost of political incentives for road maintenance in Pittsburgh. ${ }^{38}$ Delayed road maintenance causes the cost of maintenance to be higher (Burningham \& Stankevich, 2005). Taking the estimates from Burningham and Stankevich (2005), an exponential curve is fit to their two data points. ${ }^{39}$ The equation of the fitted exponential curve is: $(1.0153 *(\exp (0.5796 *$ delayed years $)))$. Plugging in 4/12 for "delayed years," this equation calculates delaying maintenance by four months causes maintenance to be 1.231 times more expensive. ${ }^{40}$

Using this multiplier requires knowing undelayed, per meter maintenance costs. The cost of 1 meter of road maintenance in Pittsburgh is $\$ 45.55$ per meter on average. ${ }^{41}$ The cost of the delayed meters multiplied by the cost multiplier extrapolated from Burningham and Stankevich (2005) (605.76 meters $* \$ 45.55$ cost/meter $* 1.231$ delay multiplier) implies an additional cost of $\$ 33,966$ due to political incentives per mayoral electoral cycle. Second, there are 605.76 meters less maintenance in politically aligned wards in June-August, but only 565.48 additional meters in politically aligned wards in October. This suggests 40.28 meters of heavy road maintenance are

\footnotetext{
${ }^{38}$ These estimates only quantify the cost for road maintenance, but there could be other costs (Bauernschuster, Hener, \& Rainer, 2017).

${ }^{39}$ Figure B.6 shows the fit. A $(0,1)$ point is added, because no delay cannot make maintenance more expensive.

${ }^{40}$ The findings are 605.76 meters of road maintenance are delayed by 3-5 months from the June-August period until October. Splitting the 3-5 month difference, all road maintenance is assumed to be delayed by four months.

${ }^{41}$ For each year, the per meter average cost is calculated by taking the total paving expenditures in Figure B.1 and dividing by the total length of maintenance. Then, the average across years is calculated, weighted by the expenditure amount in each year. This is done to account for years that happened to have larger amounts of spending on paving. Not weighting like this does not change the average per meter cost by more than $\$ 1.92$ per meter.
} 
not completed in each mayoral election cycle. For reference, one small pothole is considered to be about 1 square meter, so one mayoral election cycle causes 40.28 small potholes in Pittsburgh. ${ }^{42}$

Assume the election cycle potholes are not repaired right away and are repaired at some point before the next election. For simplicity, the potholes assumed to be repaired in two years (splitting the difference between 0 and four years later). At 40.28 meters and a cost of $\$ 45.55 /$ meter, the initial cost of this foregone maintenance is $\$ 1,835$. Given a two-year delay multiplier of 3.236 , the total cost of the roadwork that was not substituted from June-August in the same year is $\$ 5,938 .{ }^{43}$ Adding together both the cost of the roads that are delayed during the season, $\$ 33,966$, and the roads that are assumed to be maintained in at a later time, $\$ 5,938$, is a total cost of $\$ 39,904$ due to one mayoral election cycle in Pittsburgh. ${ }^{44}$

\subsubsection{Across Comparable Cities}

The previous section calculates costs for Pittsburgh; however, local election cycles are frequent and widespread, so estimates across the whole U.S. calculated. Comparable cities from the Federal Highway Administration's list of urban areas with more than 750,000 residents in 2018 are used. $^{45}$ One-election-cycle delayed maintenance costs Pittsburgh $\$ 39,904$, so this figure is multiplied across forty-seven cities in the Federal Highway Administration (FHWA)'s list of urban areas. The cost of maintenance delays, across 47 cities, from one U.S. local election is $\$ 1,875,488 .{ }^{46}$

\footnotetext{
${ }^{42}$ Average pothole information found at: https://suma.org/img/uploads/documents/ communitiesoftomorrow/Pothole20Guidelines.pdf. Additional costs of potholes that are not included in the estimates are potential damages to vehicles attributable to potholes and potential time costs due to slower commutes caused by potholes.

${ }^{43}$ This is conservative, because the road maintenance could be put off much longer than two years.

${ }^{44}$ For reference, the per capita income for a Pittsburgh resident in 2017 was $\$ 51,187$.

${ }^{45}$ Source: https://www. fhwa.dot.gov/ohim/onh00/onh2p11.htm. Table B.1 shows these cities.

${ }^{46}$ To use more comparable cities, several variables from the FHWA data are used to exclude cities measurably dissimilar from Pittsburgh. Variables used include population, population density, total highway miles, highway miles per capita, highway miles travelled per capita, average annual daily traffic (AADT), etc. Because Pittsburgh sits near the average for these variables, cities not within two standard deviations of the average of each variable are dropped for not being comparable. Table B.1 also shows cities that were dropped and a description of the variable that caused ten cities to be dropped to build a more similar comparison group. Using these comparable thirty-seven cities instead, the total cost of one U.S. local election cycle for only similar, large cities is $\$ 1,476,448$.
} 
In addition to large cities, smaller-sized cities are also likely to suffer from mayoral election cycle distortions. There are 310 cities with a population of at least 100,000 (World Population Review, 2020). ${ }^{47}$ Additionally, local election cycles take place frequently, so a time period over which to calculate costs must be chosen. There are three periods of road construction in recent U.S. history according to Glaeser and Ponzetto (2018); the second one begins in $1960 .{ }^{48}$ Since 1960 , sixty years ago, there have been fifteen local election cycles in thirty-seven comparable cities. ${ }^{49}$ Multiplying the cost over cities with a 2020 population of at least 100,000 , over the last sixty years, $\$ 185.5$ million dollars has been lost due to delayed maintenance from local U.S. elections. An \$185.5 million loss could maintain 4,072,446 meters at the Pittsburgh maintenance cost per meter, or the entire city of local roads in Pittsburgh (2.8 million 1-meter segments) 1.45 times.

\subsubsection{Low Political Competition Implies Estimates are Lower Bounds}

Another factor leading costs being underestimated is if distortion due to political incentives is larger in other cities. This is a fair concern, especially given that Pittsburgh has not had a Republican mayor since 1934, and the nine person city council has been entirely Democratic since 1933. To understand how much potential there is for under-estimation of costs due to more political competition in other cities, compared to the Pittsburgh baseline, data on party of mayors are gathered going back to $1960 .^{50}$ Table B.1 lists the number of Republican mayors for each of the forty-seven cities from the FHWA list. ${ }^{51}$ Of the forty-seven cities on this list, thirty-one have had at least one

\footnotetext{
${ }^{47}$ According to World Population Review (2020), there are 19,495 incorporated cities, towns, and villages in the United States and 14,768 have populations under 5,000, making them very different than Pittsburgh.

${ }^{48}$ This period is characterized by increasing political organization and opposition to new construction, so it is used as the period over which local elections increase the cost of maintenance.

${ }^{49}$ Assuming a local election occurs every four years.

${ }^{50}$ Data were collected from city websites and publicly available information. Some cities have incomplete information regarding the political party of their mayor over time. Nevertheless, this constructed variable shows the variability of cities relative political "competitiveness" across the county.

${ }^{51}$ Number of Republican mayors is an appropriate approximation of political competition because the closer this number is to the midpoint of the number of local elections since $1960(0,15)$, the more times the office has changed party control.
} 
Republican mayor, implying they are more politically competitive than Pittsburgh. ${ }^{52}$ This supports the claim the cost estimates are conservative when multiplied across other similar cities in the U.S.

\subsubsection{Maintenance Shifts Have Consequences for Road Safety}

Table B.2 shows suggestive evidence that local election cycle maintenance shifts are also related to car crash outcomes. ${ }^{53}$ In ward-month-years with less maintenance, there are fewer crashes (Panel A, column 4), people involved in crashes (Panel B, column 4), and heavy truck accidents (Panel D, column 4). In ward-month-years with more maintenance, there are a greater number of major injuries (Panel C, column 1). These additional effects on safety are not included in any of the cost calculations presented in the previous section.

\subsection{Conclusion}

This paper finds politically aligned wards have less maintenance projects in months farther from the election, but more maintenance projects in months close to the election. The results are not caused by maintenance seasonality, too few clusters, arbitrary definitions of political alignment or relying solely on temporal variation. Oppositely signed coefficients for months on either side of the inter-election period suggest road maintenance is both a disamenity and a signal of competence.

This paper makes three contributions. First, political budget cycle analysis is extended to a salient, observable public good. Evidence that political incentives interfere with road maintenance beyond reducing maintenance in favor of new projects is found. If maintenance is planned despite politicians favoring new construction, political incentives delay maintenance, leading to higher costs (Burningham \& Stankevich, 2005). This is another way political incentives interfere with the optimal spending of public money, in the context of road maintenance.

\footnotetext{
${ }^{52}$ The average number of Republican mayors is 2.33 , suggesting that some other cities may be orders of magnitude more competitive than Pittsburgh.

${ }^{53}$ Car crash data comes from the Pennsylvania Department of Transportation (PennDOT) website: https: // crashinfo.penndot.gov/PCIT/welcome.html.
} 
The second contribution is advancing literature at the intersection of infrastructure and political incentives. This paper finds results consistent with both Glaeser and Ponzetto (2018) and Huet-Vaughn (2019), suggesting road maintenance can be both a signal of competence and a disamenity. Furthermore, some results are consistent with Huet-Vaughn (2019) at a smaller spatial scale, suggesting the interaction of maintenance and political incentives may not depend on scale.

Third, the results document a new source of political distortions to infrastructure maintenance: local election cycles. This new source of political distortion can be added to several already proposed by Winston (2013). The cost of this political distortion to infrastructure maintenance is calculated across cities with at least 100,000 residents (in 2020) and found to cost at least $\$ 185.5$ million. These results and cost calculations provide a warning to policy-makers concerning road maintenance decisions; allowing politics to enter the maintenance decision-making process will harm the fiscal position of cities by increasing expenses at no benefit other than for political gain.

Some limitations which could be addressed with future research. First, other cities are not investigated, because historical maintenance data is not publicly available for other cities. The data includes only maintenance projects on existing roads, not construction of new roads. Construction is the main topic of interest in Glaeser and Ponzetto (2018), but maintenance is a close substitute. The maintenance data includes an end date but not an exact start date, so the exact amount of maintenance time for each project is unknown. Finally, the city of Pittsburgh is not politically competitive relative to other large cities. Low political competition suggests the findings could be lower bounds of the political incentive mechanism's effect on local road maintenance.

Detter and Fölster (2017) suggest a way to reduce the impact of political concerns is to have financial asset managers make decisions. This has the drawback of reducing accountability, but a potential benefit of reducing distortion due to political incentives. In Pittsburgh, one election costs less than the income per capita of a Pittsburgh resident, making effects ambiguous. ${ }^{54}$

\footnotetext{
${ }^{54}$ In a more politically competitive city with more distortions, this option warrants further consideration.
} 
Figure 2.1: Monthly Completion of Heavy Road Maintenance in Pittsburgh, Pennsylvania

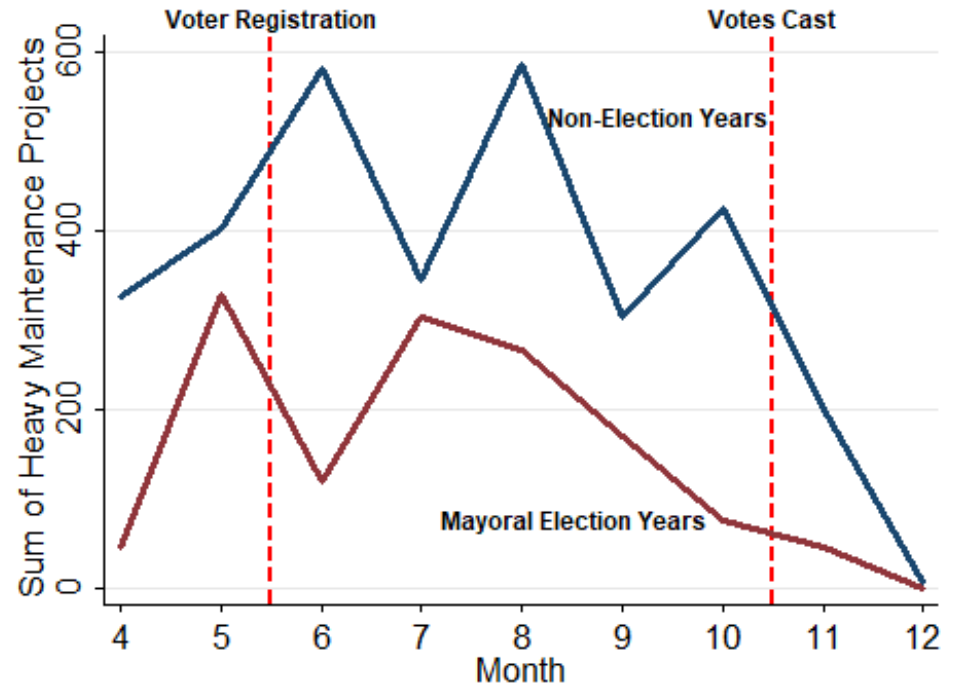

Note: Graph displays sum of heavy paving projects per year in the city of Pittsburgh from 2009-2017. The red line represents years when there is a mayoral election. The blue line represents years that do not have a mayoral election. Mayoral elections are held in 2009, 2013, and 2017. Numbers represent raw project, not adjusted to yearly averages. Red-dashed lines mark the length of the inter-election period. Non-election years refers to non-mayoral election years, which includes national election years of 2012 and 2016. 
Table 2.1: Types of Maintenance Projects

\begin{tabular}{|c|c|c|}
\hline Type of Maintenance & Description & Classification \\
\hline \multicolumn{3}{|l|}{ Heavy } \\
\hline Base Repair & $\begin{array}{l}\text { Removing damaged pavement, determining cause } \\
\text { of failure and appropriate solution, resurfacing } \\
\text { of road }\end{array}$ & Heavy \\
\hline SuperPave & $\begin{array}{l}\text { Pavement mix designed to combat deformation } \\
\text { and low temperature cracking }\end{array}$ & Heavy \\
\hline Mill and Overlay (SuperPave) & $\begin{array}{l}\text { Existing pavement removed, milled, surface } \\
\text { overlaid with SuperPave pavement }\end{array}$ & Heavy \\
\hline Mill and Overlay, $\geq 3 "$ & $\begin{array}{l}\text { Existing pavement surface removed, milled to a } \\
\text { depth of greater than } 3 \text { inches, surface overlaid } \\
\text { with new asphalt pavement }\end{array}$ & Heavy \\
\hline \multicolumn{3}{|l|}{ Non-Heavy } \\
\hline Mill and Overlay, <3" & $\begin{array}{l}\text { Existing pavement surface is removed, milled to } \\
\text { depth of less than } 3 \text { inches, surface is overlaid } \\
\text { with new asphalt pavement }\end{array}$ & Non-Heavy \\
\hline AC Overlay & $\begin{array}{l}\text { Pavement is placed down on top of existing } \\
\text { pavement, no milling of existing road }\end{array}$ & Non-Heavy \\
\hline Mechanical Patching & Small areas and irregularities patched over & Non-Heavy \\
\hline Profile Milling & Just the edges of the road are milled down & Non-Heavy \\
\hline
\end{tabular}

Note: Types of maintenance projects completed in Pittsburgh are shown above. 
Figure 2.2: Within-Ward Political Alignment by Time and Space
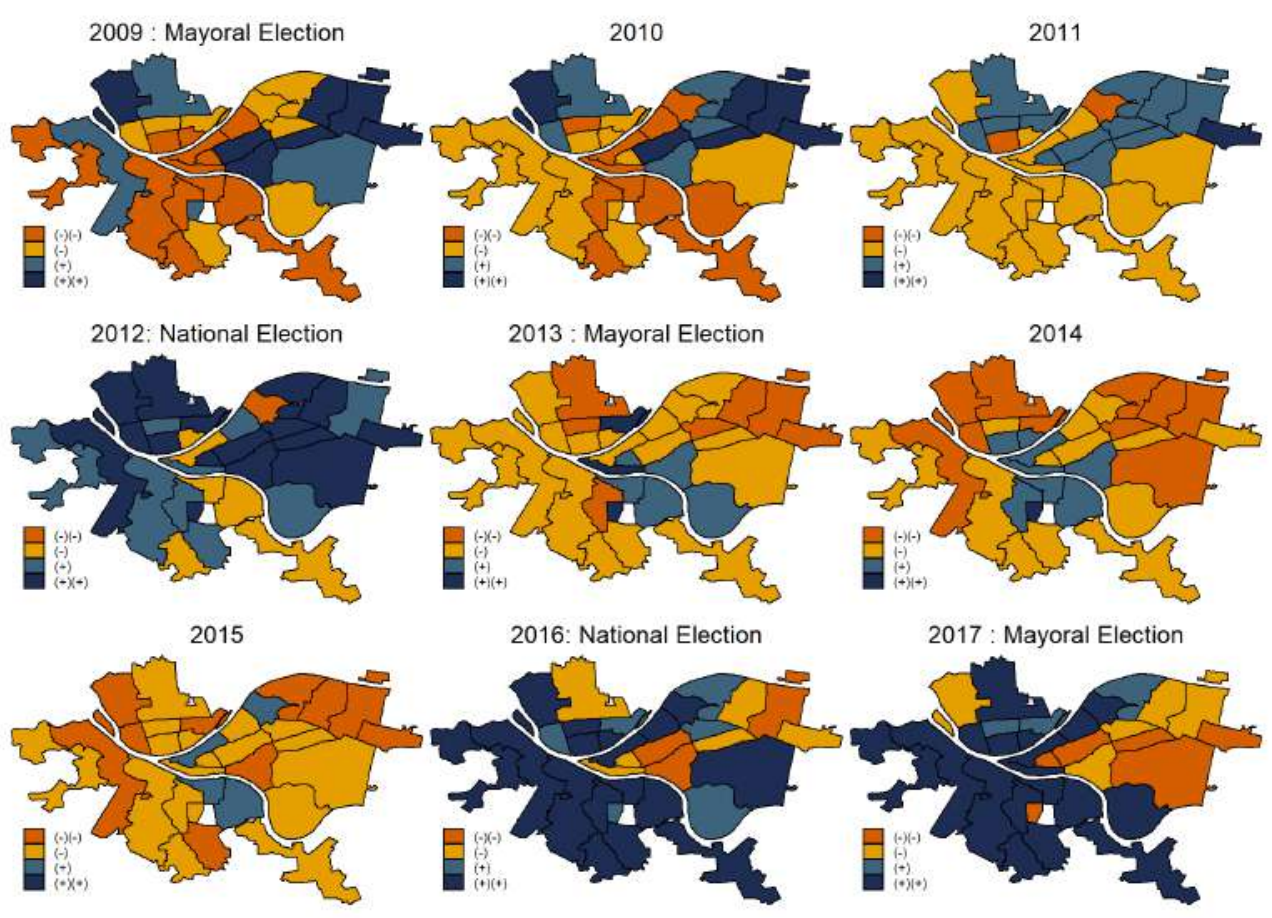

Note: Within-ward political alignment deviations across Pittsburgh wards for all years of data (2009-2017). Mayoral election years are on the diagonal. Deviations in alignment within a ward are measured as 0.675 standard deviation changes from that same ward's median political alignment measure. The proportion of registered Democratic voters is used to proxy for political alignment. If a ward became "less politically aligned" (more registered Republicans) relative to its average alignment across the sample time period, it is shown in orange above as a negative change (-); "more politically aligned" (less registered Republicans) is shown in navy above as a positive change (+). Between 0 and 0.675 standard deviations from the median are shown in lighter shades of these respective colors (Small negative change: (-); small positive change: (+)) Greater than 0.675 standard deviations from the median in either direction are represented by darker shades of their respective colors (Large negative change: $(-)(-)$; large positive change: $(+)(+))$. 
Table 2.2: Descriptive Statistics, Number of Heavy Maintenance Projects Completed

\begin{tabular}{|c|c|c|c|c|c|}
\hline & \multicolumn{5}{|c|}{ Mayoral Election Year } \\
\hline & \multicolumn{2}{|c|}{ Non-Election Year } & \multicolumn{2}{|l|}{ Election Year } & \multirow{2}{*}{$\begin{array}{l}\text { Row T-Test } \\
\text { Difference }\end{array}$} \\
\hline & Maintenance Mean & SE & Maintenance Mean & SE & \\
\hline \multicolumn{6}{|l|}{ Before Inter-Election Period } \\
\hline April-Unaligned $(n=144)$ & 1.45 & $(0.54)$ & 0.31 & $(0.19)$ & 1.14 \\
\hline April-Aligned $(n=144)$ & 1.96 & $(0.52)$ & 0.65 & $(0.29)$ & $1.31^{*}$ \\
\hline May-Unaligned $(n=144)$ & 2.34 & $(0.58)$ & 4.35 & $(1.21)$ & $-2.01 *$ \\
\hline May-Aligned $(n=144)$ & 1.84 & $(0.47)$ & 2.50 & $(0.77)$ & -0.66 \\
\hline \multicolumn{6}{|l|}{ Inter-Election Period } \\
\hline June-Unaligned $(n=144)$ & 2.44 & $(0.80)$ & 1.52 & $(0.90)$ & 0.92 \\
\hline June-Aligned $(n=144)$ & 3.61 & $(0.80)$ & 0.98 & $(0.31)$ & $2.64 * *$ \\
\hline July-Unaligned (n=144) & 1.47 & $(0.42)$ & 4.31 & $(1.01)$ & $-2.84 * * *$ \\
\hline July-Aligned $(n=144)$ & 2.13 & $(0.44)$ & 2.00 & $(0.74)$ & 0.13 \\
\hline August-Unaligned $(n=144)$ & 3.41 & $(0.67)$ & 3.77 & $(0.81)$ & -0.36 \\
\hline August-Aligned $(\mathrm{n}=144)$ & 2.70 & $(0.67)$ & 1.77 & $(0.52)$ & 0.93 \\
\hline September-Unaligned $(n=144)$ & 0.67 & $(0.22)$ & 0.98 & $(0.40)$ & -0.31 \\
\hline September-Aligned $(n=144)$ & 2.50 & $(0.45)$ & 2.58 & $(0.87)$ & -0.08 \\
\hline October-Unaligned $(n=144)$ & 2.93 & $(0.73)$ & 0.38 & $(0.19)$ & $2.55 * *$ \\
\hline October-Aligned $(n=144)$ & 1.50 & $(0.38)$ & 1.21 & $(0.39)$ & 0.29 \\
\hline \multicolumn{6}{|l|}{ After Inter-Election Period } \\
\hline November-Unaligned $(\mathrm{n}=144)$ & 1.29 & $(0.33)$ & 0.56 & $(0.28)$ & 0.73 \\
\hline November-Aligned $(n=144)$ & 0.79 & $(0.24)$ & 0.38 & $(0.14)$ & 0.42 \\
\hline December-Unaligned $(n=120)$ & 0.06 & $(0.05)$ & 0.00 & $(0.00)$ & 0.06 \\
\hline December-Aligned $(n=136)$ & 0.01 & $(0.01)$ & 0.00 & $(0.00)$ & 0.01 \\
\hline
\end{tabular}

Note: The mean count of heavy maintenance projects per ward in each month-alignment classification is shown, separated by whether it is a mayoral election year $(2009,2013,2017)$ or not. Descriptions of heavy projects are shown in Table 2.1. There are three election years and six non-election years in the data. The mean count of heavy maintenance over the total nine years is also shown. Alignment classification is determined by within-ward deviations in political alignment in a given year. $\mathrm{N}$ is the number of wards that fall into each month-alignment classification over the length of the data (2009-2017). SE = standard error. Row T-test conducted to compare election year completed road maintenance to non-election year completed road maintenance in each month. For the T-test column: *** $\mathrm{p}<0.01,{ }^{* *} \mathrm{p}<0.05$, * $\mathrm{p}<0.1$. 
Figure 2.3: Meters of Maintenance by Within-Ward Political Deviation Z-Score and Month in Inter-Election Year
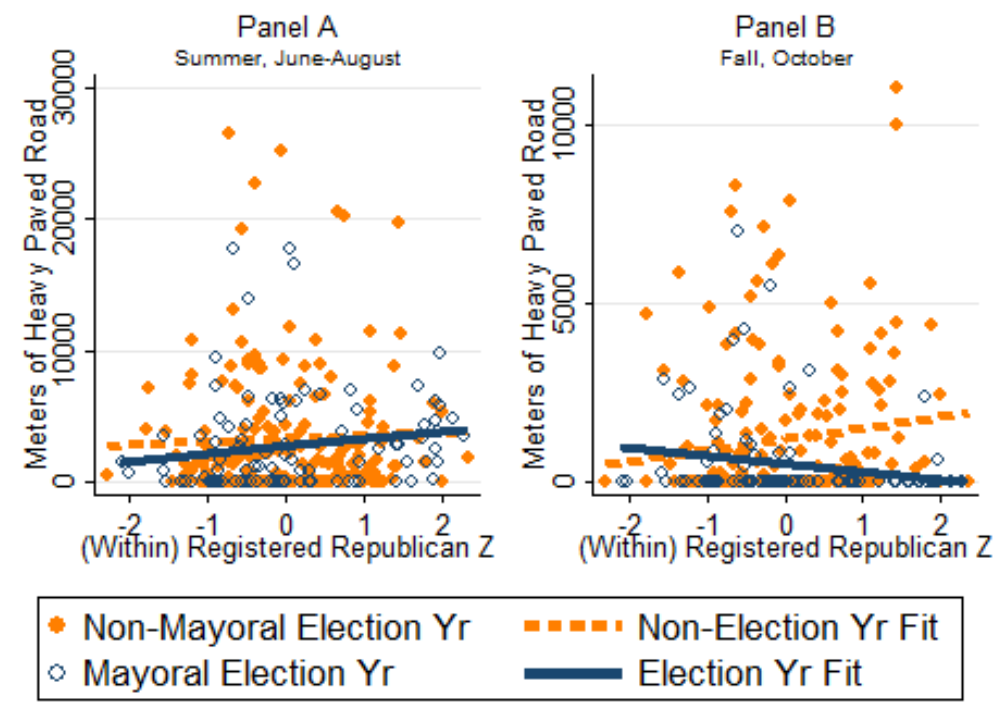

Note: $\mathrm{n}=288$ ward-year observations (144 observations each for election and non-election years). Dependent variable is meters of road maintained. Independent variable is within-ward registered Republican deviations from within-ward average (Republican Z). Only heavy maintenance included. Legend consistent for all panels. Orange points represent meters of completed maintenance at each Z-score in non-mayoral election years, while blue points represent meters of completed maintenance at each Z-score in mayoral election years. The dashed-orange line is the line of best fit for non-election years and the solid blue line is the line of best fit for election years. 
Figure 2.4: Political Alignment and Maintenance Project Trends by Year
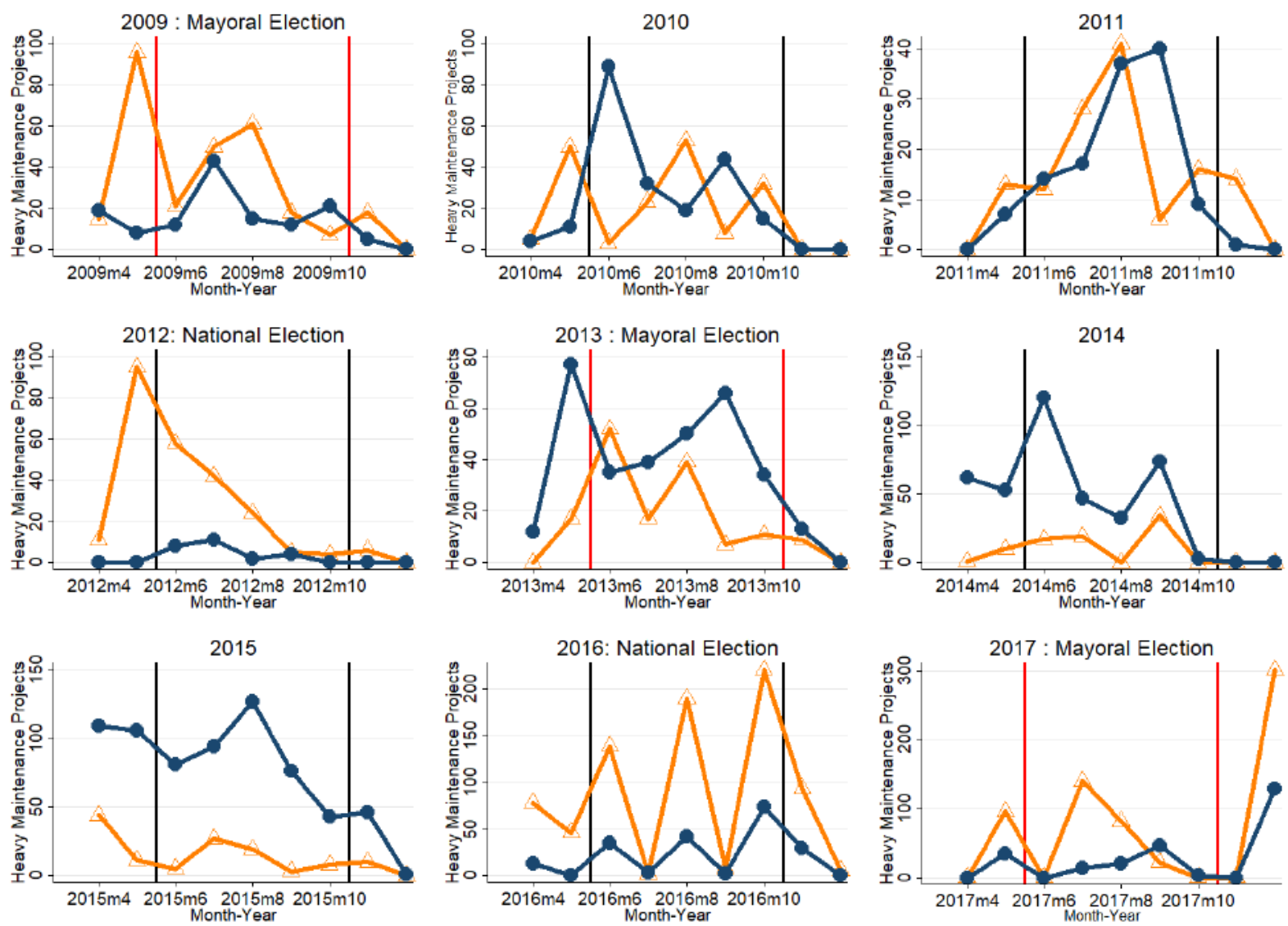

Note: Election years $(2009,2013$, and 2017) for the mayor are shown on the diagonal using red vertical lines to define the inter-election period. Non-election years, representing the counterfactual inter-election periods in which the mayor is not up for election, are shown in all other figures and use black vertical lines to define the inter-election period. The navy series in each year represents the maintenance projects in wards that had a higher within-ward deviations towards being more politically aligned with the mayor (higher deviations towards less registered Republicans for a given ward-year). The orange series in each year represents the maintenance projects in wards that had higher within-ward deviations towards being politically unaligned. Dependent variable is count of heavy maintenance projects completed. 
Table 2.3: How Narrowing Months Affects Number of Heavy Maintenance Projects Panel A: Removing Summer Months

(1)

Jun-Oct Aug-Oct

Political Alignment Above Deviatio
Jun-Oct in Election Year (IEP)
IEP X PAUp
Aug-Oct in Election Year (IEP)
IEP X PAUp
Oct in Election Year (IEP)
IEP X PAUp

$\begin{array}{cc} & -0.16 \\ (0.13) & -0.20 \\ & 0.03 \\ (0.33) & -0.22 \\ (0.20) & \\ & \end{array}$

$(0.13)$

$(0.13)$

$(0.33)$

$-0.22$

$(0.20)$

(0.12)

$-0.26$

(0.21)

0.22

$(0.25)$

$-0.24 * * \quad-0.24 *$

(0.12)

(3)

Oct

Treated Observations

240

$-1.77 * * *$

(0.57)

$1.30 * * *$

$(0.50)$

\begin{tabular}{lccc}
\hline Panel B: Removing Months Near Election & & & \\
& Jun & Jun-Aug & Jun-Oct \\
\hline Political Alignment Above Deviation Median (PAUp) & -0.20 & -0.07 & -0.16 \\
Jun in Election Year (IEP) & $(0.12)$ & $(0.12)$ & $(0.13)$ \\
IEP X PAUp & -0.68 & & \\
Jun-Aug in Eletion Year (IEP) & $-0.64)$ & & \\
IEP X PAUp & $(0.62)$ & & \\
Jun-Oct in Election Year (IEP) & & $0.46^{*}$ & \\
IEP X PAUp & & $-0.78^{* * *}$ & \\
& & $(0.21)$ & \\
& & & 0.03 \\
Treated Observations & & & $-0.33)$ \\
Observations & & & $(0.20)$ \\
\hline
\end{tabular}

Notes: $* \mathrm{p}<0.1, * * \mathrm{p}<0.05, * * * \mathrm{p}<0.01$. Standard errors clustered at the ward level are shown in parentheses. Estimates are from Poisson conditional fixed effect model, shown in Equation 2.1. Ward, month, and year (uninteracted) fixed effects are included in every column. Grouping months by relative distance to the election are shown in columns 1-3. Panel A isolates the months closest to the election, while Panel B isolates the months furthest from the election. IEP stands for inter-election period. PAUp stands for political alignment. The DD coefficient of interest for every column in both panels is "IEPxPAUp." Treated observations denote the number of ward-month-year observations which are 1 for IEPXPAUp. 
Figure 2.5: Randomization Inference

\section{Panel A: June-August DD Coefficient Placebo Z-Statistics Distribution}

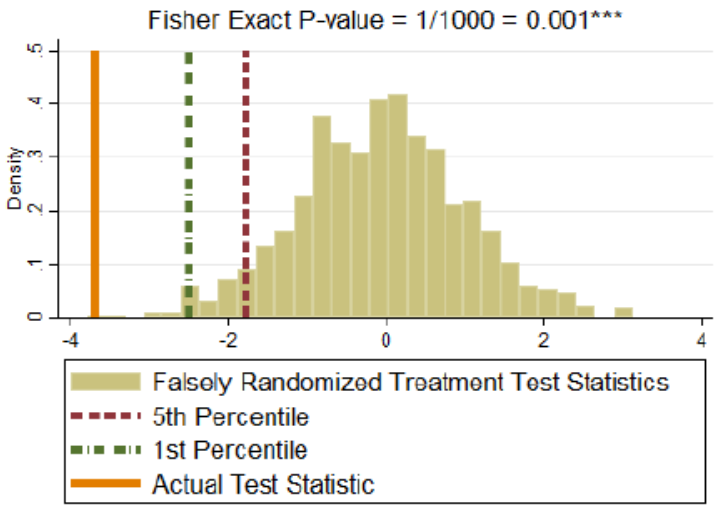

Panel B: October DD Coefficient Placebo Z-Statistics Distribution

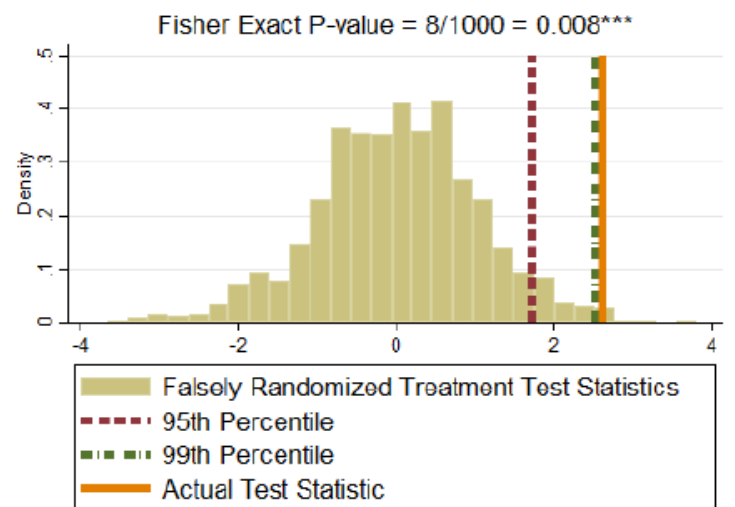

Note: Political alignment is shuffled within wards, across years. This leaves the distribution of alignment within-ward the same. Panel A: The test statistics displayed are from estimating IEP X PAUp in the Panel A, column 2 of Table 2.3 under falsely randomly assigned political alignment within ward across years. The actual test statistic is lower than the falsely randomized test statistics in 999/1000 permutations. In Panel B: The test statistics displayed are from estimating IEP X PAUp in Panel B, column 3 of Table 2.3 under falsely randomly assigned political alignment within ward across years. The actual test statistic is greater than the falsely randomized test statistics in 992/1000 permutations. 
Figure 2.6: Ward-Level Spatial RD Plots, Combining Tests and Falsification

Panel A: Mayoral Elections, June-August, Alignment $\quad$ Panel B: Mayoral Elections, October, Alignment

Change at Border

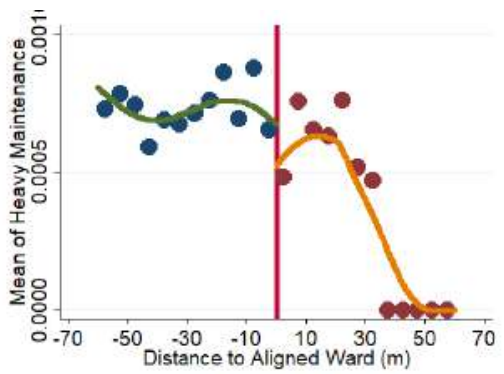

Panel C: Non-Mayoral Elections, June-August, Alignment Change at Border

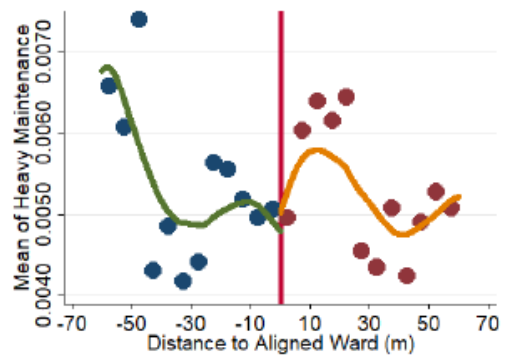

Panel E: Mayoral Elections, June-August, Alignment Same at Border

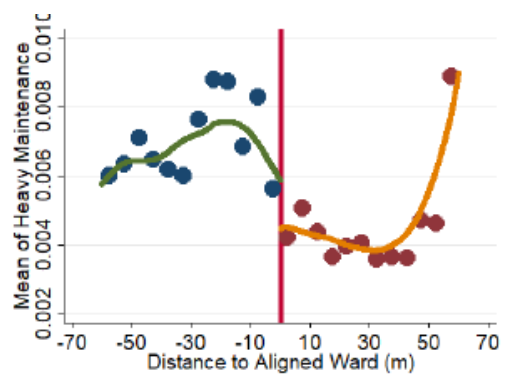

Panel G: Non-Mayoral Elections, June-August, Alignment Same at Border

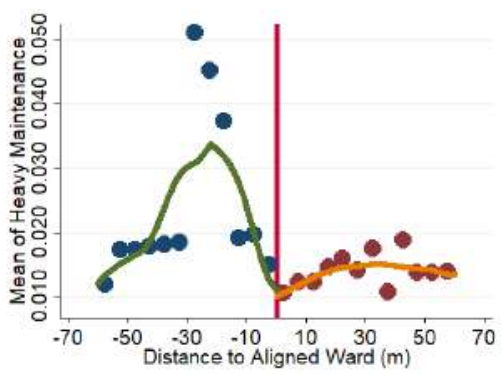

Change at Border

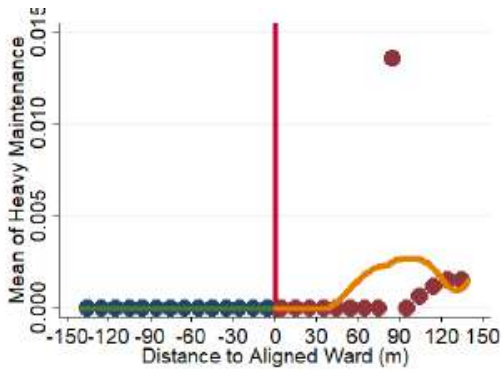

Panel D: Non-Mayoral Elections, October, Alignment Change at Border

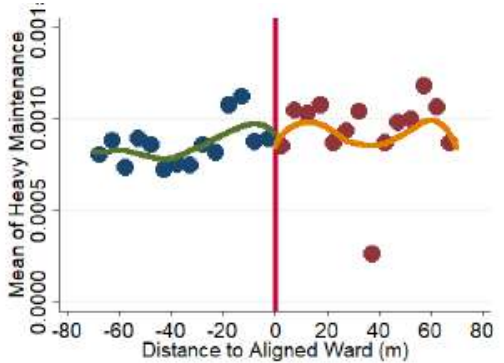

Panel F: Mayoral Elections, October, Alignment Same at Border

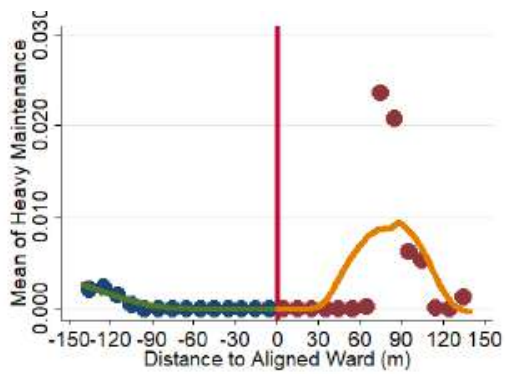

Panel H: Non-Mayoral Elections, October, Alignment Same at Border

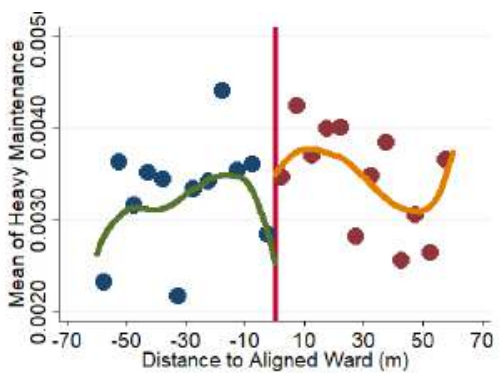

Note: Panels D and H drop out national election years, 2012 and 2016. Blue dots are politically unaligned, red dots are politically aligned. $\mathrm{X}$-axis is distance to more politically aligned ward (meters). Within 10 meters of boundary dropped due to the likelihood they are exactly on the border. Fitted lines are locally weighted sum of squares (lowess) using a tricube weighting function. 
Table 2.4: Continuous Meters

\begin{tabular}{|c|c|c|c|c|c|}
\hline & \multicolumn{2}{|c|}{ More Maintenance } & \multirow{3}{*}{$\frac{\text { Entire IEP }}{(3)}$} & \multicolumn{2}{|c|}{ Less Maintenance } \\
\hline & (1) & (2) & & (4) & $(5)$ \\
\hline & Oct & Aug-Oct & & Jun-Aug & Jun \\
\hline \multirow[t]{2}{*}{ IEP } & $-881.34 * * *$ & $-295.13 * *$ & -59.49 & 303.87 & -535.91 \\
\hline & $(218.48)$ & $(137.40)$ & $(202.73)$ & $(228.20)$ & $(446.76)$ \\
\hline \multirow[t]{2}{*}{$\mathrm{IEP} * \mathrm{PA}$} & $565.48 * *$ & 323.81 & -69.37 & $-605.76 * * *$ & -150.94 \\
\hline & $(254.61)$ & $(213.18)$ & $(161.45)$ & $(195.40)$ & $(345.44)$ \\
\hline Treated Observations & 48 & 144 & 240 & 144 & 48 \\
\hline Observations & 2560 & 2560 & 2560 & 2560 & 2560 \\
\hline
\end{tabular}

Note: $* \mathrm{p}<0.1, * * \mathrm{p}<0.05, * * * \mathrm{p}<0.01$ Estimates are from OLS two-way fixed effects models. Model includes ward, year, and month (uninteracted) fixed effects. Standard errors, clustered at the ward level, are shown in parentheses. DD coefficient of interest is "IEPxPA." The dependent variable is meters of road maintenance in a ward-month-year. 


\section{Chapter 3}

\section{Unintended Consequences of the}

\section{Appalachian Development Highway System}

\section{on Mortality}

Transportation infrastructure construction has been linked to the location of employment, innovation, population, and economic growth (A. Agrawal et al., 2017; Baum-Snow, 2007; Chandra \& Thompson, 2000; Duranton \& Turner, 2011, 2012; Michaels, 2008). ${ }^{1}$ Increased accessibility through lower transportation costs represents one of the main mechanisms through which infrastructure impacts locations (Brooks \& Donovan, 2020; Holl, 2016). Little economic research focuses on the relationship between transportation driven accessibility changes and health outcomes. ${ }^{2}$ Standard economic models of health outcomes do not include locational characteristics among factors affecting health outcomes (M. Grossman, 1972). However, changes in transportation infrastructure could generate both intended and unintended impacts on health outcomes. For example, a more extensive road network could increase access to physicians and doctors, improving individual health outcomes.

\footnotetext{
${ }^{1}$ See Redding and Turner (2015) for an overview of this literature.

${ }^{2}$ Currie and Walker (2011) and Knittel et al. (2016) discuss the effect of transportation infrastructure on infant health outcomes; this paper focuses on end-of-life outcomes for the entire population.
} 
The economic history literature contains a few examples of papers that estimate a causal relationship between infrastructure construction and health outcomes. These papers focus on the advent of modern transportation modes in the 19th century. Zimran (2020) analyzed the impact of the expansion of canals on mortality in Antebellum United States and Tang (2017) analyzed the impact of railway expansion on mortality in Japan. Both papers found significant increases in mortality from communicable diseases caused by the expansion of modern transportation modes. Other papers that examine the direct relationship between health and transportation infrastructure fail to establish a causal relationship or only examine inputs to health, rather than health outcomes themselves (Bell \& van Dillen, 2018; Blimpo, Harding, \& Wantchekon, 2013).

Recent research found reduced travel times positively associated with decreased mortality among hospital patients. An analysis conducted in both rural and urban counties in Oregon and Washington found rural patients more likely to die within 24 hours, relative to urban patients, due to higher transfer rates between health care centers and longer travel times to hospitals (Newgard et al., 2017). In several regression models in Røislien, Lossius, and Kristiansen (2015), travel time was a significant predictor of mortality in Norwegian municipalities.

This literature identifies important differences in health outcomes for urban and rural patients. Urban patients are more likely to live near hospitals and health care facilities. Over 40 million Americans lack access to a level I trauma center within a 60 minute drive from their home; most of those 40 million live in rural areas (Branas et al., 2005). This distinction likely affects health outcomes in Appalachia, a largely rural, isolated region.

Due to the lack of comprehensive public transportation across Appalachia, access to healthcare and other amenities depends heavily on road networks. Appalachia is a region historically associated with concentrations of poverty and reduced accessibility in terms of transportation. To overcome these issues, particularly focused on accessibility concerns, Congress created the Appalachian Regional Commission (ARC) to provide federal funding to states and counties in the Appalachian region to address limited accessibility by building highways. This highway construction project represents one of the largest place-based policies ever implemented in the United 
States. At its inception in 1968, ARC allocated over $75 \%$ of the initial $\$ 1.1$ billion of federal funds received to construct the Appalachian Development Highway System (ADHS). ${ }^{3}$ Construction of the ADHS began in the late 1960s and continued for over 50 years. This research focuses on the impact of the ADHS on morality in Appalachia. It investigates the presence of both intended and unintended effects on mortality.

Estimating the causal influence of the ADHS on mortality outcomes requires accounting for the non-random assignment of highway segment construction over space and time in Appalachia. I exploit an instrumental variables (IV) approach similar to past research using historic infrastructure maps to analyze the current effects of infrastructure (A. Agrawal et al., 2017; Baum-Snow, 2007; Baum-Snow, Brandt, Henderson, Turner, \& Zhang, 2017; Duranton, Morrow, \& Turner, 2014; Duranton \& Turner, 2011; Garcia-López, Holl, \& Viladecans-Marsal, 2015; Hsu \& Zhang, 2014). ${ }^{4}$ The new instrument proposed in this paper is the President's Appalachian Regional Commission (PARC) highway map created during the Kennedy administration. This map was drawn before the guarantee of federal funding for Appalachian highway construction and before official federal classification of the "Appalachian" region.

The instrument is relevant because the unused highway plan resembles, and directly informed, the actual construction plans used for the ADHS. The instrument is excludable, like Baum-Snow (2007) and Duranton and Turner (2011), because it is plausible that the only reason an unused 1964 Appalachian highway plan affects mortality over time is through its strong relationship to actual ADHS road construction. This exclusion restriction becomes more plausible when conditioning on county level factors such as hospital density, simultaneous ARC health development projects, and historic road infrastructure density.

Instrumental variable results show that ADHS construction causes reductions in heart disease and hypertension mortality rates. A decrease in county centroid distance to an ADHS segment decreases mortality rates in certain decades in the sample. These results likely reflect a mecha-

\footnotetext{
${ }^{3}$ The remaining $25 \%$ of the $\$ 1.1$ billion was allocated to other development projects in the region (Comptroller General of the United States, 1976).

${ }^{4}$ In addition to historic infrastructure maps, economic analyses have included old maps to study a variety of topics including, but not limited to, Africa's slave trades (Nunn, 2008) and Indian city shape and sprawl (Harari, 2020).
} 
nism in which ADHS road construction improved individual access and travel time to healthcare facilities. Controlling for the number of local hospitals, the number of contemporaneous ARC health-related investment projects, and 1960 county-level road density confirm these results. The impact dissipates in later decades in the sample.

Findings also suggest that accident mortality rates in Appalachia increased as distance to ADHS segments decreased, especially in the last two decades in the sample period. The increase in accident mortality reflects increases in drug and medicinal overdoses and not other accident causes such as car accidents. Overdose mortality increases by 0.80 standard deviation. This result implies that, while the ADHS road construction improved some mortality outcomes early in the sample period, it caused an increase in other mortality outcomes as the highway network, and use of the network, increased later in the sample period. In sum, not all segments of the ADHS generated the same effects on mortality, and not all mortality outcomes changed in the same way over time.

As of 2021, the ADHS spans over 3,000 miles across 13 states. Over the course of construction, approximately $\$ 11.2$ billion dollars was spent to reach current completion levels. ${ }^{5}$ An additional $\$ 10.9$ billion dollars in spending will be required to complete the remaining segments of the ADHS. Due to the large share of federal funding devoted to the ADHS compared to other non-infrastructure ARC funded projects, the current research critically informs the evaluation of the overall impact of the ADHS on the Appalachian region.

The net mortality changes caused by the ADHS over the sample period contributed approximately $\$ 24.2$ billion dollars morality-related costs to society. However, the statistical value of additional lives lost does not outweigh the total benefits from improved travel times, increased employment, and higher incomes in the Appalachian region (Economic Development Research Group, 2017). This implies the ADHS infrastructure project still generated a net benefit despite the large costs associated with mortality.

This paper contributes to three bodies of literature. This paper contributes to the analysis of the effectiveness of place-based transportation infrastructure policies by analyzing end-of-life health

\footnotetext{
${ }^{5}$ Reported in current year spending, not adjusted for inflation (Economic Development Research Group, 2017).
} 
outcomes, not previously examined in the literature, generated by a large-scale place-based policy. The paper employs a novel historical map, the President's Appalachian Regional Commission highway map, as an instrument, contributing to the literature using historical maps as instruments. This work also contributes to the literature evaluating ARC policies by using a causal inference approach.

The remainder of the paper is organized as followed - Section 3.1 provides a brief history of the ADHS and reviews relevant literature, Section 3.2 describes the primary data sources utilized, Section 3.3 discusses the method and identification strategy, Section 3.4 presents the results, Section 3.5 provides robustness and mechanism arguments, Section 3.6 provides a benefit-cost analysis of the ADHS, and Section 3.7 concludes.

\subsection{Historical Background and Literature Review}

\subsubsection{Appalachian Development Highway System}

The President's Appalachian Regional Commission (PARC) was created by President John F. Kennedy in the early 1960s to carefully analyze problems throughout Appalachia and suggest policy recommendations to help the region "catch-up" with the rest of the country. On the subject of isolation, the report noted that "the Interstate Highway System has largely bypassed by Appalachian Region, going through or around the Region's rugged terrain as cost-effectively as possible" (PARC, 1964). To potentially overcome this isolation, the report says the following:

Developmental activity in Appalachia cannot proceed until the regional isolation has been overcome...by a transportation network which provides access to and from the rest of the nation and within the region itself...The remoteness and isolation of the region, lying directly adjacent to the greatest concentrations of people and wealth in the country, is the very basis of the Appalachian lag. Its penetration by an adequate transportation network is the first requisite of its full participation in industrial America. 
Figure 3.1a shows a copy of the planned "development highway" described in the PARC report. ${ }^{6}$ After continuous lobbying by the Conference of Appalachian Governors, the Appalachian Regional Development Act (ARDA) was proposed in Congress in the spring of 1964. At first the ARDA failed to receive sufficient support, however, the bill was resubmitted to Congress in 1965 following a few changes, including the addition of Ohio and South Carolina as beneficiaries of federally funded projects. The modified ARDA was signed into law on March 9, 1965. The Act created the Appalachian Regional Commission (ARC) and initially designated counties in Alabama, Georgia, Kentucky, Maryland, North Carolina, Ohio, Pennsylvania, South Carolina, Tennessee, Virginia, and West Virginia to receive $\$ 1.1$ billion in federal grants with $\$ 840$ million earmarked for highway spending (Comptroller General of the United States, 1976) ${ }^{7}$.

Since its inception in 1965, the ARC region has grown. In 1967, as shown in Appendix Figure C.1, Mississippi and New York saw several counties' entry into the ARC boundary. Including this 1967 expansion, 47 counties have been added inside the ARC boundary to be eligible for federal grants, bringing the total count of Appalachian counties from 373 in 1965 to 420 in $2020 .^{8}$

This paper's focus is related to highway development in the Appalachian region due to the creation of the ARC. The purpose of highway construction in Appalachia has been cited to be two-fold: open areas with an economic developmental potential and improve local access to educational, health, recreational, commercial, and industrial facilities (Rephann \& Isserman, 1994). As of 2021, approximately $90 \%$ of the highway system has been constructed and opened to traffic.

Jaworski and Kitchens (2019) aim to answer questions concerning the effect of the ADHS on total income in the United States, and how various counterfactual highway networks would have impacted total income differently. Motivated by a model of inter-regional trade, the authors estimate the elasticity of total income with respect to market access, which they then use to evaluate the overall impact of the ADHS. They find that removing the ADHS would have reduced total

\footnotetext{
${ }^{6}$ Figure 3.1b shows a digitized version of Figure 3.1a with just the planned highway segments extracted.

${ }^{7}$ The remaining \$260 million was devoted to a wide-reaching collection of development projects from education to land stabilization (Comptroller General of the United States, 1976)

${ }^{8}$ In addition, eight independent cities in Virginia have also joined the ARC region over time, with most joining in 2008 .
} 
income by $\$ 54$ billion in the United States and $\$ 38$ billion, or 4.4 percent, in the Appalachian region.

The road data from Jaworski and Kitchens (2019) come from newly digitized network data of the Appalachian, interstate, national, and state highway systems in 1960, 1985, and 2010. Jaworski and Kitchens (2019) notably use an instrumental variables strategy to isolate variation in changes in market access based on physical distance and the change in average speed between county pairs due to improvements throughout the transportation network. In regards to the current work, the same area has been georeferenced, but a larger quantity of construction progress maps have been digitized to capture yearly variations in road segment openings across time.

\subsubsection{Mortality and Place-Based Policies}

Location-based health outcomes runs contrary to popular health models. In traditional models of the demand for health (M. Grossman, 1972), one's utility from health is realized with investment in medical care. The Grossman model, however, assumes individual factors such as education, income and geographic location to be independent from one's health demand. Exploring these factors as they relate to mortality outcomes has important implications for the health economics literature and policy. The current work contributes to the growing "place-based health outcomes"

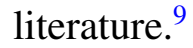

The association between location and mortality, although not traditionally modelled, has a few empirical footholds in the literature. Early works attempted to find correlations between economic development and life expectancy. For example, Preston (1975) examines the positive correlation between income and life-expectancy across the United States. Murphy and Topel (2006) find improvements in long-run health outcomes create substantial economic gain to society.

Later empirical studies have focused on quasi-experimental approaches to examine the effects of location on mortality. Doyle (2011) uses health emergencies of visitors to Florida to show that

\footnotetext{
${ }^{9}$ For more general overviews of the mortality literature, please see Cutler, Deaton, and Lleras-Muney (2006), Currie and Schwandt (2016), and Chetty et al. (2016).
} 
hospitals in high-spending areas produce better health outcomes than hospitals in low-spending areas. J. Hall and Neto (2018) test the impact of MedExpress entry on different health outcomes in the Appalachia region. They find MedExpress entry leads to a reduction in short-term hospital admissions, inpatient days, outpatient visits, and trips to the emergency room (supply side outcomes). Finkelstein, Gentzkow, and Williams (2019) find that individuals moving from a 10th to a 90th percentile location would increase life expectancy at age 65 by 1.1 years, and equalizing location effects would reduce cross-sectional variation in life expectancy by 15 percent. Places with favorable life expectancy effects tend to have higher quality and quantity of health care, less extreme climates, lower crime rates, and higher socioeconomic status. The large role the authors estimate for health capital (individual behaviors) is consistent with conventional wisdom, but the results also show that there is a substantial causal impact of place-based factors that conventional health modeling approaches may underestimate. Using Hurricane Katrina as a natural experiment, Deryugina and Molitor (2020) track Medicare survivors who were displaced by Hurricane Katrina. Those who moved to higher-mortality regions experienced higher mortality rates than those who moved to lower-mortality regions.

A growing literature cites the importance of community-based health departments and centers. Hoehn-Velasco (2018) describes the role of community health departments on rural infant mortality in the early 20th century and finds decreased infant mortality because of community health departments. Hoehn-Velasco (2020) finds improved later-life outcomes due to early exposure to public health programs. Bailey and Goodman-Bacon (2015) examine the expansion of community health centers (CHCs) in the United States. They note that access to primary care has long-term health benefits, even for those with near full-coverage insurance. The authors find that the CHCs themselves are responsible for a two percent reduction in age-adjusted mortality rates for those fifty years and older.

In general, the approach surrounding place-based healthcare studies falls in line with studies of place-based policies in general. ${ }^{10}$ One potential policy initiative to increase positive outcomes

\footnotetext{
${ }^{10}$ Bartik (2020), for example, recently discusses the potential benefits associated with place-based job policies and the need for greater targeting of distressed areas.
} 
in rural areas is increasing access to more urbanized areas. These urban areas arguably offer more amenities and opportunities to potentially increase the quality of life of rural residents. Greenberg (2016) emphasizes the importance of place-based, sub-county initiatives for poverty alleviation in Appalachia. Partridge and Rickman (2008) suggest that one potential policy for alleviating poverty in rural counties in the United States could be by increasing access through road construction. The current work directly evaluates the impact of a large, transportation place-based policy in terms of mortality outcomes.

\subsubsection{Quantifying Impact of Roads}

This work also fits broadly into the literature quantifying the various impacts of roads in the United States and throughout the world. Chandra and Thompson (2000) examine the relationship between highway spending and economic activity. Interestingly, this paper finds that highways have different impacts across industries and across counties. New highways are associated with growth in industries that can benefit from the reduced transportation costs, and shrinkage in some industries because of the reallocation of economic activity along the highway. From a spatial perspective, this paper finds that new highways raise the level of economic activity in the counties they pass through while drawing activity away from adjacent counties, essentially having a zero net effect on regional economic activity. This paper assumes that new highways are an exogenous shock to the non-metropolitan counties that they run through, and uses a simple linear fixed effects model to conduct its empirical analysis. Although this assumption may hold true for many places across the country, in Appalachia particularly, the use of federal funds to construct highways in rural counties is not exogenous. Rogers and Marshment (2000) also attempt to quantify the impact of highway bypasses on small town retail sales. The authors examine the impact of highways bypassing small towns using a difference-in-differences analysis, finding no significant impact of bypasses on local retail sales.

Newer empirical contributions to this literature attempt to overcome the endogeneity problems associated with highway placement: areas showing more population growth, income growth, or 
employment growth may have more highways or may attract new highway openings more than a comparable control group. Therefore, estimates of the "true" effect of highways on any of the before-mentioned outcome variables could be upwardly biased. Rephann and Isserman (1994) find that the counties that benefited the most from interstate highways are those counties that had a highway route pass directly through them and were in close proximity to an urban area; these areas saw significant growth in their populations. Counties that bordered "interstate" counties or rural counties exhibited few positive direct effects from highway construction.

Several papers use old highway plans that were never utilized as instruments for current highway placement; these old maps meet both the relevance and exclusion properties of a valid instrument variable. After using a 1947 highway map plan to instrument for current highways, BaumSnow (2007) finds one new highway passing through a central city reduces its population by about 18 percent. Using old highway plans as an instrument, Michaels (2008) identifies the labor market effects of the reduced trade barriers associated with the construction of the interstate highway system; it shows that counties where the interstate highway system passed through experienced an increase in trade-related activities, such as trucking and retail sales. ${ }^{11}$

There are also many papers that examine the impact of roads in developing countries. ${ }^{12}$ The results from these papers generally do not find as large of an impact of roads on various outcome variables as do the studies that focus on cities in the United States. For example, Asher and Novosad (2020) study the impact of rural roads in India. Due to the institutional nature of the Prime Minister's Village Road Program, this paper is able to tease out the causal effect of road construction on various development outcomes. Using a fuzzy regression discontinuity design, this paper finds no significant impact of roads causing development in remote Indian villages. The paper does point to evidence that the main effect of rural roads in India is allowing farmers access to non-farm employment opportunities.

\footnotetext{
${ }^{11}$ More recent papers using old highway maps as instruments in a U.S. setting include Duranton and Turner (2011), Duranton and Turner (2012), and Duranton et al. (2014).

${ }^{12}$ For example, see Hsu and Zhang (2014) and Baum-Snow et al. (2017).
} 


\subsubsection{General Analysis of ARC Policies}

A plethora of books and reports published over the past several decades highlight the successes (and non-successes) of ARC policies in the Appalachian region. Bradshaw (1992), for example, discusses the successes and failures of ARC in its first 25 years in existence, highlighting the political influences on the direct contributions and goals of the commission in its early years. Widner (1990) summarizes key statistics from ARC's first 25 years, citing improved incomes, health, and employment in the region. Several other technical reports cite the decline of poverty (Black \& Sanders, 2004), rise in standards of living (Black \& Sanders, 2007), and increases in educational attainment (Haaga, 2004) due to ARC involvement in the Appalachian region. On the other hand, Glaeser and Gottlieb (2008) are hesitant to call ARC outright effective, noting that finding the true effect of the ARC separate from all other simultaneous policy interventions may never clearly present itself in the data.

More recent empirical papers have examined the impacts of ARC policies and funding without specific attention to highway funding. Isserman and Rephann (1995) provide one of the first major empirical analyses of the effects of the Appalachian Regional Commission (ARC) on the 391 counties that were in Appalachia at the time of the study. Using matching methods, this paper finds that Appalachia grew significantly faster than did the control group in income, earnings, population, and per capita income. This paper, in additional to the empirical contribution, also provides an extensive historical background on the ARC and criticisms the commission has received. Sayago-Gomez, Piras, Jackson, and Lacombe (2018) find that, after using matching methods, counties that received ARC funding grew faster than control counties in terms of per capita income and employment from 1970 to 2012. D. Grossman, Humphreys, and Ruseski (2019), using difference-in-differences, examine the effect of water, sewage, and sanitation-related ARC investment projects on individual outcomes like the presence of complete indoor plumbing and running water in dwellings.

Beyond general reports published by the ARC and other empirical contributions concerning non-highway ARC impacts, the analysis of rural roads in Appalachia has some limited empiri- 
cal footholds. Apart from Jaworski and Kitchens (2019), a relatively comprehensive and rigorous analysis of the impact of the ADHS, one component of total ARC projects, has not been thoroughly studied in the literature. Quantifying the impact of this rural highway network on mortality outcomes in the Appalachian region contributes to several bodies of literature simultaneously, adding to our understanding of the possible unintended consequences of this federal road building project in the United States.

\subsection{Primary Data Sources}

\subsubsection{Data Creation: Appalachian Development Highway System (1965-2018)}

Although the history and progress of the ADHS has been tracked extensively by state and federal agencies, a usable data set capable of being manipulated by statistical or GIS software is not publicly available. Newly digitized maps were created to determine what states and counties received a new section of the ADHS and when that section's construction was completed. PDFs and scans of historical maps, similar to Figure 3.1a, were collected from the mid-1960s to the present. After digitizing these maps over time using QGIS, a manipulable data set tracking the construction of road segments can be utilized to explore various outcome variables. ${ }^{13}$ The result of this process is a dynamic representation of the ADHS construction, similar to Figure 3.2.

Figure 3.2 displays the progress of ADHS construction from 1968 until 2017. The black lines in each figure show the existing road network at the beginning of the time period and the red lines show the construction progress over the length of the decade. Most of the construction occurred between 1968 and 1978.

\footnotetext{
${ }^{13}$ The exact opening dates of the road segments are unknown. It is possible that the road segments could have been open to traffic before construction was officially completed. However, the current empirical strategy hopes to overcome this by examining medium- to long-run mortality outcomes.
} 


\subsubsection{NVSS: NCHS Restricted-Use Mortality Files (1968-2017)}

The main objective of this paper is to isolate the causal effect of the ADHS on mortality outcomes in the Appalachian region. The National Center for Health Statistics (NCHS), through the National Vital Statistics System (NVSS), has data on mortality outcomes in the United States. This sample starts from 1968 and continues to 2017. Restricted-use vital statistics are used to track the number of deaths in Appalachian counties over time. ${ }^{14}$ This restricted-use data set is particularly informative because it not only has the location of residence and death, but also has the specific cause of death, as indicated by International Classification of Diseases (ICD) codes, for every individual in the data. This fact can be utilized to isolate the causes of death where quick access to healthcare could have played a role in preventing premature death.

Throughout the length of the mortality data (1968-2017), the ICD codes went through three revisions, essentially changing the way causes of death were coded in the data. Appendix Table C. 1 shows the changes in the ICD code system over time and lists what ICD codes translate to each broad cause of death that will be analyzed in this study.

Figure 3.3 depicts Appalachian death trends over the length of the sample using the consistent death definitions described in Appendix Table C.1. The top left panel shows all-cause deaths in the Appalachian region have increased over time. Other causes of death vary in their trends throughout time. Changes in mortality at the county level are shown in Figure 3.4. Darker shades of blue represent decreases in mortality rates over the decade, white represents relatively no change, and orange shades represent increases in mortality rates. Figure 3.5 isolates the change in heart disease mortality over time and Figure 3.6 shows total accident mortality rate changes. Other causes of death mapped over time can be found in Appendix C.

\footnotetext{
${ }^{14}$ The public-use data sets do not include fine geographic indicators for place of birth, residence or death beyond 1988. This is why restricted-use data is used.
} 
All model specifications will use case-specific mortality rates as outcome variables. Specifically, the case-specific mortality rate takes the following form:

$$
m_{i y}=\frac{N_{i y}}{C_{i y}} *(100,000)
$$

where $m$ is the case-specific mortality rate in county $i$ in year $y, N$ is the number of deaths from a specific cause in county $i$ in year $y$, and $C$ is the total population of county $i$ in year $y .{ }^{15}$ This rate is multiplied by 100,000 to express the rate as a whole number: deaths per 100,000 people. Expressing deaths as a rate per 100,000 controls for high population levels that may be driving mortality outcomes.

\subsection{Method and Identification Strategy}

\subsubsection{Endogeneity Concerns of ADHS Segment Construction}

Construction of segments of the ADHS was not randomly determined across space. The PARC set out specific guidelines that the ARC used to determine what areas of the country, more specifically what areas of Appalachia, were in need of more access to markets, employment opportunities, and health care options. The PARC map places road segments in these areas of Appalachia. However, the actual timing of the segments' opening varies across time. Places that were arguably more "remote" in the eyes of the federal government potentially saw construction and completion of road segments sooner than other areas of Appalachia. On the other hand, areas isolated due to the mountainous terrain could have potentially seen construction and completion of segments at later dates compared to areas with more level terrain. Either way, this non-random assignment of both potential and actual segment allocation and construction over time could lead to potentially

\footnotetext{
${ }^{15}$ Estimates of county-level intercensal populations from 1970-2014 are available from Roth (2016). 1970 population estimates were used to proxy for 1968 and 1969 population. 2014 population estimates were used to proxy for 2015-2017 populations.
} 
biased estimates of the impact of the ADHS. Unfortunately, this concern has not been considered in empirical studies until very recently.

To overcome this potential bias, an instrumental variable approach will be used to instrument for the location of ADHS segments.

\subsubsection{Instrumental Variable Approach}

Construction of the ADHS will be instrumented with the original PARC plan for Appalachian highway construction. This plan can be seen in Figure 3.1a.

Notably, this original plan is much smaller than what the ADHS has eventually become. One can argue that this instrument is both relevant and excludable. The PARC highway plan, developed in 1964, was never officially utilized once construction of the ADHS began. Between the initial development of the PARC highway plan and the creation of ARC, many counties that were not originally considered to be possible recipients of federal funding for highways were added to the definition of the "Appalachian" region. Therefore, the highway plans were redrawn after the creation of ARC. The original PARC plan has been digitized using QGIS's geo-referencing tools as shown in Figure 3.1b. A comparison of the 1964 PARC plan versus a plan created in 1966 after the formation of ARC is shown in Figure 3.7. ${ }^{16}$ Although relatively similar in the general routeplanning aspects, the 1966 plan was created after the guarantee of federal funds. This, plus the addition of several parts of the country into the Appalachian region, rendered Figure 3.1a obsolete.

It is important to point out another characteristic of Figure 3.7 that informs the predicted sign of the first stage relationship in Equation 3.2. Even though the two plans shown are generally similar in terms of the highway system as a whole, decade to decade changes in a county centroid distance to the 1964 PARC plan is constant over time, while actual construction of the ADHS segments is completed in smaller chunks. Therefore, if a county was planned to get a route relatively close to its centroid in the 1964 plan, the distance measure would be a small length. If, following the suggestions of the 1964 plan (and subsequent later plans), that same county received an ADHS

\footnotetext{
${ }^{16}$ The original 1966 plan is shown in Appendix Figure C.2.
} 
segment when there were no other segments that were generally close to that county constructed up until then, then there will be a large change in the distance to an ADHS segment. In other words, small distances to the 1964 plan are likely to translate to large, negative distance changes to actual ADHS construction. If this line of logic holds, then one should expect a negative first stage relationship.

Formally, the first stage relationship takes the following form:

$$
\Delta A D H S_{c d}=\alpha+\phi_{1} P A R C 1964_{c}+\beta_{1} \mathbf{X}_{c d}+\epsilon_{c d}
$$

where $\triangle A D H S_{c d}$ stands for the change in county centroid distance to nearest ADHS road segment across a given decade, $P A R C 1964_{c}$ stands for county centroid distance to nearest planned PARC highway segment. Subscript $c$ represents county-level data. $d$ stands for the decade across which the changes in ADHS and mortality rates are examined. There are five decade changes examined: 1968-1978, 1978-1988, 1988-1998, 1998-2008, and 2008-2017. ${ }^{17} \mathbf{X}$ is a vector of county-level controls added in fully specified equations. These controls are described in Section III.c. The second testable hypothesis is whether or not exogenous increases in ADHS construction locations have consequences on mortality rate outcomes. This is estimated in Equation 3.3:

$$
\Delta \text { Mortality Rate }_{c d}=\theta+\beta_{1} \Delta \widehat{A D H} S_{c d}+\beta_{2} \mathbf{X}_{c d}+u_{c d}
$$

where $\triangle A \widehat{D H} S_{c}$ stands for the fitted values from estimating Equation 3.2. $\beta_{1}$ is the coefficient of interest. Meeting additional assumptions of independence, SUTVA, and monotonicity, $\beta_{1}$ represents the local average treatment effect (LATE).

SUTVA Concerns - The stable unit treatment value assumption (SUTVA) requires treated units to be only impacted by the treatment the unit was assigned, not the treatment assignment of surrounding units. This assumption could potentially not hold when geographic units are considered;

\footnotetext{
${ }^{17}$ The last "decade" is only nine years instead of ten due to mortality data availability.
} 
geographic units may be impacted not only by the treatment they receive but the treatment of neighboring geographic units. In the context of this research design, there could be potential spatial spillovers of mortality outcomes into neighboring counties when there is an ADHS segment in one county, even if the neighboring counties did not receive an ADHS segment themselves.

A common solution to contain potential spillovers of treatment is to aggregate to a higher spatial unit (Duranton, Henderson, \& Strange, 2015). Papers typically aggregate up from county level analyses to MSA level to contain potential spillovers if SUTVA concerns exist (Duranton \& Turner, 2011). To address SUTVA concerns, Jaworski and Kitchens (2019) examine entire changes to road network travel times to address SUTVA concerns. ${ }^{18}$

\subsubsection{Potential Threats to Internal Validity}

To pin down the mechanism of increased healthcare accessibility through the ADHS construction, additional controls are arguably necessary to confirm the internal validity of the estimation techniques used. In other words, to be confident that the estimations yield unconfounded estimates, one would have to control for factors that both reduce mortality and occur relatively at the same time as an ADHS segment's opening.

The following subsections discuss additional data used to aid in confirming the proposed mechanism.

Hospital Density - The county-level density of hospitals is a potentially confounding variable: a higher density of hospitals may be correlated with mortality outcomes in a county. This correlation exists regardless of ADHS construction in a county, so not including this control will overestimate the impact of the ADHS. As of 2020, there were 643 hospitals open in Appalachia. ${ }^{19}$ Unfortunately, a data set with both the exact geographic (lat/long) location, as well as the opening dates/closing dates of hospitals does not exist. So, tracking these 643 hospitals over time is impos-

\footnotetext{
${ }^{18}$ Future extensions of this work will address potential SUTVA violations.

${ }^{19}$ These hospital locations are shown in Appendix Figure C.7. Source: https://hifld-geoplatform -opendata.arcgis.com/datasets/hospitals
} 
sible; it is also unknown how many hospitals that were open earlier in the sample have closed, and therefore, not counted in the current data.

To remedy this problem, County Business Patterns (CBP) data from the U.S. Census will be utilized. The CBP data include a measure of the number of hospital establishments at the county level. This measure can be used to control for existing health care facilities in a particular county. ${ }^{20}$ 21 These data are available for Appalachian counties for the entire length of the sample period: $1968-2017 .^{22}$

Figure 3.8a shows that the number of hospitals in Appalachia did fluctuate over the length of the sample. Even though it appears that the number of hospitals began to decline after 1990, the number of counties with hospitals steadily increased, as shown in Figure 3.8b. At the start of the sample, less than half of counties in Appalachia had at least one hospital. By the end of the sample, almost all counties had at least one hospital.

Simultaneous Federal Development Projects - ADHS construction was not the only form of federal development investment occurring in Appalachia during this time period. Administrative data on ARC-funded projects from 1968-2016 is used to control for simultaneous development projects that may have impacted the health outcomes of Appalachian residents. These data include the type of development project, as well as the states and/or counties to which they were targeted. ${ }^{23}$ As shown in Figure 3.9, there was a large spike in both total ARC investment, as well as just health-related investment projects between 1968 and 1978. After this time, investment projects of all types decreased and remained relatively constant after 1988. In fully specified models, a sum of the number of health-related investment projects at the county level over a decade is used to proxy for potentially simultaneous federally funded health improvements in the region.

\footnotetext{
${ }^{20}$ Bailey and Goodman-Bacon (2015) has detailed Community Health Center (CHC) data, but not hospital data.

${ }^{21}$ Hospital SIC code: 8062 ; NAICS code: 622110

${ }^{22}$ Source: https: / / catalog.archives.gov/search?f . ancestorNaIds=613576\&q=* : $\star \&$ sort $=$ naIdSort $\% 20$ asc

${ }^{23} \mathrm{~A}$ list of the types of development projects can be found in Appendix Table C.2.
} 
Existing Road Density - Additionally, the existing road density could play a role in determining the relative impact of the ADHS. Existing roads could have also increased the accessibility to healthcare facilities in the Appalachian region regardless of ADHS construction. To control for these other roads to isolate the effect of the ADHS on mortality rates, a control for the existing 1960 road density is added to fully specified models. ${ }^{24}$

\subsection{Results: ADHS and Heterogeneous Impacts Across Time}

The following subsections describe the IV results of estimating the two-step process described in Equations 3.2 and 3.3. To summarize, the ADHS's impact on mortality outcomes depend both on the time period examined and the cause of death of interest. In all specifications and decades examined, there is a significant, negative, first-stage relationship between a county centroid's distance to the 1964 PARC plan and that county's change in distance to an ADHS segment. Cumulative summary statistics by decade can be found in Table 3.1. Results for additional mortality outcomes can be found in Appendix C.1. All 2SLS models without controls can be found in Appendix C.2.

Total Mortality - 2SLS results with added controls for ARC health investment projects, count of hospital establishments, and historic road density are shown in Table 3.2. Panels A-E represent different decades of analysis. The F-statistic is above 10 in all decades, except 2008-2017 in Panel E. Robustness checks in the next section account for potentially biased standard error calculations due to the weak instrument. In all decades, there is not a significant relationship between total mortality and construction of the ADHS.

Heart Disease - 2SLS results with added controls are shown in Table 3.3. Again, there is a consistently significant first stage result. In Panels B and D, a large change in county centroid distance to an ADHS segment is associated with lower rates of heart disease mortality between

\footnotetext{
${ }^{24}$ Data on 1960 road density comes from Jaworski and Kitchens (2019). Appendix Figure C.8 shows the road network in 1960, before the construction of the ADHS. The length of the historic road network is calculated at the county level.
} 
1978-1988 as well as 1998-2008. In other words, in those decades, a county centroid being closer to an ADHS segment caused a significant reduction in heart disease deaths. This result supports the proposed mechanism of the ADHS causing increased accessibility to healthcare facilities. The decreases in heart disease mortality, however, are relatively small compared to the sample average changes shown in column 1 of Table 3.3.

A possible explanation for the dissipation of results over time concerns the hospital density variable. Counties with at least one hospital became more prevalent over the course of the sample, as shown in Figure 3.8b. The fact that more counties were receiving hospitals in the 1988-1998 time period would explain why the distance to the ADHS did not matter as much to heart disease mortality. If a county that never had a hospital finally received one, people would no longer have to cross county borders to reach a hospital, which is what the ADHS helped facilitate. During the 1998-2008 time period, the large decrease in the number of hospitals in the Appalachian region could explain the return of statistical significance of the ADHS again.

Hypertension - 2SLS results with added controls are shown in Table 3.4. The only decade with significant results is 1988-1998, displayed in Panel C. Just like heart disease, there is a negative relationship between mortality and distance to the ADHS, suggesting that the ADHS caused a decrease in hypertension deaths between 1988 and 1998. This is an interesting result given the general mortality rate in the Appalachian region associated with hypertension was increasing during this time, as shown in Figure 3.3c and in column 1 of Table 3.4.

Total Accidents/Trauma - Table 3.5 displays the two-stage results for accident death rates in Appalachia. In earlier decades of the sample, there is no significant relationship between ADHS and accident mortality rates. However, in the last two decades of the sample, as shown in Panels D and $\mathrm{E}$, there is a positive, significant second stage relationship: as a county centroid got closer to an ADHS segment, the larger accident mortality rates became in the 2000s. This is in contrast to the negative and significant relationship estimated in the reduced form models in the same decades. 
The increase in accident mortality between 2008-2017 is equivalent to a 0.93 standard deviation increase in the accident mortality change compared to the sample mean.

The total accident outcome includes a wide breadth of possible causes of death. Accident rates in all decades include car accidents, so this could be a potential mechanism for the positive and significant second stage results in later decades. As the ADHS was constructed over time, more and more drivers took advantage of the roads. This increased demand for road usage over time could have potentially led to an increase in car accident mortality rates. Additionally, greater access to larger urban areas could also lead to an increase in accidental drug and medicinal overdoses. Further disaggregation into these two more specific outcomes - car accidents and overdoses - is shown in the following section.

\subsection{Robustness and Mechanism}

The following subsections discuss robustness exercises conducted.

Disaggregation of Total Accidents - In the previous section, the analysis of accident mortality rates includes all accidental deaths. These causes of death range from car accidents, to falls and poisonings. To add further weight to the proposed mechanism, two types of accidents are examined separately: car accidents and overdoses. Figure 3.10 displays the mortality rates for car accidents and accidental overdoses. Independently, these types of accidental deaths may have some associated with decreased distance to an ADHS road segment. If more people use the highway system, over time, one would expect to see an increase in car accident mortality rates. However, as shown in Table 3.6, this does not seem to be the case.

In terms of overdose deaths, one could expect to see counties that became closer to the ADHS over time had increased access to larger, urban areas. ${ }^{25}$ With the potential for income and employment also comes increased access to more negatively associated aspects of city life. In fully

\footnotetext{
${ }^{25}$ For example, Corridor H, when completed, will connect interior West Virginia to the Washington, D.C. metro area. Source: http://www.wvcorridorh.com/route/route.html
} 
specified IV models, shown in Table 3.7, there is a positive and statistically significant coefficient for overdose mortality in the last three decades of the sample: counties that got closer to ADHS segments experienced a significant increase in overdose mortality rates. ${ }^{26}$ In the last decade of the sample, the increase in the change in overdose mortality estimated is equivalent to a 0.80 standard deviation increase.

Corrections for Weak Instrument - In all of the 2SLS specifications for 2008-2017 discussed in Section IV, the F-statistic testing for weak identification was below 10, a signal that the instrument is considered "weak." This could be driven by the fact that the ADHS was practically completed by this time, so few areas of Appalachia experienced large changes, if any changes at all, in the distance to an ADHS segment. Panel E in Tables 3.5 and 3.7 include Anderson-Rubin (AR) confidence sets for the second stage point estimate. ${ }^{27}$ Andrews, Stock, and Sun (2019) note that AR confidence sets are efficient for just-identified models.

In Panel $\mathrm{E}$ of the above-mentioned tables for total mortality, heart disease, total accidents, and overdose mortality outcomes, the significant second-stage coefficient in the 2008-2017 decade does not appear to be driven by a statistically weak instrument. The coefficients fall between the two-step confidence set proposed; this suggests that the significant relationships found in the 2008-2017 decade for total accidents and overdoses is not due to a relatively weak instrument.

Cumulative Effect of the ADHS on Mortality - The main results presented in Section 3.4 are a set of repeated cross-sections. The cumulative effect of the ADHS on various mortality outcomes can be estimated by pooling the results across the entire length of the sample. Formally, the panel 2SLS approach takes the following form, with Equation 3.4 the first stage and Equation 3.5 the second stage:

$$
A D H S_{c y}=\alpha+\phi_{1} P A R C 1964_{c} * \gamma_{y}+\beta_{1} \mathbf{X}_{c y}+\gamma_{y}+\delta_{s}+\epsilon_{c y s}
$$

\footnotetext{
${ }^{26}$ In terms of comparability across time, the mortality data does not track what specific drugs or medicines were the cause of overdose deaths.

${ }^{27}$ Appendix Tables C.2.1, C.2.2, and C.2.8 also include the adjusted confidence sets.
} 
where $A D H S_{c d}$ stands for the county centroid distance to nearest ADHS road segment across a given decade, $P A R C 1964_{c}$ stands for county centroid distance to nearest planned PARC highway segment. In this panel setting, the PARC distance is interacted with a year fixed effect to allow the instrument to be time-varying. Subscript $c$ represents county-level data. $y$ stands for the year in which mortality rates and distances are examined. $\mathbf{X}$ is a vector of county-level controls added. ${ }^{28}$ In the panel setting, year fixed effects $\left(\gamma_{y}\right)$ and state fixed effects $\left(\delta_{s}\right)$ are employed.

$$
\text { MortalityRate }_{c y}=\theta+\beta_{1} A \widehat{D H} S_{c y}+\beta_{2} \mathbf{X}_{c y}+\gamma_{y}+\delta_{s}+u_{c y s}
$$

where $A \widehat{D H} S_{c}$ stands for the fitted values from estimating Equation 3.4. $\beta_{1}$ is the coefficient of interest.

Appendix Table C.3.1 reports the total effect of the ADHS across the entire length of the sample. Select causes of death are examined: total mortality, heart disease mortality, hypertension mortality, total accident mortality, and accidental overdose mortality. All second stage F-statistics are above 10. Although marginally significant results are found for certain causes of death, overall it appears the cumulative impact of the ADHS on mortality was minimal. Decade-to-decade examinations of the ADHS, however, yield a deeper story of the relationship between the ADHS and mortality.

County of Residence - In Appalachia over the sample, counties appear to have more mobile residents. This is explicitly shown in Figure 3.11. Every death in the data has an indicator for both county of death and county of residence. Therefore, one can get a sense if an Appalachian county is home to a large share of people who died outside of the county in a given year. If the total count of deaths occurring in a "county of residence" in county $i$ is larger than the deaths categorized as a "county of death" in county $i$, more residents died outside of the county compared to those that

\footnotetext{
${ }^{28}$ These controls are the same used in Section 3.4: count of hospitals in a county, number of ARC investment projects in a county, and the existing 1960 road density.
} 
died within the county. ${ }^{29}$ Over time, Appalachian counties increasingly saw more residents dying outside of the county of residence. This is suggestive evidence that Appalachian residents became more mobile during the ADHS construction time period.

Unobservable Changes in Health Inputs - One limitation of the current analysis is the inability to account for unobserved historical changes in health inputs. The construction of the ADHS implies many simultaneous connections: connections to urban areas increase wealth and employment opportunities in addition to reducing travel times. The current estimation does not seek to directly estimate these benefits. However, there have been estimates of the benefits to the Appalachian region caused by the ADHS, as shown by Economic Development Research Group (2017); these benefits will be utilized more in the following section. Additionally, over the course of the sample, quality of care improvements or mortality-prevention activities by individuals go unobserved.

\subsection{Benefit-Cost Analysis}

Using the estimates discussed in Section 3.4, calculations of the relative benefits and costs of the ADHS are examined below. For each cause of death, the additional increase or decrease in mortality caused by the ADHS can be translated into fewer or greater deaths in the Appalachian region.

Heart Disease Lives Saved - As shown in Table 3.3, there was a significant decrease in heart disease mortality between 1978-1988 as well as between 1998-2008. To calculate the lives saved by the ADHS, the decrease in the heart disease mortality rate can be converted to reflect the number of lives saved in Appalachia. The average population across Appalachian in the 1978-1988 time period was 21.371 million people. ${ }^{30}$ With a decreased death rate of 2.974 per 100,000 , this

\footnotetext{
${ }^{29}$ For example, if county $i$ had 1000 deaths in the county of residence measure and 800 deaths in the county of death measure, county $i$ had more people's deaths occur outside of the county compared to deaths that occurred inside of the county.

${ }^{30}$ Figure C.9 shows the intercensal population estimates of Appalachia from 1970-2014. Population in 1978: 21.1531 million, population in 1988: 21.6101 million.
} 
corresponds to 636 fewer deaths in the Appalachian region due to heart disease between 19781988. ${ }^{31}$ Between 1998 and 2008, the average Appalachian population was 23.961 million residents. ${ }^{32}$ With a decreased death rate of 4.132 per 100,000, this corresponds to 990 fewer deaths in the Appalachian region due to heart disease between 1998-2008 because of the ADHS.

In total, because of the ADHS, 1626 fewer Appalachian residents died due to heart disease over the length of the sample.

Hypertension Lives Saved - Table 3.4 shows there was a significant decrease in hypertension mortality between 1988 and 1998. The mean Appalachian population during this time period was 22.327 million people. ${ }^{33} 106$ fewer people in the Appalachian region did not die of hypertension between 1988 and 1998 due to the ADHS.

In sum, 1732 fewer people died in the Appalachian region of heart disease or hypertension because of the ADHS.

Overdose Lives Lost - Although there were fewer lives lost to heart-related conditions, there were more lives lost to accidental overdoses because of the ADHS, as shown in Panels D and E of Table 3.7. Between 1998 and 2008, the average population of the Appalachian region was 23.961 million people. ${ }^{34}$ With an increased death rate of 0.920 per 100,000 , this corresponds to 220 more deaths in the Appalachian region due to accidental overdoses between 1998-2008. Between 2008 and 2017 , the 15.622 per 100,000 increased death rate can be interpreted as 3933 more people who died of accidental overdoses because of the ADHS..$^{35}$

In sum, 4153 more people died in the Appalachian region of accidental overdoses because of the ADHS.

\footnotetext{
${ }^{31}$ A mortality rate of 2.974 per $100,000=0.00002974$ chance of one person dying. Out of a total of $21.371 \mathrm{million}$ people: $0.00002974 \times 21371000=636$ fewer deaths.

${ }^{32}$ Population in 1998: 23.043 million, population in 2008: 24.878 million.

${ }^{33}$ Population in 1988: 21.610 million, population in 1998: 23.043 million.

${ }^{34}$ Population of 1998: 23.043 million, population of 2008: 24.878 million.

${ }^{35}$ The average population of the Appalachian region between 2008 and 2017 was 25.178 million. Population in 2008: 24.878, population in 2015: 25.478 .
} 
Benefit-Cost Analysis - Based on the findings above, there was a net increase in 2421 lives lost in the Appalachian region due to the ADHS. This means 2.3 times more people died of overdose deaths than those that were saved with heart disease or hypertension. To be able to compares the financial costs and benefits of the ADHS, the "value of a statistical life" (VSL) will be used. The VSL is a common measurement used in policy-informing research. The average value of a statistical U.S. life is $\$ 10$ million (Kniesner \& Viscusi, 2019). ${ }^{36}$ This estimate can directly translate as the willingness to pay for a small reduction in the probability of death. So, if an individual is willing to pay $\$ 100$ per year to reduce the probability of dying by 0.00001 , then collectively a group of 100,000 would be willing-to-pay $\$ 10$ million per year to prevent the loss of one "statistical life" (Colmer, 2020).

The previous subsections noted there was a net increase of 2421 deaths due to the ADHS in the Appalachian region. In terms of the value of a statistical life, this would amount to $\$ 24.2$ billion, in addition to the direct construction costs of the ADHS. The construction costs of the current ADHS has been estimated to be $\$ 11.2$ billion; the remaining, unbuilt segments of the ADHS are estimated to cost another $\$ 10.9$ billion (Economic Development Research Group, 2017). ${ }^{37}$ The $\$ 24.2$ billion in unintended mortality consequences plus the $\$ 22.1$ billion in past and future construction costs brings the total cost of the ADHS to $\$ 46.3$ billion.

As mentioned in the previous section, direct benefits of the ADHS are not calculated in this paper. However, potential benefits of the ADHS include travel time savings, employment growth, income growth, and increased domestic and international trade. Other health-related benefits not calculated include preventative health measures taken by individuals in the Appalachian region. According to a 2017 ARC report, the total benefits of the ADHS, quantified in transportation cost savings and productivity gains to the Appalachian region, amount to $\$ 10.7$ billion per year (Economic Development Research Group, 2017). Over the 49 years of the sample period (19682017), this amounts to approximately $\$ 524.3$ billion cumulative benefits. Based on this estimation

\footnotetext{
${ }^{36}$ Estimate in 2017 dollars.

${ }^{37}$ About $90 \%$ of the ADHS has been constructed. The remaining $10 \%$ of the ADHS is being constructed in more rugged terrains, which is why the price is significantly more per mile.
} 
of total benefits, it appears that, despite the total costs of the ADHS more than doubling with the addition of unintended mortality consequences, the benefits of the ADHS outweigh the total costs.

\subsection{Conclusion}

The construction of the Appalachian Development Highway System (ADHS) was one of the largest federally funded infrastructure projects in U.S. history. Using a newly digitized instrument, newly digitized construction maps, and restricted vital statistics, this work contributes to the growing economics literature connecting health outcomes to location-based attributes. This work has uncovered an undocumented positive consequence of the ADHS - improved mortality outcomes of time-sensitive conditions such as heart disease and hypertension. However, there is also evidence of increased mortality rates in certain decades for certain causes of death, notably accidents; these increases appear later in the sample and are driven by overdose mortality rates. Controlling for potential confounding factors such as hospital density, simultaneous ARC health-related investment projects, and existing 1960 road density does not diminish the IV results.

Although Appalachian mobility, in terms of county of death, appears to have increased over the sample, various relationships that could have also changed given the construction of the ADHS (quality of healthcare as well as individual wealth and employment) are not directly estimated in this paper. Using simple benefit-cost analysis, the unintended mortality costs caused by the ADHS are more than double the actual construction costs incurred. However, these increased costs do not overtake previously calculated benefits of improved travel times, employment, and income growth associated with the ADHS in the Appalachian region. Future extension of this work will incorporate aggregated changes to the road network to address potential spillovers of accessibility to neighboring counties.

While approaching internal validity, the current estimation approaches and research questions considered do not touch much on external validity. The ADHS was a very unique federally funded infrastructure project in the United States. Because this infrastructure stock now exists, another 
project at this scale is unlikely to be seen in the United States. However, in developing counties, these results could be pertinent in cost-benefit analyses of large, infrastructure projects. 
Figure 3.1: 1964 President's Appalachian Regional Commission (PARC) Highway Plan

Panel A: 1964 Original Map

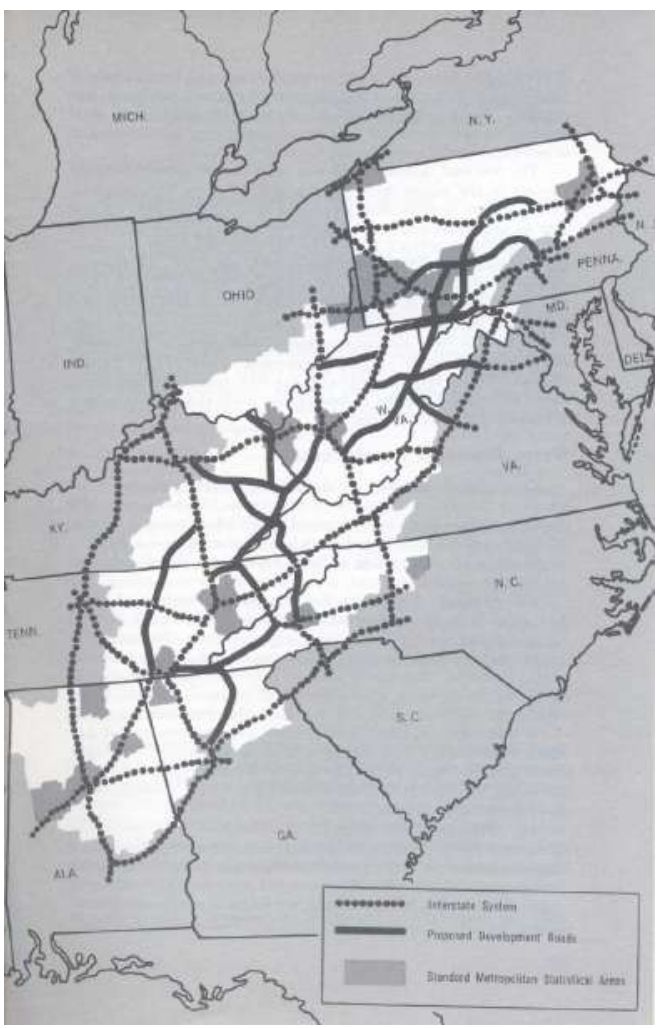

Panel B: 1964 PARC Highway Plan Digitized

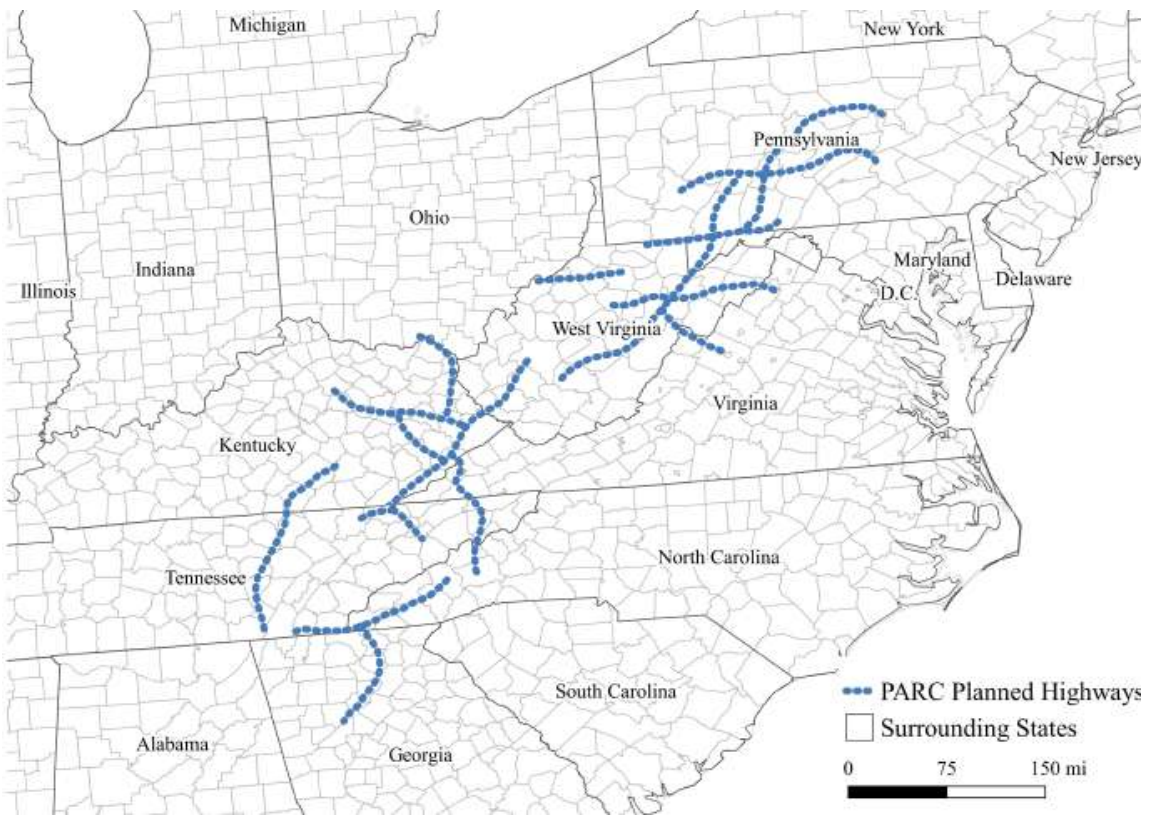

Note: Panel A shows the 1964 PARC highway plan map. Solid lines show the original plan for federally funded highways in the region. This plan was never utilized after the creation of the Appalachian Regional Commission (ARC) in 1965. New plans were drawn (See Figure C.2) after the guarantee of federal funding, as well as the expansion of the Appalachian region into New York, Alabama, and Mississippi by 1967. Panel B is a digitized version of Panel A, which shows the proposed highway segments in the PARC report as blue-dashed lines. Figure was digitized using QGIS. Source for Panel A: PARC (1964). 
Figure 3.2: Appalachian Development Highway System Progress: 1968-2017

Panel A: ADHS Progress 1968-1978

Panel B: ADHS Progress 1978-1988

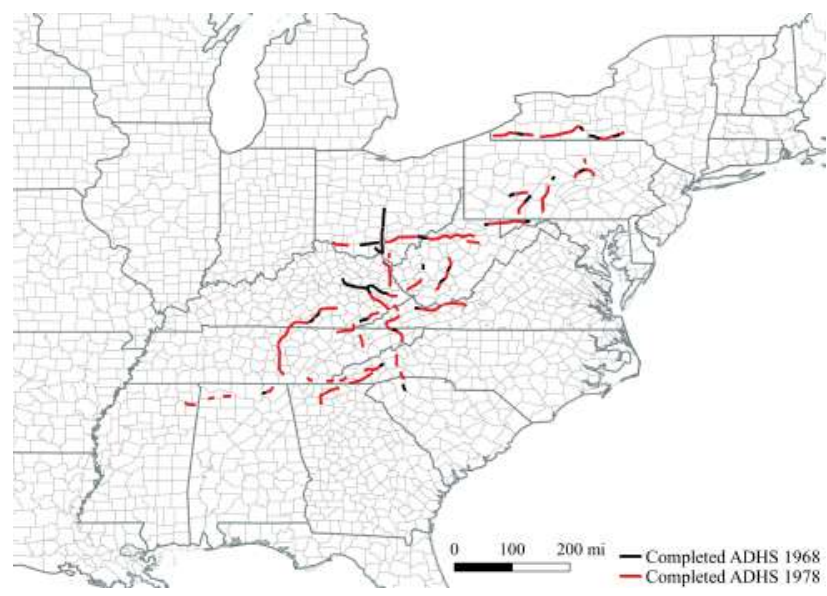

Panel C: ADHS Progress 1988-1998

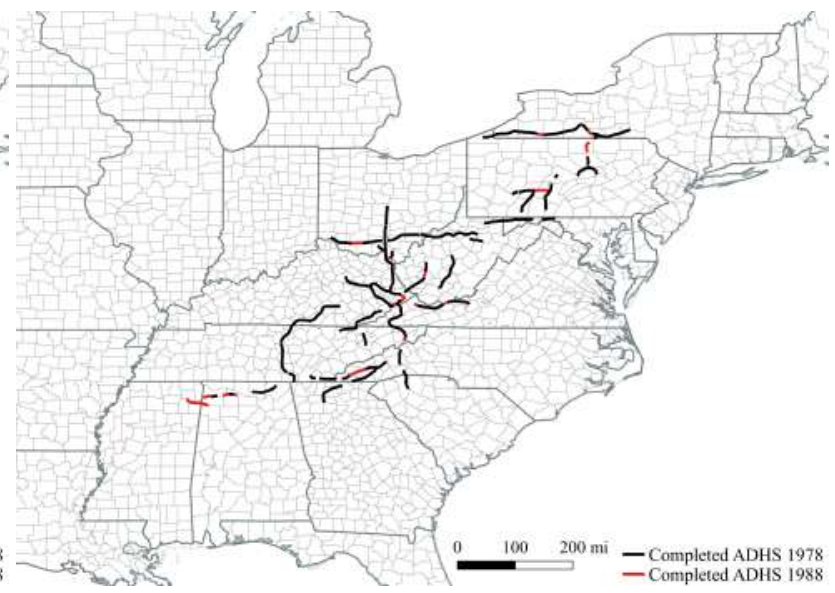

Panel D: ADHS Progress 1998-2008
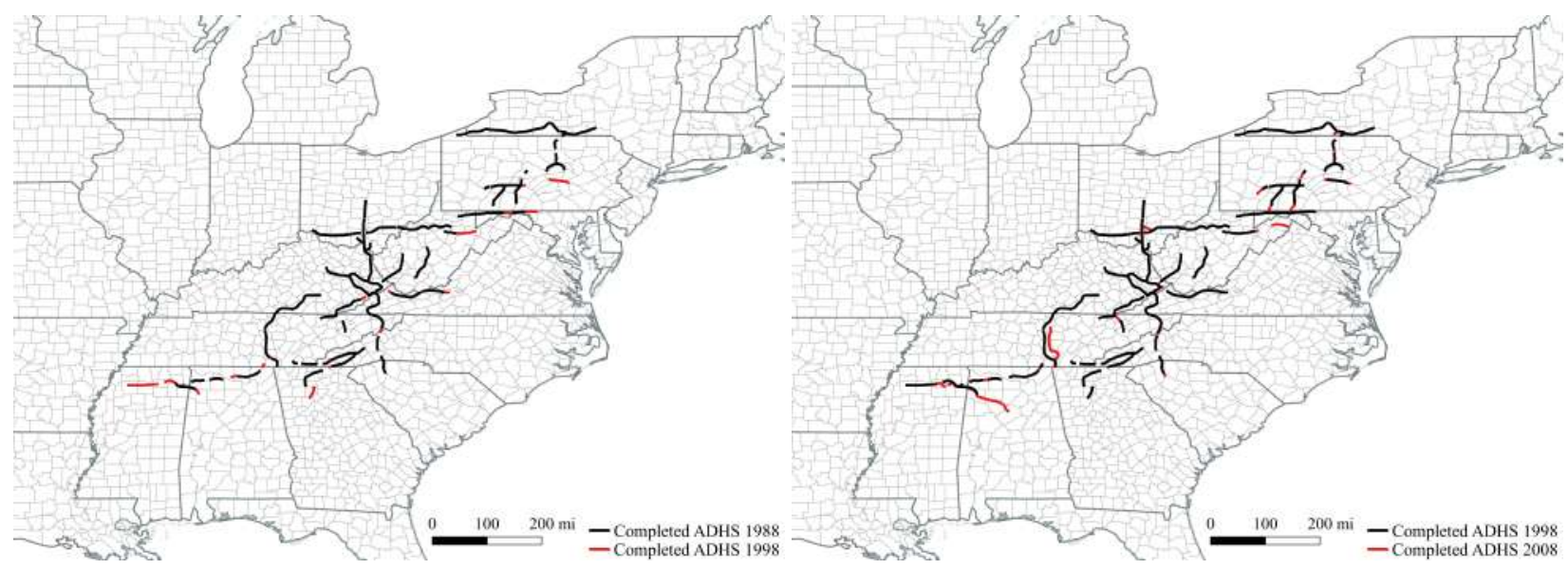

Panel E: ADHS Progress 2008-2017

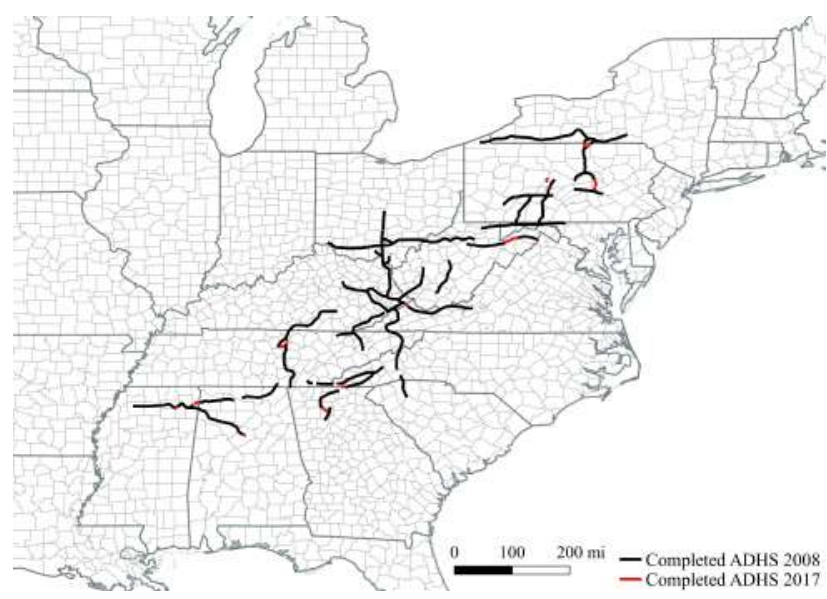

Note: Figures display construction progress of the Appalachian Development Highway System. In all Panels, black lines represent highway segments already constructed at the start of the period. Red lines represent highway segments completed in each time period. Figure created using QGIS. 
Figure 3.3: Appalachian Mortality Rates 1968-2017: Per 100,000

Panel A: Total Death Rate

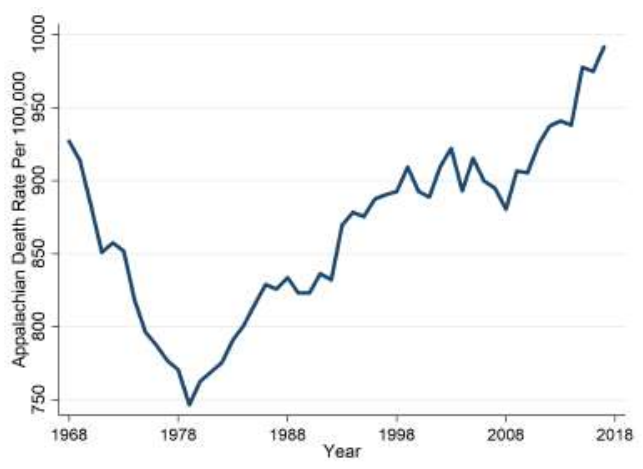

Panel C: Hypertension Rate

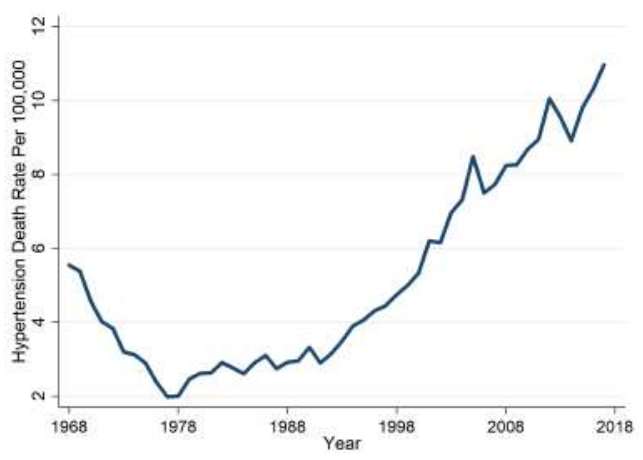

Panel E: Aortic Aneurysm Rate

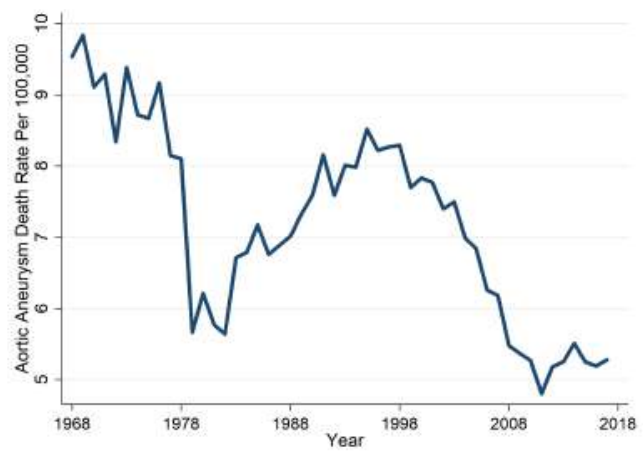

Panel G: Complications with Pregnancy Rate

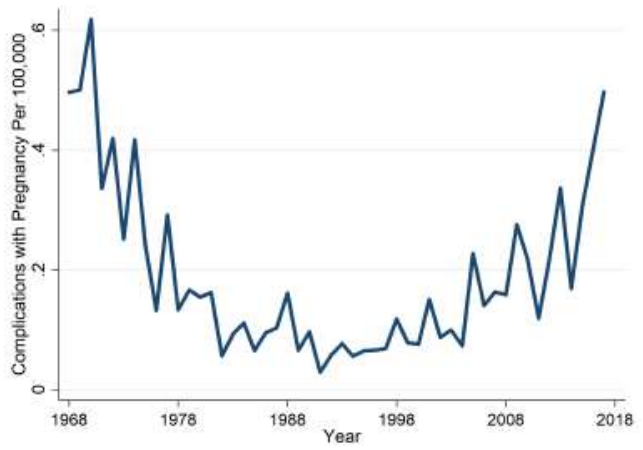

Panel B: Heart Disease Rate

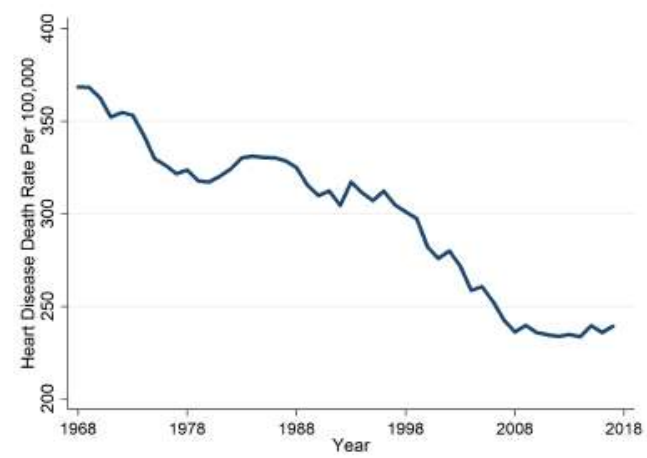

Panel D: Cerebrovascular Disease Rate

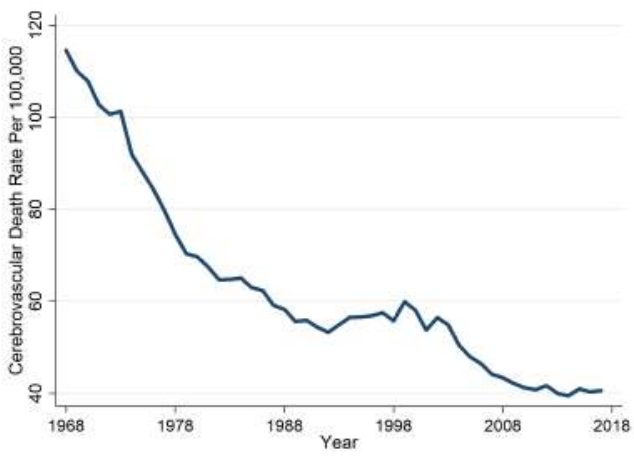

Panel F: Pneumonia \& Influenza Rate

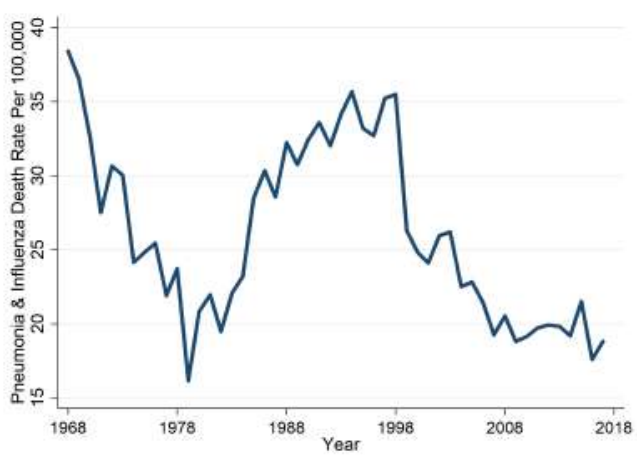

Panel H: Accident Rate

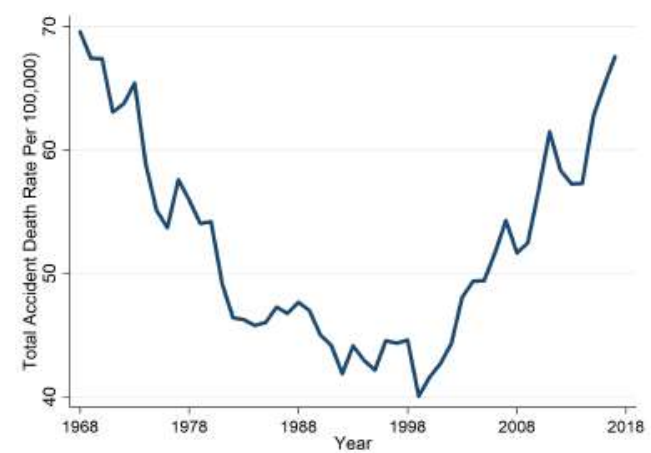

Note: Appalachian death rates per 100,000 for various causes of death are shown above. Rates for county of death graphed. 
Figure 3.4: Appalachian County Change in Mortality Rates: 1968-2017

Panel A: Change in Total Mortality: 1968-1978

Panel B: Change in Total Mortality: 1978-1988

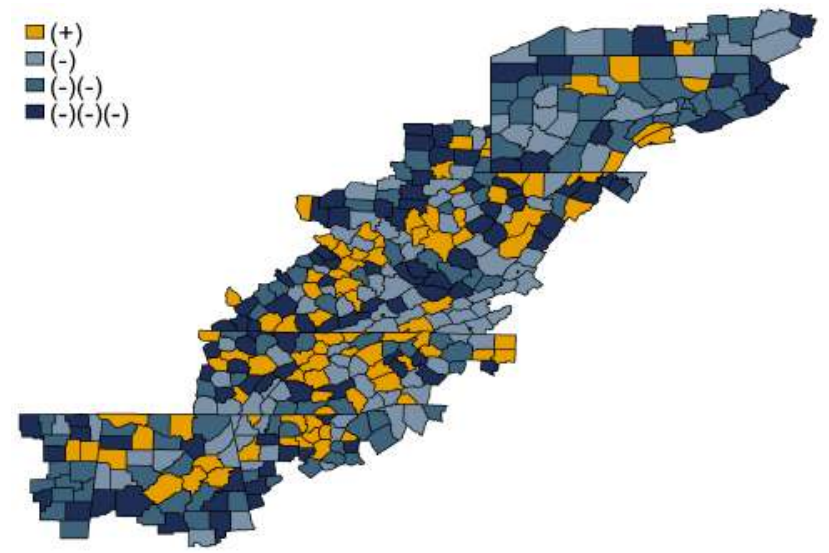

Panel C: Change in Total Mortality: 1988-1998

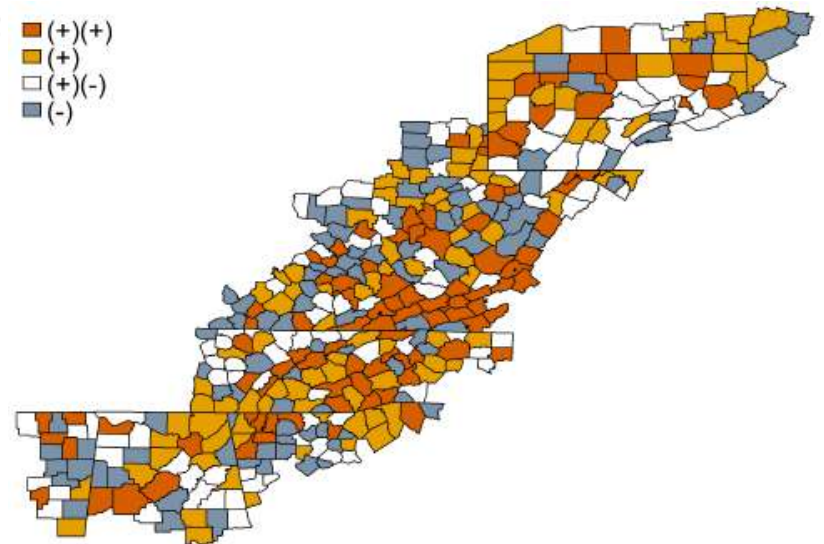

Panel D: Change in Total Mortality: 1998-2008
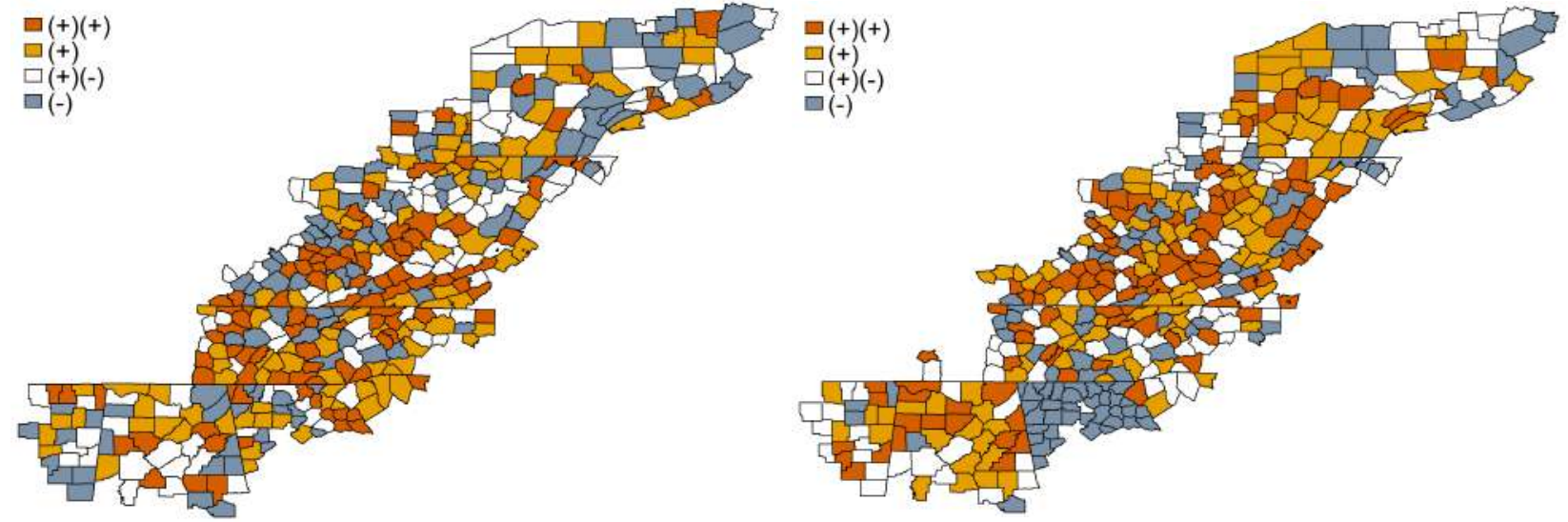

Panel E: Change in Total Mortality: 2008-2017

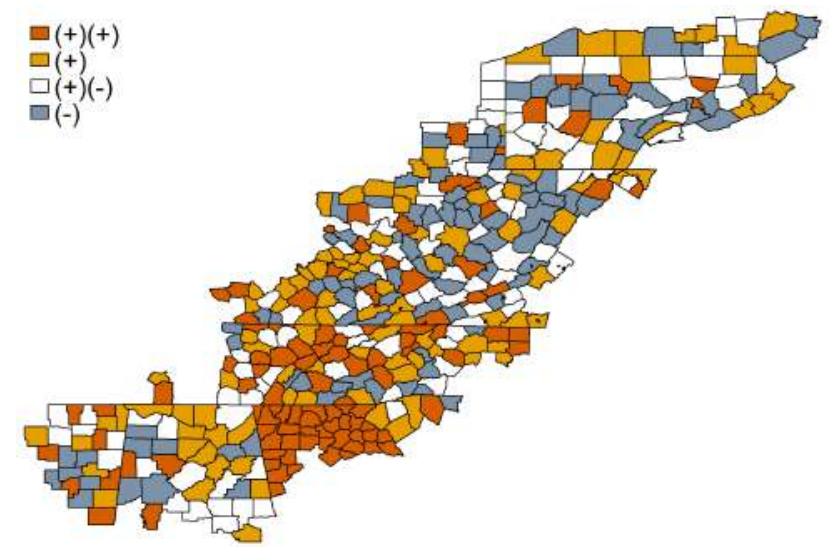

Note: Appalachian county changes in total mortality rates are shown above. Darker shades of blue represent negative changes (improved mortality over the decade), while darker shades of orange represent positive changes (worse mortality over the decade). White counties represent no significant change. Counties grouped into equal quantiles per decade. County of death mapped. 
Figure 3.5: Appalachian County Change in Heart Disease Mortality Rates: 1968-2017

Panel A: Change in Heart Disease Mortality:

1968-1978

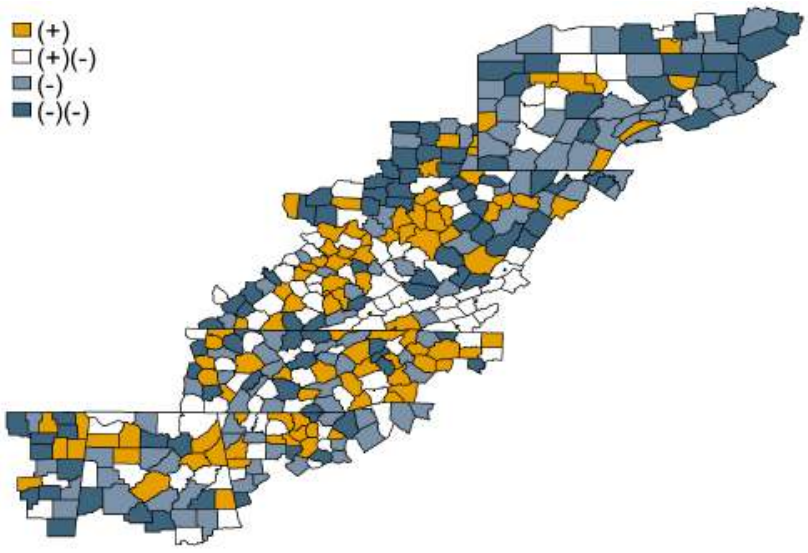

Panel C: Change in Heart Disease Mortality: 1988-1998

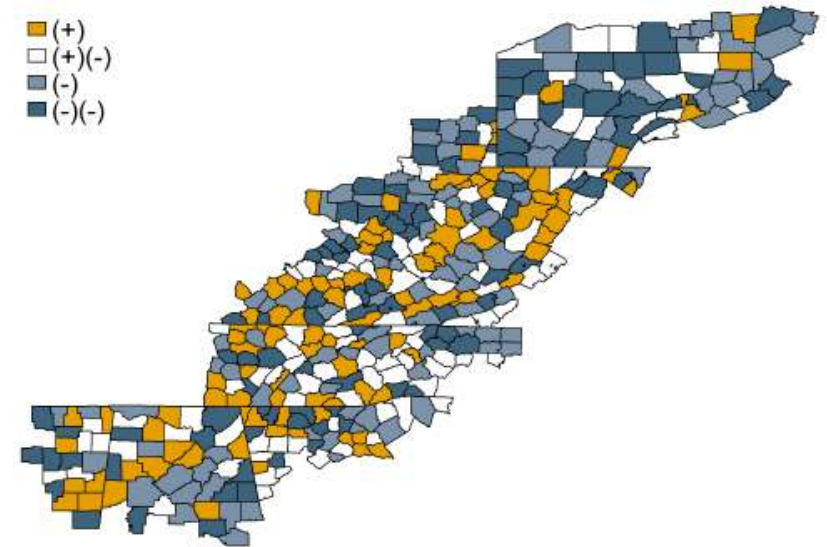

Panel E: Change in Heart Disease Mortality:

2008-2017

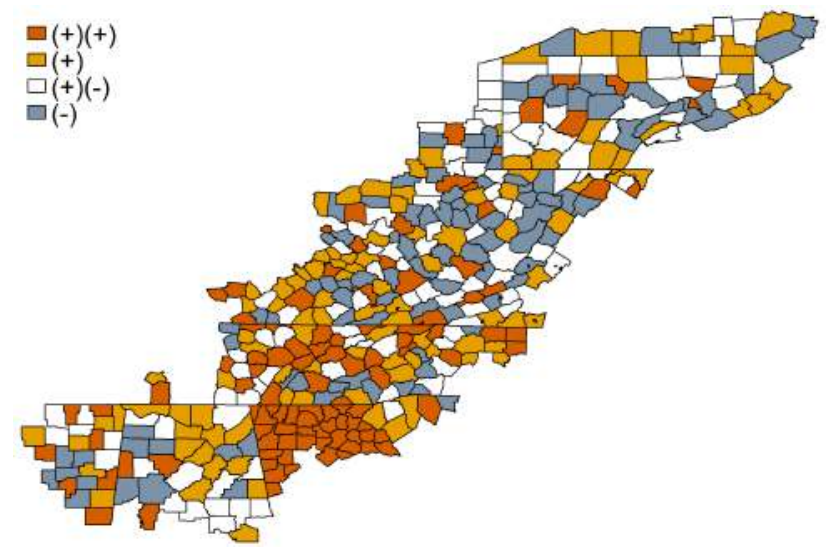

Panel B: Change in Heart Disease Mortality: 1978-1988

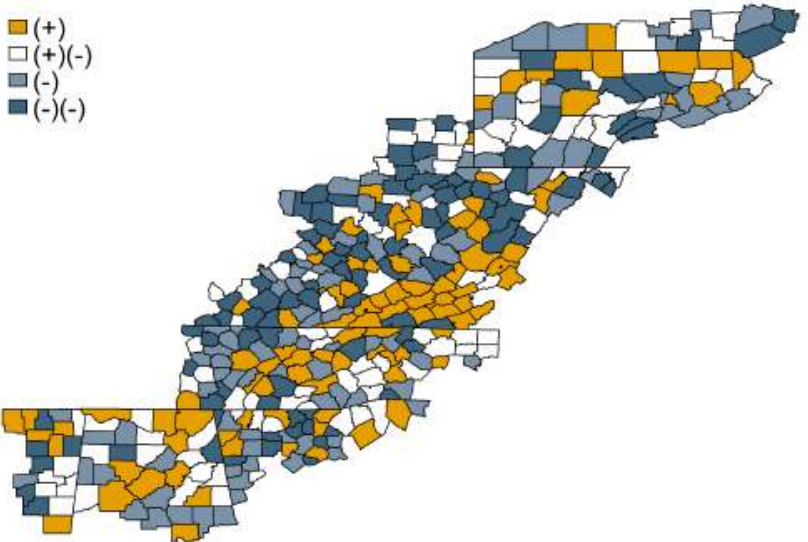

Panel D: Change in Heart Disease Mortality: 1998-2008

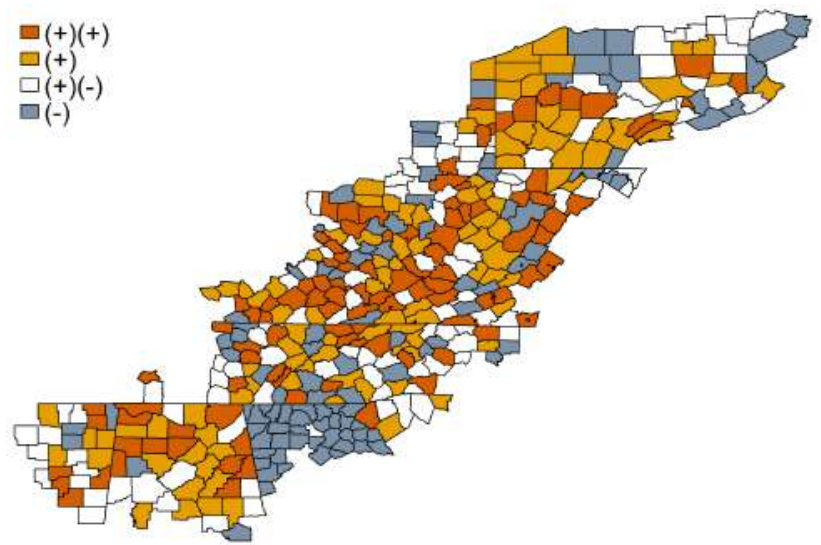

Note: Appalachian county changes in heart disease mortality rates are shown above. Darker shades of blue represent negative changes (improved mortality over the decade), while darker shades of orange represent positive changes (worse mortality over the decade). White counties represent no significant change. Counties grouped into equal quantiles per decade. County of death mapped. 
Figure 3.6: Appalachian County Change in Total Accident Mortality Rates: 1968-2017

Panel A: Change in Total Accident Mortality: 1968-1978

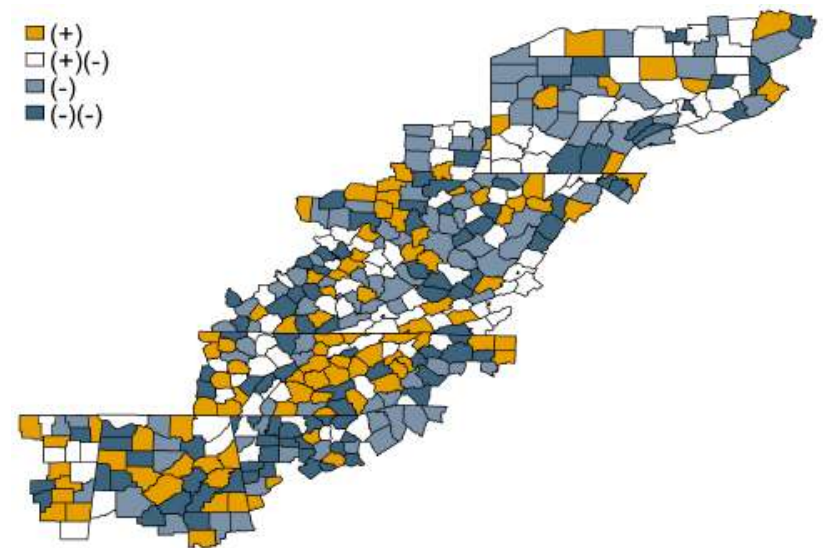

Panel C: Change in Total Accident Mortality: 1988-1998

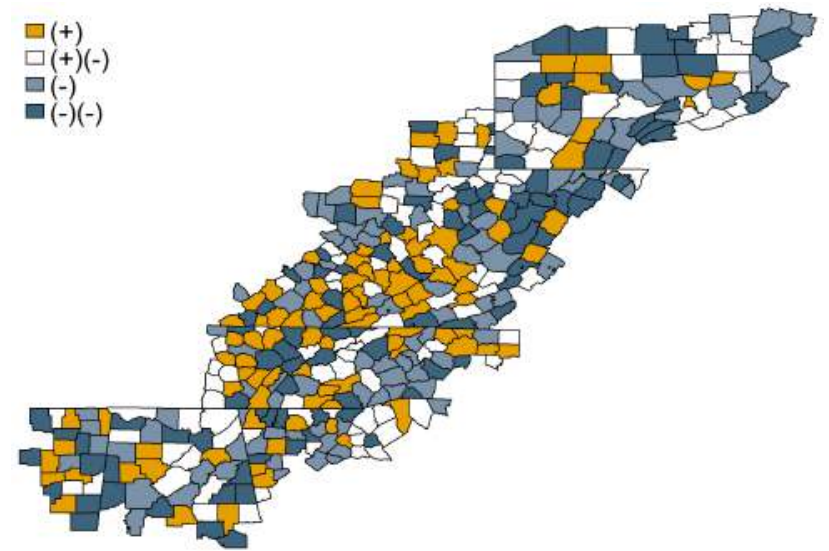

Panel E: Change in Total Accident Mortality: 2008-2017

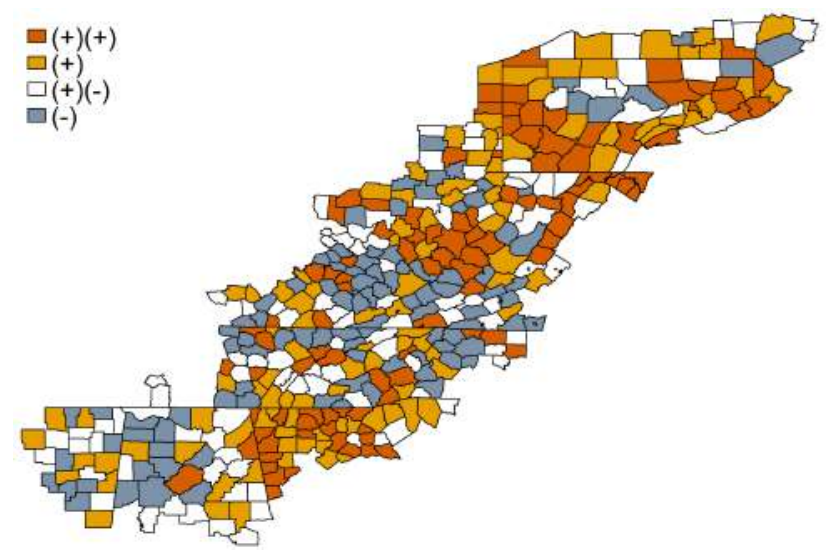

Panel B: Change in Total Accident Mortality: 1978-1988

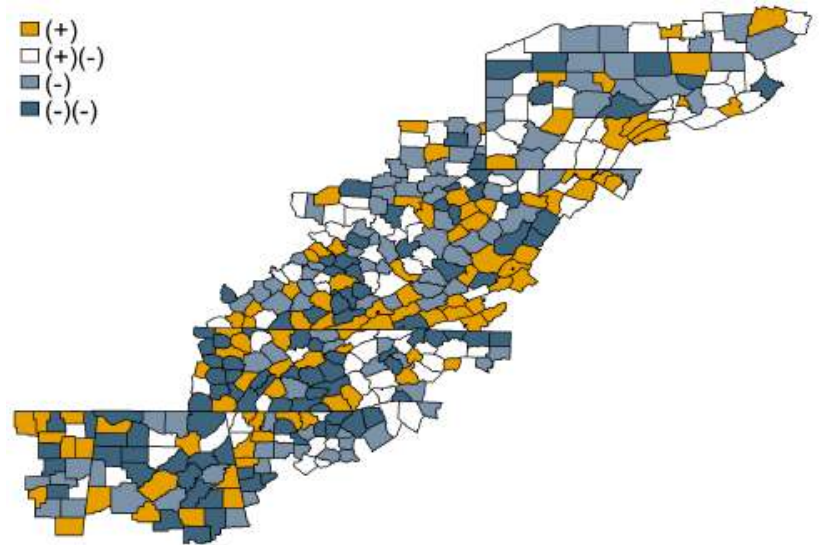

Panel D: Change in Total Accident Mortality: 1998-2008

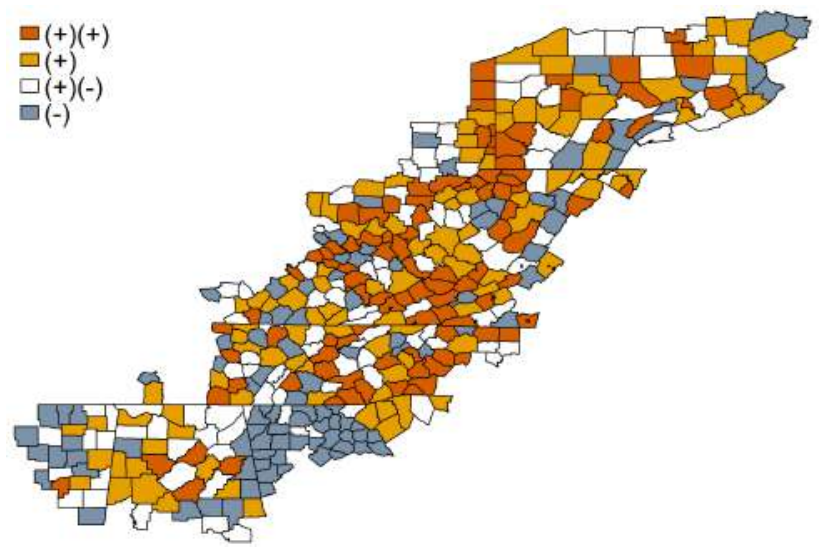

Note: Appalachian county changes in total accident mortality rates are shown above. Darker shades of blue represent negative changes (improved mortality over the decade), while darker shades of orange represent positive changes (worse mortality over the decade). White counties represent no significant change. Counties grouped into equal quantiles per decade. County of death mapped. 
Figure 3.7: 1964 PARC Planned Highways vs. 1966 ADHS Planned Highways

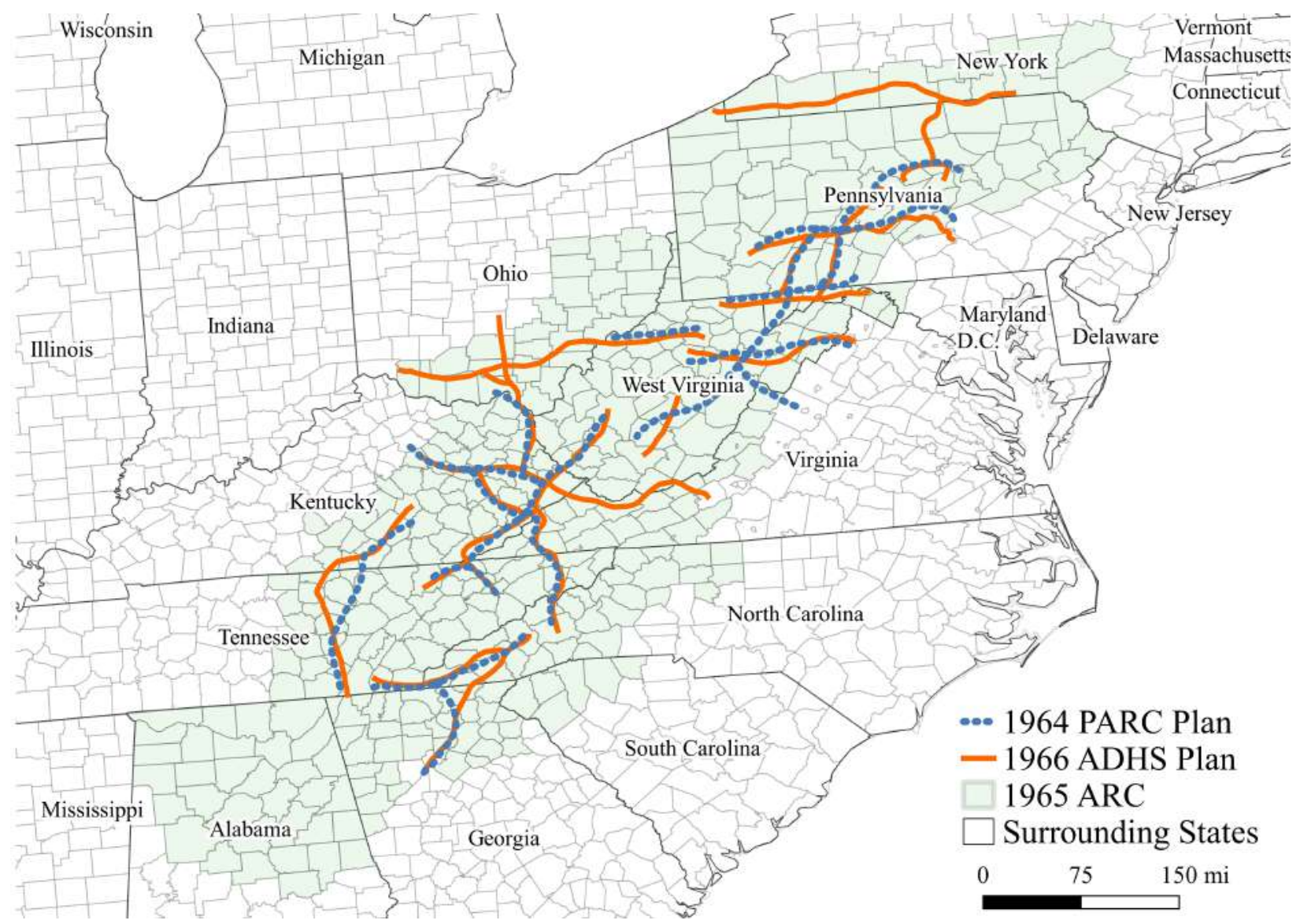

Note: This map visually compares the PARC planned highways location compared to a later plan after the creation of ARC. Figure was created using QGIS. 
Figure 3.8: Hospitals in Appalachia over Time

Panel A: Count of Hospital Establishments

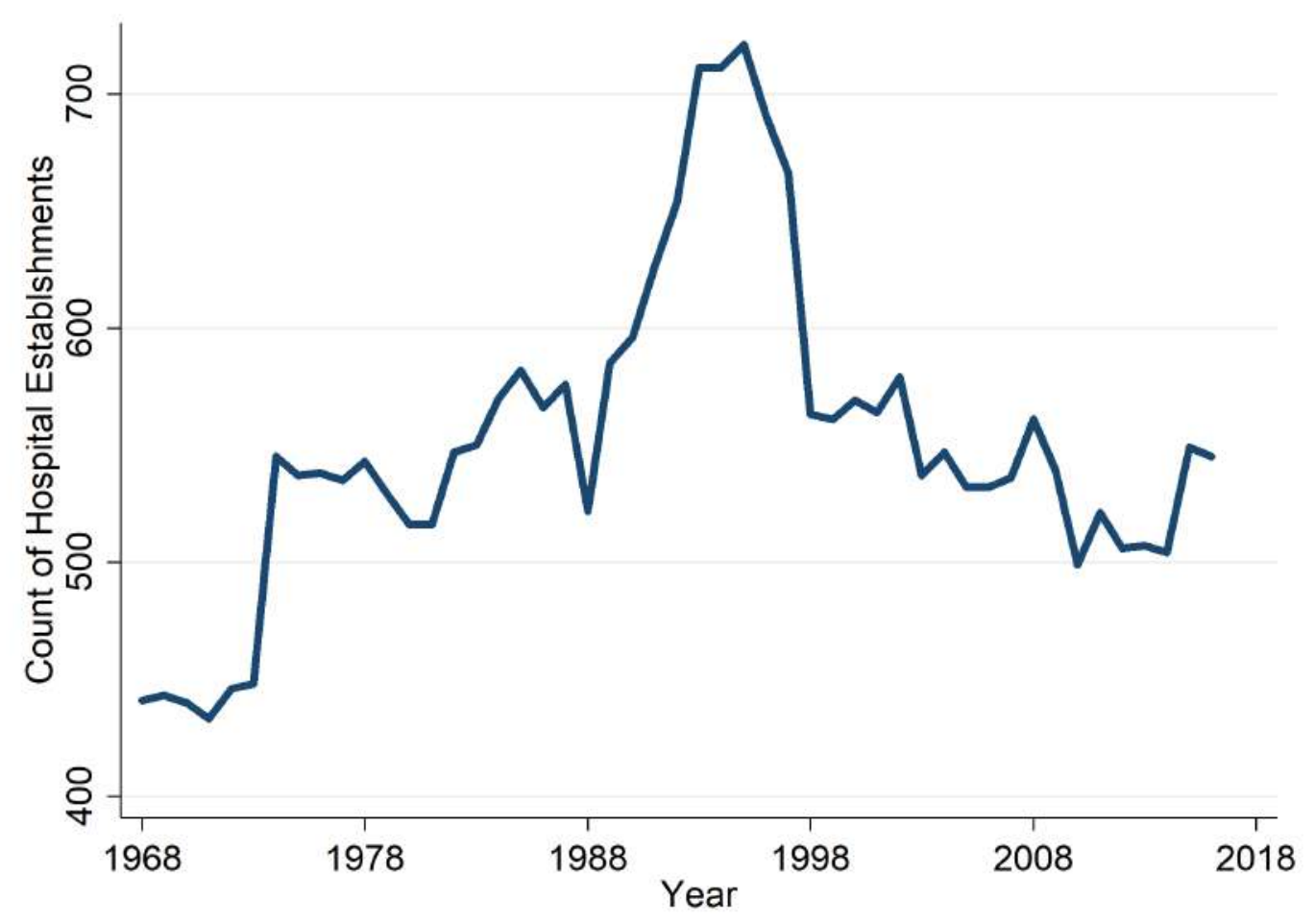

Panel B: Number of Counties with at Least One Hospital

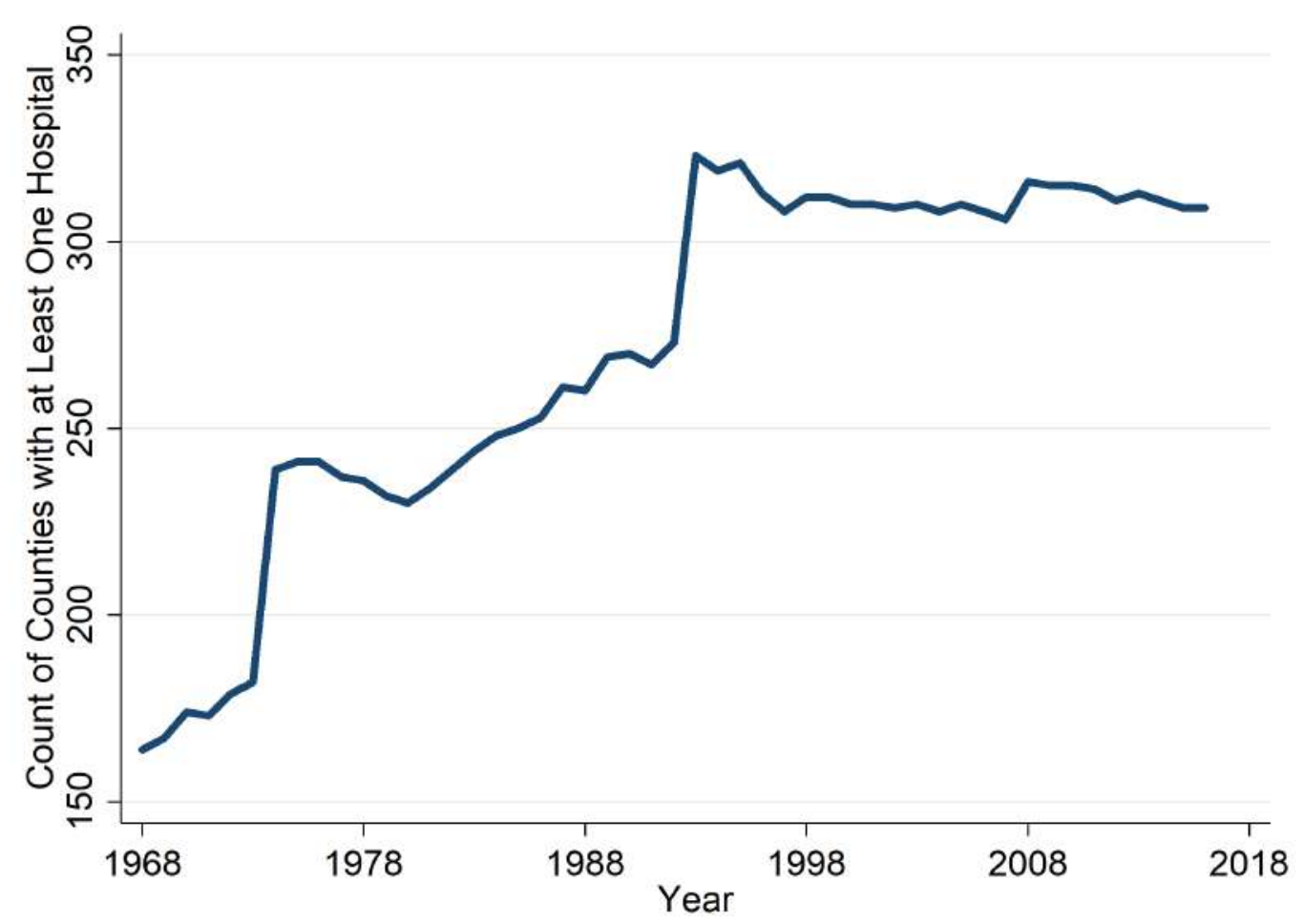

Note: Panel A displays the count of hospitals in the Appalachian region over time. Panel B displays the number of counties in Appalachia with at least one hospital. 
Figure 3.9: Count of ARC Investment Projects: 1968-2016

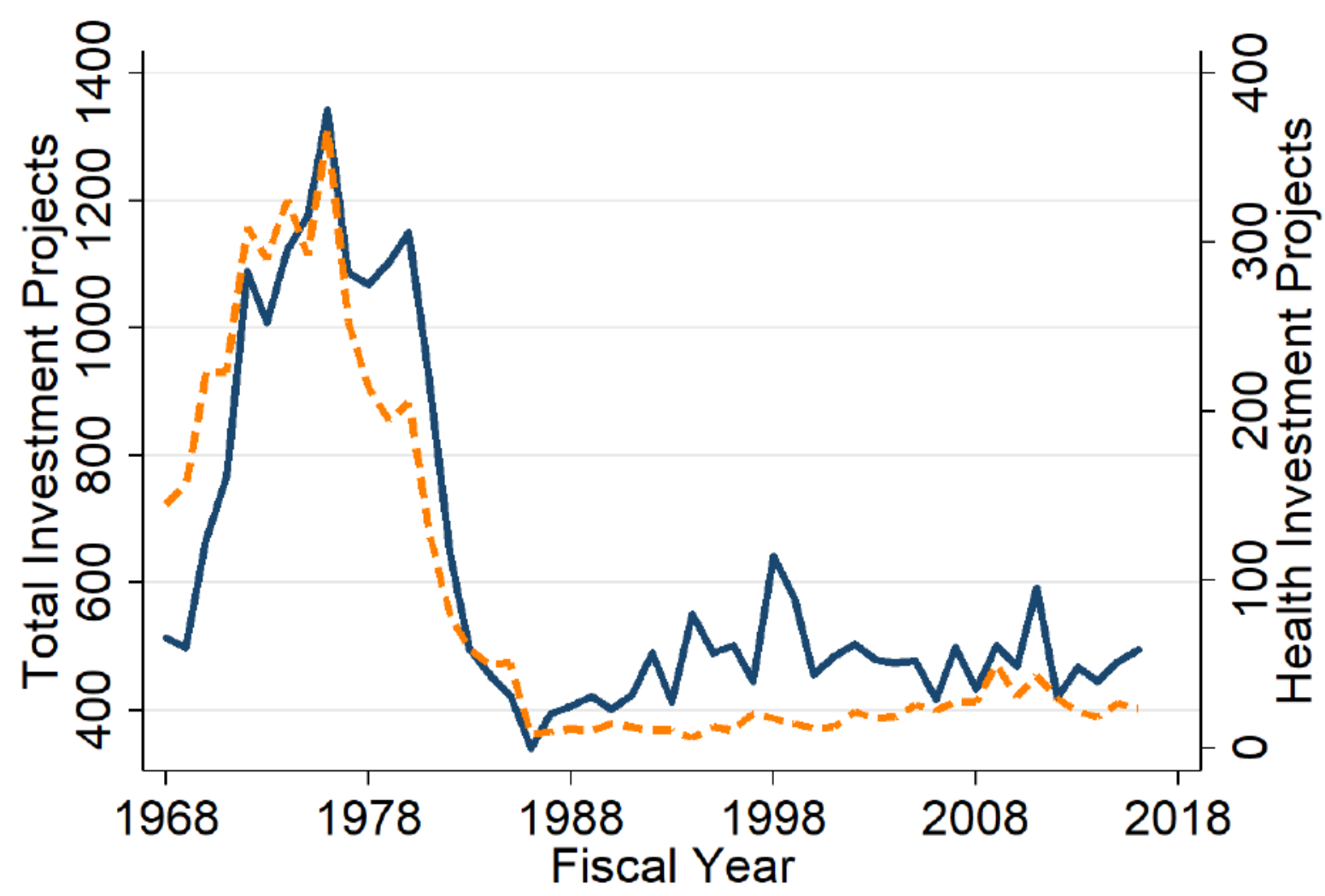

\section{ARC Total Projects $\quad=-=-=$ ARC Health Projects}

Note: Graph shows ARC investment projects from 1968-2016. The blue line shows the total count of ARC investment projects, while the orange dashed line shows the total count of projects that explicitly cite "health" in the project description. 
Figure 3.10: Disaggregating Total Accidents: Car Accidents and Overdoses

Panel A: Car Accident Mortality Rate

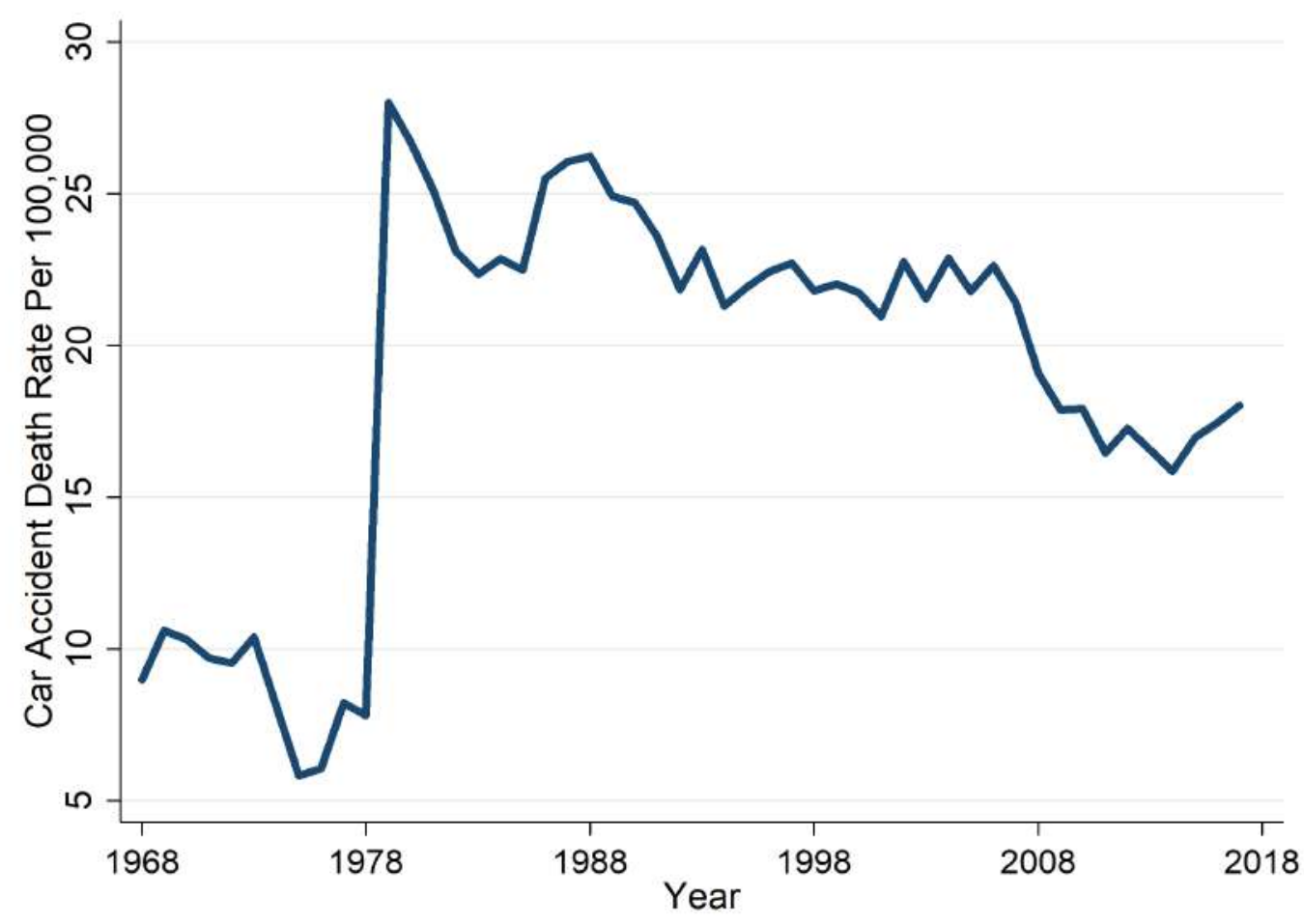

Panel B: Overdose Mortality Rate

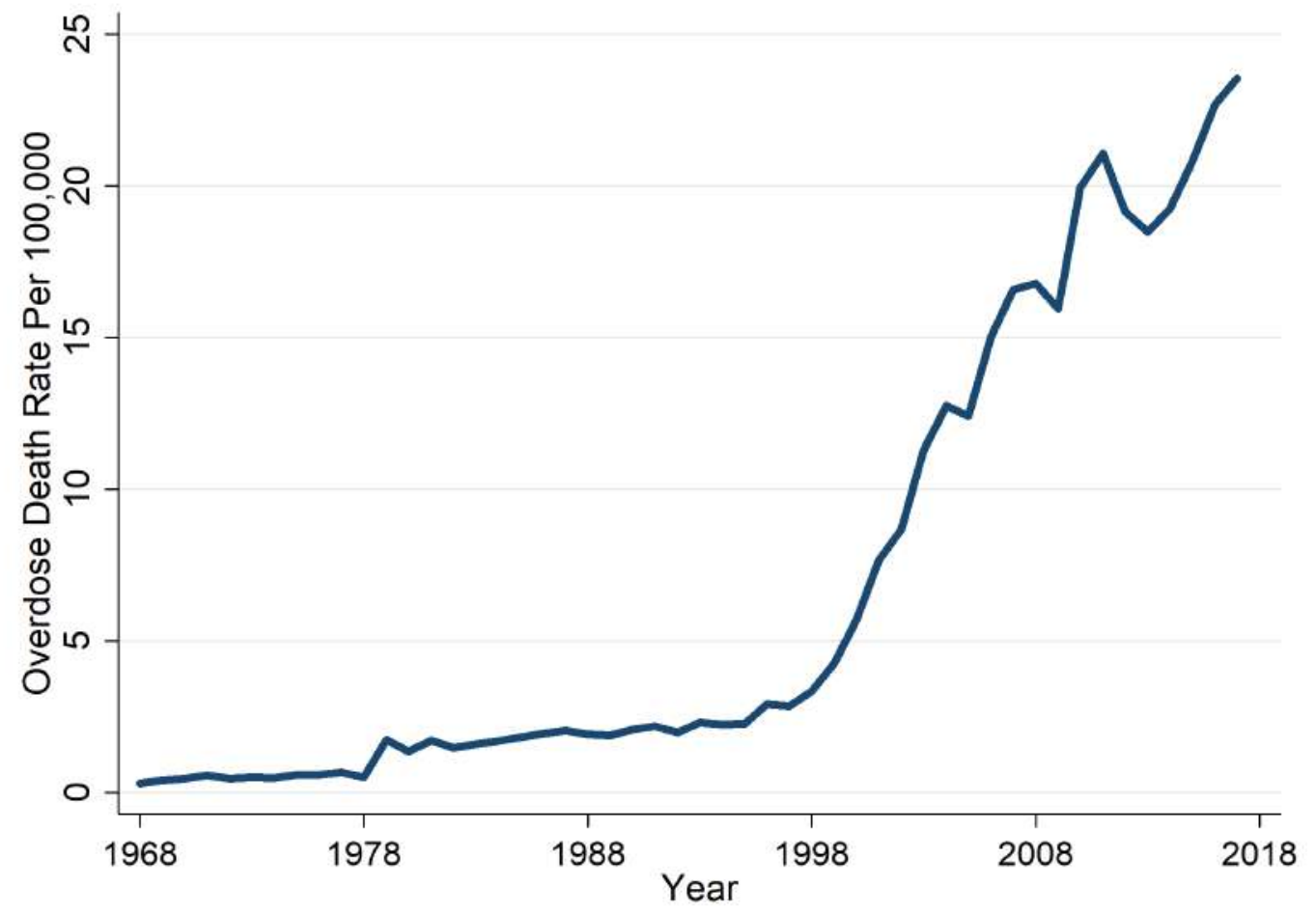

Note: Panel A displays the car accident mortality rate in Appalachia. Panel B displays the accidental overdose mortality rate in Appalachia. 
Figure 3.11: Proportion of Appalachian Counties with More Residents Dying Outside of the

\section{County}

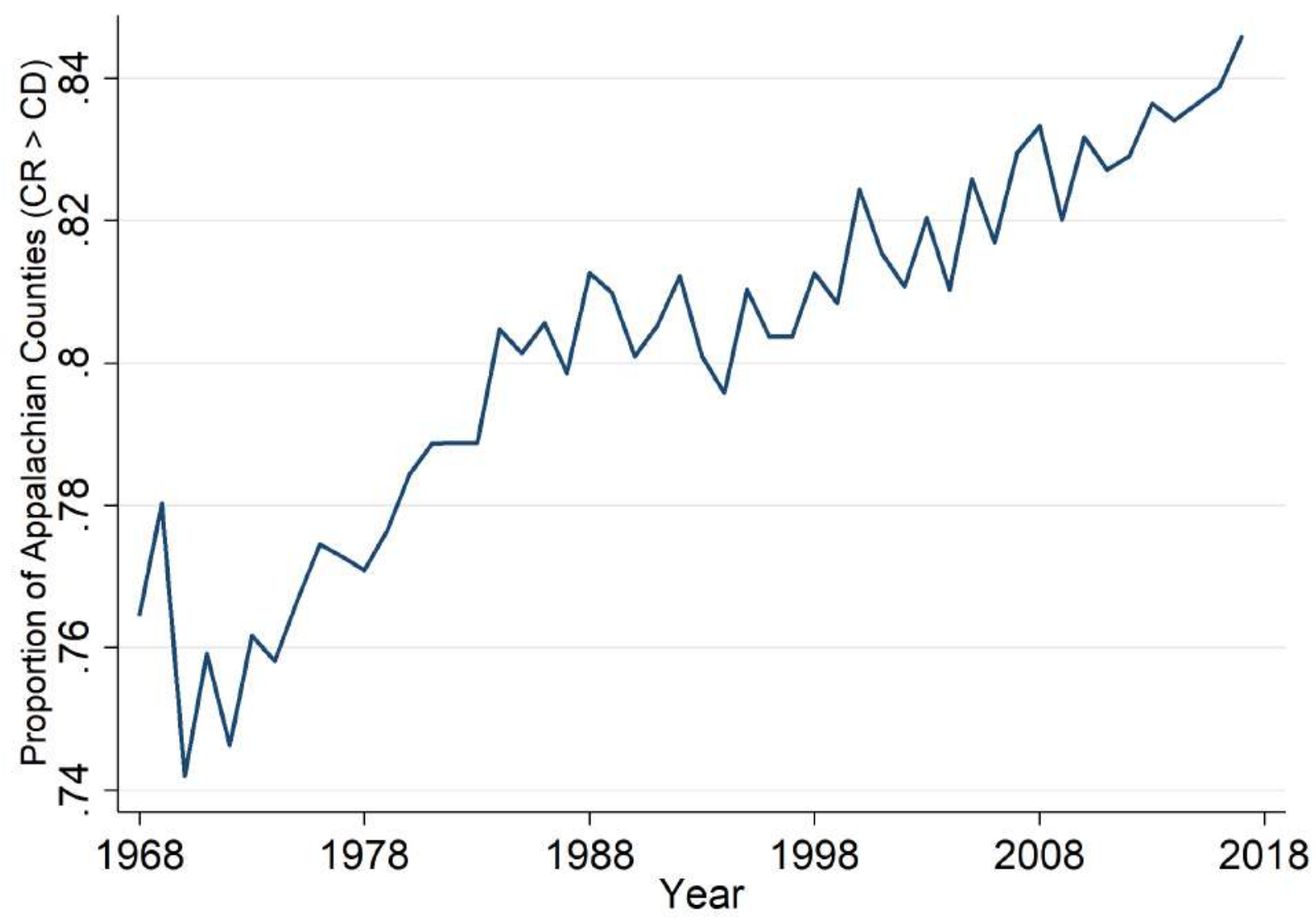

Note: Graph shows the proportion of Appalachian counties that have larger share of "county of residence" (CR) deaths compared to "county of death" (CD) deaths. In other words, this graph shows that more people in Appalachia over time died in a county that is not their county of residence, adding evidence of increased mobility in the region. 
Table 3.1: Summary Statistics by Decade

\begin{tabular}{|c|c|c|c|c|c|}
\hline & $\begin{array}{l}(1) \\
\text { Mean }\end{array}$ & $\begin{array}{l}\text { (2) } \\
\text { S.D. }\end{array}$ & $\begin{array}{l}(3) \\
\text { Min. }\end{array}$ & $\begin{array}{l}\text { (4) } \\
\text { Max. }\end{array}$ & $\begin{array}{c}(5) \\
\text { Count }\end{array}$ \\
\hline \multicolumn{6}{|l|}{ Panel A: 1968-1978 } \\
\hline Distance to ADHS & 47.4 & 38.00 & 0.29 & 191.91 & 3840 \\
\hline Distance to PARC Plan & 48.5 & 53.95 & 0.25 & 250.42 & 3840 \\
\hline Hospital Count & 1.2 & 2.48 & 0.00 & 39.00 & 3840 \\
\hline ARC Health Projects & 0.4 & 0.89 & 0.00 & 8.00 & 3758 \\
\hline 1960 Road Miles & 192631.3 & 118629.67 & 32593.95 & 761721.75 & 3840 \\
\hline \multicolumn{6}{|l|}{ Panel B: 1978-1988 } \\
\hline Distance to ADHS & 30.1 & 28.20 & 0.13 & 145.08 & 3916 \\
\hline Distance to PARC Plan & 48.4 & 53.59 & 0.25 & 250.42 & 3916 \\
\hline Hospital Count & 1.4 & 2.81 & 0.00 & 48.00 & 3916 \\
\hline ARC Health Projects & 0.2 & 0.53 & 0.00 & 8.00 & 3821 \\
\hline 1960 Road Miles & 191554.0 & 117816.16 & 32593.95 & 761721.75 & 3916 \\
\hline \multicolumn{6}{|l|}{ Panel C: 1988-1998 } \\
\hline Distance to ADHS & 28.1 & 25.86 & 0.13 & 145.08 & 3970 \\
\hline Distance to PARC Plan & 48.4 & 53.34 & 0.25 & 250.42 & 3970 \\
\hline Hospital Count & 1.6 & 2.89 & 0.00 & 43.00 & 3970 \\
\hline ARC Health Projects & 0.0 & 0.23 & 0.00 & 4.00 & 3870 \\
\hline 1960 Road Miles & 190806.3 & 117247.65 & 32593.95 & 761721.75 & 3970 \\
\hline \multicolumn{6}{|l|}{ Panel D: 1998-2008 } \\
\hline Distance to ADHS & 26.3 & 24.64 & 0.13 & 145.08 & 3970 \\
\hline Distance to PARC Plan & 48.4 & 53.34 & 0.25 & 250.42 & 3970 \\
\hline Hospital Count & 1.4 & 1.91 & 0.00 & 31.00 & 3964 \\
\hline ARC Health Projects & 0.2 & 0.49 & 0.00 & 3.00 & 3870 \\
\hline 1960 Road Miles & 190806.3 & 117247.65 & 32593.95 & 761721.75 & 3970 \\
\hline \multicolumn{6}{|l|}{ Panel E: 2008-2017 } \\
\hline Distance to ADHS & 24.4 & 21.89 & 0.06 & 145.08 & 3961 \\
\hline Distance to PARC Plan & 48.4 & 53.34 & 0.25 & 250.42 & 3970 \\
\hline Hospital Count & 1.3 & 2.09 & 0.00 & 46.00 & 3970 \\
\hline ARC Health Projects & 0.3 & 0.58 & 0.00 & 5.00 & 3870 \\
\hline 1960 Road Miles & 190806.3 & 117247.65 & 32593.95 & 761721.75 & 3970 \\
\hline
\end{tabular}

Note: Summary statistics for the county-year level, separated by decade, are shown above. Distance to ADHS is county centroid distance to nearest ADHS segment in miles. Distance to PARC plan is county centroid distance to nearest PARC planned segment. 1960 road miles is the total county road network in 1960 measured in miles. 
Table 3.2: 2SLS Estimates of Appalachian Development Highway System on Total Mortality Rate With Controls

\begin{tabular}{|c|c|c|c|c|}
\hline Panel A: 1968-1978 $\Delta$ in Total Mortality & $\begin{array}{c}(1) \\
\text { Mean } \Delta \text { Mortality }\end{array}$ & $\begin{array}{c}(2) \\
\text { Reduced Form }\end{array}$ & $\begin{array}{c}(3) \\
\text { 1st Stage }\end{array}$ & $\begin{array}{c}(4) \\
\text { 2nd Stage }\end{array}$ \\
\hline Distance to PARC 1964 Plan & & $\begin{array}{c}0.340 \\
(0.709)\end{array}$ & $\begin{array}{c}-0.207 * * * \\
(0.022)\end{array}$ & \\
\hline$\triangle \widehat{A D H S}$ & $\begin{array}{l}-161.263 \\
(954.674)\end{array}$ & & & $\begin{array}{l}-1.642 \\
(3.415)\end{array}$ \\
\hline $\begin{array}{l}\text { Counties } \\
\text { Kleibergen-Paap F }\end{array}$ & 396 & 396 & 396 & $\begin{array}{c}396 \\
91.28\end{array}$ \\
\hline \multicolumn{5}{|l|}{ Panel B: 1978-1988 $\Delta$ in Total Mortality } \\
\hline Distance to PARC 1964 Plan & & $\begin{array}{l}0.191 \\
(0.274)\end{array}$ & $\begin{array}{c}-0.102 * * * \\
(0.010)\end{array}$ & \\
\hline$\triangle \widehat{A D H S}$ & $\begin{array}{c}37.413 \\
(402.965)\end{array}$ & & & $\begin{array}{l}-1.865 \\
(2.677)\end{array}$ \\
\hline $\begin{array}{l}\text { Counties } \\
\text { Kleibergen-Paap F }\end{array}$ & 396 & 396 & 396 & $\begin{array}{c}396 \\
103.81\end{array}$ \\
\hline \multicolumn{5}{|l|}{ Panel C: 1988-1998 $\Delta$ in Total Mortality } \\
\hline Distance to PARC 1964 Plan & & $\begin{array}{l}-0.248^{*} \\
(0.143)\end{array}$ & $\begin{array}{c}-0.035^{* * *} \\
(0.009)\end{array}$ & \\
\hline$\triangle \widehat{A D H S}$ & $\begin{array}{c}49.578 \\
(158.240)\end{array}$ & & & $\begin{array}{c}7.705 \\
(4.354) \\
\end{array}$ \\
\hline $\begin{array}{l}\text { Counties } \\
\text { Kleibergen-Paap F }\end{array}$ & 406 & 406 & 406 & $\begin{array}{c}406 \\
14.76\end{array}$ \\
\hline \multicolumn{5}{|l|}{ Panel D: 1998-2008 $\Delta$ in Total Mortality } \\
\hline Distance to PARC 1964 Plan & & $\begin{array}{c}0.079 \\
(0.143)\end{array}$ & $\begin{array}{c}-0.041 * * * \\
(0.011)\end{array}$ & \\
\hline$\triangle \widehat{A D H S}$ & $\begin{array}{c}-12.176 \\
(234.105)\end{array}$ & & & $\begin{array}{l}-1.932 \\
(3.568)\end{array}$ \\
\hline $\begin{array}{l}\text { Counties } \\
\text { Kleibergen-Paap F }\end{array}$ & 427 & 427 & 427 & $\begin{array}{c}427 \\
13.67\end{array}$ \\
\hline \multicolumn{5}{|l|}{ Panel E: 2008-2017 $\Delta$ in Total Mortality } \\
\hline Distance to PARC 1964 Plan & & $\begin{array}{l}-0.304 * \\
(0.162)\end{array}$ & $\begin{array}{c}-0.003 * * * \\
(0.001)\end{array}$ & \\
\hline$\triangle \widehat{A D H} S$ & $\begin{array}{c}111.009 \\
(235.044)\end{array}$ & & & $\begin{array}{c}98.912 \\
(61.741)\end{array}$ \\
\hline $\begin{array}{l}\text { Counties } \\
\text { Kleibergen-Paap F }\end{array}$ & 427 & 427 & 427 & $\begin{array}{l}427 \\
8.13\end{array}$ \\
\hline
\end{tabular}

Notes: $* \mathrm{p}<0.1, * * \mathrm{p}<0.05, * * * \mathrm{p}<0.01$. Dependent variable is change in total mortality in Appalachia. Each panel, A-E, shows the results for a different time period. Column 1 shows the mean change in total mortality, with standard deviations in parentheses. Column 2 shows reduced form results (PARC distance on mortality), Column 3 shows first stage results (PARC distance on ADHS distance), and Column 4 shows second stage results (instrumented ADHS distance on mortality). Controls included in every panel are the count of hospital establishments in the last year of the decade, the total number of health-related ARC investment projects over the decade at the county level, and the length of existing road network in 1960 at the county level. County-clustered standard errors are used in every column and panel. 
Table 3.3: 2SLS Estimates of Appalachian Development Highway System on Heart Disease Mortality Rate With Controls

\begin{tabular}{|c|c|c|c|c|}
\hline Panel A: 1968-1978 $\Delta$ in Mortality & $\begin{array}{c}(1) \\
\text { Mean } \Delta \text { Mortality }\end{array}$ & $\begin{array}{c}(2) \\
\text { Reduced Form }\end{array}$ & $\begin{array}{c}\text { (3) } \\
\text { 1st Stage }\end{array}$ & $\begin{array}{c}(4) \\
\text { 2nd Stage }\end{array}$ \\
\hline Distance to PARC 1964 Plan & & $\begin{array}{l}-0.049 \\
(0.161)\end{array}$ & $\begin{array}{c}-0.207 * * * \\
(0.021)\end{array}$ & \\
\hline$\triangle \widehat{A D H S}$ & $\begin{array}{l}-45.110 \\
(208.795)\end{array}$ & & & $\begin{array}{c}0.234 \\
(0.775)\end{array}$ \\
\hline $\begin{array}{l}\text { Counties } \\
\text { Kleibergen-Paap F }\end{array}$ & 396 & 396 & 396 & $\begin{array}{c}396 \\
91.28\end{array}$ \\
\hline \multicolumn{5}{|l|}{ Panel B: 1978-1988 $\Delta$ in Mortality } \\
\hline Distance to PARC 1964 Plan & & $\begin{array}{c}0.304 * * \\
(0.128)\end{array}$ & $\begin{array}{c}-0.102 * * * \\
(0.010)\end{array}$ & \\
\hline$\triangle \widehat{A D H S}$ & $\begin{array}{c}-8.456 \\
(182.499)\end{array}$ & & & $\begin{array}{c}-2.974 * * \\
(1.309)\end{array}$ \\
\hline $\begin{array}{l}\text { Counties } \\
\text { Kleibergen-Paap F }\end{array}$ & 396 & 396 & 396 & $\begin{array}{c}396 \\
103.81\end{array}$ \\
\hline \multicolumn{5}{|l|}{ Panel C: 1988-1998 $\Delta$ in Mortality } \\
\hline Distance to PARC 1964 Plan & & $\begin{array}{c}0.004 \\
(0.066)\end{array}$ & $\begin{array}{c}-0.035^{* * *} \\
(0.009)\end{array}$ & \\
\hline$\triangle \widehat{A D H S}$ & $\begin{array}{l}-27.219 \\
(77.396)\end{array}$ & & & $\begin{array}{l}-0.119 \\
(1.886)\end{array}$ \\
\hline $\begin{array}{l}\text { Counties } \\
\text { Kleibergen-Paap F }\end{array}$ & 406 & 406 & 406 & $\begin{array}{c}406 \\
14.76\end{array}$ \\
\hline \multicolumn{5}{|l|}{ Panel D: 1998-2008 $\Delta$ in Mortality } \\
\hline Distance to PARC 1964 Plan & & $\begin{array}{c}0.168^{* * *} \\
(0.068)\end{array}$ & $\begin{array}{c}-0.040^{* * * *} \\
(0.011)\end{array}$ & \\
\hline$\triangle \widehat{A D H S}$ & $\begin{array}{l}-65.146 \\
(98.173)\end{array}$ & & & $\begin{array}{c}-4.132 * * \\
(1.978)\end{array}$ \\
\hline $\begin{array}{l}\text { Counties } \\
\text { Kleibergen-Paap F }\end{array}$ & 427 & 427 & 427 & $\begin{array}{c}427 \\
13.67\end{array}$ \\
\hline \multicolumn{5}{|l|}{ Panel E: 2008-2017 $\Delta$ in Mortality } \\
\hline Distance to PARC 1964 Plan & & $\begin{array}{l}-0.084 \\
(0.063)\end{array}$ & $\begin{array}{c}-0.003 * * * \\
(0.001)\end{array}$ & \\
\hline$\triangle \widehat{A D H S}$ & $\begin{array}{c}2.984 \\
(85.988)\end{array}$ & & & $\begin{array}{c}27.157 \\
(23.015)\end{array}$ \\
\hline $\begin{array}{l}\text { Counties } \\
\text { Kleibergen-Paap F }\end{array}$ & 427 & 427 & 427 & $\begin{array}{l}427 \\
8.13\end{array}$ \\
\hline
\end{tabular}

Notes: $* \mathrm{p}<0.1, * * \mathrm{p}<0.05, * * * \mathrm{p}<0.01$. Dependent variable is change in heart disease mortality in Appalachia. Each panel, A-E, shows the results for a different time period. Column 1 shows the mean change in heart disease mortality, with standard deviations in parentheses. Column 2 shows reduced form results (PARC distance on mortality), Column 3 shows first stage results (PARC distance on ADHS distance), and Column 4 shows second stage results (instrumented ADHS distance on mortality). Controls included in every panel are the count of hospital establishments in the last year of the decade, the total number of health-related ARC investment projects over the decade at the county level, and the length of existing road network in 1960 at the county level. County-clustered standard errors are used in every column and panel. 
Table 3.4: 2SLS Estimates of Appalachian Development Highway System on Hypertension Mortality Rate With Controls

\begin{tabular}{|c|c|c|c|c|}
\hline Panel A: 1968-1978 $\Delta$ in Mortality & $\begin{array}{c}(1) \\
\text { Mean } \Delta \text { Mortality }\end{array}$ & $\begin{array}{c}(2) \\
\text { Reduced Form }\end{array}$ & $\begin{array}{c}\text { (3) } \\
\text { 1st Stage }\end{array}$ & $\begin{array}{c}(4) \\
\text { 2nd Stage }\end{array}$ \\
\hline Distance to PARC 1964 Plan & & $\begin{array}{l}-0.007 \\
(0.011)\end{array}$ & $\begin{array}{c}-0.207 * * * \\
(0.022)\end{array}$ & \\
\hline$\triangle \widehat{A D H S}$ & $\begin{array}{c}-3.433 \\
(14.555)\end{array}$ & & & $\begin{array}{c}0.033 \\
(0.054)\end{array}$ \\
\hline $\begin{array}{l}\text { Counties } \\
\text { Kleibergen-Paap F }\end{array}$ & 396 & 396 & 396 & $\begin{array}{c}396 \\
91.28\end{array}$ \\
\hline \multicolumn{5}{|l|}{ Panel B: 1978-1988 $\Delta$ in Mortality } \\
\hline Distance to PARC 1964 Plan & & $\begin{array}{l}-0.001 \\
(0.004)\end{array}$ & $\begin{array}{c}-0.102 * * * \\
(0.010)\end{array}$ & \\
\hline$\triangle \widehat{A D H S}$ & $\begin{array}{c}0.923 \\
(5.223)\end{array}$ & & & $\begin{array}{c}0.008 \\
(0.039)\end{array}$ \\
\hline $\begin{array}{l}\text { Counties } \\
\text { Kleibergen-Paap F }\end{array}$ & 396 & 396 & 396 & $\begin{array}{c}396 \\
103.81\end{array}$ \\
\hline \multicolumn{5}{|l|}{ Panel C: 1988-1998 $\Delta$ in Mortality } \\
\hline Distance to PARC 1964 Plan & & $\begin{array}{c}0.017 * * \\
(0.007)\end{array}$ & $\begin{array}{c}-0.035^{* * *} \\
(0.009)\end{array}$ & \\
\hline$\triangle \widehat{A D H S}$ & $\begin{array}{c}1.694 \\
(5.893)\end{array}$ & & & $\begin{array}{c}-0.474 * * \\
(0.216)\end{array}$ \\
\hline $\begin{array}{l}\text { Counties } \\
\text { Kleibergen-Paap F }\end{array}$ & 406 & 406 & 406 & $\begin{array}{c}406 \\
14.76\end{array}$ \\
\hline \multicolumn{5}{|l|}{ Panel D: 1998-2008 $\Delta$ in Mortality } \\
\hline Distance to PARC 1964 Plan & & $\begin{array}{c}0.000 \\
(0.014)\end{array}$ & $\begin{array}{c}-0.041 * * * \\
(0.010)\end{array}$ & \\
\hline$\triangle \widehat{A D H S}$ & $\begin{array}{l}3.508 \\
(9.686)\end{array}$ & & & $\begin{array}{l}-0.002 \\
(0.357)\end{array}$ \\
\hline $\begin{array}{l}\text { Counties } \\
\text { Kleibergen-Paap F }\end{array}$ & 427 & 427 & 427 & $\begin{array}{c}427 \\
13.67\end{array}$ \\
\hline \multicolumn{5}{|l|}{ Panel E: 2008-2017 $\Delta$ in Mortality } \\
\hline Distance to PARC 1964 Plan & & $\begin{array}{l}-0.016 \\
(0.014)\end{array}$ & $\begin{array}{c}-0.003 * * * \\
(0.001)\end{array}$ & \\
\hline$\triangle \widehat{A D H S}$ & $\begin{array}{c}2.723 \\
(11.977)\end{array}$ & & & $\begin{array}{l}5.280 \\
(4.890)\end{array}$ \\
\hline $\begin{array}{l}\text { Counties } \\
\text { Kleibergen-Paap F }\end{array}$ & 427 & 427 & 427 & $\begin{array}{l}427 \\
8.13\end{array}$ \\
\hline
\end{tabular}

Notes: $* \mathrm{p}<0.1, * * \mathrm{p}<0.05, * * * \mathrm{p}<0.01$. Dependent variable is change in hypertension mortality in Appalachia. Each panel, A-E, shows the results for a different time period. Column 1 shows the mean change in hypertension mortality, with standard deviations in parentheses. Column 2 shows reduced form results (PARC distance on mortality), Column 3 shows first stage results (PARC distance on ADHS distance), and Column 4 shows second stage results (instrumented ADHS distance on mortality). Controls included in every panel are the count of hospital establishments in the last year of the decade, the total number of health-related ARC investment projects over the decade at the county level, and the length of existing road network in 1960 at the county level. County-clustered standard errors are used in every column and panel. 
Table 3.5: 2SLS Estimates of Appalachian Development Highway System on Accident Mortality Rate With Controls

\begin{tabular}{|c|c|c|c|c|}
\hline Panel A: 1968-1978 $\Delta$ in Mortality & Mean $\Delta$ Mortality & $\begin{array}{c}(2) \\
\text { Reduced Form }\end{array}$ & $\begin{array}{c}\text { (3) } \\
\text { 1st Stage }\end{array}$ & $\begin{array}{c}(4) \\
\text { 2nd Stage }\end{array}$ \\
\hline Distance to PARC 1964 Plan & & $\begin{array}{l}-0.003 \\
(0.037)\end{array}$ & $\begin{array}{c}-0.207 * * * \\
(0.022)\end{array}$ & \\
\hline$\triangle \widehat{A D H S}$ & $\begin{array}{l}-13.667 \\
(47.674)\end{array}$ & & & $\begin{array}{c}0.016 \\
(0.179)\end{array}$ \\
\hline $\begin{array}{l}\text { Counties } \\
\text { Kleibergen-Paap F }\end{array}$ & 396 & 396 & 396 & $\begin{array}{c}396 \\
91.28\end{array}$ \\
\hline \multicolumn{5}{|l|}{ Panel B: 1978-1988 $\Delta$ in Mortality } \\
\hline Distance to PARC 1964 Plan & & $\begin{array}{c}0.070 \\
(0.051)\end{array}$ & $\begin{array}{c}-0.102 * * * \\
(0.010)\end{array}$ & \\
\hline$\triangle \widehat{A D H S}$ & $\begin{array}{c}-9.333 \\
(62.190)\end{array}$ & & & $\begin{array}{l}-0.686 \\
(0.496)\end{array}$ \\
\hline $\begin{array}{l}\text { Counties } \\
\text { Kleibergen-Paap F }\end{array}$ & 396 & 396 & 396 & $\begin{array}{c}396 \\
103.81\end{array}$ \\
\hline \multicolumn{5}{|l|}{ Panel C: 1988-1998 $\Delta$ in Mortality } \\
\hline Distance to PARC 1964 Plan & & $\begin{array}{l}-0.027 \\
(0.030)\end{array}$ & $\begin{array}{c}-0.035^{* * *} \\
(0.009)\end{array}$ & \\
\hline$\triangle \widehat{A D H S}$ & $\begin{array}{c}-3.898 \\
(23.430)\end{array}$ & & & $\begin{array}{c}0.769 \\
(0.836)\end{array}$ \\
\hline $\begin{array}{l}\text { Counties } \\
\text { Kleibergen-Paap F }\end{array}$ & 406 & 406 & 406 & $\begin{array}{c}406 \\
14.76\end{array}$ \\
\hline \multicolumn{5}{|l|}{ Panel D: 1998-2008 $\Delta$ in Mortality } \\
\hline Distance to PARC 1964 Plan & & $\begin{array}{c}-0.068 * * * \\
(0.020)\end{array}$ & $\begin{array}{c}-0.041 * * * \\
(0.011)\end{array}$ & \\
\hline$\triangle \widehat{A D H S}$ & $\begin{array}{c}7.073 \\
(29.025)\end{array}$ & & & $\begin{array}{l}1.666^{* *} \\
(0.709)\end{array}$ \\
\hline $\begin{array}{l}\text { Counties } \\
\text { Kleibergen-Paap F }\end{array}$ & 427 & 427 & 427 & $\begin{array}{c}427 \\
13.67\end{array}$ \\
\hline \multicolumn{5}{|l|}{ Panel E: 2008-2017 $\Delta$ in Mortality } \\
\hline Distance to PARC 1964 Plan & & $\begin{array}{c}-0.093 * * * \\
(0.023)\end{array}$ & $\begin{array}{c}-0.003 * * * \\
(0.001)\end{array}$ & \\
\hline$\triangle \widehat{A D H S}$ & $\begin{array}{c}15.812 \\
(32.603)\end{array}$ & & & $\begin{array}{l}30.343 * * \\
(12.347)\end{array}$ \\
\hline $\begin{array}{l}\text { Counties } \\
\text { Kleibergen-Paap F } \\
\text { Two-Step AR-CIs }\end{array}$ & 427 & 427 & 427 & $\begin{array}{c}427 \\
8.13 \\
{[14.454,95.118]}\end{array}$ \\
\hline
\end{tabular}

Notes: $* \mathrm{p}<0.1, * * \mathrm{p}<0.05, * * * \mathrm{p}<0.01$. Dependent variable is change in accident mortality in Appalachia. Each panel, A-E, shows the results for a different time period. Column 1 shows the mean change in accident mortality, with standard deviations in parentheses. Column 2 shows reduced form results (PARC distance on mortality), Column 3 shows first stage results (PARC distance on ADHS distance), and Column 4 shows second stage results (instrumented ADHS distance on mortality). Controls included in every panel are the count of hospital establishments in the last year of the decade, the total number of health-related ARC investment projects over the decade at the county level, and the length of existing road network in 1960 at the county level. County-clustered stangard errors are used in every column and panel. Panel E includes two-step Anderson-Rubin confidence interval. 
Table 3.6: 2SLS Estimates of Appalachian Development Highway System on Car Accident Mortality Rate With Controls

\begin{tabular}{|c|c|c|c|c|}
\hline Panel A: 1968-1978 $\Delta$ in Mortality & $\begin{array}{c}(1) \\
\text { Mean } \Delta \text { Mortality }\end{array}$ & $\begin{array}{c}(2) \\
\text { Reduced Form }\end{array}$ & $\begin{array}{c}\text { (3) } \\
\text { 1st Stage }\end{array}$ & $\begin{array}{c}(4) \\
\text { 2nd Stage }\end{array}$ \\
\hline Distance to PARC 1964 Plan & & $\begin{array}{c}0.005 \\
(0.012)\end{array}$ & $\begin{array}{c}-0.207 * * * \\
(0.022)\end{array}$ & \\
\hline$\triangle \widehat{A D H S}$ & $\begin{array}{c}-0.974 \\
(12.675)\end{array}$ & & & $\begin{array}{l}-0.028 \\
(0.061)\end{array}$ \\
\hline $\begin{array}{l}\text { Counties } \\
\text { Kleibergen-Paap F }\end{array}$ & 396 & 396 & 396 & $\begin{array}{c}396 \\
91.28\end{array}$ \\
\hline \multicolumn{5}{|l|}{ Panel B: 1978-1988 $\Delta$ in Mortality } \\
\hline Distance to PARC 1964 Plan & & $\begin{array}{c}0.026 \\
(0.020)\end{array}$ & $\begin{array}{c}-0.102 * * * \\
(0.010)\end{array}$ & \\
\hline$\triangle \widehat{A D H S}$ & $\begin{array}{c}18.177 \\
(19.350)\end{array}$ & & & $\begin{array}{l}-0.253 \\
(0.186)\end{array}$ \\
\hline $\begin{array}{l}\text { Counties } \\
\text { Kleibergen-Paap F }\end{array}$ & 396 & 396 & 396 & $\begin{array}{c}396 \\
103.81\end{array}$ \\
\hline \multicolumn{5}{|l|}{ Panel C: 1988-1998 $\Delta$ in Mortality } \\
\hline Distance to PARC 1964 Plan & & $\begin{array}{l}-0.003 \\
(0.019)\end{array}$ & $\begin{array}{c}-0.035^{* * *} \\
(0.009)\end{array}$ & \\
\hline$\triangle \widehat{A D H S}$ & $\begin{array}{c}-4.623 \\
(16.572)\end{array}$ & & & $\begin{array}{c}0.071 \\
(0.534)\end{array}$ \\
\hline $\begin{array}{l}\text { Counties } \\
\text { Kleibergen-Paap F }\end{array}$ & 406 & 406 & 406 & $\begin{array}{c}406 \\
14.76\end{array}$ \\
\hline \multicolumn{5}{|l|}{ Panel D: 1998-2008 $\Delta$ in Mortality } \\
\hline Distance to PARC 1964 Plan & & $\begin{array}{l}-0.001 \\
(0.014)\end{array}$ & $\begin{array}{c}-0.041 * * * \\
(0.011)\end{array}$ & \\
\hline$\triangle \widehat{A D H S}$ & $\begin{array}{c}-2.773 \\
(15.439)\end{array}$ & & & $\begin{array}{c}0.023 \\
(0.347)\end{array}$ \\
\hline $\begin{array}{l}\text { Counties } \\
\text { Kleibergen-Paap F }\end{array}$ & 427 & 427 & 427 & $\begin{array}{c}427 \\
13.67\end{array}$ \\
\hline \multicolumn{5}{|l|}{ Panel E: 2008-2017 $\Delta$ in Mortality } \\
\hline Distance to PARC 1964 Plan & & $\begin{array}{l}0.026^{*} \\
(0.014)\end{array}$ & $\begin{array}{c}-0.003 * * * \\
(0.001)\end{array}$ & \\
\hline$\triangle \widehat{A D H S}$ & $\begin{array}{c}-1.035 \\
(15.703)\end{array}$ & & & $\begin{array}{l}-8.295 \\
(5.417)\end{array}$ \\
\hline $\begin{array}{l}\text { Counties } \\
\text { Kleibergen-Paap F }\end{array}$ & 427 & 427 & 427 & $\begin{array}{l}427 \\
8.13\end{array}$ \\
\hline
\end{tabular}

Notes: $* \mathrm{p}<0.1, * * \mathrm{p}<0.05, * * * \mathrm{p}<0.01$. Dependent variable is change in car accident mortality in Appalachia. Each panel, A-E, shows the results for a different time period. Column 1 shows the mean change in car accident mortality, with standard deviations in parentheses. Column 2 shows reduced form results (PARC distance on mortality), Column 3 shows first stage results (PARC distance on ADHS distance), and Column 4 shows second stage results (instrumented ADHS distance on mortality). Controls included in every panel are the count of hospital establishments in the last year of the decade, the total number of health-related ARC investment projects over the decade at the county level, and the length of existing road network in 1960 at the county level. County-clustered standard errors are used in every column and panel. 
Table 3.7: 2SLS Estimates of Appalachian Development Highway System on Accidental Overdose Mortality Rate With Controls

\begin{tabular}{|c|c|c|c|c|}
\hline Panel A: 1968-1978 $\Delta$ in Mortality & $\begin{array}{c}(1) \\
\text { Mean } \Delta \text { Mortality }\end{array}$ & $\begin{array}{c}(2) \\
\text { Reduced Form }\end{array}$ & $\begin{array}{c}(3) \\
\text { 1st Stage }\end{array}$ & $\begin{array}{c}(4) \\
\text { 2nd Stage }\end{array}$ \\
\hline Distance to PARC 1964 Plan & & $\begin{array}{c}0.001 \\
(0.002)\end{array}$ & $\begin{array}{c}-0.207 * * * \\
(0.022)\end{array}$ & \\
\hline$\triangle \widehat{A D H S}$ & $\begin{array}{c}0.206 \\
(1.879)\end{array}$ & & & $\begin{array}{l}-0.003 \\
(0.010)\end{array}$ \\
\hline $\begin{array}{l}\text { Counties } \\
\text { Kleibergen-Paap F }\end{array}$ & 396 & 396 & 396 & $\begin{array}{c}396 \\
91.28\end{array}$ \\
\hline \multicolumn{5}{|l|}{ Panel B: 1978-1988 $\Delta$ in Mortality } \\
\hline Distance to PARC 1964 Plan & & $\begin{array}{l}-0.002 \\
(0.004)\end{array}$ & $\begin{array}{c}-0.102 * * * \\
(0.010)\end{array}$ & \\
\hline$\triangle \widehat{A D H S}$ & $\begin{array}{c}1.434 \\
(2.994)\end{array}$ & & & $\begin{array}{c}0.026 \\
(0.035)\end{array}$ \\
\hline $\begin{array}{l}\text { Counties } \\
\text { Kleibergen-Paap F }\end{array}$ & 396 & 396 & 396 & $\begin{array}{c}396 \\
103.81\end{array}$ \\
\hline \multicolumn{5}{|l|}{ Panel C: 1988-1998 $\Delta$ in Mortality } \\
\hline Distance to PARC 1964 Plan & & $\begin{array}{c}-0.010 * * * \\
(0.004)\end{array}$ & $\begin{array}{c}-0.035^{* * *} \\
(0.009)\end{array}$ & \\
\hline$\triangle \widehat{A D H S}$ & $\begin{array}{l}1.346 \\
(4.523)\end{array}$ & & & $\begin{array}{c}0.292 * * \\
(0.125)\end{array}$ \\
\hline $\begin{array}{l}\text { Counties } \\
\text { Kleibergen-Paap F }\end{array}$ & 406 & 406 & 406 & $\begin{array}{c}406 \\
14.76\end{array}$ \\
\hline \multicolumn{5}{|l|}{ Panel D: 1998-2008 $\Delta$ in Mortality } \\
\hline Distance to PARC 1964 Plan & & $\begin{array}{c}-0.037 * * * \\
(0.010)\end{array}$ & $\begin{array}{c}-0.041 * * * \\
(0.011)\end{array}$ & \\
\hline$\triangle \widehat{A D H S}$ & $\begin{array}{c}13.461 \\
(15.332)\end{array}$ & & & $\begin{array}{c}0.920^{* *} \\
(0.362)\end{array}$ \\
\hline $\begin{array}{l}\text { Counties } \\
\text { Kleibergen-Paap F }\end{array}$ & 427 & 427 & 427 & $\begin{array}{c}427 \\
13.67\end{array}$ \\
\hline \multicolumn{5}{|l|}{ Panel E: 2008-2017 $\Delta$ in Mortality } \\
\hline Distance to PARC 1964 Plan & & $\begin{array}{c}-0.048 * * * \\
(0.011)\end{array}$ & $\begin{array}{c}-0.003 * * * \\
(0.001)\end{array}$ & \\
\hline$\triangle \widehat{A D H S}$ & $\begin{array}{c}6.724 \\
(19.479)\end{array}$ & & & $\begin{array}{c}15.622 * * \\
(6.356)\end{array}$ \\
\hline $\begin{array}{l}\text { Counties } \\
\text { Kleibergen-Paap F } \\
\text { Two-Step AR-CIs }\end{array}$ & 427 & 427 & 427 & $\begin{array}{c}427 \\
8.13 \\
{[7.442,50.228]}\end{array}$ \\
\hline
\end{tabular}

Notes: $* \mathrm{p}<0.1, * * \mathrm{p}<0.05, * * * \mathrm{p}<0.01$. Dependent variable is change in accidental overdose mortality in Appalachia. Each panel, A-E, shows the results for a different time period. Column 1 shows the mean change in overdose mortality, with standard deviations in parentheses. Column 2 shows reduced form results (PARC distance on mortality), Column 3 shows first stage results (PARC distance on ADHS distance), and Column 4 shows second stage results (instrumented ADHS distance on mortality). Controls included in every panel are the count of hospital establishments in the last year of the decade, the total number of health-related ARC investment projects over the decade at the county level, and the length of existing road network in 1960 at the county leyel County-clustered standard errors are used in every column and panel. Panel E includes two-step Anderson-Rubin confidence interval. 


\section{References}

Agénor, P.-R. (2009). Infrastructure investment and maintenance expenditure: Optimal allocation rules in a growing economy. Journal of Public Economic Theory, 11(2), 233-250.

Agrawal, A., Galasso, A., \& Oettl, A. (2017). Roads and innovation. The Review of Economics and Statistics, 99(3), 417-434.

Agrawal, D. R. (2015). The tax gradient: Spatial aspects of fiscal competition. American Economic Journal: Economic Policy, 7(2), 1-29.

Akbar, P. A., Couture, V., Duranton, G., Ghani, E., \& Storeygard, A. (2018). Mobility and congestion in urban India. The World Bank.

Albouy, D., \& Lue, B. (2015). Driving to opportunity: Local rents, wages, commuting, and sub-metropolitan quality of life. Journal of Urban Economics, 89, 74-92.

Allison, P. D., \& Waterman, R. P. (2002). Fixed-effects negative binomial regression models. Sociological Methodology, 32(1), 247-265.

Anderson, M. L. (2014). Subways, strikes, and slowdowns: The impacts of public transit on traffic congestion. American Economic Review, 104(9).

Andrews, I., Stock, J. H., \& Sun, L. (2019). Weak instruments in instrumental variables regression: Theory and practice. Annual Review of Economics, 11, 727-753.

Asher, S., \& Novosad, P. (2017). Politics and local economic growth: Evidence from India. American Economic Journal: Applied Economics, 9(1), 229-73.

Asher, S., \& Novosad, P. (2020). Rural roads and local economic development. American Economic Review, 110(3), 797-823. 
Bailey, M. J., \& Goodman-Bacon, A. (2015). The war on poverty's experiment in public medicine: Community health centers and the mortality of older Americans. American Economic Review, 105(3), 1067-1104.

Barrios, J. M., Hochberg, Y. V., \& Yi, H. (2019). The cost of convenience: Ridehailing and traffic fatalities. Available at SSRN 3361227.

Bartik, T. J. (2020). Using place-based jobs policies to help distressed communities. Journal of Economic Perspectives, 34(3), 99-127.

Bauernschuster, S., Hener, T., \& Rainer, H. (2017). When labor disputes bring cities to a standstill: The impact of public transit strikes on traffic, accidents, air pollution, and health. American Economic Journal: Economic Policy, 9(1), 1-37.

Baum-Snow, N. (2007). Did highways cause suburbanization? The Quarterly Journal of Economics, 122(2), 775-805.

Baum-Snow, N., Brandt, L., Henderson, J. V., Turner, M. A., \& Zhang, Q. (2017). Roads, railroads, and decentralization of Chinese cities. The Review of Economics and Statistics, 99(3), 435448.

Bell, C., \& van Dillen, S. (2018). On the way to good health? Rural roads and morbidity in Upland Orissa. Journal of Transport \& Health, 10, 369 - 380.

Bento, A. M., Hughes, J. E., \& Kaffine, D. (2013). Carpooling and driver responses to fuel price changes: Evidence from traffic flows in Los Angeles. Journal of Urban Economics, 77, $41-56$.

Berdejó, C., \& Yuchtman, N. (2013). Crime, punishment, and politics: An analysis of political cycles in criminal sentencing. Review of Economics and Statistics, 95(3), 741-756.

Black, D. A., \& Sanders, S. G. (2004). Labor market performance, poverty, and income inequality (Tech. Rep.). Appalachian Regional Commission.

Black, D. A., \& Sanders, S. G. (2007). Standards of living in Appalachia: 1960-2000 (Tech. Rep.). Population Reference Bureau.

Blimpo, M. P., Harding, R., \& Wantchekon, L. (2013). Public investment in rural infrastructure: 
Some political economy considerations. Journal of African Economies, 22(suppl 2), ii57ii83.

Bracco, E., Lockwood, B., Porcelli, F., \& Redoano, M. (2015). Intergovernmental grants as signals and the alignment effect: Theory and evidence. Journal of Public Economics, 123, 78-91.

Bradshaw, M. (1992). The Appalachian Regional Commission: Twenty-five years of government policy. University Press of Kentucky.

Branas, C. C., MacKenzie, E. J., Williams, J. C., Schwab, C. W., Teter, H. M., Flanigan, M. C., ... ReVelle, C. S. (2005). Access to trauma centers in the United States. JAMA, 293(21), 2626-2633.

Brollo, F., \& Nannicini, T. (2012). Tying your enemy's hands in close races: The politics of federal transfers in Brazil. The American Political Science Review, 106(4), 742-761.

Brooks, W., \& Donovan, K. (2020). Eliminating uncertainty in market access: The impact of new bridges in rural Nicaragua. Econometrica, 88(5), 1965-1997.

Brueckner, J. K., \& Selod, H. (2006). The political economy of urban transport-system choice. Journal of Public Economics, 90(6-7), 983-1005.

Burningham, S., \& Stankevich, N. (2005). Why road maintenance is important and how to get it done (Tech. Rep.). World Bank, Washington, DC.

Burris, M., Alemazkoor, N., Benz, R., \& Wood, N. (2014). The impacts of HOT lanes on carpools. Research in Transportation Economics, 44, 43-51.

California Department of Transportation. (2018). High occupancy vehicle lanes. Retrieved 2018-11-15, from http://www.dot.ca.gov/hq/tsip/gis/datalibrary/ Metadata/HOV.html

Cameron, A. C., \& Miller, D. L. (2015). A practitioner's guide to cluster-robust inference. Journal of Human Resources, 50(2), 317-372.

Cameron, A. C., \& Trivedi, P. K. (2005). Microeconometrics: Methods and Applications. Cambridge University Press.

Cantoni, E. (2020). A precinct too far: Turnout and voting costs. American Economic Journal: 
Applied Economics, 12(1), 61-85.

Chandra, A., \& Thompson, E. (2000). Does public infrastructure affect economic activity? Evidence from the rural interstate highway system. Regional Science and Urban Economics, $30,457-490$.

Chang, J. W. A. S., M., \& Bilotto, C. (2008). A compendium of existing of HOV lane facilities in the United States. Final report to the US DOT FHWA.

Chetty, R., Stepner, M., Abraham, S., Lin, S., Scuderi, B., Turner, N., ... Cutler, D. (2016). The association between income and life expectancy in the United States, 2001-2014. JAMA, 315(16), 1750-1766.

Colmer, J. (2020). What is the meaning of (statistical) life? Benefit-cost analysis in the time of COVID-19. Oxford Review of Economic Policy, 36(Supplement 1 ), S56 - S63.

Comptroller General of the United States. (1976). PSAD-76-155 The Appalachian Development Highway System in West Virginia: Too Little Funding Too Late? (Tech. Rep.). Comptroller General of the United States: Washington, D.C.

Cunningham, S., \& Shah, M. (2018). Decriminalizing indoor prostitution: Implications for sexual violence and public health. The Review of Economic Studies, 85(3), 1683-1715.

Currie, J., \& Schwandt, H. (2016). Mortality inequality: The good news from a county-level approach. Journal of Economic Perspectives, 30(2), 29-52.

Currie, J., \& Walker, R. (2011). Traffic congestion and infant health: Evidence from E-ZPass. American Economic Journal: Applied Economics, 3(1), 65-90.

Cutler, D., Deaton, A., \& Lleras-Muney, A. (2006). The determinants of mortality. Journal of Economic Perspectives, 20(3), 97-120.

Dahlgren, J. (1998). High occupancy vehicle lanes: Not always more effective than general purpose lanes. Transportation Research, Part A: Policy and Practice, 32(2), 99-114.

Deryugina, T., Heutel, G., Miller, N. H., Molitor, D., \& Reif, J. (2016). The mortality and medical costs of air pollution: Evidence from changes in wind direction (Tech. Rep.). National Bureau of Economic Research. 
Deryugina, T., \& Molitor, D. (2020). Does when you die depend on where you live? Evidence from Hurricane Katrina. American Economic Review, 110(11), 3602-33.

Detter, D., \& Fölster, S. (2017). The public wealth of cities: How to unlock hidden assets to boost growth and prosperity. Brookings Institution Press.

Doyle, J. J. (2011). Returns to local-area health care spending: Evidence from health shocks to patients far from home. American Economic Journal: Applied Economics, 3(3), 221-43.

Duranton, G., Henderson, V., \& Strange, W. (2015). Handbook of regional and urban economics. Elsevier.

Duranton, G., Morrow, P. M., \& Turner, M. A. (2014). Roads and trade: Evidence from the US. The Review of Economic Studies, 81(2), 681-724.

Duranton, G., \& Turner, M. (2011). The fundamental law of road congestion: Evidence from US cities. American Economic Review, 101(6), 2616-2652.

Duranton, G., \& Turner, M. A. (2012). Urban growth and transportation. The Review of Economic Studies, 79(4), 1407-1440.

Economic Development Research Group. (2017). Economic analysis of completing the Appalachian Development Highway System (Tech. Rep.). Appalachian Regional Commission.

Eliasson, J. (2009). A cost-benefit analysis of the Stockholm congestion charging system. Transportation Research Part A: Policy and Practice, 43(4), 468-480.

Finkelstein, A., Gentzkow, M., \& Williams, H. L. (2019). Place-based drivers of mortality: Evidence from migration (Working Paper No. 25975). National Bureau of Economic Research.

Fisher, R. A. (1935). The design of experiments. Oliver \& Boyd.

Garcia-López, M.-À., Holl, A., \& Viladecans-Marsal, E. (2015). Suburbanization and highways in Spain when the Romans and the Bourbons still shape its cities. Journal of Urban Economics, $85,52-67$.

Gibson, J., \& Rioja, F. (2017). Public infrastructure maintenance and the distribution of wealth. Economic Inquiry, 55(1), 175-186.

Glaeser, E. L., \& Gottlieb, J. D. (2008). The Economics of Place-Making Policies. Brookings 
Papers on Economic Activity, 39(1), 155-253.

Glaeser, E. L., \& Ponzetto, G. A. (2018). The political economy of transportation investment. Economics of Transportation, 13, 4-26.

Glaeser, E. L., \& Shleifer, A. (2005). The Curley Effect: The economics of shaping the electorate. Journal of Law, Economics, and Organization, 21(1), 1-15.

Green, C. P., Heywood, J. S., \& Navarro Paniagua, M. (2020). Did the London congestion charge reduce pollution? Regional Science and Urban Economics, 84, 103573.

Greenberg, P. (2016). Spatial inequality and uneven development: The local stratification of poverty in Appalachia. Journal of Appalachian Studies, 22(2), 187-209.

Grossman, D., Humphreys, B. R., \& Ruseski, J. E. (2019). Out of the outhouse: The impact of place-based policies on dwelling characteristics in Appalachia. Journal of Regional Science, $59(1), 5-28$.

Grossman, M. (1972). The demand for health: A theoretical and empirical investigation (Tech. Rep.). National Bureau of Economic Research, Inc.

Haaga, J. (2004). Educational attainment in Appalachia (Tech. Rep.). Appalachian Regional Commission.

Hall, J., \& Neto, A. B. F. (2018). The effect of health care entrepreneurship on local health: The case of MedExpress in Appalachia. Journal of Regional Analysis \& Policy, 48(2).

Hall, J. D. (2018). Pareto improvements from Lexus Lanes: The effects of pricing a portion of the lanes on congested highways. Journal of Public Economics, 158, 113 - 125.

Hanna, R., Kreindler, G., \& Olken, B. A. (2017). Citywide effects of high-occupancy vehicle restrictions: Evidence from "three-in-one" in Jakarta. Science, 357(6346), 89-93.

Harari, M. (2020). Cities in bad shape: Urban geometry in India. American Economic Review, $110(8), 2377-2421$.

Hennessy, D. A., \& Wiesenthal, D. L. (1999). Traffic congestion, driver stress, and driver aggression. Aggressive Behavior, 25(6), 409-423.

Hoehn-Velasco, L. (2018). Explaining declines in US rural mortality, 1910-1933: The role of 
county health departments. Explorations in Economic History, 70, 42 - 72.

Hoehn-Velasco, L. (2020). The long-term impact of preventative public health programs. The Economic Journal.

Holl, A. (2016). Highways and productivity in manufacturing firms. Journal of Urban Economics, 93, $131-151$.

Hsu, W.-T., \& Zhang, H. (2014). The fundamental law of highway congestion revisited: Evidence from national expressways in Japan. Journal of Urban Economics, 81, 65 - 76.

Huet-Vaughn, E. (2019). Stimulating the vote: ARRA road spending and vote share. American Economic Journal: Economic Policy, 11(1), 292-316.

Hughes, J. E., \& Kaffine, D. (2019). When should drivers be encouraged to carpool in HOV lanes? Economic Inquiry, 57(1), 667-684.

Iacus, S. M., King, G., \& Porro, G. (2011). Multivariate matching methods that are monotonic imbalance bounding. Journal of the American Statistical Association, 106(493), 345-361.

Isserman, A., \& Rephann, T. (1995). The economic effects of the Appalachian Regional Commission: An empirical assessment of 26 years of regional development planning. Journal of the American Planning Association, 61(3), 345-364.

Jaworski, T., \& Kitchens, C. T. (2019). National policy for regional development: Historical evidence from Appalachian highways. The Review of Economics and Statistics, 101(5), $1-14$.

Kalaitzidakis, P., \& Kalyvitis, S. (2004). On the macroeconomic implications of maintenance in public capital. Journal of Public Economics, 88(3-4), 695-712.

Kalaitzidakis, P., \& Kalyvitis, S. (2005). "New” public investment and/or public capital maintenance for growth? The Canadian experience. Economic Inquiry, 43(3), 586-600.

Kalyvitis, S., \& Vella, E. (2015). Productivity effects of public capital maintenance: Evidence from US states. Economic Inquiry, 53(1), 72-90.

Kniesner, T. J., \& Viscusi, W. K. (2019). The value of a statistical life. Forthcoming, Oxford Research Encyclopedia of Economics and Finance, 19-15. 
Knight, B. (2005). Estimating the value of proposal power. American Economic Review, 95(5), $1639-1652$.

Knittel, C. R., Miller, D. L., \& Sanders, N. J. (2016). Caution, drivers! Children present: Traffic, pollution, and infant health. Review of Economics and Statistics, 98(2), 350-366.

Konishi, H., \& Mun, S. (2010). Carpooling and congestion pricing: HOV and HOT lanes. Regional Science and Urban Economics, 40, 173-186.

Leape, J. (2006). The London congestion charge. Journal of Economic Perspectives, 20(4), 157-176.

Lehne, J., Shapiro, J. N., \& Eynde, O. V. (2018). Building connections: Political corruption and road construction in india. Journal of Development Economics, 131, 62-78.

Matute, J., \& Pincetl, S. (2013). High-occupancy vehicle expansion through lane conversion rather than new construction. Petroleum Policy Brief Series.

Michaels, G. (2008). The effect of trade on the demand for skill: Evidence from the Interstate Highway System. The Review of Economics and Statistics, 90(4), 683-701.

Migueis, M. (2013). The effect of political alignment on transfers to Portuguese municipalities. Economics \& Politics, 25(1), 110-133.

Murphy, K., \& Topel, R. (2006). The value of health and longevity. Journal of Political Economy, 114(5), 871-904.

Newgard, C. D., Fu, R., Bulger, E., Hedges, J. R., Mann, N. C., Wright, D. A., ... Hansen, M. (2017). Evaluation of rural vs urban trauma patients served by 9-1-1 emergency medical services. JAMA Surgery, 152(1), 11-18.

Nunn, N. (2008). The long-term effects of Africa's slave trades. The Quarterly Journal of Economics, 123(1), 139-176.

PARC. (1964). Appalachia: A Report by the President's Appalachian Regional Commission (PARC).

Partridge, M. D., \& Rickman, D. S. (2008). Distance from urban agglomeration economies and rural poverty. Journal of Regional Science, 48(2), 285-310. 
Patrick, C., \& Mothorpe, C. (2017). Demand for new cities: Property value capitalization of municipal incorporation. Regional Science and Urban Economics, 67, 78-89.

Plotz, J., Konduri, K., \& Pendyala, R. (2010). To what extent can high-occupancy vehicle lanes reduce vehicle trips and congestion? Exploratory analysis using national statistics. Transportation Research Record, 2178.1, 170-176.

Preston, S. H. (1975). The changing relation between mortality and level of economic development. Population Studies, 29(2), 231-248.

Redding, S. J., \& Turner, M. A. (2015). Transportation costs and the spatial organization of economic activity. In Handbook of Regional and Urban Economics (Vol. 5, pp. 1339-1398). Elsevier.

Rephann, T., \& Isserman, A. (1994). New highways as economic development tools: An evaluation using quasi-experimental matching methods. Regional Science and Urban Economics, 24(6), $723-751$.

Rioja, F. K. (2003). Filling potholes: Macroeconomic effects of maintenance versus new investments in public infrastructure. Journal of Public Economics, 87(9-10), 2281-2304.

Rogers, C. L., \& Marshment, R. (2000). Measuring highway bypass impacts on small town business districts. Review of Urban \& Regional Development Studies, 12(3), 250.

Røislien, J., Lossius, H. M., \& Kristiansen, T. (2015). Does transport time help explain the high trauma mortality rates in rural areas? New and traditional predictors assessed by new and traditional statistical methods. Injury Prevention, 21(6), 367-373.

Roth, J. (2016). Census US intercensal county population data, 1970-2014. Washington DC: US Census Bureau.

Santos, G. (2005). Urban congestion charging: A comparison between London and Singapore. Transport Reviews, 25(5), 511-534.

Sayago-Gomez, J.-T., Piras, G., Jackson, R., \& Lacombe, D. (2018). Impact evaluation of investments in the Appalachian region: A reappraisal. International Regional Science Review, 41(6), 601-629. 
Schmitt, A. (2015). 3 Reasons Politicians Like Building New Roads More Than Fixing Old Ones. https://usa.streetsblog.org/2015/09/01/3-reasons-politicians -like-building-new-roads-more-than-fixing-old-ones/. (Accessed: August 2020)

Shewmake, S. (2018). The impact of high occupancy vehicle lanes on vehicle miles traveled. Working Paper.

Solé-Ollé, A., \& Sorribas-Navarro, P. (2008). The effects of partisan alignment on the allocation of intergovernmental transfers: Differences-in-differences estimates for Spain. Journal of Public Economics, 92(12), 2302-2319.

Spiller, E., Stephens, H., Timmins, C. D., \& Smith, A. (2012). Does the substitutability of public transit affect commuters' response to gasoline price changes? Resources for the Future Discussion Paper No.12-29.

Tang, J. P. (2017). The engine and the reaper: Industrialization and mortality in late nineteenth century Japan. Journal of Health Economics, 56, 145-162.

United States House of Representatives. (1947). A report on the National Interregional Highway Committee, outlining and recommending a national system of interregional highways (Tech. Rep.). Washington, DC: US Government Printing Office.

U.S. Department of Transportation: Federal Highway Administration. (2018). National household travel survey. Retrieved 2018-10-10, from https://nhts.ornl.gov/

Weingast, B. R., Shepsle, K. A., \& Johnsen, C. (1981). The political economy of benefits and costs: A neoclassical approach to distributive politics. Journal of Political Economy, 89(4), 642-664.

Widner, R. R. (1990). Appalachian development after 25 years: An assessment. Economic Development Quarterly, 4(4), 291-312.

Winston, C. (2013). On the performance of the U.S. transportation system: Caution ahead. Journal of Economic Literature, 51(3), 773-824.

Wooldridge, J. M. (1999). Distribution-free estimation of some nonlinear panel data models. 
Journal of Econometrics, 90(1), 77-97.

World Population Review. (2020). How many cities are in the US? https:// worldpopulationreview.com/us-cities/how-many-cities-are-in -the-us/. (Accessed: August 2020)

Zhao, J. Z., Fonseca-Sarimento, C., \& Tan, J. (2019). America's trillion-dollar repair bill (Tech. Rep.). The Volcker Alliance.

Zimran, A. (2020). Transportation and health in the Antebellum United States 1820-1847. The Journal of Economic History, 1-40. 


\section{Appendix}

\section{A Additional Tables and Figures for Chapter 1}


Table A.1: Trip and Driver Characteristics Before Matching: 50 miles or less

\begin{tabular}{lccc}
\hline & Control County & Treated County & Difference \\
\hline Trip Characteristics & & & \\
\hline Time to Work & 21.06 & 30.53 & $-20.59^{* * *}$ \\
& $(0.30)$ & $(0.260)$ & {$[0.00]$} \\
Short Commute & 0.999 & 0.55 & $65.38^{* * *}$ \\
& $(0.004)$ & $(0.004)$ & {$[0.00]$} \\
Long Commute & 0.001 & 0.45 & $-65.38^{* * *}$ \\
& $(0.004)$ & $(0.004)$ & {$[0.00]$} \\
Distance to work & 22.12 & 20.39 & -0.95 \\
& $(2.00)$ & $(0.83)$ & {$[0.17]$} \\
\hline Driver Characteristics & & & \\
\hline Male driver & 0.48 & 0.51 & $-3.57^{* * *}$ \\
& $(0.006)$ & $(0.004)$ & {$[0.00]$} \\
Female driver & 0.52 & 0.49 & $3.57^{* * *}$ \\
& $(0.006)$ & $(0.004)$ & {$[0.00]$} \\
Less than high school & 0.03 & 0.02 & $3.33^{* * *}$ \\
& $(0.002)$ & $(0.001)$ & {$[0.00]$} \\
Age & 46.51 & 45.25 & $5.48^{* * *}$ \\
& $(0.20)$ & $(0.12)$ & {$[0.00]$} \\
\hline Work Characteristics & \multicolumn{3}{l}{} \\
\hline Sales & 0.25 & 0.21 & $6.23^{* * * *}$ \\
& $(0.006)$ & $(0.003)$ & {$[0.00]$} \\
Manufacturing & 0.14 & 0.09 & $9.46^{* * *}$ \\
& $(0.004)$ & $(0.003)$ & {$[0.00]$} \\
\hline Number of trips & 5,268 & 13,671 & \\
\hline
\end{tabular}

Notes: $* \mathrm{p}<0.1, * * \mathrm{p}<0.05,{ }^{* * *} \mathrm{p}<0.01$. Means for control and treated counties are shown above. T-tests were used to test for the difference in means. Standard errors are shown in parentheses and p-values are shown in brackets. 
Table A.2: Trip and Driver Characteristics After Matching: 50 miles or less

\begin{tabular}{lccc}
\hline & Control County & Treated County & Difference \\
\hline Trip Characteristics & & & \\
\hline Time to Work & 21.04 & 29.72 & $-17.55^{* * *}$ \\
& $(0.30)$ & $(0.40)$ & {$[0.00]$} \\
Short Commute & 0.999 & 0.57 & $62.81^{* * *}$ \\
& $(0.004)$ & $(0.007)$ & {$[0.00]$} \\
Long Commute & 0.001 & 0.43 & $-62.81^{* * *}$ \\
& $(0.004)$ & $(0.007)$ & {$[0.00]$} \\
Distance to work & 14.34 & 17.32 & $-2.18^{* * *}$ \\
& $(0.96)$ & $(0.97)$ & {$[0.01]$} \\
\hline Driver Characteristics & & & \\
\hline Male driver & 0.48 & 0.48 & 0.00 \\
& $(0.007)$ & $(0.007)$ & {$[0.50]$} \\
Female driver & 0.52 & 0.52 & 0.00 \\
& $(0.007)$ & $(0.007)$ & {$[0.50]$} \\
Less than high school & 0.03 & 0.03 & 0.00 \\
& $(0.002)$ & $(0.002)$ & {$[0.50]$} \\
Age & 46.46 & 46.45 & 0.02 \\
& $(0.20)$ & $(0.20)$ & {$[0.51]$} \\
\hline Work Characteristics & & & \\
\hline Sales & 0.25 & 0.25 & 0.57 \\
& $(0.006)$ & $(0.006)$ & {$[0.71]$} \\
Manufacturing & 0.14 & 0.12 & $4.78^{* * *}$ \\
& $(0.005)$ & $(0.004)$ & {$[0.00]$} \\
\hline Number of trips & 5,210 & 5,210 & \\
\hline
\end{tabular}

Notes: $* \mathrm{p}<0.1, * * \mathrm{p}<0.05, * * * \mathrm{p}<0.01$. Means for control and treated counties are shown above. T-tests were used to test for the difference in means. Standard errors are shown in parentheses and p-values are shown in brackets. 
Table A.3: Trip and Driver Characteristics Before Matching: 25 miles or less

\begin{tabular}{|c|c|c|c|}
\hline & Control County & Treated County & Difference \\
\hline \multicolumn{4}{|l|}{ Trip Characteristics } \\
\hline \multirow[t]{2}{*}{ Time to Work } & 22.65 & 32.78 & $-24.70 * * *$ \\
\hline & $(0.32)$ & $(0.25)$ & [0.00] \\
\hline \multirow[t]{2}{*}{ Short Commute } & 0.99 & 0.38 & $120.02 * * *$ \\
\hline & $(0.001)$ & $(0.005)$ & [0.00] \\
\hline \multirow[t]{2}{*}{ Long Commute } & 0.001 & 0.62 & $-120.00 * * *$ \\
\hline & $(0.001)$ & $(0.004)$ & [0.00] \\
\hline \multirow[t]{2}{*}{ Distance to work } & 20.38 & 21.32 & -0.57 \\
\hline & $(1.36)$ & $(0.95)$ & {$[0.28]$} \\
\hline \multicolumn{4}{|c|}{ Driver Characteristics } \\
\hline \multirow[t]{2}{*}{ Male driver } & 0.49 & 0.51 & $-2.43 * * *$ \\
\hline & $(0.01)$ & $(0.01)$ & {$[0.01]$} \\
\hline \multirow[t]{2}{*}{ Female driver } & 0.51 & 0.49 & $2.43 * * *$ \\
\hline & $(0.01)$ & $(0.01)$ & {$[0.01]$} \\
\hline \multirow[t]{2}{*}{ Less than high school } & 0.03 & 0.02 & $2.13 * * *$ \\
\hline & $(0.002)$ & $(0.002)$ & {$[0.02]$} \\
\hline \multirow[t]{2}{*}{ Age } & 45.82 & 45.40 & $2.03 * * *$ \\
\hline & $(0.15)$ & $(0.14)$ & {$[0.02]$} \\
\hline \multicolumn{4}{|l|}{ Work Characteristics } \\
\hline \multirow[t]{2}{*}{ Sales } & 0.24 & 0.20 & $6.98 * * *$ \\
\hline & $(0.004)$ & $(0.004)$ & {$[0.00]$} \\
\hline \multirow[t]{2}{*}{ Manufacturing } & 0.13 & 0.09 & $7.46^{* * *}$ \\
\hline & $(0.003)$ & $(0.003)$ & {$[0.00]$} \\
\hline Number of trips & 9,128 & 9,811 & \\
\hline
\end{tabular}

Notes: $* \mathrm{p}<0.1, * * \mathrm{p}<0.05, * * * \mathrm{p}<0.01$. Means for control and treated counties are shown above. T-tests were used to test for the difference in means. Standard errors are shown in parentheses and p-values are shown in brackets. 
Table A.4: Trip and Driver Characteristics After Matching: 25 miles or less

\begin{tabular}{lccc}
\hline & Control County & Treated County & Difference \\
\hline Trip Characteristics & & & \\
\hline Time to Work & 22.63 & 32.43 & $-23.12^{* * *}$ \\
& $(0.26)$ & $(0.34)$ & {$[0.00]$} \\
Short Commute & 0.99 & 0.39 & $110.36^{* * *}$ \\
& $(0.001)$ & $(0.005)$ & {$[0.00]$} \\
Long Commute & 0.006 & 0.61 & $-110.00^{* * *}$ \\
& $(0.001)$ & $(0.054)$ & {$[0.00]$} \\
Distance to work & 13.88 & 17.81 & -4.61 \\
& $(0.59)$ & $(0.61)$ & {$[0.00]$} \\
\hline Driver Characteristics & & & \\
\hline Male driver & 0.49 & 0.49 & 0.00 \\
& $(0.01)$ & $(0.01)$ & {$[0.50]$} \\
Female driver & 0.51 & 0.51 & 0.00 \\
Less than high school & $(0.01)$ & $(0.01)$ & {$[0.50]$} \\
& 0.03 & 0.03 & 0.00 \\
Age & $(0.002)$ & $(0.002)$ & {$[0.50]$} \\
& 45.68 & 45.71 & -0.14 \\
& $(0.16)$ & $(0.16)$ & {$[0.45]$} \\
\hline Work Characteristics & & & \\
\hline Sales & 0.24 & 0.20 & $2.29 * * *$ \\
& $(0.005)$ & $(0.005)$ & {$[0.00]$} \\
Manufacturing & 0.12 & 0.10 & $2.80^{* * *}$ \\
& $(0.004)$ & $(0.003)$ & {$[0.00]$} \\
\hline Number of trips & 8,188 & 8,188 & \\
\hline
\end{tabular}

Notes: $* \mathrm{p}<0.1, * * \mathrm{p}<0.05, * * * \mathrm{p}<0.01$. Means for control and treated counties are shown above. T-tests were used to test for the difference in means. Standard errors are shown in parentheses and p-values are shown in brackets. 
Table A.5: Trip and Driver Characteristics Before Matching: 10 miles or less

\begin{tabular}{lccc}
\hline & Control County & Treated County & Difference \\
\hline Trip Characteristics & & & \\
\hline Time to Work & 24.04 & 33.09 & $-21.75^{* * *}$ \\
Short Commute & $(0.25)$ & $(0.35)$ & {$[0.00]$} \\
& 0.92 & 0.35 & $104.23^{* * *}$ \\
Long Commute & $(0.003)$ & $(0.005)$ & {$[0.00]$} \\
& 0.08 & 0.65 & $-100.00^{* * *}$ \\
Distance to work & $(0.003)$ & $(0.005)$ & {$[0.00]$} \\
& 20.10 & 21.90 & -1.09 \\
\hline Driver Characteristics & $(1.18)$ & $(1.08)$ & {$[0.14]$} \\
\hline Male driver & & & \\
Female driver & 0.49 & 0.51 & $-2.55^{* * *}$ \\
Less than high school & $(0.01)$ & $(0.01)$ & {$[0.01]$} \\
Age & 0.51 & 0.49 & $2.55^{* * *}$ \\
& $(0.01)$ & $(0.01)$ & {$[0.01]$} \\
& 0.03 & 0.02 & $2.84 * * *$ \\
Work Characteristics & $(0.002)$ & $(0.002)$ & {$[0.02]$} \\
\hline Sales & 45.77 & 45.36 & $1.94 * * *$ \\
Manufacturing & $(0.14)$ & $(0.15)$ & {$[0.02]$} \\
\hline Number of trips & & & {$[0.00]$} \\
\hline
\end{tabular}

Notes: $* \mathrm{p}<0.1, * * \mathrm{p}<0.05, * * * \mathrm{p}<0.01$. Means for control and treated counties are shown above. T-tests were used to test for the difference in means. Standard errors are shown in parentheses and p-values are shown in brackets. 
Table A.6: Trip and Driver Characteristics After Matching: 10 miles or less

\begin{tabular}{lccc}
\hline & Control County & Treated County & Difference \\
\hline Trip Characteristics & & & \\
\hline Time to Work & 24.22 & 32.74 & $-19.38^{* * *}$ \\
& $(0.28)$ & $(0.34)$ & {$[0.00]$} \\
Short Commute & 0.92 & 0.35 & $90.92^{* * *}$ \\
& $(0.003)$ & $(0.005)$ & {$[0.00]$} \\
Long Commute & 0.08 & 0.65 & $-90.92^{* * *}$ \\
& $(0.003)$ & $(0.005)$ & {$[0.00]$} \\
Distance to work & 13.94 & 17.67 & $-4.90^{* * *}$ \\
& $(0.53)$ & $(0.55)$ & {$[0.00]$} \\
\hline Driver Characteristics & & & \\
\hline Male driver & 0.51 & 0.51 & 0.00 \\
& $(0.01)$ & $(0.01)$ & {$[0.50]$} \\
Female driver & 0.49 & 0.49 & 0.00 \\
& $(0.01)$ & $(0.01)$ & {$[0.50]$} \\
Age & 45.27 & 45.29 & -0.09 \\
& $(0.16)$ & $(0.16)$ & {$[0.46]$} \\
Less than high school & 0.02 & 0.02 & 0.00 \\
& $(0.002)$ & $(0.002)$ & {$[0.50]$} \\
\hline Work Characteristics & & & \\
\hline Sales & 0.21 & 0.20 & 1.00 \\
& $(0.003)$ & $(0.003)$ & {$[0.16]$} \\
Manufacturing & 0.11 & 0.09 & $2.57^{* * *}$ \\
& $(0.003)$ & $(0.003)$ & {$[0.01]$} \\
\hline Number of trips & 7,856 & 7,856 & \\
\hline
\end{tabular}

Notes: $* \mathrm{p}<0.1, * * \mathrm{p}<0.05,{ }^{* * *} \mathrm{p}<0.01$. Means for control and treated counties are shown above. T-tests were used to test for the difference in means. Standard errors are shown in parentheses and p-values are shown in brackets. 
Table A.7: Trip and Driver Characteristics Before Matching: 5 miles or less

\begin{tabular}{lccc}
\hline & Control County & Treated County & Difference \\
\hline Trip Characteristics & & & \\
\hline Time to Work & 24.79 & 33.14 & $-19.58^{* * *}$ \\
& $(0.24)$ & $(0.38)$ & {$[0.00]$} \\
Short Commute & 0.86 & 0.37 & $79.78^{* * *}$ \\
& $(0.003)$ & $(0.006)$ & {$[0.00]$} \\
Long Commute & 0.14 & 0.63 & $-79.78^{* * *}$ \\
& $(0.003)$ & $(0.006)$ & {$[0.00]$} \\
Distance to work & 20.96 & 20.71 & 0.14 \\
& $(1.13)$ & $(1.08)$ & {$[0.44]$} \\
\hline Driver Characteristics & & & \\
\hline Male driver & 0.49 & 0.51 & $-2.67^{* * *}$ \\
& $(0.01)$ & $(0.01)$ & {$[0.03]$} \\
Female driver & 0.51 & 0.48 & $2.67^{* * *}$ \\
& $(0.01)$ & $(0.01)$ & {$[0.00]$} \\
Age & 45.84 & 45.19 & $3.04 * * *$ \\
& $(0.13)$ & $(0.16)$ & {$[0.00]$} \\
Less than high school & 0.03 & 0.02 & $2.88^{* * *}$ \\
& $(0.002)$ & $(0.002)$ & {$[0.00]$} \\
\hline Work Characteristics & & & \\
\hline Sales & 0.23 & 0.20 & $5.00^{* * * *}$ \\
& $(0.004)$ & $(0.005)$ & {$[0.00]$} \\
Manufacturing & 0.12 & 0.09 & $5.41^{* * *}$ \\
& $(0.002)$ & $(0.003)$ & {$[0.00]$} \\
\hline Number of trips & 11,889 & 7,050 & \\
\hline
\end{tabular}

Notes: $* \mathrm{p}<0.1, * * \mathrm{p}<0.05,{ }^{* * *} \mathrm{p}<0.01$. Means for control and treated counties are shown above. T-tests were used to test for the difference in means. Standard errors are shown in parentheses and p-values are shown in brackets. 
Table A.8: Trip and Driver Characteristics After Matching: 5 miles or less

\begin{tabular}{lccc}
\hline & Control County & Treated County & Difference \\
\hline Trip Characteristics & & & \\
\hline Time to Work & 25.15 & 32.92 & $-16.47^{* * *}$ \\
& $(0.30)$ & $(0.36)$ & {$[0.00]$} \\
Short Commute & 0.85 & 0.37 & $66.99^{* * *}$ \\
& $(0.004)$ & $(0.006)$ & {$[0.00]$} \\
Long Commute & 0.14 & 0.63 & $-66.99^{* * *}$ \\
& $(0.004)$ & $(0.006)$ & {$[0.00]$} \\
Distance to work & 14.82 & 17.45 & $-3.14^{* * *}$ \\
& $(0.58)$ & $(0.61)$ & {$[0.00]$} \\
\hline Driver Characteristics & & & \\
\hline Male driver & 0.51 & 0.51 & 0.00 \\
& $(0.01)$ & $(0.01)$ & {$[0.50]$} \\
Female driver & 0.49 & 0.49 & 0.00 \\
& $(0.01)$ & $(0.01)$ & {$[0.50]$} \\
Age & 45.16 & 45.16 & -0.03 \\
& $(0.16)$ & $(0.16)$ & {$[0.48]$} \\
Less than high school & 0.02 & 0.02 & 0.00 \\
& $(0.002)$ & $(0.002)$ & {$[0.50]$} \\
\hline Work Characteristics & & & \\
\hline Sales & 0.21 & 0.20 & $1.50^{*}$ \\
& $(0.005)$ & $(0.005)$ & {$[0.06]$} \\
Manufacturing & 0.10 & 0.09 & $1.57^{*}$ \\
& $(0.004)$ & $(0.003)$ & {$[0.06]$} \\
\hline Number of trips & 7,008 & 7,008 & \\
\hline
\end{tabular}

Notes: $* \mathrm{p}<0.1, * * \mathrm{p}<0.05,{ }^{* * *} \mathrm{p}<0.01$. Means for control and treated counties are shown above. T-tests were used to test for the difference in means. Standard errors are shown in parentheses and p-values are shown in brackets. 
Table A.9: Nearest Neighbor Matching Analysis

\begin{tabular}{lcc}
\hline & Average Treatment Effect & Average Treatment Effect on the Treated \\
\hline Binary Treatment & $5.68^{* * *}$ & $6.85^{* * *}$ \\
& $(0.34)$ & $(0.36)$ \\
$\leq 50$ miles & $7.91^{* * *}$ & $8.83^{* * *}$ \\
& $(0.31)$ & $(0.31)$ \\
$\leq 25$ miles & $6.84 * * *$ & $8.28^{* * *}$ \\
& $(0.34)$ & $(0.34)$ \\
$\leq 10$ miles & $5.19^{* * *}$ & $6.81^{* * *}$ \\
& $(0.34)$ & $(0.38)$ \\
$\leq 5$ miles & $5.01 * * *$ & $6.56^{* * *}$ \\
& $(0.36)$ & $(0.39)$ \\
\hline
\end{tabular}

Notes: $* \mathrm{p}<0.1, * * \mathrm{p}<0.05, * * * \mathrm{p}<0.01$. Nearest neighbor average treatment effects and average treatment effects on the treated are displayed for all HOV treatment definitions' impacts on commute time. The four nearest neighbors were used to calculate these effects. Robust standard errors are shown in parentheses. 


\section{Figure A.1: 1947 Interstate Highway Plan Digitized}

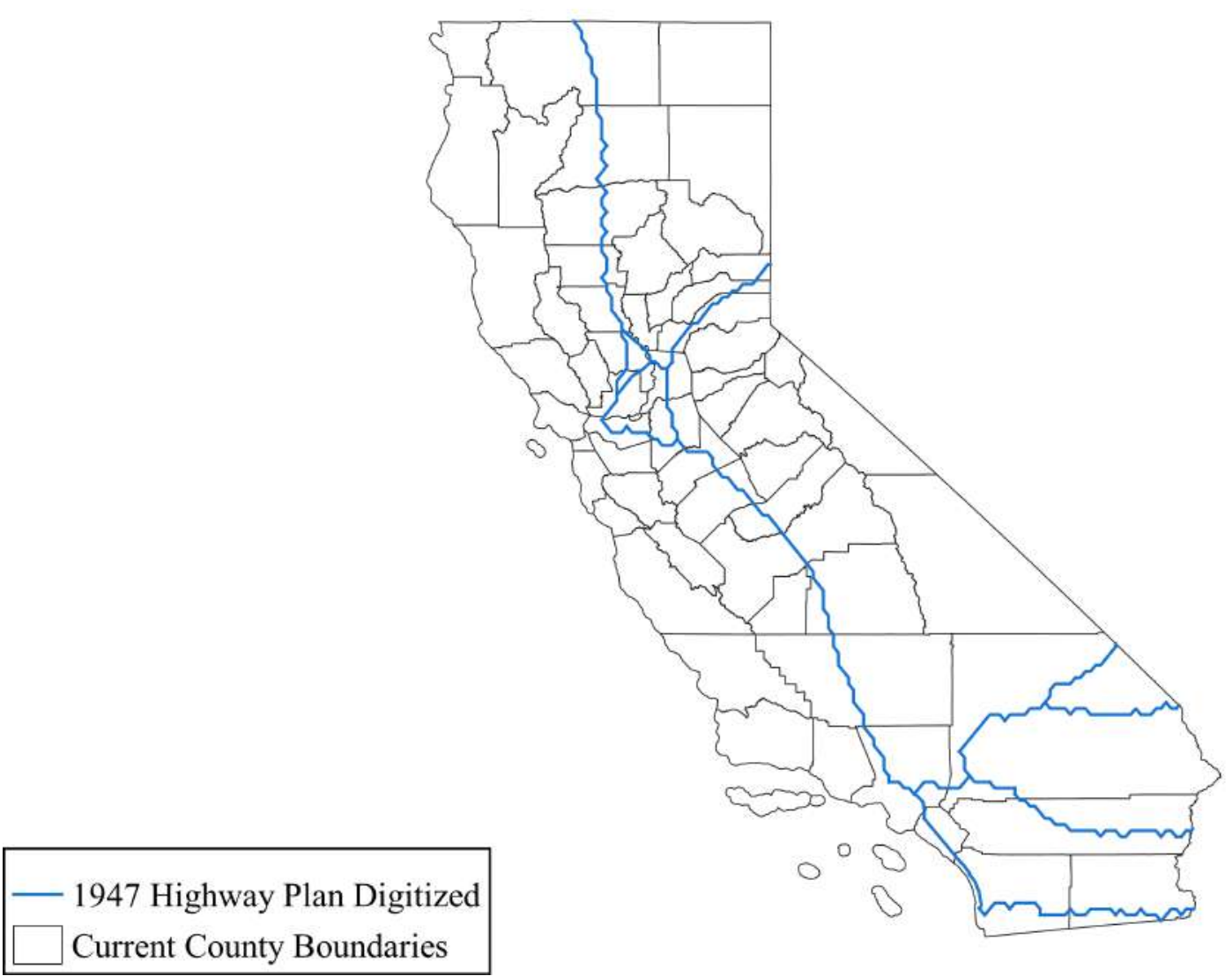

Note: Figure displays the 1947 highway plan drawn by the U.S. House of Representatives (Figure 1.4) in its digitized form. Figure only displays the plan's lines drawn for California. Figure created using QGIS. 
B Additional Tables and Figures for Chapter 2 
Figure B.1: Pittsburgh Expenditures (2009-2017)

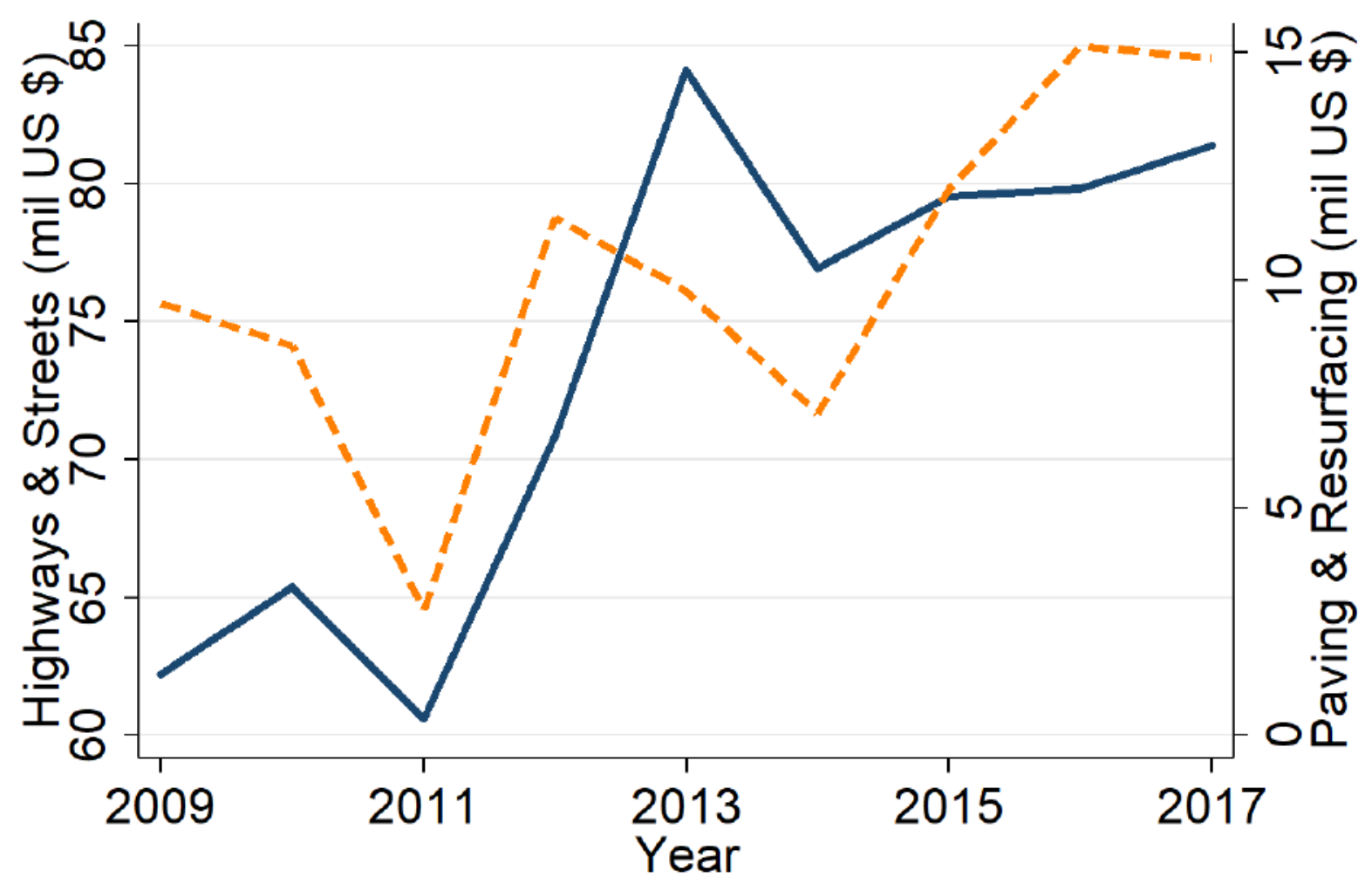

Highways and Streets $=-ー-$ Paving and Resurfacing

Note: Graph charts the expenditures on roads and road maintenance in the city of Pittsburgh for the length of the sample (2009-2017). The navy line represents total expenditures on highways and streets (construction, repair, etc.), while the orange-dashed line represents the expenditures just on paving and resurfacing. Sources: Pittsburgh Comprehensive Annual Financial Reports (https://pittsburghpa.gov/controller/cafr) and Pittsburgh Capital Budgets (https://pittsburghpa.gov/council/capital-budgets) 
Figure B.2: Maintenance Projects and Roads Superimposed Above Political Wards

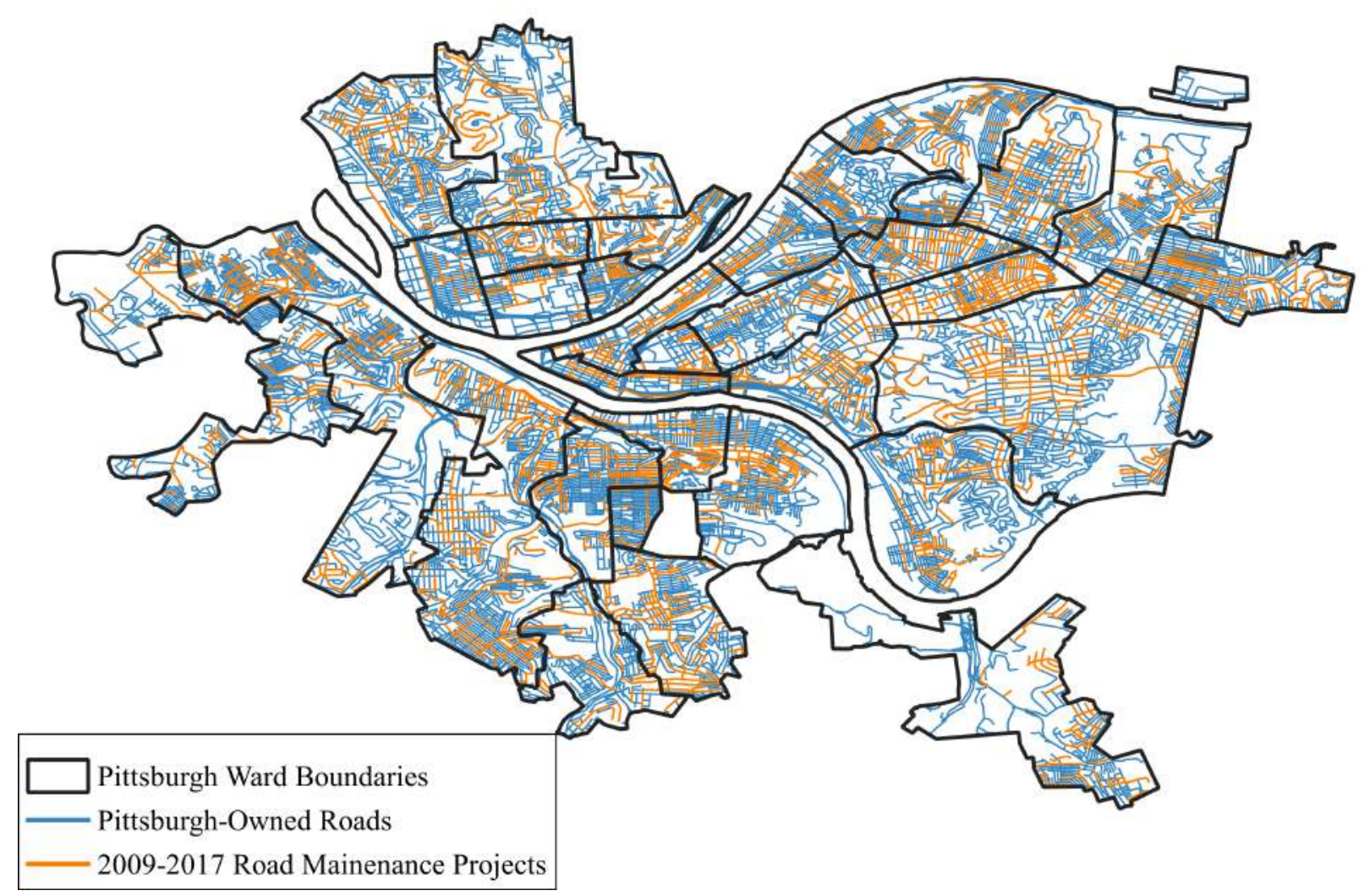

Note: This map of Pittsburgh shows the total universe of city-maintained roads and where maintenance occurred during the sample period. The blue lines are all city-maintained roads, and the orange lines show segments where maintenance occurred. Thick black lines denote ward boundaries. 
Figure B.3: Distribution of Political Alignment

Panel A: Within-Ward Alignment Cutoff

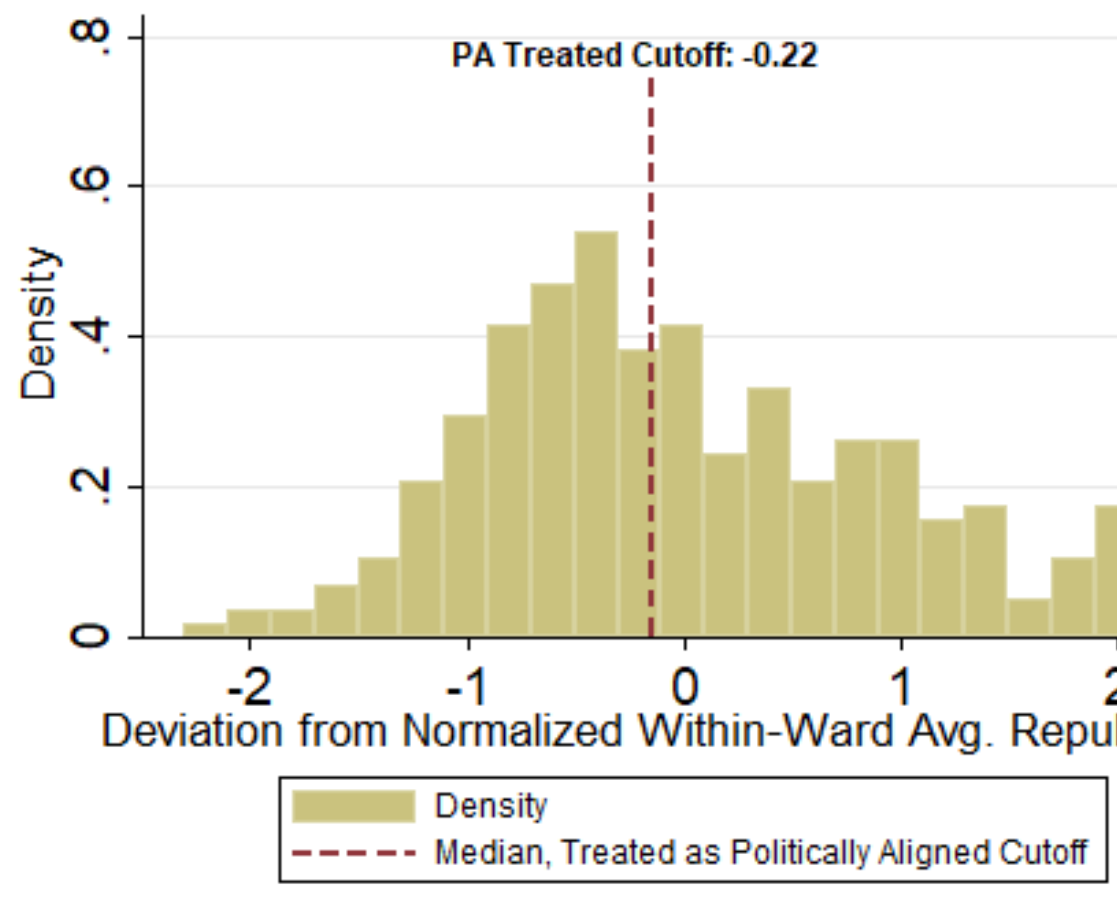

Panel B: Raw Republican Percentage Proportion

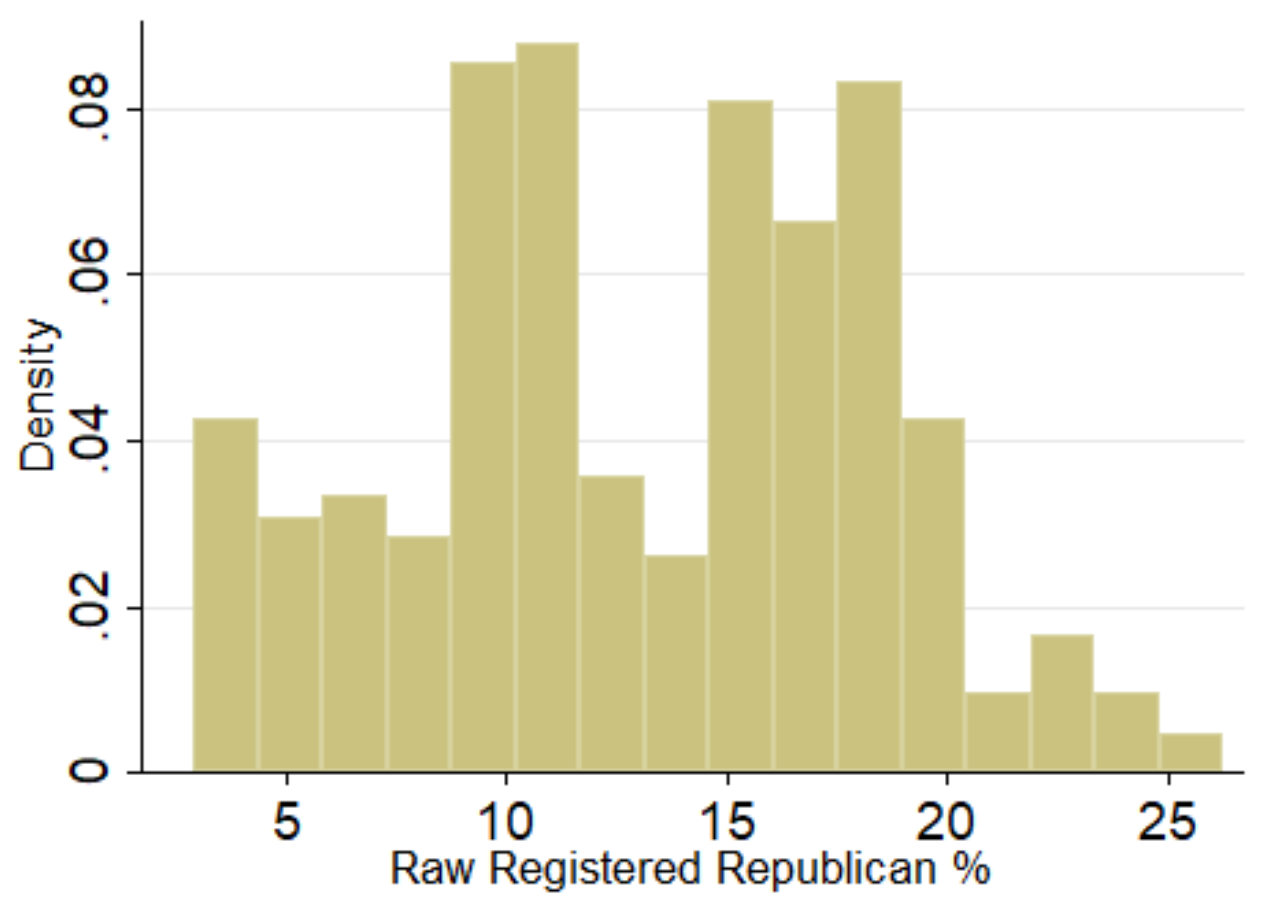

Note: $\mathrm{N}=288$ ward-year observations 
Figure B.4: Number of 1 Meter Road Segments by Distance to Ward Boundary

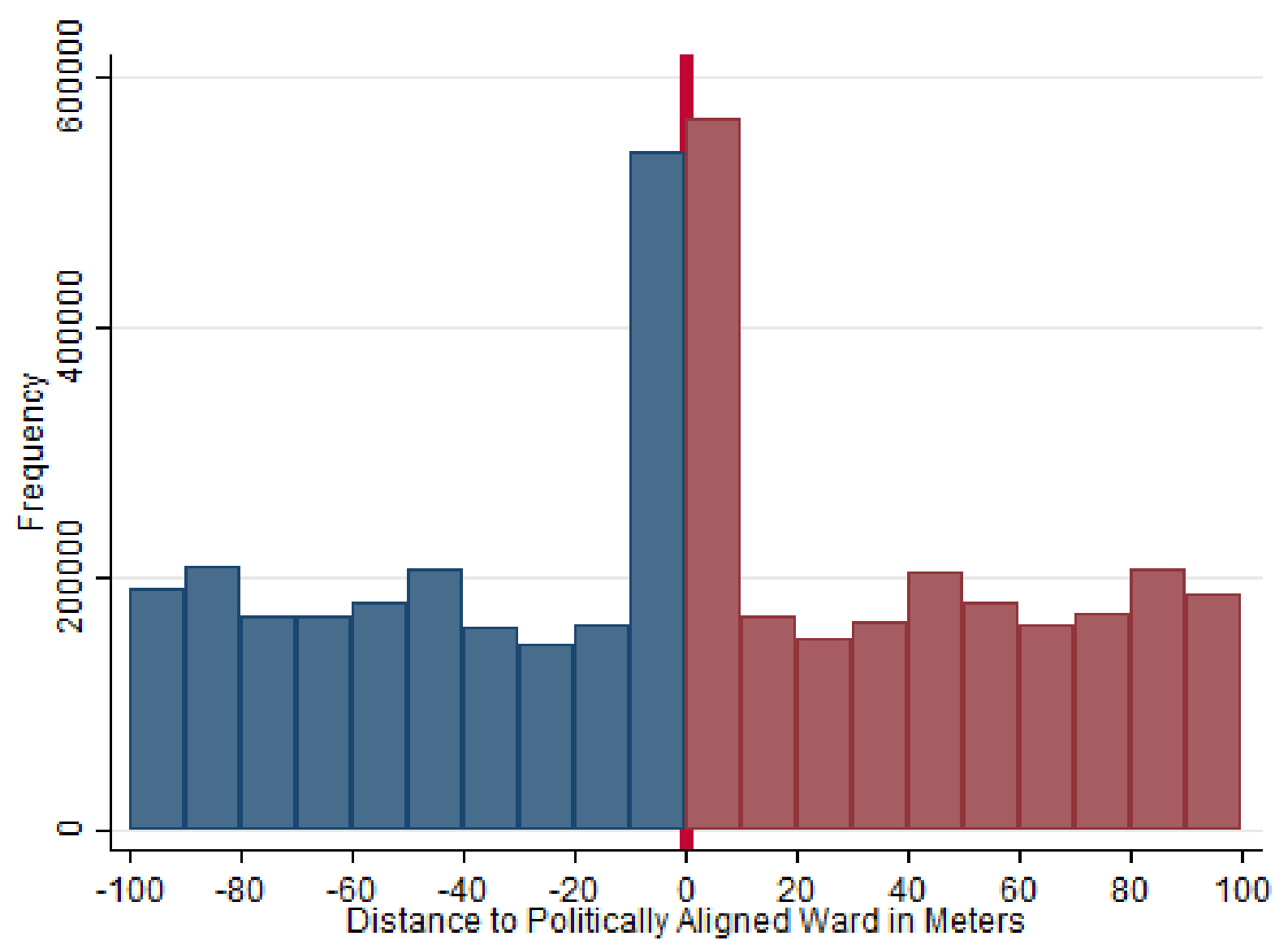

Note: 1 segment per year kept, because political alignment changes yearly. 
Figure B.5: Ward-Level Spatial RD Plots, Combining Tests and Falsification

Panel A: Mayoral Elections, June-August, Alignment Change at Border

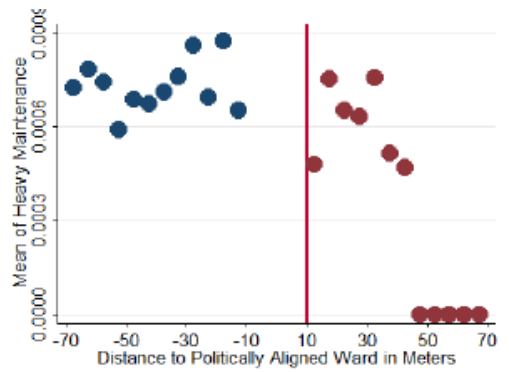

Panel C: Non-Mayoral Elections, June-August, Alignment Change at Border

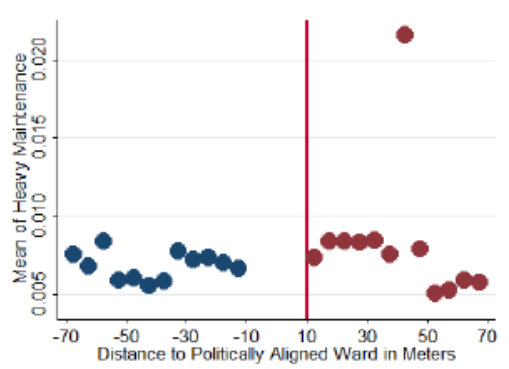

Panel E: Mayoral Elections, June-August, Alignment Same at Border

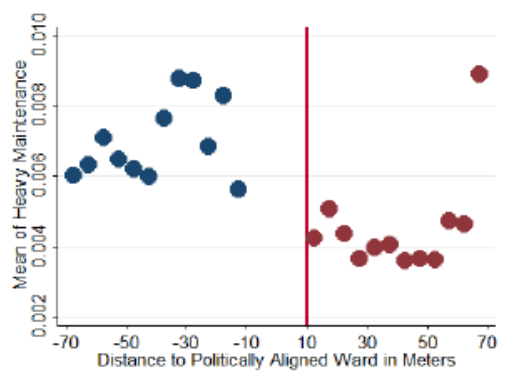

Panel G: Non-Mayoral Elections, June-August, Alignment Same at Border

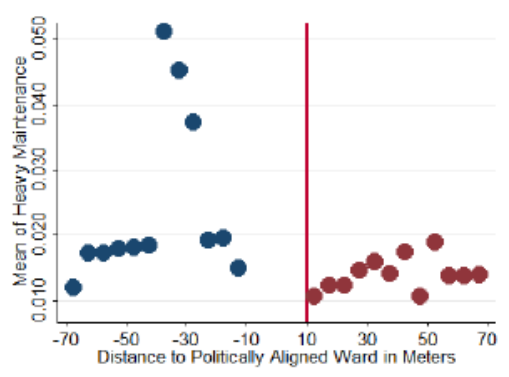

Panel B: Mayoral Elections, October, Alignment Change at Border

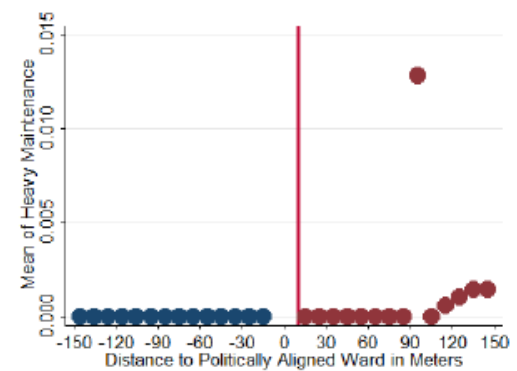

Panel D: Non-Mayoral Elections, October, Alignment Change at Border

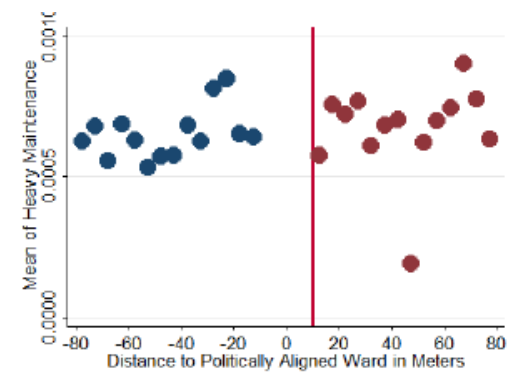

Panel F: Mayoral Elections, October, Alignment Same at Border

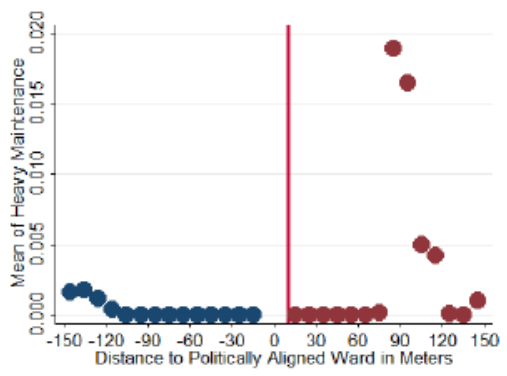

Panel H: Non-Mayoral Elections, October, Alignment Same at Border

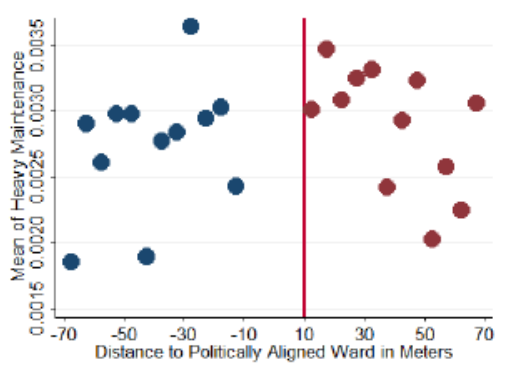

Note: Panels D and H drop out national election years, 2012 and 2016. Blue dots are politically unaligned, red dots are politically aligned. X-axis is distance to more politically aligned ward. Within 10 meters of boundary dropped due to the likelihood they are exactly on the border. 
Figure B.6: The Cost of Road Maintenance Delays

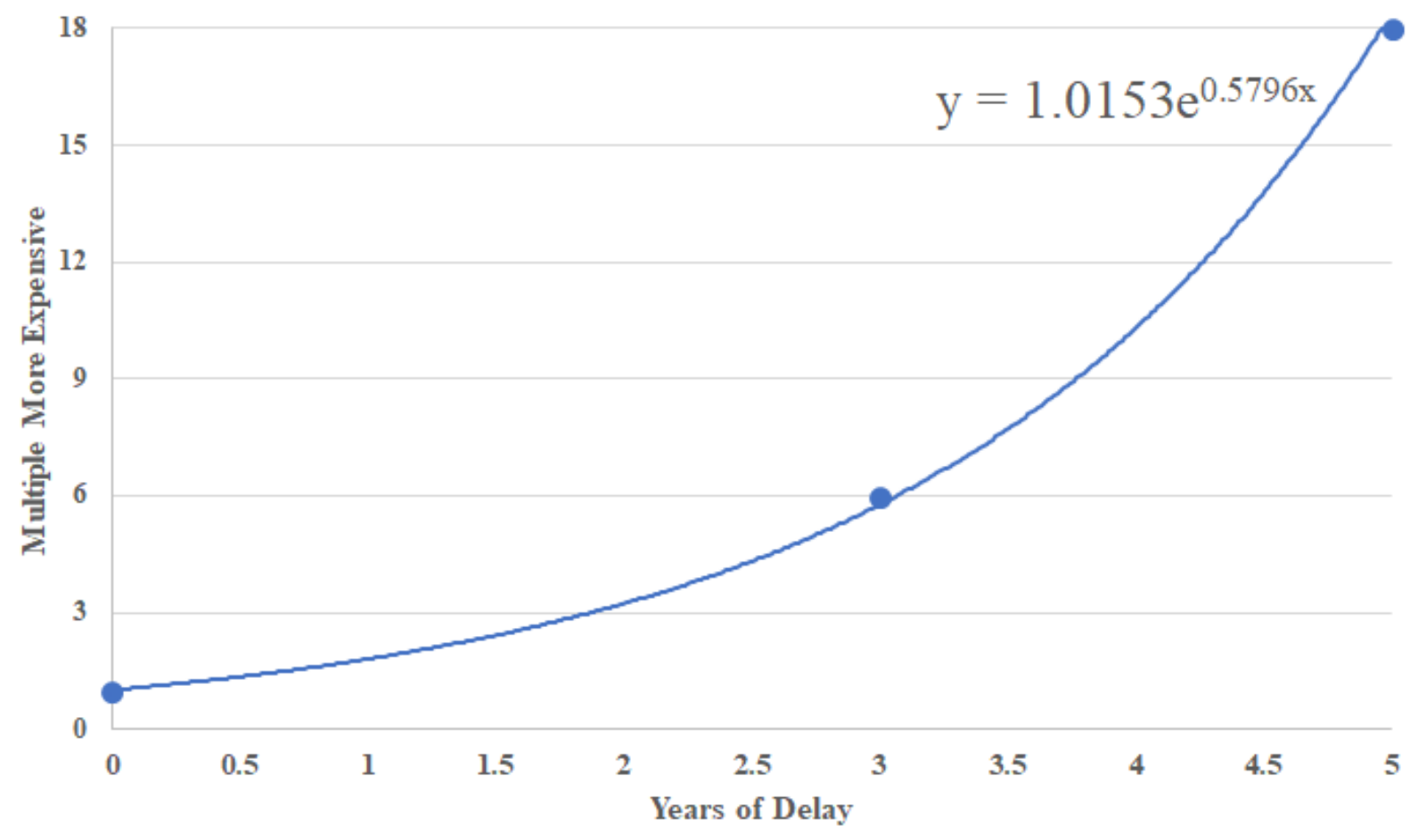

Note: Exponential function extrapolated from two points which are noted in Burningham and Stankevich (2005). We added a point at $(0,1)$, because it is likely there is no extra cost from no delay. This reduces the R-squared from 1 to 0.9995 . 
Table B.1: Federal Highway Administration State \& Urbanized Area Statistics: Population over 750,000

\begin{tabular}{|c|c|c|}
\hline Urban Area & $\begin{array}{l}\text { Variable Outside of } \\
\text { Two SD from Mean }\end{array}$ & $\begin{array}{l}\text { Number of Republican } \\
\text { Mayors since } 1960\end{array}$ \\
\hline New York Northeastern NJ, NY & Urbanized Population $\uparrow$ & 3 \\
\hline Los Angeles, CA & Urbanized Population $\uparrow$ & 2 \\
\hline Chicago - Northwestern IN, IL & Federal-Aid Urbanized Land Area $\uparrow$ & 0 \\
\hline Philadelphia, PA & & 0 \\
\hline San Francisco - Oakland, CA & & 1 \\
\hline Detroit, MI & & 1 \\
\hline Dallas - Ft. Worth, TX & & 4 \\
\hline Washington, DC & & 0 \\
\hline Atlanta, GA & Daily Vehicle Miles per Capita $\uparrow$ & 0 \\
\hline Boston, MA & & 0 \\
\hline San Diego, CA & & 8 \\
\hline Houston, TX & Daily Vehicle Miles per Capita $\uparrow$ & 2 \\
\hline Minneapolis - St. Paul, MN & & 2 \\
\hline Miami - Hialeah, FL & Persons per Square Mile $\uparrow$ & 6 \\
\hline Phoenix, AZ & & 7 \\
\hline Baltimore, MD & & 1 \\
\hline St. Louis, MO & & 0 \\
\hline Seattle, WA & & 1 \\
\hline Denver, $\mathrm{CO}$ & & 1 \\
\hline Tampa - St. Petersburg, FL & $\%$ of Travel Served by Freeways $\downarrow$ & 3 \\
\hline Cleveland, $\mathrm{OH}$ & & 2 \\
\hline San Jose, CA & & 0 \\
\hline Ft. Lauderdale - Hollywood, FL & & 1 \\
\hline Pittsburgh, PA & & $\mathbf{0}$ \\
\hline Milwaukee, WI & & 0 \\
\hline Norfolk - VA Beach - Newport News, VA & & 0 \\
\hline Kansas City, MO & Total Freeway Miles per Urban Pop. $\uparrow$ & 1 \\
\hline Sacramento, CA & & 0 \\
\hline Riverside - San Bernardino, CA & & 1 \\
\hline Portland - Vancouver, OR & & 1 \\
\hline San Juan, PR & Daily Vehicle Miles per Capita $\downarrow$ & NA \\
\hline Las Vegas, NV & & 1 \\
\hline Cincinnati, $\mathrm{OH}$ & & 4 \\
\hline Orlando, FL & & 2 \\
\hline San Antonio, TX & & 1 \\
\hline Buffalo - Niagara Falls, NY & & 1 \\
\hline Oklahoma City, OK & & 5 \\
\hline New Orleans, LA & Daily Vehicle Miles per Capita $\downarrow$ & 0 \\
\hline W. Palm Beach - Boca Raton - Delray Bch, FL & & 0 \\
\hline Columbus, $\mathrm{OH}$ & & 4 \\
\hline Memphis, TN & & 0 \\
\hline Indianapolis, IN & & 4 \\
\hline Providence - Pawtucket, RI & & 0 \\
\hline Jacksonville, FL & & 3 \\
\hline Salt Lake City, UT & & 2 \\
\hline Louisville, KY & & 2 \\
\hline Tulsa, OK & & 7 \\
\hline
\end{tabular}

Note: Urbanized areas in the United States with populations above 750,000 people, listed in order of population. $\uparrow$ : two standard deviations above the mean of all cities listed $\downarrow$ : two standard deviations below the mean of all cities listed. Source: Federal Highway Administration (https : / / www . fhwa.dot.gov/ ohim/onh00/onh2p11.htm) Number of Republican mayors since 1960 measures the relative political "competitiveness" of the cities on the list. 
Table B.2: Investigating Political Cycles on Car Crashes

\begin{tabular}{|c|c|c|c|c|c|}
\hline \multirow[b]{2}{*}{ Panel A: Number of Crashes } & \multicolumn{5}{|c|}{ More MaintenanceEntire IEPLess Maintenance } \\
\hline & $\begin{array}{l}(1) \\
\text { Oct }\end{array}$ & $\begin{array}{c}(2) \\
\text { Aug-Oct }\end{array}$ & $\begin{array}{c}(3) \\
\text { Jun-Oct }\end{array}$ & $\begin{array}{c}\text { (4) } \\
\text { Jun-Aug }\end{array}$ & $\begin{array}{l}\text { (5) } \\
\text { Jun }\end{array}$ \\
\hline $\mathrm{IEP} * \mathrm{PA}$ & $\begin{array}{c}0.02 \\
(0.07)\end{array}$ & $\begin{array}{c}0.02 \\
(0.05) \\
\end{array}$ & $\begin{array}{c}-0.04 \\
(0.04)\end{array}$ & $\begin{array}{c}-0.09 * * \\
(0.04)\end{array}$ & $\begin{array}{c}-0.02 \\
(0.08) \\
\end{array}$ \\
\hline Mean of Crashes & & & & & 7.565 \\
\hline Panel B: People Involved in $\mathrm{Cr}$ & & & & & \\
\hline $\mathrm{IEP} * \mathrm{PA}$ & $\begin{array}{c}0.00 \\
(0.09)\end{array}$ & $\begin{array}{c}0.03 \\
(0.05)\end{array}$ & $\begin{array}{c}-0.05 \\
(0.05)\end{array}$ & $\begin{array}{l}-0.11 * \\
(0.06)\end{array}$ & $\begin{array}{c}-0.03 \\
(0.08)\end{array}$ \\
\hline Person Count Mean & & & & & 18.49 \\
\hline Panel C: Count of Major Injuri & & & & & \\
\hline $\mathrm{IEP} * \mathrm{PA}$ & $\begin{array}{l}0.98 * \\
(0.51) \\
\end{array}$ & $\begin{array}{c}0.37 \\
(0.38) \\
\end{array}$ & $\begin{array}{c}0.19 \\
(0.27) \\
\end{array}$ & $\begin{array}{c}-0.19 \\
(0.39) \\
\end{array}$ & $\begin{array}{c}-0.11 \\
(0.37) \\
\end{array}$ \\
\hline Mean of Major Injuries & & & & & 0.160 \\
\hline Panel D: Heavy Truck Acciden & & & & & \\
\hline $\mathrm{IEP} * \mathrm{PA}$ & $\begin{array}{c}-0.12 \\
(0.58)\end{array}$ & $\begin{array}{l}-0.09 \\
(0.24)\end{array}$ & $\begin{array}{l}-0.34^{*} \\
(0.19)\end{array}$ & $\begin{array}{c}-0.71 * * \\
(0.28)\end{array}$ & $\begin{array}{c}-0.26 \\
(0.55) \\
\end{array}$ \\
\hline Heavy Truck Accidents Mean & & & & & 0.215 \\
\hline
\end{tabular}

Notes: $* \mathrm{p}<0.1, * * \mathrm{p}<0.05, * * * \mathrm{p}<0.01$ Estimates are from Poisson conditional fixed effect model, shown in Equation 2.1. Ward, month, and year (uninteracted) fixed effects are included in every column. Standard errors, clustered at the ward level, are shown in parentheses. DD coefficient of interest is "IEPXPA." Panel A-D change the dependent variables of interest from heavy maintenance count to various car accident outcomes. Only car crashes from 2009-2017 that occur on Pittsburghowned roads are included in every column. 


\section{Additional Tables and Figures for Chapter 3}


Figure C.1: Appalachian Regional Commission (ARC) Counties Over Time

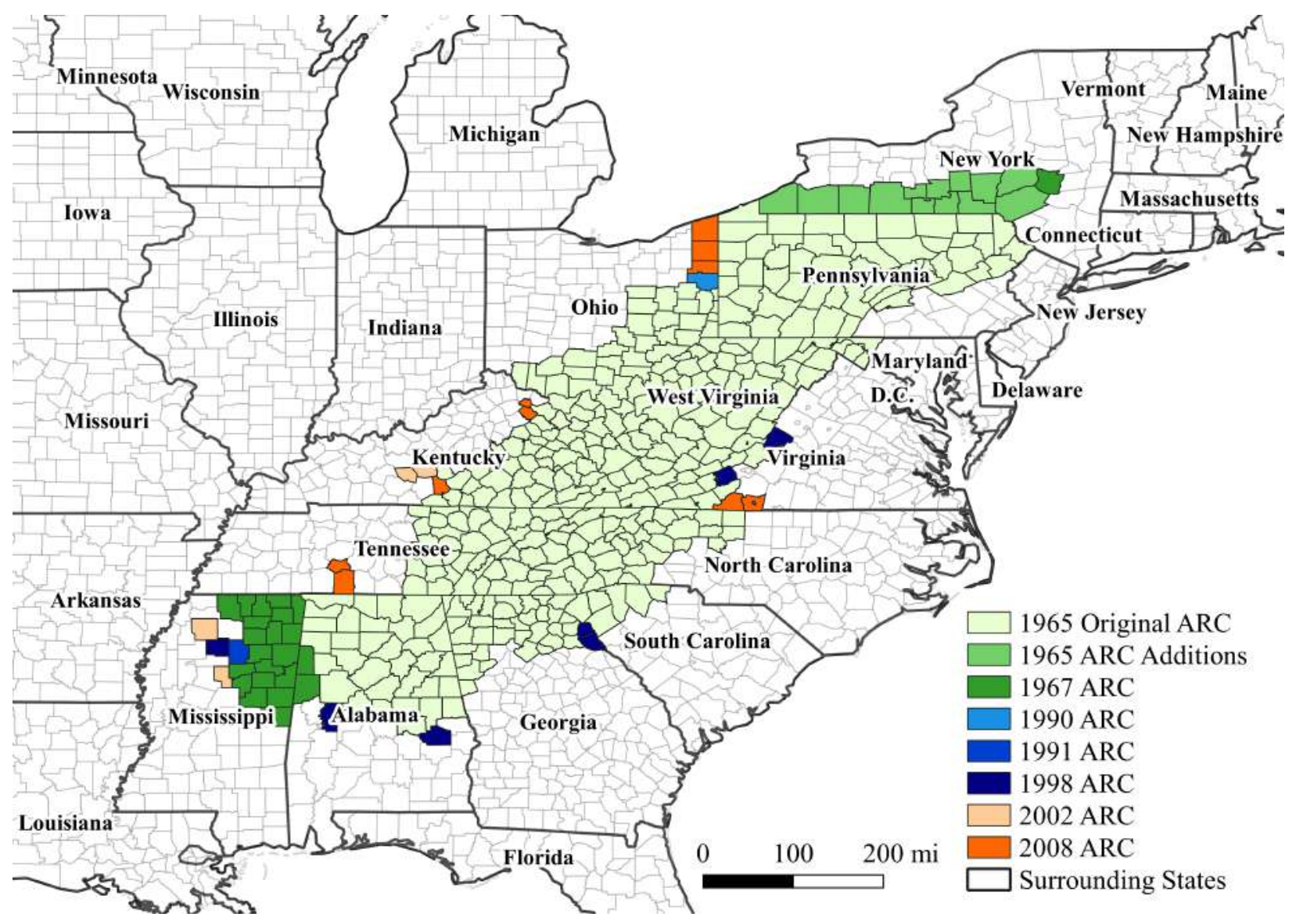

Note: This map shows the Appalachian Regional Commission (ARC) over time (1965-present). Each new color represents a year when a new county or counties were added to the ARC. The ARC remained relatively consistent in geography from 1967 until 1990. Throughout the 1990s-2000s, several counties were added, bringing the current total of ARC counties to 420. West Virginia is the only state with all of its counties in ARC. Figure was created using QGIS. 
Figure C.2: 1966 ARC Plan for the ADHS

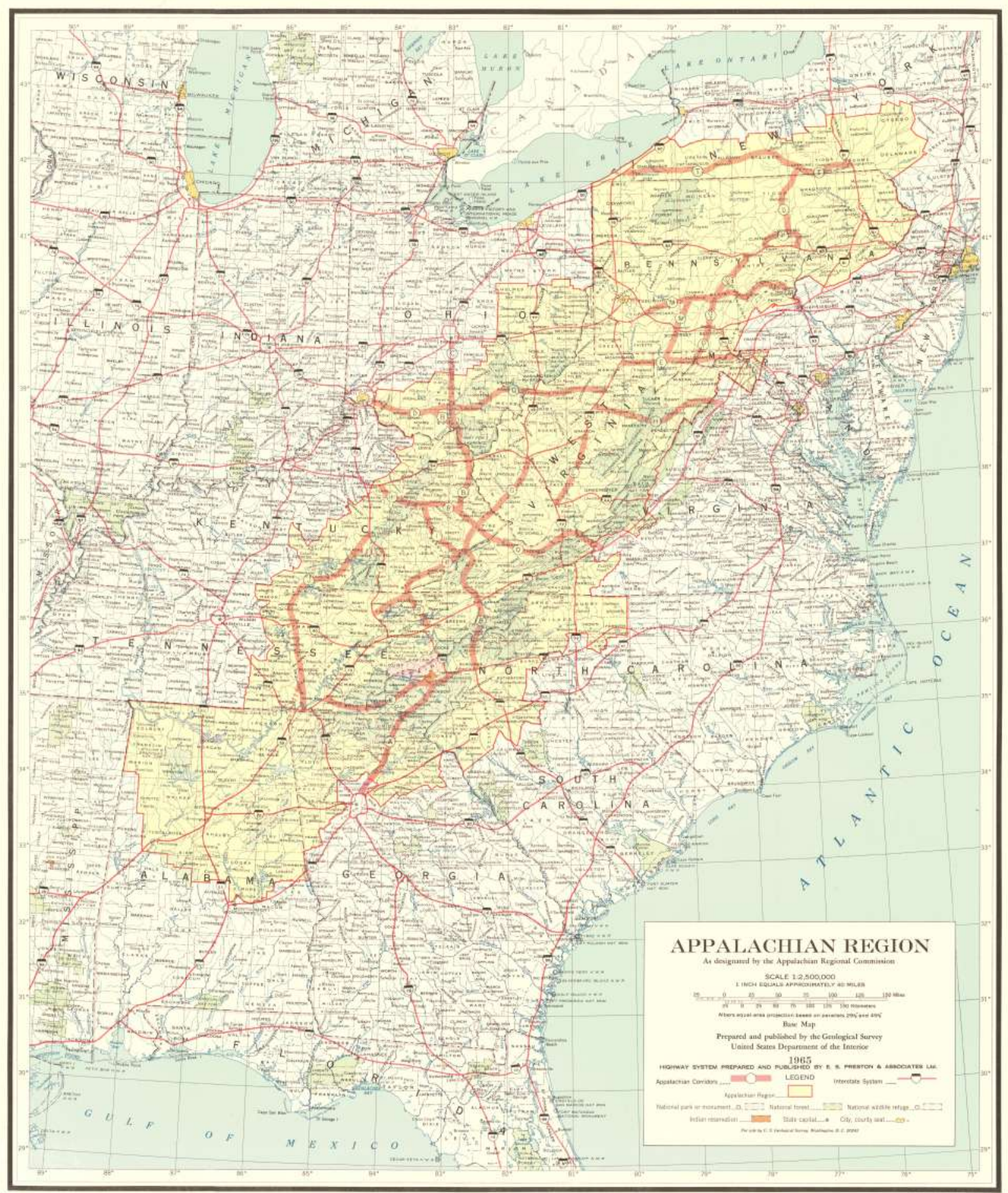

Note: This is a map of the 1966 planned ADHS route. Compared to Figure 3.1, this map was updated to include the larger extent of the Appalachian region under ARC. 
Figure C.3: Appalachian County Change in Hypertension Mortality Rates: 1968-2017

Panel A: Change in Hypertension Mortality:

1968-1978

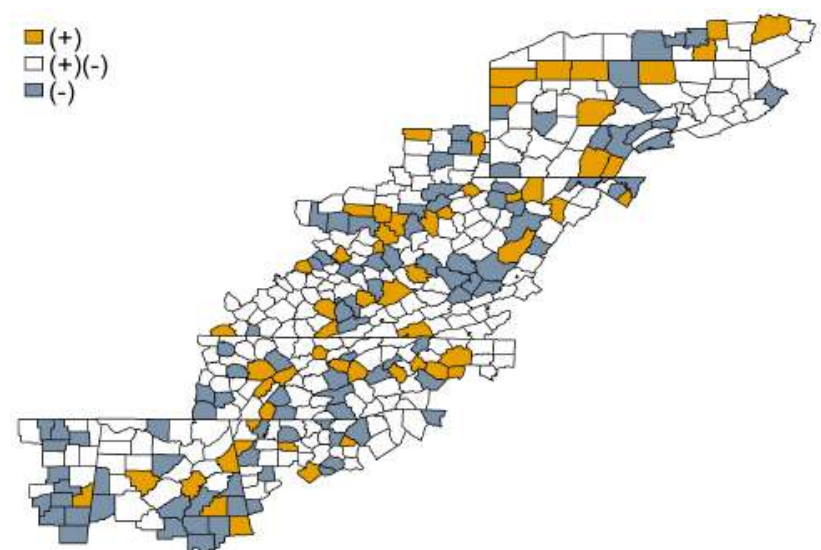

Panel C: Change in Hypertension Mortality: 1988-1998

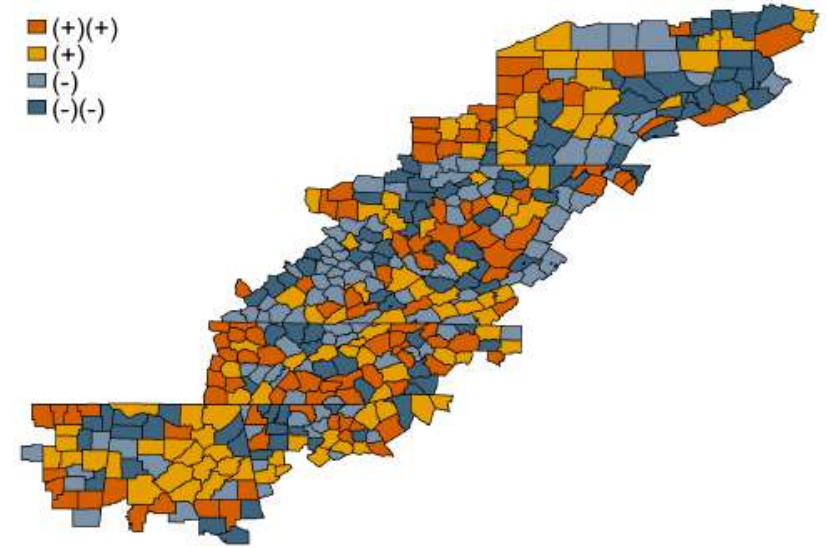

Panel E: Change in Hypertension Mortality: 2008-2017

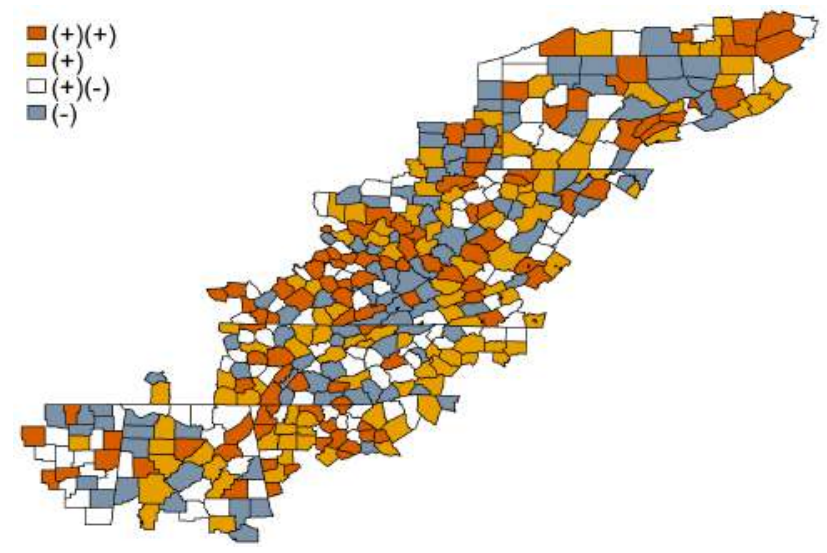

Panel B: Change in Hypertension Mortality: 1978-1988

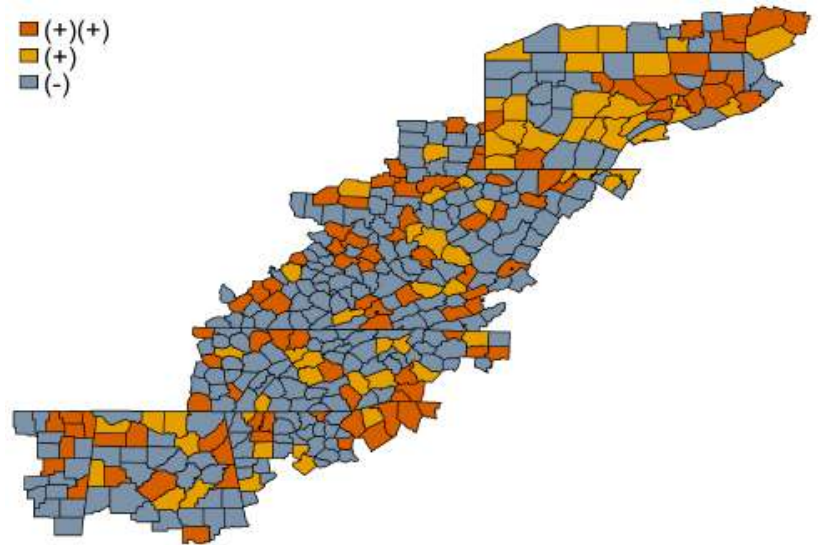

Panel D: Change in Hypertension Mortality: 1998-2008

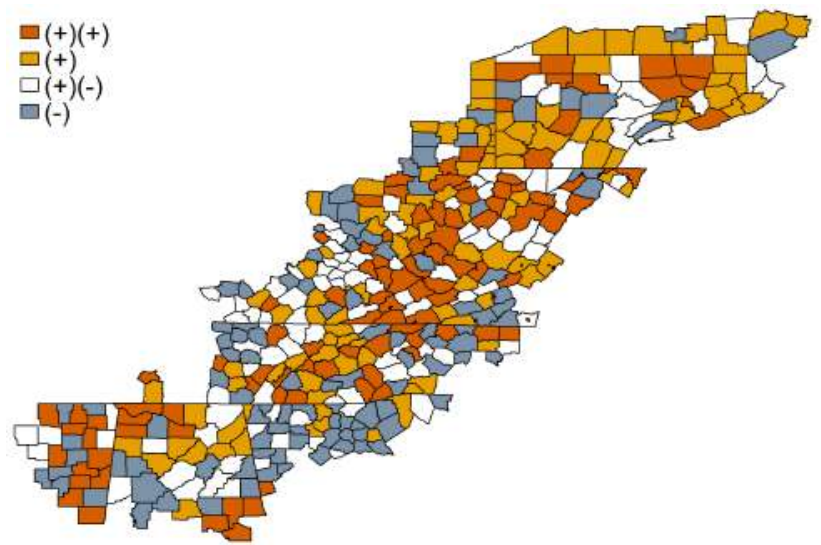

Note: Appalachian county changes in hypertension mortality rates are shown above. Darker shades of blue represent negative changes (improved mortality over the decade), while darker shades of orange represent positive changes (worse mortality over the decade). White counties represent no significant change. Counties grouped into equal quantiles per decade. County of death mapped. 
Figure C.4: Appalachian County Change in Cerebrovascular Disease Mortality Rates: 1968-2017

Panel A: Change in Cerebrovascular Disease

Mortality: 1968-1978

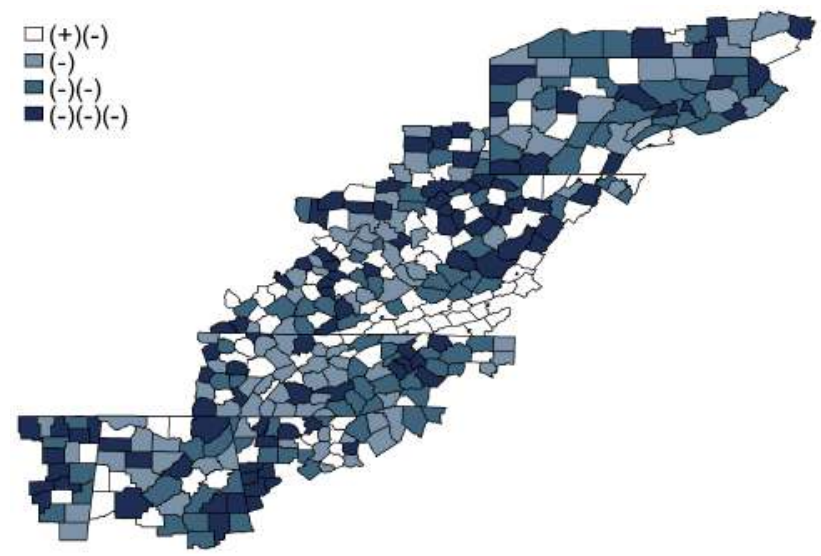

Panel C: Change in Cerebrovascular Disease Mortality: 1988-1998

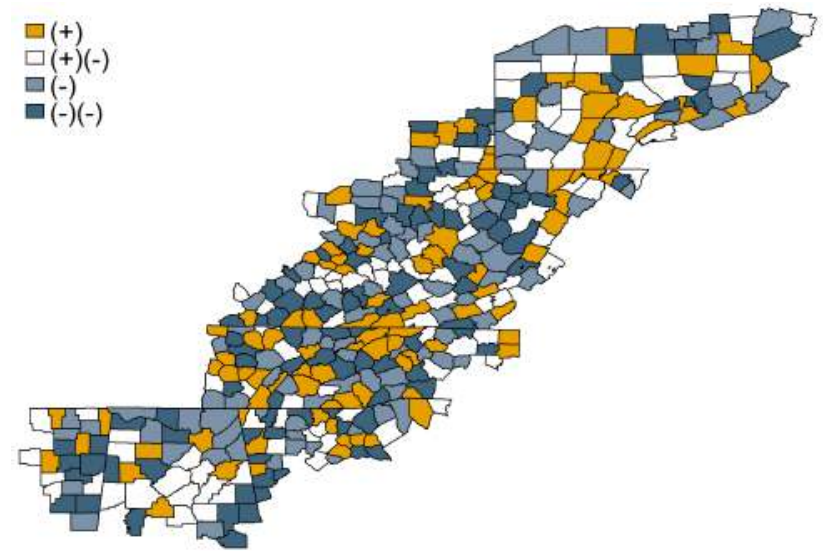

Panel E: Change in Cerebrovascular Disease Mortality: 2008-2017

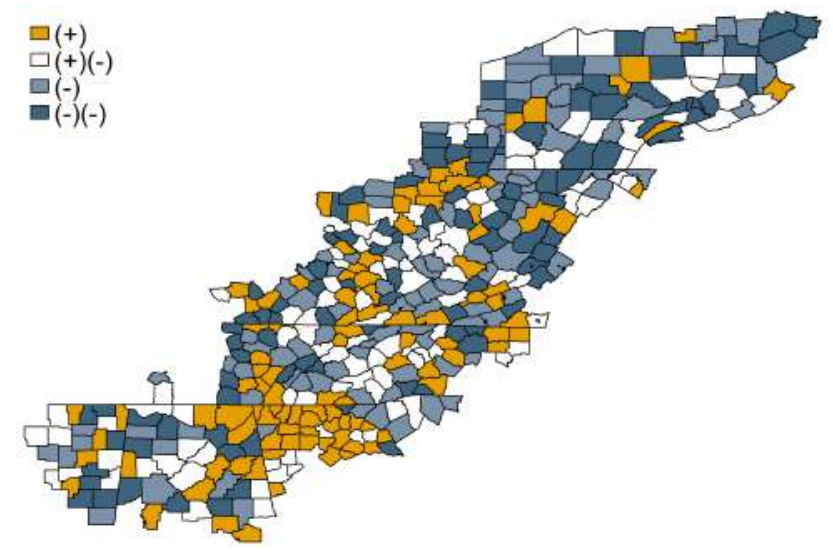

Panel B: Change in Cerebrovascular Disease Mortality: 1978-1988

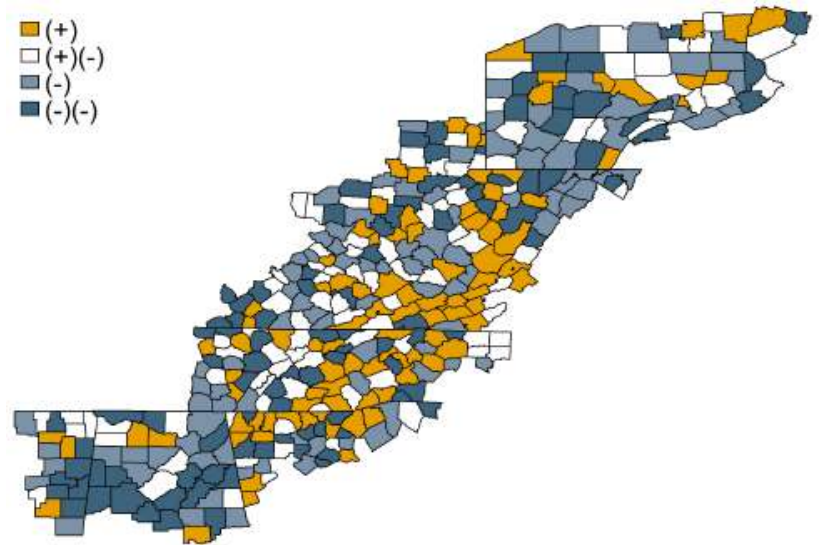

Panel D: Change in Cerebrovascular Disease Mortality: 1998-2008

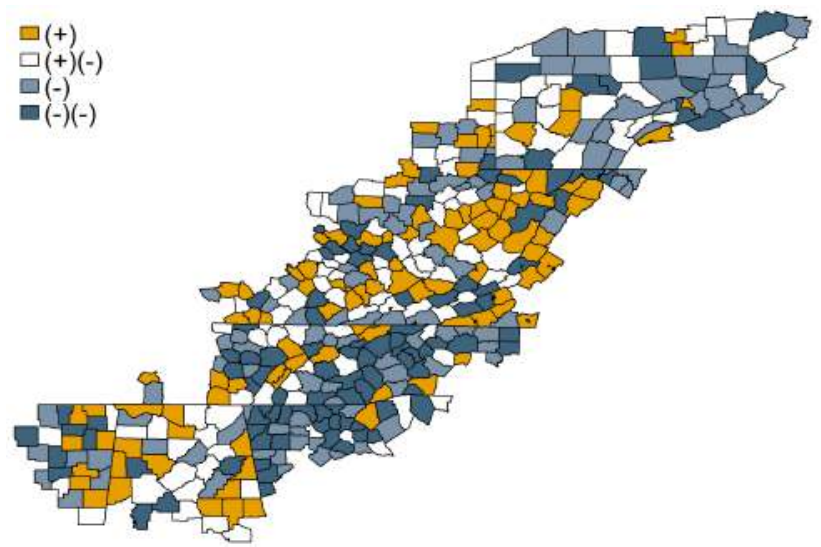

Note: Appalachian county changes in cerebrovascular disease mortality rates are shown above. Darker shades of blue represent negative changes (improved mortality over the decade), while darker shades of orange represent positive changes (worse mortality over the decade). White counties represent no significant change. Counties grouped into equal quantiles per decade. County of death mapped. 
Figure C.5: Appalachian County Change in Aortic Aneurysm Mortality Rates: 1968-2017

Panel A: Change in Aortic Aneurysm Mortality: $\quad$ Panel B: Change in Aortic Aneurysm Mortality: 1968-1978 1978-1988

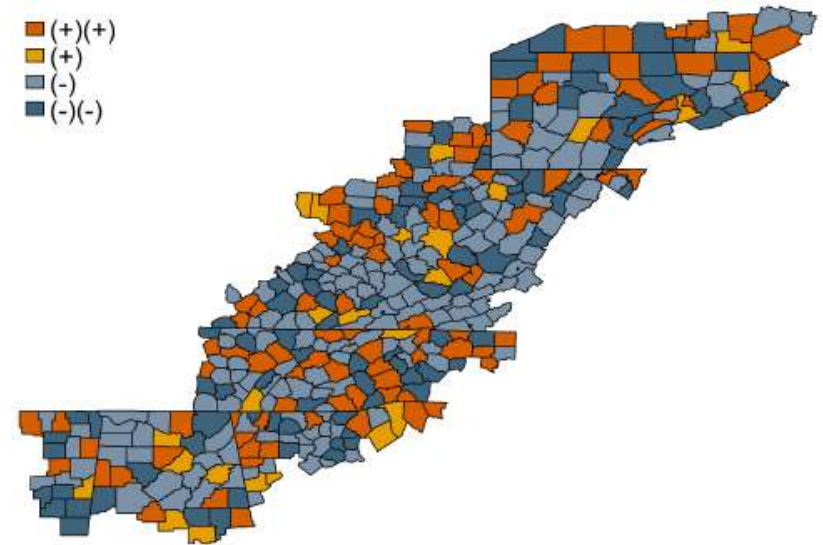

Panel C: Change in Aortic Aneurysm Mortality: 1988-1998

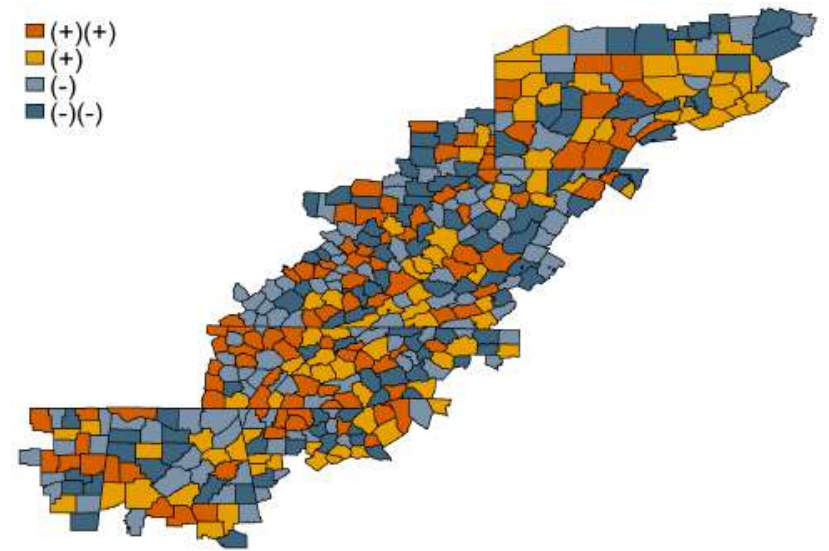

Panel E: Change in Aortic Aneurysm Mortality: 2008-2017

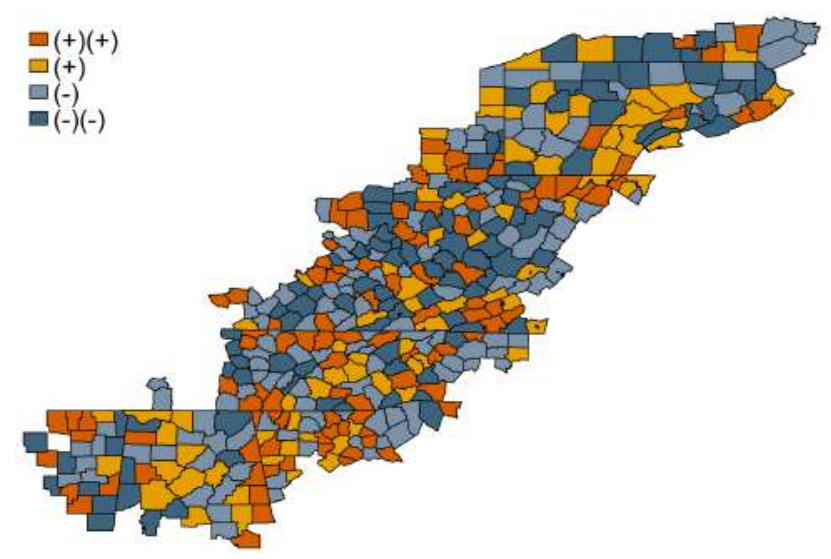

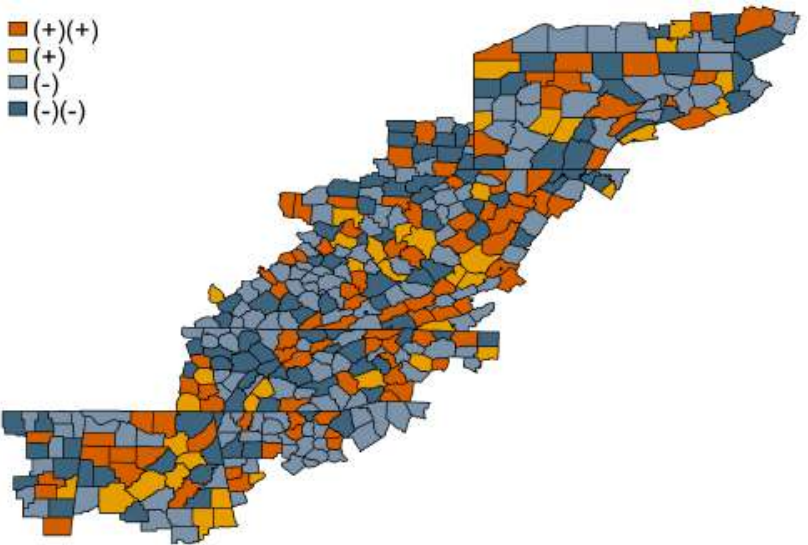

Panel D: Change in Aortic Aneurysm Mortality: 1998-2008

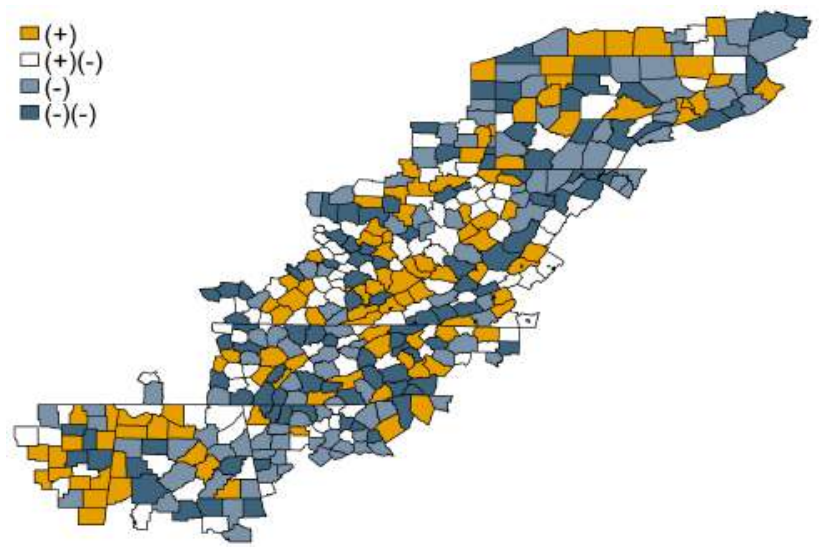

Note: Appalachian county changes in aortic aneurysm mortality rates are shown above. Darker shades of blue represent negative changes (improved mortality over the decade), while darker shades of orange represent positive changes (worse mortality over the decade). White counties represent no significant change. Counties grouped into equal quantiles per decade. County of death mapped. 
Figure C.6: Appalachian County Change in Pneumonia and Influenza Mortality Rates: 1968-2017

Panel A: Change in Pneumonia and Influenza

Mortality: 1968-1978

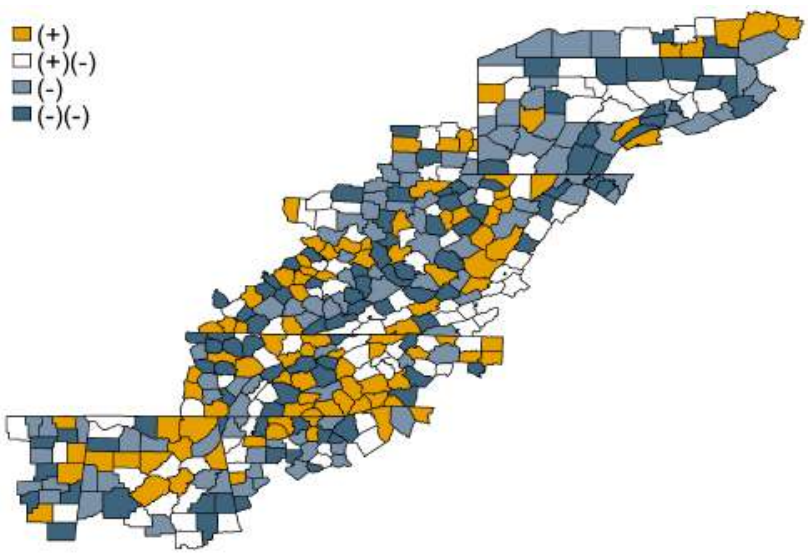

Panel C: Change in Pneumonia and Influenza

Mortality: 1988-1998

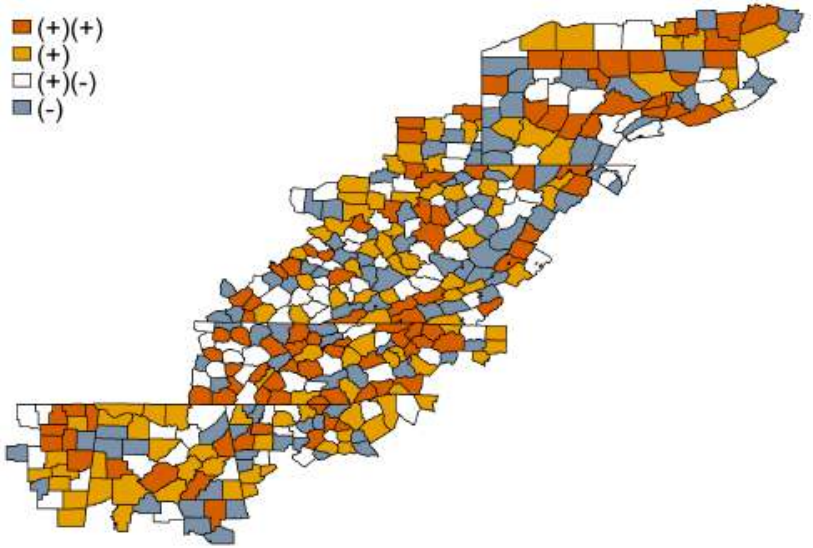

Panel E: Change in Pneumonia and Influenza

Mortality: 2008-2017

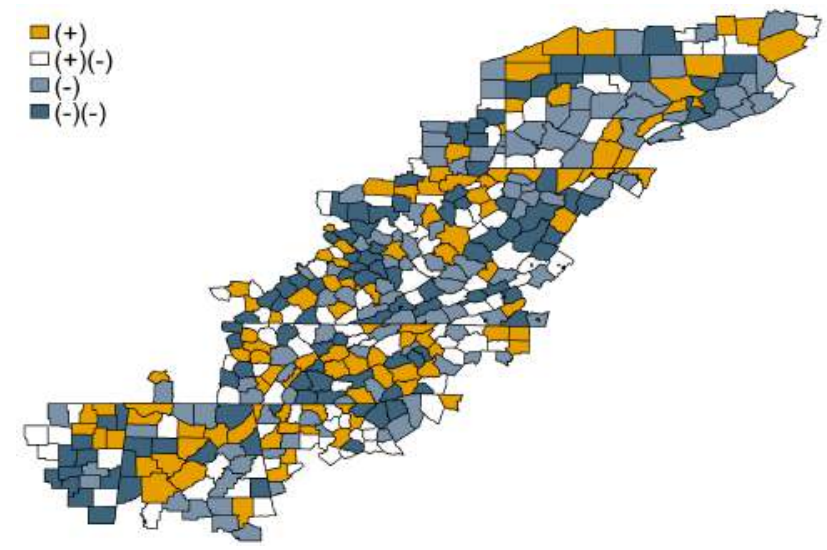

Panel B: Change in Pneumonia and Influenza Mortality: 1978-1988

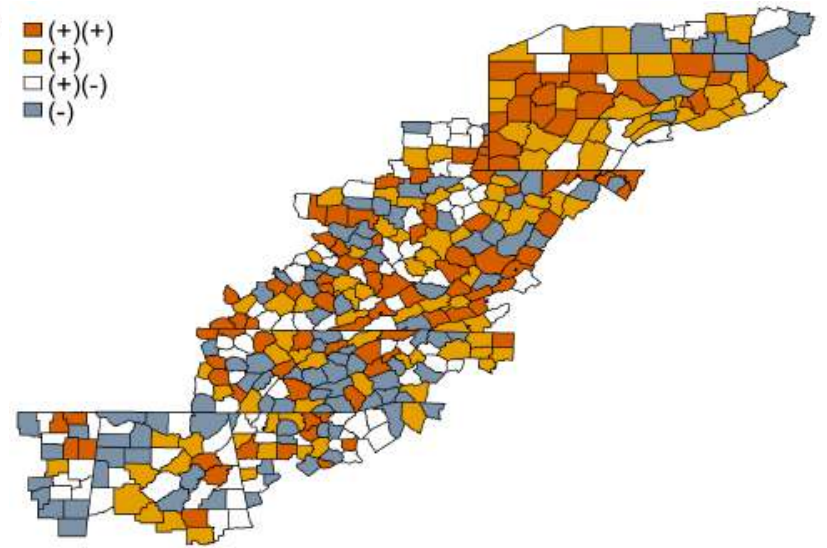

Panel D: Change in Pneumonia and Influenza Mortality: 1998-2008

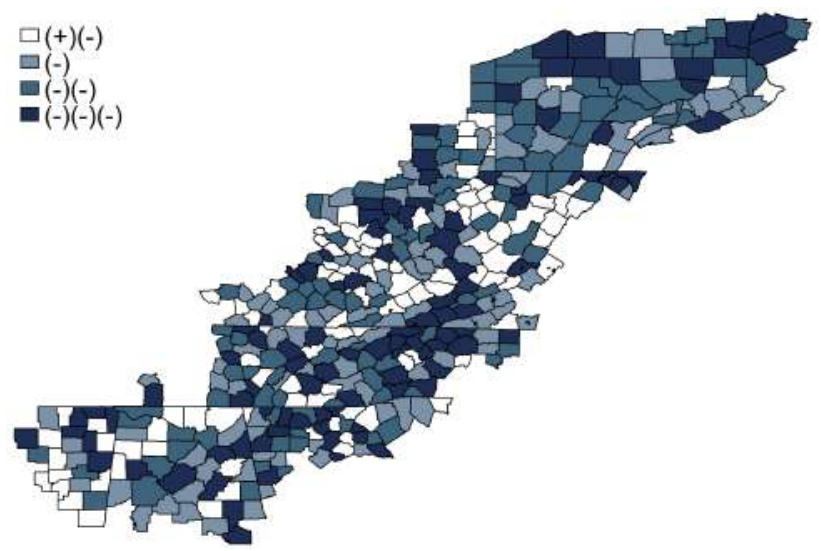

Note: Appalachian county changes in pneumonia and influenza mortality rates are shown above. Darker shades of blue represent negative changes (improved mortality over the decade), while darker shades of orange represent positive changes (worse mortality over the decade). White counties represent no significant change. Counties grouped into equal quantiles per decade. County of death mapped. 
Figure C.7: Hospitals in Appalachia in 2020

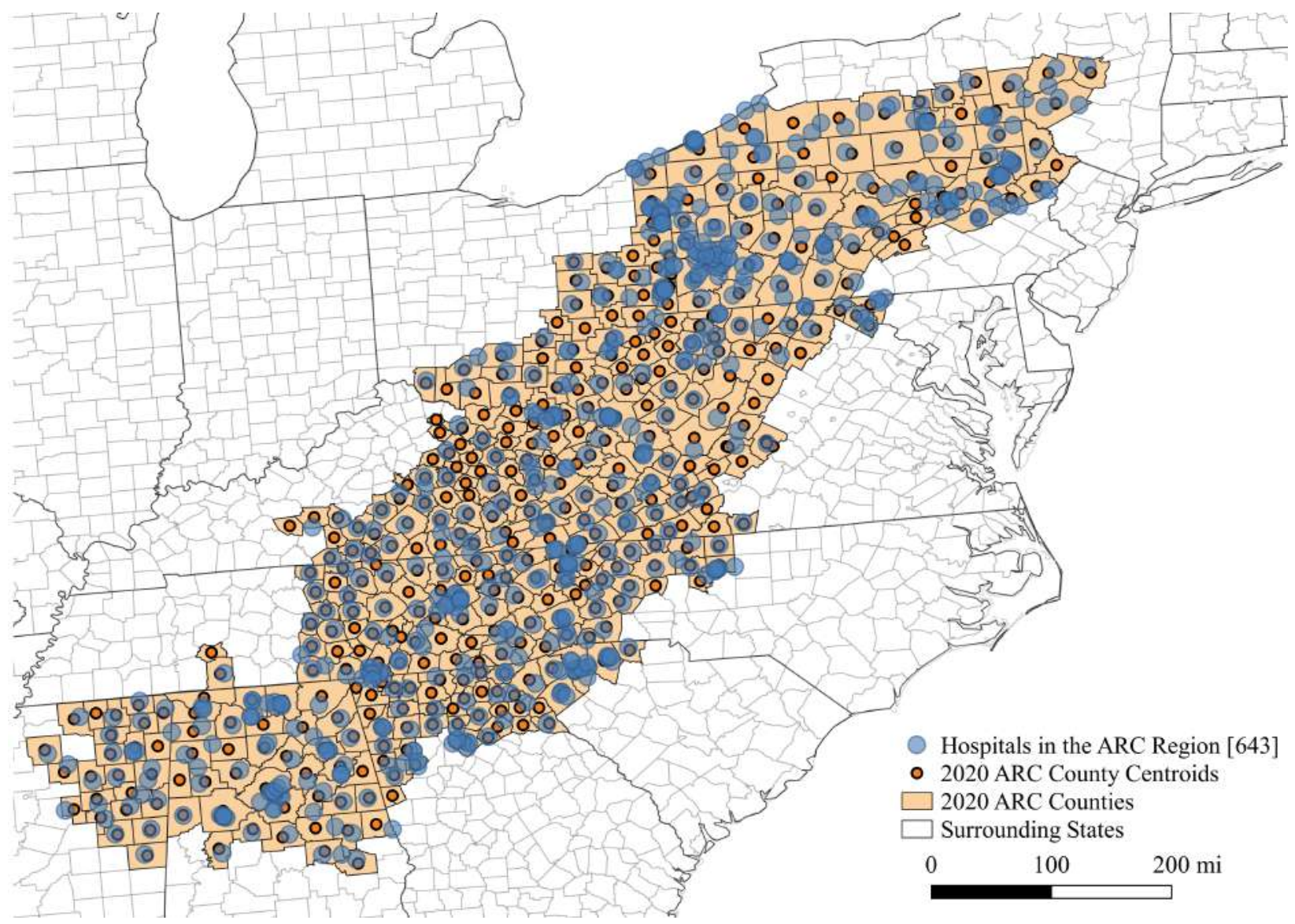

Note: Map displays the current ARC region and the hospitals currently open (as of December 2020). A blue dot represents one open hospital. The orange dots show the county centroids. There are currently 643 open hospitals in the ARC region. Figure created using QGIS. 
Figure C.8: Existing Road Network: 1960

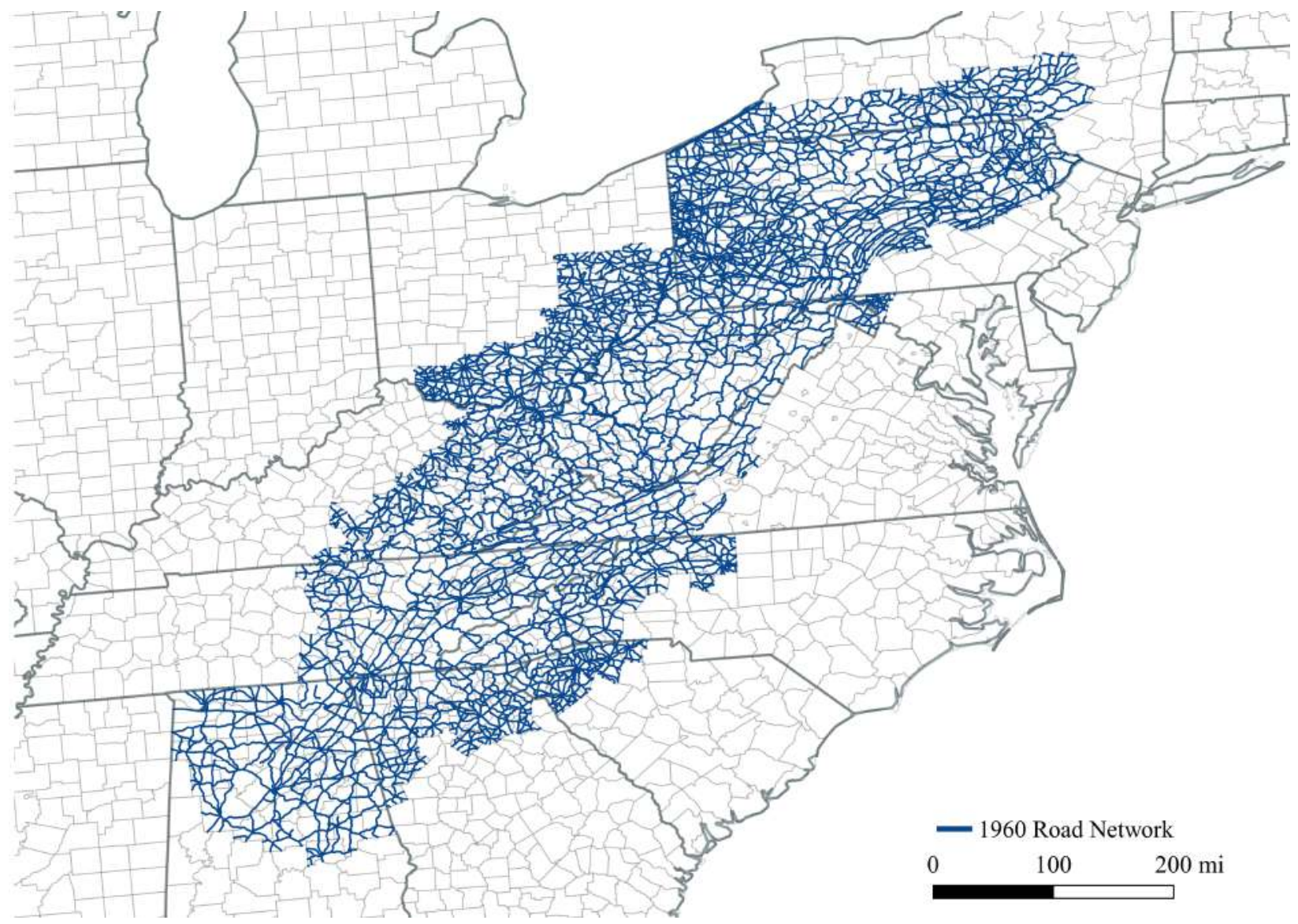

Note: Map displays the 1960 road network in the Appalachian region. This includes interstates, U.S. routes, and state routes. Data sourced from Jaworski and Kitchens (2019). Figure created using QGIS. 
Figure C.9: Appalachian Population: 1970-2014

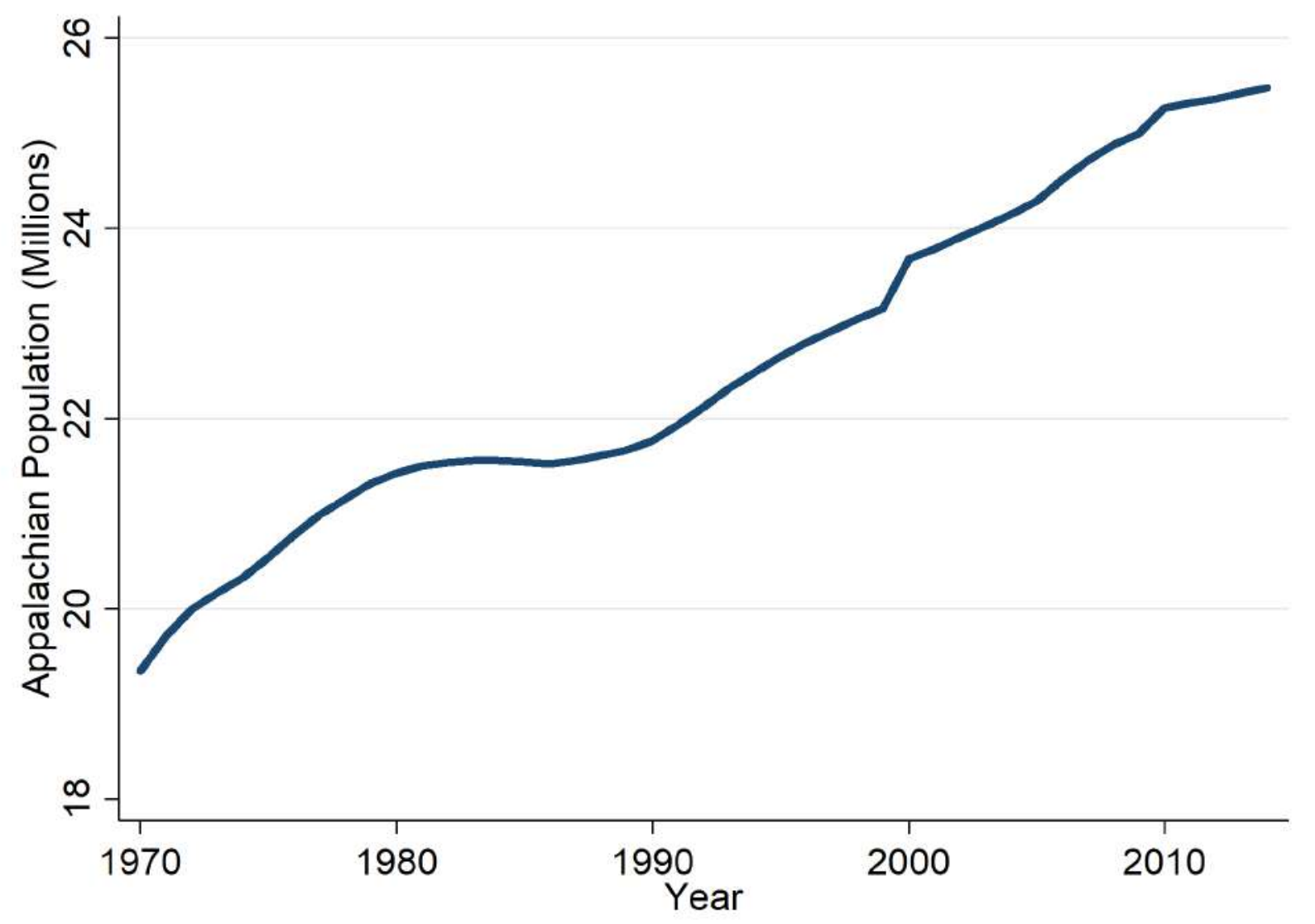

Note: Graph displays Appalachian population in millions from 1970-2014. Estimates of county-level intercensal populations from 1970-2014 are available from Roth (2016). 
Table C.1: ICD Code Definitions and Changes

\begin{tabular}{lccc}
\hline Cause of Death & ICD-8 (1968-1978) & ICD-9 (1979-1998) & ICD-10 (1999-present) \\
\hline Diseases of the Heart & $390-398,402,404,410,429390-398,402,404,410-429$ I00-I09, I11, I13, I20-I51 \\
\hline $\begin{array}{l}\text { Hypertension without } \\
\text { Heart Disease }\end{array}$ & $400-401,403$ & 401,403 & I10-I12 \\
\hline $\begin{array}{l}\text { Cerebrovascular } \\
\text { Diseases }\end{array}$ & $430-438$ & $430-438$ & I60-I69 \\
\hline Aortic Aneurysm & 441 & 441 & I71 \\
\hline Pneumonia and Influenza & $470-474,480-486$ & $480-487$ & J09-J18 \\
\hline $\begin{array}{l}\text { Complications of Pregnancy, } \\
\text { Childbirth, Puerperium }\end{array}$ & $630-678$ & $630-676$ & A34, O00-O95, O98-O99 \\
\hline Accidents and Adverse Effects & E800-949 & $800-949$ & V01-X59, Y85-Y86 \\
\hline Car Accidents & E810-E823 & E810-E823 & V40-V89 \\
\hline Overdoses & E850-E859 & E850-E859 & X40-X44 \\
\hline
\end{tabular}

Note: International Classification of Diseases (ICD) code changes throughout the length of the sample are shown above. The ICD codes used here arguably not exhaustive, but chosen to increase comparability across time. Overdoses - "accidental poisoning by drug and/or medicinal substance" - includes only overdoses classified as a non-intentional death. Online sources include: ICD-8 - http://www.wolfbane.com/icd/icd8.htm; ICD-9-http://www.icd9data.com/; ICD-10-http://www.icd10data.com/ 
Table C.2: ARC Investment Projects: 1968-2016

\begin{tabular}{lcc}
\hline & Count of ProjectsPercent of Projects \\
\hline Asset-Based Development & 180 & 0.60 \\
Business Development & 3,452 & 11.46 \\
Child Development & 2,133 & 7.08 \\
Civic Entrepreneurship & 107 & 0.36 \\
Community Development & 5,900 & 19.59 \\
Education \& Workforce Development & 486 & 1.61 \\
Education and Job Training & 4,509 & 14.98 \\
Environment and Natural Resources & 431 & 1.43 \\
Health & $\mathbf{4 , 1 7 9}$ & $\mathbf{1 3 . 8 8}$ \\
Highways \& Access Roads & 1,093 & 3.63 \\
Housing & 1,216 & 4.04 \\
Leadership and Civic Capacity & 704 & 2.34 \\
Local Development Distric Planning \& Admin. & 3,676 & 12.21 \\
Research \& Evaluation & 44 & 0.15 \\
Research and Technical Assistance & 1,488 & 4.94 \\
State \& LDD Administration & 512 & 1.70 \\
\hline Total & 30,110 & 100.00 \\
\hline
\end{tabular}

Notes: Table displays types of ARC-funded investment projects from 1968-2016.

\section{C.1 Other Mortality Outcomes}

Cerebrovascular Disease - Table C.1.1 display the 2SLS results for cerebrovascular disease mortality rates. In all decades considered, the second stage relationship is never significant.

Aortic Aneurysm - Table C.1.2 shows, similar to cerebrovascular disease, the second stage relationship is never statistically significant. This could be due to the relatively small mortality rate for aortic aneurysm in the Appalachian region, as shown in Figure 3.3e.

Pneumonia and Influenza - Table C.1.3 shows a non-significant relationship between ADHS construction and pneumonia and influenza mortality rates in Appalachia.

Complications with Pregnancy - Table C.1.4 shows, again, no significant relationship between ADHS construction and mortality rates from complications with pregnancy. Again, this could be 
due to the relatively small amount of recorded complications with pregnancy in Appalachia; this is shown in Figure 3.3g. 
Table C.1.1: 2SLS Estimates of Appalachian Development Highway System on Cerebrovascular Disease Mortality Rate With Controls

\begin{tabular}{|c|c|c|c|}
\hline Panel A: 1968-1978 & $\begin{array}{c}(1) \\
\text { Reduced Form }\end{array}$ & $\begin{array}{c}(2) \\
\text { 1st Stage }\end{array}$ & $\begin{array}{c}\text { (3) } \\
\text { 2nd Stage }\end{array}$ \\
\hline Distance to PARC 1964 Plan & $\begin{array}{l}-0.003 \\
(0.094)\end{array}$ & $\begin{array}{c}-0.197 * * * \\
(0.023)\end{array}$ & \\
\hline$\triangle \widehat{A D H S}$ & & & $\begin{array}{c}0.015 \\
(0.474)\end{array}$ \\
\hline $\begin{array}{l}\text { Counties } \\
\text { Kleibergen-Paap F }\end{array}$ & 396 & 396 & $\begin{array}{c}396 \\
74.05\end{array}$ \\
\hline \multicolumn{4}{|l|}{ Panel B: 1978-1988 } \\
\hline Distance to PARC 1964 Plan & $\begin{array}{l}-0.041 \\
(0.038)\end{array}$ & $\begin{array}{c}-0.100^{* * *} \\
(0.010)\end{array}$ & \\
\hline$\triangle \widehat{A D H S}$ & & & $\begin{array}{c}0.407 \\
(0.383)\end{array}$ \\
\hline $\begin{array}{l}\text { Counties } \\
\text { Kleibergen-Paap F }\end{array}$ & 396 & 396 & $\begin{array}{c}396 \\
95.95\end{array}$ \\
\hline \multicolumn{4}{|l|}{ Panel C: 1988-1998 } \\
\hline Distance to PARC 1964 Plan & $\begin{array}{l}-0.041 \\
(0.031)\end{array}$ & $\begin{array}{l}-0.034 * * * \\
(0.009)\end{array}$ & \\
\hline$\triangle \widehat{A D H S}$ & & & $\begin{array}{c}1.194 \\
(1.041)\end{array}$ \\
\hline $\begin{array}{l}\text { Counties } \\
\text { Kleibergen-Paap F }\end{array}$ & 406 & 406 & $\begin{array}{c}406 \\
14.12\end{array}$ \\
\hline \multicolumn{4}{|l|}{ Panel D: 1998-2008 } \\
\hline Distance to PARC 1964 Plan & $\begin{array}{l}-0.021 \\
(0.026)\end{array}$ & $\begin{array}{c}-0.040 * * * \\
(0.010)\end{array}$ & \\
\hline$\triangle \widehat{A D H S}$ & & & $\begin{array}{c}0.509 \\
(0.677)\end{array}$ \\
\hline $\begin{array}{l}\text { Counties } \\
\text { Kleibergen-Paap F }\end{array}$ & 427 & 427 & $\begin{array}{c}427 \\
13.91\end{array}$ \\
\hline \multicolumn{4}{|l|}{ Panel E: 2008-2017 } \\
\hline Distance to PARC 1964 Plan & $\begin{array}{l}-0.009 \\
(0.020)\end{array}$ & $\begin{array}{c}-0.003 * * * \\
(0.001)\end{array}$ & \\
\hline$\triangle \widehat{A D H S}$ & & & $\begin{array}{c}2.971 \\
(6.252)\end{array}$ \\
\hline $\begin{array}{l}\text { Counties } \\
\text { Kleibergen-Paap F }\end{array}$ & 427 & 427 & $\begin{array}{l}427 \\
9.08\end{array}$ \\
\hline
\end{tabular}

Notes: $* \mathrm{p}<0.1, * * \mathrm{p}<0.05, * * * \mathrm{p}<0.01$. Dependent variable is change in cerebrovascular disease mortality in Appalachia. Each panel, A-E, shows the results for a different time period. Column 1 shows reduced form results (PARC distance on mortality), Column 2 shows first stage results (PARC distance on ADHS distance), and Column 3 shows second stage results (instrumented ADHS distance on mortality). Controls included in every panel are the count of hospital establishments in the last year of the decade and the total number of health-related ARC investment projects over the decade at the county level. County-clustered standard errors are used in every column and panel. 
Table C.1.2: 2SLS Estimates of Appalachian Development Highway System on Aortic Aneurysm Mortality Rate With Controls

\begin{tabular}{|c|c|c|c|}
\hline Panel A: 1968-1978 & $\begin{array}{c}(1) \\
\text { Reduced Form }\end{array}$ & $\begin{array}{c}(2) \\
\text { 1st Stage }\end{array}$ & $\begin{array}{c}(3) \\
\text { 2nd Stage }\end{array}$ \\
\hline Distance to PARC 1964 Plan & $\begin{array}{c}0.007 \\
(0.012)\end{array}$ & $\begin{array}{c}-0.197 * * * \\
(0.023)\end{array}$ & \\
\hline$\triangle \widehat{A D H S}$ & & & $\begin{array}{l}-0.034 \\
(0.062)\end{array}$ \\
\hline $\begin{array}{l}\text { Counties } \\
\text { Kleibergen-Paap F }\end{array}$ & 396 & 396 & $\begin{array}{c}396 \\
74.05\end{array}$ \\
\hline \multicolumn{4}{|l|}{ Panel B: 1978-1988 } \\
\hline Distance to PARC 1964 Plan & $\begin{array}{l}-0.004 \\
(0.009)\end{array}$ & $\begin{array}{c}-0.100^{* * * *} \\
(0.010)\end{array}$ & \\
\hline$\triangle \widehat{A D H S}$ & & & $\begin{array}{c}0.044 \\
(0.088)\end{array}$ \\
\hline $\begin{array}{l}\text { Counties } \\
\text { Kleibergen-Paap F }\end{array}$ & 396 & 396 & $\begin{array}{c}396 \\
95.95\end{array}$ \\
\hline \multicolumn{4}{|l|}{ Panel C: 1988-1998 } \\
\hline Distance to PARC 1964 Plan & $\begin{array}{l}-0.004 \\
(0.006)\end{array}$ & $\begin{array}{c}-0.034 * * * \\
(0.009)\end{array}$ & \\
\hline$\triangle \widehat{A D H S}$ & & & $\begin{array}{c}0.118 \\
(0.180)\end{array}$ \\
\hline $\begin{array}{l}\text { Counties } \\
\text { Kleibergen-Paap F }\end{array}$ & 406 & 406 & $\begin{array}{c}406 \\
14.12\end{array}$ \\
\hline \multicolumn{4}{|l|}{ Panel D: 1998-2008 } \\
\hline Distance to PARC 1964 Plan & $\begin{array}{c}0.009 \\
(0.006)\end{array}$ & $\begin{array}{c}-0.040^{* * * *} \\
(0.010)\end{array}$ & \\
\hline$\triangle \widehat{A D H S}$ & & & $\begin{array}{l}-0.214 \\
(0.172)\end{array}$ \\
\hline $\begin{array}{l}\text { Counties } \\
\text { Kleibergen-Paap F }\end{array}$ & 427 & 427 & $\begin{array}{c}427 \\
13.91\end{array}$ \\
\hline \multicolumn{4}{|l|}{ Panel E: 2008-2017 } \\
\hline Distance to PARC 1964 Plan & $\begin{array}{c}0.000 \\
(0.007)\end{array}$ & $\begin{array}{c}-0.003^{* * *} \\
(0.001)\end{array}$ & \\
\hline$\triangle \widehat{A D H S}$ & & & $\begin{array}{l}-0.088 \\
(2.157)\end{array}$ \\
\hline $\begin{array}{l}\text { Counties } \\
\text { Kleibergen-Paap F }\end{array}$ & 427 & 427 & $\begin{array}{l}427 \\
9.08\end{array}$ \\
\hline
\end{tabular}

Notes: $* \mathrm{p}<0.1, * * \mathrm{p}<0.05, * * * \mathrm{p}<0.01$. Dependent variable is change in aortic aneurysm mortality in Appalachia. Each panel, A-E, shows the results for a different time period. Column 1 shows reduced form results (PARC distance on mortality), Column 2 shows first stage results (PARC distance on ADHS distance), and Column 3 shows second stage results (instrumented ADHS distance on mortality). Controls included in every panel are the count of hospital establishments in the last year of the decade and the total number of health-related ARC investment projects over the decade at the county level. County-clustered standard errors are used in every column and panel. 
Table C.1.3: 2SLS Estimates of Appalachian Development Highway System on Pneumonia and Influenza Mortality Rate With Controls

\begin{tabular}{|c|c|c|c|}
\hline Panel A: 1968-1978 & $\begin{array}{c}(1) \\
\text { Reduced Form }\end{array}$ & $\begin{array}{c}(2) \\
\text { 1st Stage }\end{array}$ & $\begin{array}{c}\text { (3) } \\
\text { 2nd Stage }\end{array}$ \\
\hline Distance to PARC 1964 Plan & $\begin{array}{c}0.031 \\
(0.054)\end{array}$ & $\begin{array}{l}-0.197 * * * \\
(0.023)\end{array}$ & \\
\hline$\triangle \widehat{A D H S}$ & & & $\begin{array}{l}-0.159 \\
(0.273)\end{array}$ \\
\hline $\begin{array}{l}\text { Counties } \\
\text { Kleibergen-Paap F }\end{array}$ & 396 & 396 & $\begin{array}{c}396 \\
74.05\end{array}$ \\
\hline \multicolumn{4}{|l|}{ Panel B: 1978-1988 } \\
\hline Distance to PARC 1964 Plan & $\begin{array}{l}-0.013 \\
(0.020)\end{array}$ & $\begin{array}{c}-0.100 * * * \\
(0.010)\end{array}$ & \\
\hline$\triangle \widehat{A D H S}$ & & & $\begin{array}{c}0.126 \\
(0.200) \\
\end{array}$ \\
\hline $\begin{array}{l}\text { Counties } \\
\text { Kleibergen-Paap F }\end{array}$ & 396 & 396 & $\begin{array}{c}396 \\
95.95\end{array}$ \\
\hline \multicolumn{4}{|l|}{ Panel C: 1988-1998 } \\
\hline Distance to PARC 1964 Plan & $\begin{array}{l}-0.013 \\
(0.019)\end{array}$ & $\begin{array}{c}-0.034 * * * \\
(0.009)\end{array}$ & \\
\hline$\triangle \widehat{A D H S}$ & & & $\begin{array}{c}0.376 \\
(0.563)\end{array}$ \\
\hline $\begin{array}{l}\text { Counties } \\
\text { Kleibergen-Paap F }\end{array}$ & 406 & 406 & $\begin{array}{c}406 \\
14.12\end{array}$ \\
\hline \multicolumn{4}{|l|}{ Panel D: 1998-2008 } \\
\hline Distance to PARC 1964 Plan & $\begin{array}{c}0.019 \\
(0.023)\end{array}$ & $\begin{array}{c}-0.040 * * * \\
(0.010)\end{array}$ & \\
\hline$\triangle \widehat{A D H S}$ & & & $\begin{array}{l}-0.465 \\
(0.592)\end{array}$ \\
\hline $\begin{array}{l}\text { Counties } \\
\text { Kleibergen-Paap F }\end{array}$ & 427 & 427 & $\begin{array}{c}427 \\
13.91\end{array}$ \\
\hline \multicolumn{4}{|l|}{ Panel E: 2008-2017 } \\
\hline Distance to PARC 1964 Plan & $\begin{array}{l}-0.003 \\
(0.018)\end{array}$ & $\begin{array}{c}-0.003 * * * \\
(0.001)\end{array}$ & \\
\hline$\triangle \widehat{A D H S}$ & & & $\begin{array}{c}1.032 \\
(5.740)\end{array}$ \\
\hline $\begin{array}{l}\text { Counties } \\
\text { Kleibergen-Paap F }\end{array}$ & 427 & 427 & $\begin{array}{l}427 \\
9.08\end{array}$ \\
\hline
\end{tabular}

Notes: $* \mathrm{p}<0.1, * * \mathrm{p}<0.05, * * * \mathrm{p}<0.01$. Dependent variable is change in pneumonia and influenza mortality in Appalachia. Each panel, A-E, shows the results for a different time period. Column 1 shows reduced form results (PARC distance on mortality), Column 2 shows first stage results (PARC distance on ADHS distance), and Column 3 shows second stage results (instrumented ADHS distance on mortality). Controls included in every panel are the count of hospital establishments in the last year of the decade and the total number of healthrelated ARC investment projects over the decade at the county level. County-clustered standard errors are used in every column and panel. 
C.2 IV Results without Controls 
Table C.1.4: 2SLS Estimates of Appalachian Development Highway System on Complications with Pregnancy Mortality Rate With Controls

\begin{tabular}{|c|c|c|c|}
\hline Panel A: 1968-1978 & $\begin{array}{c}(1) \\
\text { Reduced Form }\end{array}$ & $\begin{array}{c}(2) \\
\text { 1st Stage }\end{array}$ & $\begin{array}{c}(3) \\
\text { 2nd Stage }\end{array}$ \\
\hline Distance to PARC 1964 Plan & $\begin{array}{c}0.002 \\
(0.002)\end{array}$ & $\begin{array}{c}-0.197 * * * \\
(0.023)\end{array}$ & \\
\hline$\triangle \widehat{A D H S}$ & & & $\begin{array}{l}-0.012 \\
(0.010)\end{array}$ \\
\hline $\begin{array}{l}\text { Counties } \\
\text { Kleibergen-Paap F }\end{array}$ & 396 & 396 & $\begin{array}{c}396 \\
74.05\end{array}$ \\
\hline \multicolumn{4}{|l|}{ Panel B: 1978-1988 } \\
\hline Distance to PARC 1964 Plan & $\begin{array}{c}0.000 \\
(0.001)\end{array}$ & $\begin{array}{c}-0.100 * * * \\
(0.010)\end{array}$ & \\
\hline$\triangle \widehat{A D H S}$ & & & $\begin{array}{l}-0.004 \\
(0.013)\end{array}$ \\
\hline $\begin{array}{l}\text { Counties } \\
\text { Kleibergen-Paap F }\end{array}$ & 396 & 396 & $\begin{array}{c}396 \\
95.95\end{array}$ \\
\hline \multicolumn{4}{|l|}{ Panel C: 1988-1998 } \\
\hline Distance to PARC 1964 Plan & $\begin{array}{l}-0.001 \\
(0.001)\end{array}$ & $\begin{array}{c}-0.034 * * * \\
(0.009)\end{array}$ & \\
\hline$\triangle \widehat{A D H S}$ & & & $\begin{array}{c}0.020 \\
(0.033)\end{array}$ \\
\hline $\begin{array}{l}\text { Counties } \\
\text { Kleibergen-Paap F }\end{array}$ & 406 & 406 & $\begin{array}{c}406 \\
14.12\end{array}$ \\
\hline \multicolumn{4}{|l|}{ Panel D: 1998-2008 } \\
\hline Distance to PARC 1964 Plan & $\begin{array}{c}0.001 \\
(0.001)\end{array}$ & $\begin{array}{c}-0.040 * * * \\
(0.010)\end{array}$ & \\
\hline$\triangle \widehat{A D H S}$ & & & $\begin{array}{l}-0.024 \\
(0.027)\end{array}$ \\
\hline $\begin{array}{l}\text { Counties } \\
\text { Kleibergen-Paap F }\end{array}$ & 427 & 427 & $\begin{array}{c}427 \\
13.91\end{array}$ \\
\hline \multicolumn{4}{|l|}{ Panel E: 2008-2017 } \\
\hline Distance to PARC 1964 Plan & $\begin{array}{l}-0.002 \\
(0.001)\end{array}$ & $\begin{array}{c}-0.003 * * * \\
(0.001)\end{array}$ & \\
\hline$\triangle \widehat{A D H S}$ & & & $\begin{array}{c}0.549 \\
(0.605)\end{array}$ \\
\hline $\begin{array}{l}\text { Counties } \\
\text { Kleibergen-Paap F }\end{array}$ & 427 & 427 & $\begin{array}{l}427 \\
9.08\end{array}$ \\
\hline
\end{tabular}

Notes: $* \mathrm{p}<0.1, * * \mathrm{p}<0.05, * * * \mathrm{p}<0.01$. Dependent variable is change in complications with pregnancy mortality in Appalachia. Each panel, A-E, shows the results for a different time period. Column 1 shows reduced form results (PARC distance on mortality), Column 2 shows first stage results (PARC distance on ADHS distance), and Column 3 shows second stage results (instrumented ADHS distance on mortality). Controls included in every panel are the count of hospital establishments in the last year of the decade and the total number of health-related ARC investment projects over the decade at the county level. County-clustered standard errors are used in every column and paphel. 
Table C.2.1: 2SLS Estimates of Appalachian Development Highway System on Total Mortality Rate Without Controls

\begin{tabular}{|c|c|c|c|}
\hline Panel A: 1968-1978 & $\begin{array}{c}(1) \\
\text { Reduced Form }\end{array}$ & $\begin{array}{c}\text { (2) } \\
\text { 1st Stage }\end{array}$ & $\begin{array}{c}\text { (3) } \\
\text { 2nd Stage }\end{array}$ \\
\hline Distance to PARC 1964 Plan & $\begin{array}{c}0.319 \\
(0.740)\end{array}$ & $\begin{array}{l}-0.198 * * * \\
(0.023)\end{array}$ & \\
\hline$\triangle \widehat{A D H S}$ & & & $\begin{array}{l}-1.611 \\
(3.742)\end{array}$ \\
\hline $\begin{array}{l}\text { Counties } \\
\text { Kleibergen-Paap F }\end{array}$ & 396 & 396 & $\begin{array}{c}396 \\
73.45\end{array}$ \\
\hline \multicolumn{4}{|l|}{ Panel B: 1978-1988 } \\
\hline Distance to PARC 1964 Plan & $\begin{array}{c}0.171 \\
(0.291)\end{array}$ & $\begin{array}{c}-0.099 * * * \\
(0.010)\end{array}$ & \\
\hline$\triangle \widehat{A D H S}$ & & & $\begin{array}{l}-1.725 \\
(2.940)\end{array}$ \\
\hline $\begin{array}{l}\text { Counties } \\
\text { Kleibergen-Paap F }\end{array}$ & 396 & 396 & $\begin{array}{c}396 \\
93.82\end{array}$ \\
\hline \multicolumn{4}{|l|}{ Panel C: 1988-1998 } \\
\hline Distance to PARC 1964 Plan & $\begin{array}{l}-0.256^{*} \\
(0.141)\end{array}$ & $\begin{array}{c}-0.034 * * * \\
(0.009)\end{array}$ & \\
\hline$\triangle \widehat{A D H S}$ & & & $\begin{array}{l}7.437^{*} \\
(4.448)\end{array}$ \\
\hline $\begin{array}{l}\text { Counties } \\
\text { Kleibergen-Paap F }\end{array}$ & 406 & 406 & $\begin{array}{c}406 \\
14.80\end{array}$ \\
\hline \multicolumn{4}{|l|}{ Panel D: 1998-2008 } \\
\hline Distance to PARC 1964 Plan & $\begin{array}{c}0.129 \\
(0.151)\end{array}$ & $\begin{array}{c}-0.040 * * * \\
(0.011)\end{array}$ & \\
\hline$\triangle \widehat{A D H S}$ & & & $\begin{array}{l}-3.202 \\
(3.867)\end{array}$ \\
\hline $\begin{array}{l}\text { Counties } \\
\text { Kleibergen-Paap F }\end{array}$ & 427 & 427 & $\begin{array}{c}427 \\
13.77\end{array}$ \\
\hline \multicolumn{4}{|l|}{ Panel E: 2008-2017 } \\
\hline Distance to PARC 1964 Plan & $\begin{array}{c}-0.381 * * \\
(0.164)\end{array}$ & $\begin{array}{c}-0.003 * * * \\
(0.001)\end{array}$ & \\
\hline$\triangle \widehat{A D H S}$ & & & $\begin{array}{l}114.696^{*} \\
(61.145)\end{array}$ \\
\hline $\begin{array}{l}\text { Counties } \\
\text { Kleibergen-Paap F } \\
\text { Two-Step AR-CIs }\end{array}$ & 427 & 427 & $\begin{array}{c}427 \\
9.06 \\
{[23.9062,362.855]}\end{array}$ \\
\hline
\end{tabular}

Notes: $* \mathrm{p}<0.1, * * \mathrm{p}<0.05, * * * \mathrm{p}<0.01$. Dependent variable is change in total mortality in Appalachia. Each panel, A-E, shows the results for a different time period. Column 1 shows reduced form results (PARC distance on mortality), Column 2 shows first stage results (PARC distance on ADHS distance), and Column 3 shows second stage results (instrumented ADHS distance on mortality). County-clustered standard errors are used in every column and panel. Panel E includes two-step Anderson-Rubin confidence interval. 
Table C.2.2: 2SLS Estimates of Appalachian Development Highway System on Heart Disease Mortality Rate Without Controls

\begin{tabular}{|c|c|c|c|}
\hline Panel A: 1968-1978 & $\begin{array}{c}(1) \\
\text { Reduced Form }\end{array}$ & $\begin{array}{c}(2) \\
\text { 1st Stage }\end{array}$ & $\begin{array}{c}(3) \\
\text { 2nd Stage }\end{array}$ \\
\hline Distance to PARC 1964 Plan & $\begin{array}{l}-0.079 \\
(0.166)\end{array}$ & $\begin{array}{c}-0.198 * * * \\
(0.023)\end{array}$ & \\
\hline$\triangle \widehat{A D H S}$ & & & $\begin{array}{c}0.398 \\
(0.837)\end{array}$ \\
\hline $\begin{array}{l}\text { Counties } \\
\text { Kleibergen-Paap F }\end{array}$ & 396 & 396 & $\begin{array}{c}396 \\
73.45\end{array}$ \\
\hline \multicolumn{4}{|l|}{ Panel B: 1978-1988 } \\
\hline Distance to PARC 1964 Plan & $\begin{array}{r}0.291 * * \\
(0.134)\end{array}$ & $\begin{array}{c}-0.099 * * * \\
(0.010)\end{array}$ & \\
\hline$\triangle \widehat{A D H S}$ & & & $\begin{array}{c}-2.934 * * \\
(1.417)\end{array}$ \\
\hline $\begin{array}{l}\text { Counties } \\
\text { Kleibergen-Paap F }\end{array}$ & 396 & 396 & $\begin{array}{c}396 \\
93.82\end{array}$ \\
\hline \multicolumn{4}{|l|}{ Panel C: 1988-1998 } \\
\hline Distance to PARC 1964 Plan & $\begin{array}{l}-0.021 \\
(0.067)\end{array}$ & $\begin{array}{c}-0.034 * * * \\
(0.009)\end{array}$ & \\
\hline$\triangle \widehat{A D H S}$ & & & $\begin{array}{c}0.607 \\
(1.900)\end{array}$ \\
\hline $\begin{array}{l}\text { Counties } \\
\text { Kleibergen-Paap F }\end{array}$ & 406 & 406 & $\begin{array}{c}406 \\
14.80\end{array}$ \\
\hline \multicolumn{4}{|l|}{ Panel D: 1998-2008 } \\
\hline Distance to PARC 1964 Plan & $\begin{array}{c}0.193 \\
(0.071)\end{array}$ & $\begin{array}{c}-0.040^{* * * *} \\
(0.011)\end{array}$ & \\
\hline$\triangle \widehat{A D H S}$ & & & $\begin{array}{c}-4.797 * * \\
(2.158)\end{array}$ \\
\hline $\begin{array}{l}\text { Counties } \\
\text { Kleibergen-Paap F }\end{array}$ & 427 & 427 & $\begin{array}{c}427 \\
13.77\end{array}$ \\
\hline \multicolumn{4}{|l|}{ Panel E: 2008-2017 } \\
\hline Distance to PARC 1964 Plan & $\begin{array}{l}-0.102 \\
(0.062)\end{array}$ & $\begin{array}{c}-0.003 * * * \\
(0.001)\end{array}$ & \\
\hline$\triangle \widehat{A D H S}$ & & & $\begin{array}{c}30.663 \\
(21.835)\end{array}$ \\
\hline $\begin{array}{l}\text { Counties } \\
\text { Kleibergen-Paap F }\end{array}$ & 427 & 427 & $\begin{array}{l}427 \\
9.06\end{array}$ \\
\hline
\end{tabular}

Notes: $* \mathrm{p}<0.1, * * \mathrm{p}<0.05, * * * \mathrm{p}<0.01$. Dependent variable is change in heart disease mortality in Appalachia. Each panel, A-E, shows the results for a different time period. Column 1 shows reduced form results (PARC distance on mortality), Column 2 shows first stage results (PARC distance on ADHS distance), and Column 3 shows second stage results (instrumented ADHS distance on mortality). County-clustered standard errors are used in every column and panel. 
Table C.2.3: 2SLS Estimates of Appalachian Development Highway System on Hypertension Mortality Rate Without Controls

\begin{tabular}{|c|c|c|c|}
\hline Panel A: 1968-1978 & $\begin{array}{c}(1) \\
\text { Reduced Form }\end{array}$ & $\begin{array}{c}(2) \\
\text { 1st Stage }\end{array}$ & $\begin{array}{c}\text { (3) } \\
\text { 2nd Stage }\end{array}$ \\
\hline Distance to PARC 1964 Plan & $\begin{array}{l}-0.006 \\
(0.012)\end{array}$ & $\begin{array}{l}-0.198 * * * \\
(0.023)\end{array}$ & \\
\hline$\triangle \widehat{A D H S}$ & & & $\begin{array}{c}0.028 \\
(0.059)\end{array}$ \\
\hline $\begin{array}{l}\text { Counties } \\
\text { Kleibergen-Paap F }\end{array}$ & 396 & 396 & $\begin{array}{c}396 \\
73.45\end{array}$ \\
\hline \multicolumn{4}{|l|}{ Panel B: 1978-1988 } \\
\hline Distance to PARC 1964 Plan & $\begin{array}{l}-0.000 \\
(0.003)\end{array}$ & $\begin{array}{c}-0.099 * * * \\
(0.010)\end{array}$ & \\
\hline$\triangle \widehat{A D H S}$ & & & $\begin{array}{c}0.000 \\
(0.003)\end{array}$ \\
\hline $\begin{array}{l}\text { Counties } \\
\text { Kleibergen-Paap F }\end{array}$ & 396 & 396 & $\begin{array}{c}396 \\
93.82\end{array}$ \\
\hline \multicolumn{4}{|l|}{ Panel C: 1988-1998 } \\
\hline Distance to PARC 1964 Plan & $\begin{array}{l}0.017 * * \\
(0.007)\end{array}$ & $\begin{array}{c}-0.034 * * * \\
(0.009)\end{array}$ & \\
\hline$\triangle \widehat{A D H S}$ & & & $\begin{array}{c}-0.503^{* *} \\
(0.217)\end{array}$ \\
\hline $\begin{array}{l}\text { Counties } \\
\text { Kleibergen-Paap F }\end{array}$ & 406 & 406 & $\begin{array}{c}406 \\
14.80\end{array}$ \\
\hline \multicolumn{4}{|l|}{ Panel D: 1998-2008 } \\
\hline Distance to PARC 1964 Plan & $\begin{array}{l}-0.001 \\
(0.014)\end{array}$ & $\begin{array}{c}-0.040 * * * \\
(0.011)\end{array}$ & \\
\hline$\triangle \widehat{A D H S}$ & & & $\begin{array}{c}0.013 \\
(0.358)\end{array}$ \\
\hline $\begin{array}{l}\text { Counties } \\
\text { Kleibergen-Paap F }\end{array}$ & 427 & 427 & $\begin{array}{c}427 \\
13.77\end{array}$ \\
\hline \multicolumn{4}{|l|}{ Panel E: 2008-2017 } \\
\hline Distance to PARC 1964 Plan & $\begin{array}{l}-0.015 \\
(0.014)\end{array}$ & $\begin{array}{c}-0.003 * * * \\
(0.001)\end{array}$ & \\
\hline$\triangle \widehat{A D H S}$ & & & $\begin{array}{c}4.531 \\
(4.421)\end{array}$ \\
\hline $\begin{array}{l}\text { Counties } \\
\text { Kleibergen-Paap F }\end{array}$ & 427 & 427 & $\begin{array}{l}427 \\
9.06\end{array}$ \\
\hline
\end{tabular}

Notes: $* \mathrm{p}<0.1, * * \mathrm{p}<0.05, * * * \mathrm{p}<0.01$. Dependent variable is change in hypertension mortality in Appalachia. Each panel, A-E, shows the results for a different time period. Column 1 shows reduced form results (PARC distance on mortality), Column 2 shows first stage results (PARC distance on ADHS distance), and Column 3 shows second stage results (instrumented ADHS distance on mortality). County-clustered standard errors are used in every column and panel. 
Table C.2.4: 2SLS Estimates of Appalachian Development Highway System on Cerebrovascular Disease Mortality Rate Without Controls

\begin{tabular}{|c|c|c|c|}
\hline Panel A: 1968-1978 & $\begin{array}{c}(1) \\
\text { Reduced Form }\end{array}$ & $\begin{array}{c}(2) \\
\text { 1st Stage }\end{array}$ & $\begin{array}{c}\text { (3) } \\
\text { 2nd Stage }\end{array}$ \\
\hline Distance to PARC 1964 Plan & $\begin{array}{l}-0.006 \\
(0.093)\end{array}$ & $\begin{array}{c}-0.198 * * * \\
(0.023)\end{array}$ & \\
\hline$\Delta$ in Cerebrovascular Disease Mortality & & & $\begin{array}{c}0.032 \\
(0.469)\end{array}$ \\
\hline $\begin{array}{l}\text { Counties } \\
\text { Kleibergen-Paap F }\end{array}$ & 396 & 396 & $\begin{array}{c}396 \\
73.45\end{array}$ \\
\hline \multicolumn{4}{|l|}{ Panel B: 1978-1988 } \\
\hline Distance to PARC 1964 Plan & $\begin{array}{l}-0.037 \\
(0.038)\end{array}$ & $\begin{array}{c}-0.099 * * * \\
(0.010)\end{array}$ & \\
\hline$\triangle \widehat{A D H S}$ & & & $\begin{array}{c}0.368 \\
(0.390)\end{array}$ \\
\hline $\begin{array}{l}\text { Counties } \\
\text { Kleibergen-Paap F }\end{array}$ & 396 & 396 & $\begin{array}{c}396 \\
93.82\end{array}$ \\
\hline \multicolumn{4}{|l|}{ Panel C: 1988-1998 } \\
\hline Distance to PARC 1964 Plan & $\begin{array}{l}-0.035 \\
(0.031)\end{array}$ & $\begin{array}{c}-0.034 * * * \\
(0.009)\end{array}$ & \\
\hline$\triangle \widehat{A D H} S$ & & & $\begin{array}{c}1.016 \\
(0.991)\end{array}$ \\
\hline $\begin{array}{l}\text { Counties } \\
\text { Kleibergen-Paap F }\end{array}$ & 406 & 406 & $\begin{array}{c}406 \\
14.80\end{array}$ \\
\hline \multicolumn{4}{|l|}{ Panel D: 1998-2008 } \\
\hline Distance to PARC 1964 Plan & $\begin{array}{l}-0.020 \\
(0.026)\end{array}$ & $\begin{array}{c}-0.040 * * * \\
(0.011)\end{array}$ & \\
\hline$\triangle \widehat{A D H S}$ & & & $\begin{array}{c}0.490 \\
(0.671)\end{array}$ \\
\hline $\begin{array}{l}\text { Counties } \\
\text { Kleibergen-Paap F }\end{array}$ & 427 & 427 & $\begin{array}{c}427 \\
13.77\end{array}$ \\
\hline \multicolumn{4}{|l|}{ Panel E: 2008-2017 } \\
\hline Distance to PARC 1964 Plan & $\begin{array}{l}-0.010 \\
(0.020)\end{array}$ & $\begin{array}{c}-0.003 * * * \\
(0.001)\end{array}$ & \\
\hline$\triangle \widehat{A D H} S$ & & & $\begin{array}{c}3.009 \\
(6.086)\end{array}$ \\
\hline $\begin{array}{l}\text { Counties } \\
\text { Kleibergen-Paap F }\end{array}$ & 427 & 427 & $\begin{array}{l}427 \\
9.06\end{array}$ \\
\hline
\end{tabular}

Notes: $* \mathrm{p}<0.1, * * \mathrm{p}<0.05, * * * \mathrm{p}<0.01$. Dependent variable is change in cerebrovascular disease mortality in Appalachia. Each panel, A-E, shows the results for a different time period. Column 1 shows reduced form results (PARC distance on mortality), Column 2 shows first stage results (PARC distance on ADHS distance), and Column 3 shows second stage results (instrumented ADHS distance on mortality). County-clustered standard errors are used in every column and panel. 
Table C.2.5: 2SLS Estimates of Appalachian Development Highway System on Aortic Aneurysm Mortality Rate Without Controls

\begin{tabular}{|c|c|c|c|}
\hline Panel A: 1968-1978 & $\begin{array}{c}(1) \\
\text { Reduced Form }\end{array}$ & $\begin{array}{c}(2) \\
\text { 1st Stage }\end{array}$ & $\begin{array}{c}(3) \\
\text { 2nd Stage }\end{array}$ \\
\hline Distance to PARC 1964 Plan & $\begin{array}{c}0.007 \\
(0.012)\end{array}$ & $\begin{array}{c}-0.198 * * * \\
(0.023)\end{array}$ & \\
\hline$\triangle \widehat{A D H S}$ & & & $\begin{array}{l}-0.034 \\
(0.062)\end{array}$ \\
\hline $\begin{array}{l}\text { Counties } \\
\text { Kleibergen-Paap F }\end{array}$ & 396 & 396 & $\begin{array}{c}396 \\
73.45\end{array}$ \\
\hline \multicolumn{4}{|l|}{ Panel B: 1978-1988 } \\
\hline Distance to PARC 1964 Plan & $\begin{array}{l}-0.004 \\
(0.009)\end{array}$ & $\begin{array}{c}-0.099 * * * \\
(0.010)\end{array}$ & \\
\hline$\triangle \widehat{A D H S}$ & & & $\begin{array}{c}0.044 \\
(0.089) \\
\end{array}$ \\
\hline $\begin{array}{l}\text { Counties } \\
\text { Kleibergen-Paap F }\end{array}$ & 396 & 396 & $\begin{array}{c}396 \\
93.82\end{array}$ \\
\hline \multicolumn{4}{|l|}{ Panel C: 1988-1998 } \\
\hline Distance to PARC 1964 Plan & $\begin{array}{l}-0.004 \\
(0.006)\end{array}$ & $\begin{array}{c}-0.034 * * * \\
(0.009)\end{array}$ & \\
\hline$\triangle \widehat{A D H S}$ & & & $\begin{array}{c}0.114 \\
(0.176)\end{array}$ \\
\hline $\begin{array}{l}\text { Counties } \\
\text { Kleibergen-Paap F }\end{array}$ & 406 & 406 & $\begin{array}{c}406 \\
14.80\end{array}$ \\
\hline \multicolumn{4}{|l|}{ Panel D: 1998-2008 } \\
\hline Distance to PARC 1964 Plan & $\begin{array}{c}0.009 \\
(0.006)\end{array}$ & $\begin{array}{c}-0.040^{* * * *} \\
(0.011)\end{array}$ & \\
\hline$\triangle \widehat{A D H S}$ & & & $\begin{array}{l}-0.220 \\
(0.176)\end{array}$ \\
\hline $\begin{array}{l}\text { Counties } \\
\text { Kleibergen-Paap F }\end{array}$ & 427 & 427 & $\begin{array}{c}427 \\
13.77\end{array}$ \\
\hline \multicolumn{4}{|l|}{ Panel E: 2008-2017 } \\
\hline Distance to PARC 1964 Plan & $\begin{array}{l}-0.000 \\
(0.007)\end{array}$ & $\begin{array}{c}-0.003 * * * \\
(0.001)\end{array}$ & \\
\hline$\triangle \widehat{A D H S}$ & & & $\begin{array}{c}0.027 \\
(2.045)\end{array}$ \\
\hline $\begin{array}{l}\text { Counties } \\
\text { Kleibergen-Paap F }\end{array}$ & 427 & 427 & $\begin{array}{l}427 \\
9.06\end{array}$ \\
\hline
\end{tabular}

Notes: $* \mathrm{p}<0.1, * * \mathrm{p}<0.05, * * * \mathrm{p}<0.01$. Dependent variable is change in aortic aneurysm mortality in Appalachia. Each panel, A-E, shows the results for a different time period. Column 1 shows reduced form results (PARC distance on mortality), Column 2 shows first stage results (PARC distance on ADHS distance), and Column 3 shows second stage results (instrumented ADHS distance on mortality). County-clustered standard errors are used in every column and panel. 
Table C.2.6: 2SLS Estimates of Appalachian Development Highway System on Pneumonia and Influenza Mortality Rate Without Controls

\begin{tabular}{|c|c|c|c|}
\hline Panel A: 1968-1978 & $\begin{array}{c}(1) \\
\text { Reduced Form }\end{array}$ & $\begin{array}{c}(2) \\
\text { 1st Stage }\end{array}$ & $\begin{array}{c}(3) \\
\text { 2nd Stage }\end{array}$ \\
\hline Distance to PARC 1964 Plan & $\begin{array}{c}0.030 \\
(0.053)\end{array}$ & $\begin{array}{c}-0.198 * * * \\
(0.023)\end{array}$ & \\
\hline$\triangle \widehat{A D H S}$ & & & $\begin{array}{l}-0.153 \\
(0.270)\end{array}$ \\
\hline $\begin{array}{l}\text { Counties } \\
\text { Kleibergen-Paap F }\end{array}$ & 396 & 396 & $\begin{array}{c}396 \\
73.45\end{array}$ \\
\hline \multicolumn{4}{|l|}{ Panel B: 1978-1988 } \\
\hline Distance to PARC 1964 Plan & $\begin{array}{l}-0.014 \\
(0.020)\end{array}$ & $\begin{array}{c}-0.099 * * * \\
(0.010)\end{array}$ & \\
\hline$\triangle \widehat{A D H S}$ & & & $\begin{array}{c}0.142 \\
(0.198)\end{array}$ \\
\hline $\begin{array}{l}\text { Counties } \\
\text { Kleibergen-Paap F }\end{array}$ & 396 & 396 & $\begin{array}{c}396 \\
93.82\end{array}$ \\
\hline \multicolumn{4}{|l|}{ Panel C: 1988-1998 } \\
\hline Distance to PARC 1964 Plan & $\begin{array}{l}-0.006 \\
(0.019)\end{array}$ & $\begin{array}{c}-0.034 * * * \\
(0.009)\end{array}$ & \\
\hline$\triangle \widehat{A D H S}$ & & & $\begin{array}{c}0.181 \\
(0.551)\end{array}$ \\
\hline $\begin{array}{l}\text { Counties } \\
\text { Kleibergen-Paap F }\end{array}$ & 406 & 406 & $\begin{array}{c}406 \\
14.80\end{array}$ \\
\hline \multicolumn{4}{|l|}{ Panel D: 1998-2008 } \\
\hline Distance to PARC 1964 Plan & $\begin{array}{c}0.019 \\
(0.023)\end{array}$ & $\begin{array}{c}-0.040 * * * \\
(0.011)\end{array}$ & \\
\hline$\triangle \widehat{A D H S}$ & & & $\begin{array}{l}-0.481 \\
(0.610)\end{array}$ \\
\hline $\begin{array}{l}\text { Counties } \\
\text { Kleibergen-Paap F }\end{array}$ & 427 & 427 & $\begin{array}{c}427 \\
13.77\end{array}$ \\
\hline \multicolumn{4}{|l|}{ Panel E: 2008-2017 } \\
\hline Distance to PARC 1964 Plan & $\begin{array}{l}-0.004 \\
(0.018)\end{array}$ & $\begin{array}{c}-0.003 * * * \\
(0.001)\end{array}$ & \\
\hline$\triangle \widehat{A D H S}$ & & & $\begin{array}{c}1.138 \\
(5.536)\end{array}$ \\
\hline $\begin{array}{l}\text { Counties } \\
\text { Kleibergen-Paap F }\end{array}$ & 427 & 427 & $\begin{array}{l}427 \\
9.06\end{array}$ \\
\hline
\end{tabular}

Notes: $* \mathrm{p}<0.1, * * \mathrm{p}<0.05, * * * \mathrm{p}<0.01$. Dependent variable is change in pneumonia and influenza mortality in Appalachia. Each panel, A-E, shows the results for a different time period. Column 1 shows reduced form results (PARC distance on mortality), Column 2 shows first stage results (PARC distance on ADHS distance), and Column 3 shows second stage results (instrumented ADHS distance on mortality). County-clustered standard errors are used in every column and panel. 
Table C.2.7: 2SLS Estimates of Appalachian Development Highway System on Complications with Pregnancy Mortality Rate Without Controls

\begin{tabular}{|c|c|c|c|}
\hline Panel A: 1968-1978 & $\begin{array}{c}(1) \\
\text { Reduced Form }\end{array}$ & $\begin{array}{c}(2) \\
\text { 1st Stage }\end{array}$ & $\begin{array}{c}\text { (3) } \\
\text { 2nd Stage }\end{array}$ \\
\hline Distance to PARC 1964 Plan & $\begin{array}{c}0.002 \\
(0.002)\end{array}$ & $\begin{array}{l}-0.198 * * * \\
(0.023)\end{array}$ & \\
\hline$\triangle \widehat{A D H S}$ & & & $\begin{array}{c}-0.01 \\
(0.010)\end{array}$ \\
\hline $\begin{array}{l}\text { Counties } \\
\text { Kleibergen-Paap F }\end{array}$ & 396 & 396 & $\begin{array}{c}396 \\
73.45\end{array}$ \\
\hline \multicolumn{4}{|l|}{ Panel B: 1978-1988 } \\
\hline Distance to PARC 1964 Plan & $\begin{array}{c}0.000 \\
(0.001)\end{array}$ & $\begin{array}{c}-0.099 * * * \\
(0.010)\end{array}$ & \\
\hline$\triangle \widehat{A D H S}$ & & & $\begin{array}{l}-0.004 \\
(0.013) \\
\end{array}$ \\
\hline $\begin{array}{l}\text { Counties } \\
\text { Kleibergen-Paap F }\end{array}$ & 396 & 396 & $\begin{array}{c}396 \\
93.82\end{array}$ \\
\hline \multicolumn{4}{|l|}{ Panel C: 1988-1998 } \\
\hline Distance to PARC 1964 Plan & $\begin{array}{l}-0.001 \\
(0.001)\end{array}$ & $\begin{array}{c}-0.034 * * * \\
(0.009)\end{array}$ & \\
\hline$\triangle \widehat{A D H S}$ & & & $\begin{array}{c}0.017 \\
(0.032)\end{array}$ \\
\hline $\begin{array}{l}\text { Counties } \\
\text { Kleibergen-Paap F }\end{array}$ & 406 & 406 & $\begin{array}{c}406 \\
14.80\end{array}$ \\
\hline \multicolumn{4}{|l|}{ Panel D: 1998-2008 } \\
\hline Distance to PARC 1964 Plan & $\begin{array}{c}0.001 \\
(0.001)\end{array}$ & $\begin{array}{c}-0.040 * * * \\
(0.011)\end{array}$ & \\
\hline$\triangle \widehat{A D H S}$ & & & $\begin{array}{l}-0.027 \\
(0.027)\end{array}$ \\
\hline $\begin{array}{l}\text { Counties } \\
\text { Kleibergen-Paap F }\end{array}$ & 427 & 427 & $\begin{array}{c}427 \\
13.77\end{array}$ \\
\hline \multicolumn{4}{|l|}{ Panel E: 2008-2017 } \\
\hline Distance to PARC 1964 Plan & $\begin{array}{l}-0.002 \\
(0.002)\end{array}$ & $\begin{array}{c}-0.003 * * * \\
(0.001)\end{array}$ & \\
\hline$\triangle \widehat{A D H S}$ & & & $\begin{array}{c}0.492 \\
(0.489) \\
\end{array}$ \\
\hline $\begin{array}{l}\text { Counties } \\
\text { Kleibergen-Paap F }\end{array}$ & 427 & 427 & $\begin{array}{l}427 \\
9.06\end{array}$ \\
\hline
\end{tabular}

Notes: $* \mathrm{p}<0.1, * * \mathrm{p}<0.05, * * * \mathrm{p}<0.01$. Dependent variable is change in complications with pregnancy mortality in Appalachia. Each panel, A-E, shows the results for a different time period. Column 1 shows reduced form results (PARC distance on mortality), Column 2 shows first stage results (PARC distance on ADHS distance), and Column 3 shows second stage results (instrumented ADHS distance on mortality). County-clustered standard errors are used in every column and panel. 
Table C.2.8: 2SLS Estimates of Appalachian Development Highway System on Accident Mortality Rate Without Controls

\begin{tabular}{|c|c|c|c|}
\hline Panel A: 1968-1978 & $\begin{array}{c}(1) \\
\text { Reduced Form }\end{array}$ & $\begin{array}{c}(2) \\
\text { 1st Stage }\end{array}$ & $\begin{array}{c}(3) \\
\text { 2nd Stage }\end{array}$ \\
\hline Distance to PARC 1964 Plan & $\begin{array}{l}-0.006 \\
(0.040)\end{array}$ & $\begin{array}{c}-0.198 * * * \\
(0.023)\end{array}$ & \\
\hline$\triangle \widehat{A D H S}$ & & & $\begin{array}{c}0.031 \\
(0.201)\end{array}$ \\
\hline $\begin{array}{l}\text { Counties } \\
\text { Kleibergen-Paap F }\end{array}$ & 396 & 396 & $\begin{array}{c}396 \\
73.45\end{array}$ \\
\hline \multicolumn{4}{|l|}{ Panel B: 1978-1988 } \\
\hline Distance to PARC 1964 Plan & $\begin{array}{c}0.070 \\
(0.052)\end{array}$ & $\begin{array}{c}-0.099 * * * \\
(0.010)\end{array}$ & \\
\hline$\triangle \widehat{A D H S}$ & & & $\begin{array}{l}-0.700 \\
(0.530)\end{array}$ \\
\hline $\begin{array}{l}\text { Counties } \\
\text { Kleibergen-Paap F }\end{array}$ & 396 & 396 & $\begin{array}{c}396 \\
93.82\end{array}$ \\
\hline \multicolumn{4}{|l|}{ Panel C: 1988-1998 } \\
\hline Distance to PARC 1964 Plan & $\begin{array}{l}-0.034 \\
(0.029)\end{array}$ & $\begin{array}{c}-0.034 * * * \\
(0.009)\end{array}$ & \\
\hline$\triangle \widehat{A D H S}$ & & & $\begin{array}{c}0.973 \\
(0.837)\end{array}$ \\
\hline $\begin{array}{l}\text { Counties } \\
\text { Kleibergen-Paap F }\end{array}$ & 406 & 406 & $\begin{array}{c}406 \\
14.80\end{array}$ \\
\hline \multicolumn{4}{|l|}{ Panel D: 1998-2008 } \\
\hline Distance to PARC 1964 Plan & $\begin{array}{c}-0.065^{* *} \\
(0.021)\end{array}$ & $\begin{array}{c}-0.040 * * * \\
(0.011)\end{array}$ & \\
\hline$\triangle \widehat{A D H S}$ & & & $\begin{array}{l}1.618 * * \\
(0.719)\end{array}$ \\
\hline $\begin{array}{l}\text { Counties } \\
\text { Kleibergen-Paap F }\end{array}$ & 427 & 427 & $\begin{array}{c}427 \\
13.77\end{array}$ \\
\hline \multicolumn{4}{|l|}{ Panel E: 2008-2017 } \\
\hline Distance to PARC 1964 Plan & $\begin{array}{c}-0.099 * * * \\
(0.023)\end{array}$ & $\begin{array}{c}-0.003 * * * \\
(0.001)\end{array}$ & \\
\hline$\triangle \widehat{A D H S}$ & & & $\begin{array}{c}29.763 * * \\
(11.742)\end{array}$ \\
\hline $\begin{array}{l}\text { Counties } \\
\text { Kleibergen-Paap F } \\
\text { Two-Step AR-CIs }\end{array}$ & 427 & 427 & $\begin{array}{c}427 \\
9.06 \\
{[14.6531,86.716]}\end{array}$ \\
\hline
\end{tabular}

Notes: $* \mathrm{p}<0.1, * * \mathrm{p}<0.05, * * * \mathrm{p}<0.01$. Dependent variable is change in accident mortality in Appalachia. Each panel, A-E, shows the results for a different time period. Column 1 shows reduced form results (PARC distance on mortality), Column 2 shows first stage results (PARC distance on ADHS distance), and Column 3 shows second stage results (instrumented ADHS distance on mortality). County-clustered standard errors are used in every column and panel. Panel E includes two-step Anderson-Rubin confidence interval. 


\section{C.3 Cumulative Effect of the ADHS on Mortality}


Table C.3.1: Panel 2SLS Estimates of Appalachian Development Highway System on Mortality Rate With Controls

\begin{tabular}{|c|c|c|c|c|}
\hline Panel A: Total Mortality & $\begin{array}{c}\text { (1) } \\
\text { Mortality Mean }\end{array}$ & $\begin{array}{c}(2) \\
\text { Reduced Form }\end{array}$ & $\begin{array}{c}\text { (3) } \\
\text { 1st Stage }\end{array}$ & $\begin{array}{c}(4) \\
\text { 2nd Stage }\end{array}$ \\
\hline Distance to PARC 1964 Plan & & $\begin{array}{l}-0.001 * \\
(0.709)\end{array}$ & $\begin{array}{c}0.000 * * * \\
(0.000)\end{array}$ & \\
\hline$A \widehat{D H} S$ & $\begin{array}{c}853.892 \\
(491.219)\end{array}$ & & & $\begin{array}{l}-2.480 * \\
(1.468)\end{array}$ \\
\hline $\begin{array}{l}\text { Observations } \\
\text { Kleibergen-Paap F }\end{array}$ & 19183 & 19183 & 19183 & $\begin{array}{l}19183 \\
130.99\end{array}$ \\
\hline \multicolumn{5}{|c|}{ Panel B: Heart Disease Mortality } \\
\hline Distance to PARC 1964 Plan & & $\begin{array}{l}-0.000^{*} \\
(0.000)\end{array}$ & $\begin{array}{c}0.000 * * * \\
(0.000)\end{array}$ & \\
\hline$A \widehat{D H} S$ & $\begin{array}{l}294.620 \\
(164.465)\end{array}$ & & & $\begin{array}{l}-0.772 * \\
(0.449)\end{array}$ \\
\hline $\begin{array}{l}\text { Observations } \\
\text { Kleibergen-Paap F }\end{array}$ & 19183 & 19183 & 19183 & $\begin{array}{l}19183 \\
131.22\end{array}$ \\
\hline \multicolumn{5}{|c|}{ Panel C: Hypertension Mortality } \\
\hline Distance to PARC 1964 Plan & & $\begin{array}{l}-0.000 \\
(0.000)\end{array}$ & $\begin{array}{c}0.000 * * * \\
(0.000)\end{array}$ & \\
\hline$A \widehat{D H} S$ & $\begin{array}{c}8.220 \\
(8.054)\end{array}$ & & & $\begin{array}{c}0.006 \\
(0.015)\end{array}$ \\
\hline $\begin{array}{l}\text { Observations } \\
\text { Kleibergen-Paap F }\end{array}$ & 19183 & 19183 & 19183 & $\begin{array}{l}19183 \\
123.22\end{array}$ \\
\hline \multicolumn{5}{|l|}{ Panel D: Accident Mortality } \\
\hline Distance to PARC 1964 Plan & & $\begin{array}{c}-0.000 * * \\
(0.000)\end{array}$ & $\begin{array}{c}0.000 * * * * \\
(0.000)\end{array}$ & \\
\hline$A \widehat{D H} S$ & $\begin{array}{c}52.565 \\
(37.689)\end{array}$ & & & $\begin{array}{l}-0.216^{*} \\
(0.112)\end{array}$ \\
\hline $\begin{array}{l}\text { Observations } \\
\text { Kleibergen-Paap F }\end{array}$ & 19183 & 19183 & 19183 & $\begin{array}{c}19183 \\
132.09\end{array}$ \\
\hline \multicolumn{5}{|l|}{ Panel E: Overdose Mortality } \\
\hline Distance to PARC 1964 Plan & & $\begin{array}{l}-0.000 \\
(0.000)\end{array}$ & $\begin{array}{c}0.000 * * * * \\
(0.000)\end{array}$ & \\
\hline$A \widehat{D H} S$ & $\begin{array}{c}40.368 \\
(38.811)\end{array}$ & & & $\begin{array}{l}-0.155 \\
(0.101)\end{array}$ \\
\hline $\begin{array}{l}\text { Observations } \\
\text { Kleibergen-Paap F }\end{array}$ & 19183 & 19183 & 19183 & $\begin{array}{l}19183 \\
145.91\end{array}$ \\
\hline
\end{tabular}

Notes: $* \mathrm{p}<0.1, * * \mathrm{p}<0.05, * * * \mathrm{p}<0.01$. Dependent variable is mortality rate in Appalachia. Each panel, A-E, shows the results for a different mortality outcome. Column 1 shows the mean mortality rate, with standard deviations in parentheses. Column 2 shows reduced form results (PARC distance on mortality), Column 3 shows first stage results (PARC distance on ADHS distance), and Column 4 shows second stage results (instrumented ADHS distance on mortality). Controls included in every panel are the count of hospital establishments in the last year of the decade, the total number of health-related ARC investment projects over the decade at the county level, and the length of existing road network in 1960 at the county level. Year and state fixed effects are used in every panel. County-clustered standard errors are used in every panel. 